\title{
Diagnostic evaluation of chest pain
}

Citation for published version (APA):

Smulders, M. W. (2020). Diagnostic evaluation of chest pain: The role of non-invasive cardiac imaging.

[Doctoral Thesis, Maastricht University]. Gildeprint Drukkerijen. https://doi.org/10.26481/dis.20200320ms

Document status and date:

Published: 01/01/2020

DOI:

10.26481/dis.20200320ms

Document Version:

Publisher's PDF, also known as Version of record

\section{Please check the document version of this publication:}

- A submitted manuscript is the version of the article upon submission and before peer-review. There can be important differences between the submitted version and the official published version of record.

People interested in the research are advised to contact the author for the final version of the publication, or visit the DOI to the publisher's website.

- The final author version and the galley proof are versions of the publication after peer review.

- The final published version features the final layout of the paper including the volume, issue and page numbers.

Link to publication

\footnotetext{
General rights rights.

- You may freely distribute the URL identifying the publication in the public portal. please follow below link for the End User Agreement:

www.umlib.nl/taverne-license

Take down policy

If you believe that this document breaches copyright please contact us at:

repository@maastrichtuniversity.nl

providing details and we will investigate your claim.
}

Copyright and moral rights for the publications made accessible in the public portal are retained by the authors and/or other copyright owners and it is a condition of accessing publications that users recognise and abide by the legal requirements associated with these

- Users may download and print one copy of any publication from the public portal for the purpose of private study or research.

- You may not further distribute the material or use it for any profit-making activity or commercial gain

If the publication is distributed under the terms of Article $25 \mathrm{fa}$ of the Dutch Copyright Act, indicated by the "Taverne" license above, 


\title{
DIAGNOSTIC EVALUATION OF CHEST PAIN \\ The role of non-invasive cardiac imaging
}

\author{
PROEFSCHRIFT \\ ter verkrijging van de graad van doctor aan de Universiteit Maastricht, \\ op gezag van de Rector Magnificus, Prof. dr. Rianne M. Letschert \\ volgens het besluit van het College van Decanen, \\ in het openbaar te verdedigen \\ op vrijdag 20 maart 2020 om 12.00 uur
}

door

Martijn Willem Smulders

geboren op 7 april 1986

te Groningen 


\section{Promotores}

Prof. dr. H.J.G.M. Crijns

Prof. dr. J.E. Wildberger

\section{Copromotores}

Dr. S.C.A.M. Bekkers

Dr. B.L.J.H. Kietselaer (Zuyderland Medisch Centrum)

\section{Beoordelingscommissie}

Prof. dr. J.C.A. Hoorntje (voorzitter)

Prof. dr. M.E. Kooi

Dr. S.J.R. Meex

Prof. dr. R. Nijveldt (Radboudumc Nijmegen)

Prof. dr. R.J. de Winter (Amsterdam UMC)

Financial support by the Dutch Heart Foundation for the publication of this thesis is gratefully acknowledged.

The research described in this thesis was supported in part by a grant of the Dutch Heart Foundation (DHF 2014T51).

Financial support for the printing of this thesis as provided by the following sponsors is gratefully acknowledged: Bayer - Ipanema - Servier Nederland Farma B.V.

\section{ISBN:}

978-94-6402-118-9

\section{Graphic design and layout by: \\ M. Mafi Rad}

\section{Printed by:}

Gildeprint

All rights reserved. No part of this thesis may be reproduced or transmitted in any form or by any means, electronic or mechanical, including photocopying, recording or any information storage or retrieval system, without permission in writing from the author, or, when appropriate, from the publishers of the publications. 
Voor mama, papa en Angelique Voor Ellen, Sil en Evi

Ik hou van jullie 


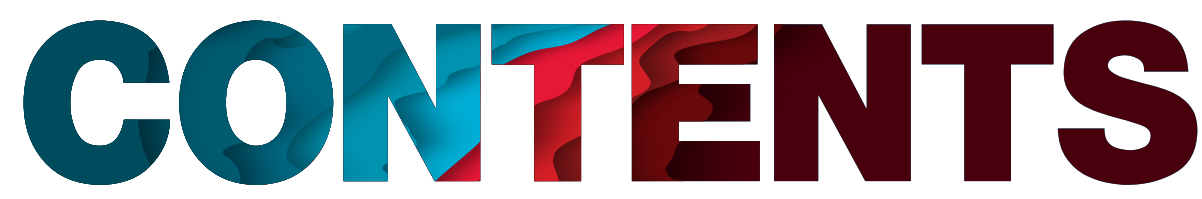

\section{pin

Acute chest pain in the high-sensitivity cardiac troponin era:

A changing role for non-invasive imaging?

American Heart Journal. 2016; 177: 102-111

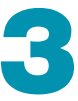

Risk stratification and role for additional diagnostic testing in patients with acute chest pain and normal high-sensitivity cardiac troponin levels

PLoS One. 2018: 13: e0203506

Editorial comment Acute chest pain and normal high-sensitivity cardiac troponin levels; is this the end of the story?

Nederlands Tijdschrift voor Geneeskunde. 2018; 162: D3540

High biomarkers, but normal angiogram: what next?

Heart Metabolism. 2015; 67: 15-20

The role of cardiovascular magnetic resonance imaging and computed tomography angiography in suspected non-ST-elevation myocardial infarction patients: Design and rationale of the CARdiovascular Magnetic rEsoNance imaging and computed Tomography Angiography (CARMENTA) trial

American Heart Journal. 2013; 166: 968-975

Initial imaging-guided strategy versus routine care in patients with non-ST-segment elevation myocardial infarction.

Journal of the American College of Cardiology. 2019; 74: 2466-2477

Editorial comment Up-front non-invasive imaging in low-risk NSTEMI 120 Journal of the American College of Cardiology. 2019; 74: 2478-2479 
Performance of CMR methods for differentiating acute from chronic MI 126 Journal of the American College of Cardiology:

Cardiovascular Imaging. 2015; 8: 669-679

Editorial comment Healing after myocardial infarction. A loosely

defined process

Journal of the American College of Cardiology:

Cardiovascular Imaging. 2015; 8: 680-683

\section{THREE}

An uncommon cause of typical cardiac chest pain

Circulation. 2014; 129: 1714

Comparison of the prognostic value of negative non-invasive cardiac investigations in patients with suspected or known coronary artery disease - a meta-analysis

European Heart Journal - Cardiovascular Imaging. 2017; 18: 980-987

Editorial comment Cardiac investigation for prognosis in coronary artery disease: where negative is positive

European Heart Journal - Cardiovascular Imaging. 2017; 18: 988-989

Dutch summary / samenvatting

Valorisation

Curriculum Vitae

List of publications 


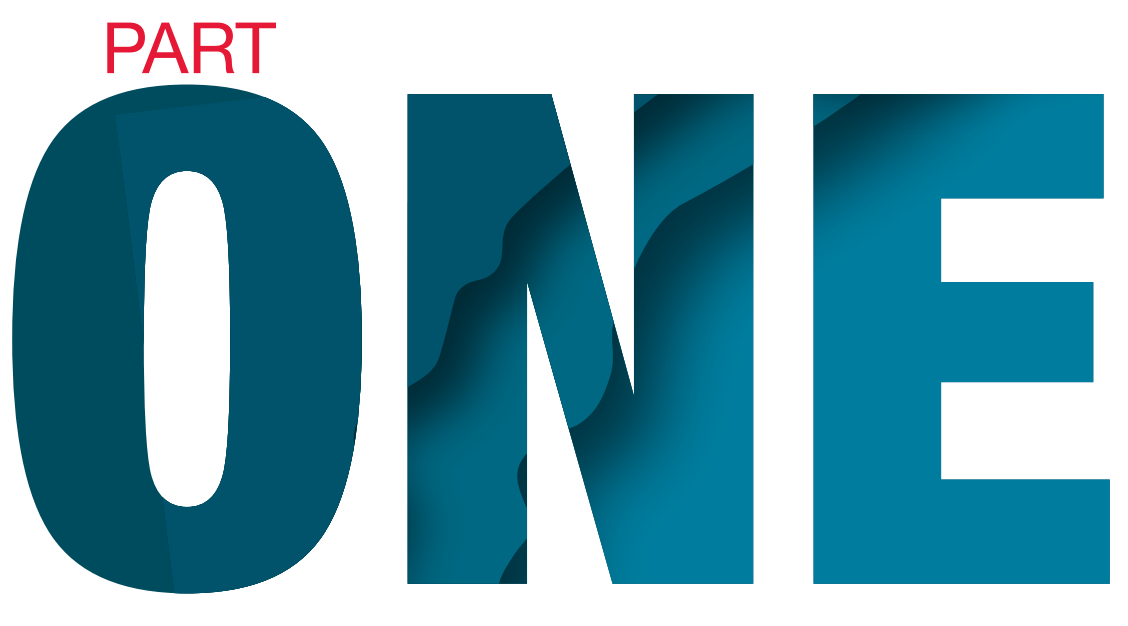


Introduction 


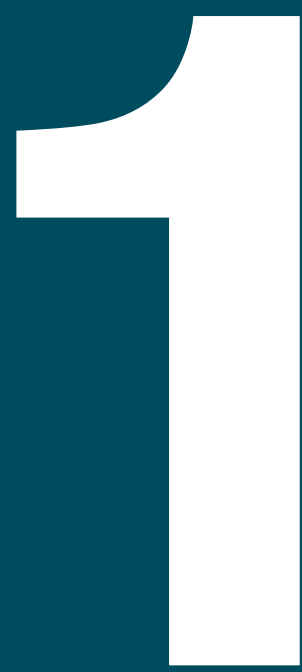

Chapter 
General introduction 
Cardiovascular disease accounts for 3.9 million deaths in Europe and remains the most common cause of death ( $45 \%$ of all deaths). ${ }^{1,2}$ The prevalence of patients with cardiovascular disease in Europe is nearly 85 million. Annually, 3 million new individuals experience symptoms of ischemic heart disease for the first time. ${ }^{2}$ The most common symptom of ischemic heart disease is chest pain. Chest pain can be categorized into acute onset and chronic (stable) chest pain, although in clinical practice it is often a continuum. Acute chest pain is the most frequent cause for an emergency department visit and accounts for more than $10 \%$ of all presentations. ${ }^{3}$ Chronic chest pain caused by myocardial ischemia (i.e. stable angina pectoris) may be present for months or years and is typically provoked by exercise or emotional stress and relieved within minutes in rest or with medication (nitrates). ${ }^{4-6}$

\section{INITIAL DIAGNOSTIC EVALUATION}

Chest pain is a symptom of a wide variety of diseases, ranging from a trivial ailment to more serious potentially life-threatening disease (Table 1). Onset of chest pain can be sudden (acute) or more gradual (chronic). The majority of patients with chest pain have less severe and non-cardiac etiologies. Initial evaluation encompasses a thorough history and physical examination to try to identify the cause and risk of adverse events. Identifying the underlying etiology can be challenging, especially when symptom presentation is atypical. ${ }^{7,8}$ Additional diagnostic testing is often necessary and include an electrocardiographic and biochemical testing at presentation. Additional inpatient or outpatient clinic testing is used when the etiology remains unknown, but the diagnostic approach is different in patients with acute and chronic chest pain.

\section{Acute chest pain}

Based on a combination of clinical history, symptoms, current vital signs and findings of physical examination, the physician assesses patient's risk of disease and may decide to initiate (supportive) therapy. Shortly after presentation in the emergency department (preferably within 10 minutes) an electrocardiogram will be obtained to identify myocardial ischemia, arrhythmias or signs suggestive of other potentially life-threatening disease. ${ }^{4,5}$ Biochemical testing in the emergency department is commonly focused on cardiac biomarkers (cardiac troponin), hemoglobin and if indicated D-dimer testing. The initial risk assessment will guide further diagnostic testing and therapy.

\section{Chronic chest pain}

In patients with chronic chest pain suspected for stable coronary artery disease (i.e. stable angina pectoris), it is important to assess whether symptoms are typical, atypical or noncardiac and whether general cardiovascular risk factors exist. Results from physical examination may provide clues directed to the underlying etiology such as severe hypertension, congestive heart failure or valvular disease. An electrocardiogram may show (transient) ischemia, atrial fibrillation, prior myocardial infarction, cardiomyopathy, hypertrophy or conduction abnormalities. ${ }^{6}$ Establishing a general cardiovascular risk profile including plasma glucose, lipids and hemoglobin concentration is indicated in patients with suspected stable angina pectoris. Based on these initial findings, the pre-test probability of disease (i.e. risk of coronary artery disease) can be determined. Still, a final diagnosis is infrequently found without the use of diagnostic testing. The diagnostic approach is tailored to the patient's pre-test risk of coronary artery disease. 
Table 1.

Cardiac and non-cardiac conditions that may cause chest pain.*

\begin{tabular}{|c|c|c|c|c|c|}
\hline Coronary & $\begin{array}{l}\text { Non-coronary } \\
\text { myocardial }\end{array}$ & Pulmonary & $\begin{array}{l}\text { Gastro-intes- } \\
\text { tinal }\end{array}$ & Orthopedic & Other \\
\hline Embolism & Arrhythmia & Asthma & $\begin{array}{l}\text { Biliary } \\
\text { disease }\end{array}$ & Cervical hernia & Anemia \\
\hline Spasm & $\begin{array}{l}\text { Blunt chest } \\
\text { trauma }\end{array}$ & Bronchitis & Cholecystitis & Costochondritis & $\begin{array}{l}\text { Aortic } \\
\text { dissection/ } \\
\text { aneurysm }\end{array}$ \\
\hline $\begin{array}{l}\text { Microvascular } \\
\text { dysfunction }\end{array}$ & $\begin{array}{l}\text { Congestive } \\
\text { heart failure }\end{array}$ & COPD & Esophagitis & Musculoskeletal & $\begin{array}{l}\text { Arteriovenous } \\
\text { fistula }\end{array}$ \\
\hline $\begin{array}{l}\text { Myocardial } \\
\text { bridging }\end{array}$ & Dilated CMP & Embolism & Gastric reflux & $\begin{array}{l}\text { Rheumatic } \\
\text { disease }\end{array}$ & Critical illness \\
\hline $\begin{array}{l}\text { Plaque erosion/ } \\
\text { rupture }\end{array}$ & $\begin{array}{l}\text { Hypertrophic } \\
\text { CMP }\end{array}$ & Hypertension & Gastritis & Trauma & Herpes zoster \\
\hline $\begin{array}{l}\text { Spontaneous } \\
\text { dissection }\end{array}$ & $\begin{array}{l}\text { (Peri-) } \\
\text { myocarditis }\end{array}$ & Infarction & Pancreatitis & & Hyperthermia \\
\hline Stable CAD & Sarcoidosis & OSAS & Peptic ulcer & & Hyperthyroidism \\
\hline \multirow[t]{6}{*}{ Thrombus } & $\begin{array}{l}\text { Severe } \\
\text { hypertension }\end{array}$ & Pleuritis & & & Malignancy \\
\hline & Stress CMP & Pneumonia & & & Mediastinitis \\
\hline & $\begin{array}{l}\text { Valve } \\
\text { dysfunction }\end{array}$ & Pneumothorax & & & Panic disorder \\
\hline & & & & & $\begin{array}{l}\text { Sickle cell } \\
\text { disease }\end{array}$ \\
\hline & & & & & Stroke \\
\hline & & & & & $\begin{array}{l}\text { Sympatho- } \\
\text { mimetic toxicity }\end{array}$ \\
\hline
\end{tabular}

* conditions are presented in alphabetical order.

$\mathrm{CAD}=$ coronary artery disease; $\mathrm{CMP}=$ cardiomyopathy; $\mathrm{COPD}=$ chronic obstructive pulmonary disease; OSAS = obstructive sleep apnea syndrome.

\section{ADDITIONAL NON-INVASIVE TESTING}

Clinicians have a large armamentarium of non-invasive diagnostic modalities at their disposal to evaluate cardiac and valvular function, to assess coronary artery disease, to detect acute and chronic myocardial disease and to characterize structural myocardial disease. Commonly used modalities include cardiac computed tomography angiography (CCTA), cardiovascular magnetic resonance imaging (CMR), echocardiography, exercise treadmill testing (ETT), and nuclear perfusion imaging (including positron emission tomography [PET] and single-photon emission computed tomography [SPECT]). Each modality has its own strengths and shortcomings. Choosing the appropriate test depends on the clinical situation and indication, the pretest 
Figure 1.

Patient examples.

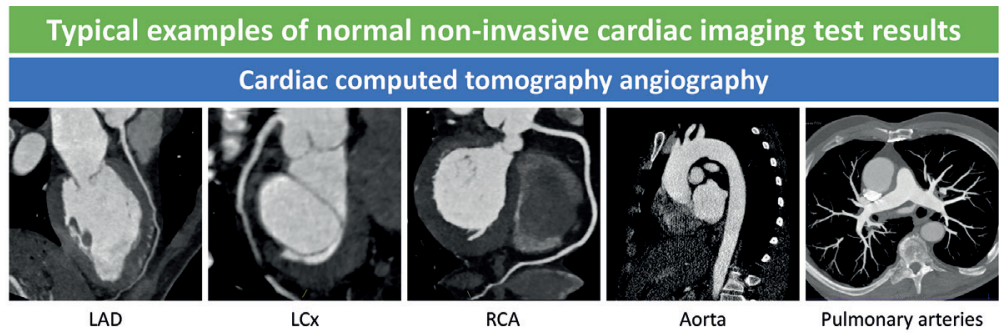

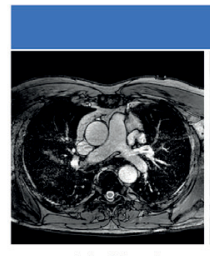

Bright blood

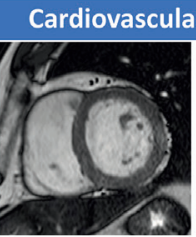

Cine SAX

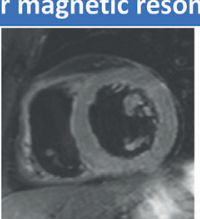

T2-weighted SAX

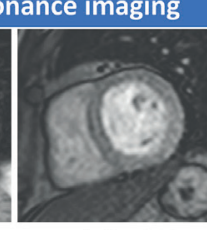

Perfusion SAX

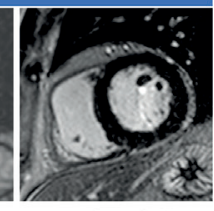

DE-CMR SAX

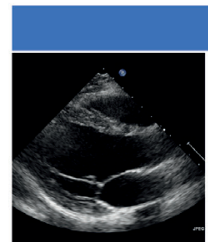

PLAX

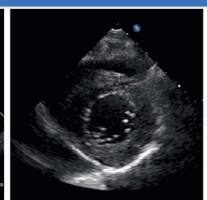

PSAX

Echocardiography

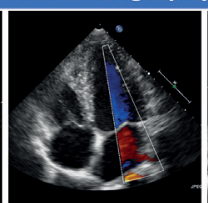

$\mathrm{Ap} 4 \mathrm{CH}$

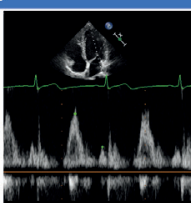

PW-Doppler mv

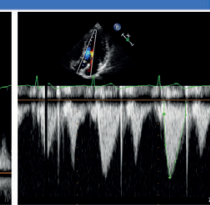

CW-Doppler av

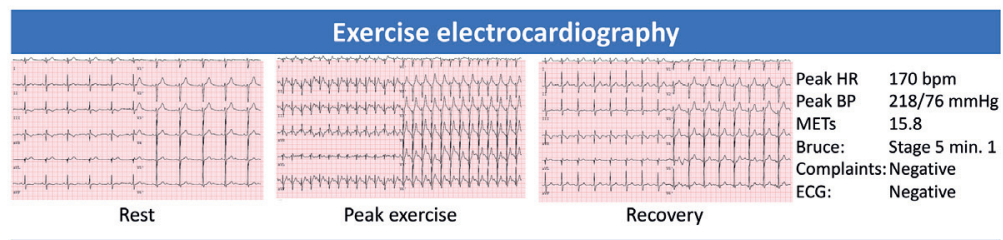

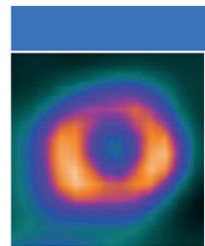

Rest SAX

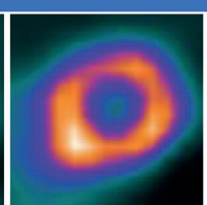

Stress SAX

Nuclear imaging

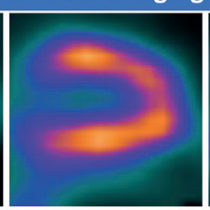

Rest VLA

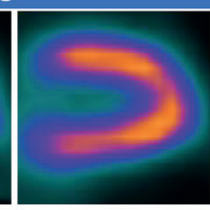

Stress VLA

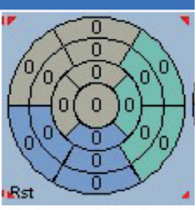

Bullseye

$\mathrm{Ap4CH}=$ apical four chamber, $\mathrm{BP}=$ blood pressure, $\mathrm{bpm}=$ beats per minute, $\mathrm{CW}$-Doppler av = continuous wave Doppler aortic valve, $\mathrm{ECG}=$ electrocardiogram, $\mathrm{DE}-\mathrm{CMR}=$ delayed enhancement cardiovascular magnetic resonance, $\mathrm{HLA}=$ horizontal long axis, $\mathrm{HR}=$ heart rate, $\mathrm{LAD}=$ left anterior descending artery, $\mathrm{LCx}=$ left circumflex artery, LVOT $=$ left ventricular outflow tract, $\mathrm{METS}=$ metabolic equivalent, $\mathrm{PLAX}=$ parasternal long axis, $\mathrm{PSAX}=$ parasternal short axis, $\mathrm{PW}$-Doppler $\mathrm{mw}=$ pulsed wave Doppler mitral valve, $\mathrm{RCA}=$ right coronary artery, $\mathrm{SAX}=$ short axis.

1. Coronary calcification in the left coronary artery using native CT and a mixed plaque in the left anterior descending artery on CT angiography. 2. "Triple rule out CT" showing a type A aortic dissection.3. A central pulmonary embolism, with thrombus in both main pulmonary arteries (image of the right pulmonary artery is magnified). 4. Hyperenhancement consistent with a small but nearly transmural inferior myocardial infarction. 5. Acute peri-myocarditis with thickened pericardium, high signal intensity of the pericardium on T2-weighted 
Figure 1. (continued)

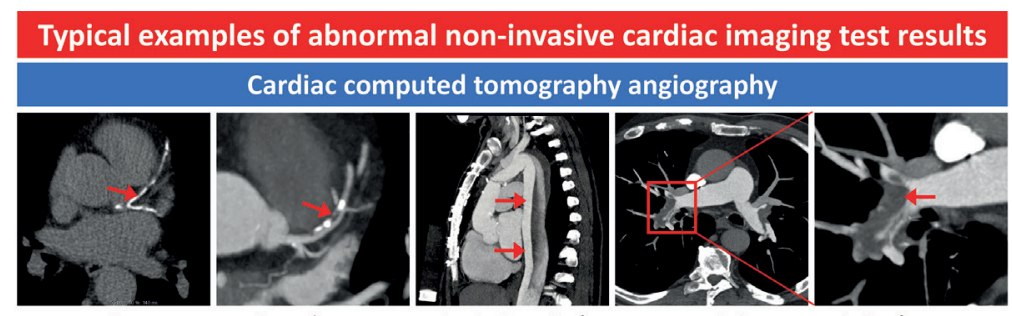

Coronary artery disease ${ }^{1}$

Aortic dissection ${ }^{2}$

Pulmonary embolism ${ }^{3}$

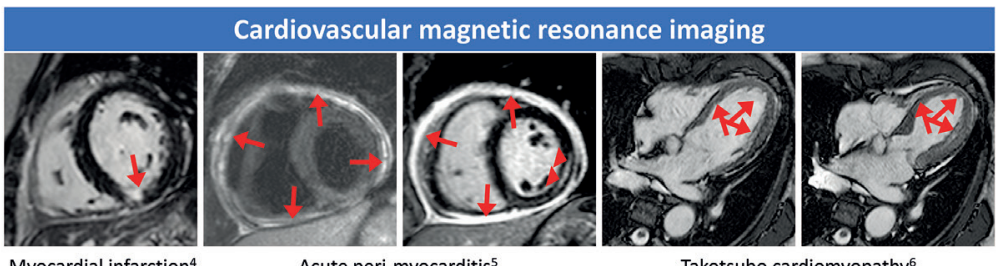

Myocardial infarction ${ }^{4}$

Acute peri-myocarditis ${ }^{5}$

Takotsubo cardiomyopathy ${ }^{6}$

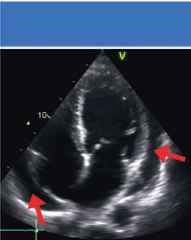

Pericarditis $^{7}$

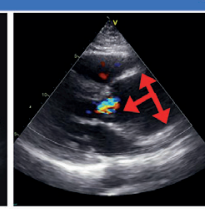

Aortic aneurysm ${ }^{8}$

Echocardiography

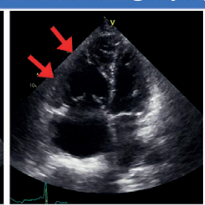

Pulmonary embolism ${ }^{9}$

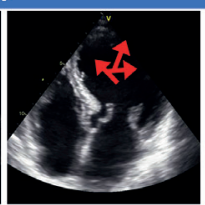

Takotsubo cardiomyopathy ${ }^{10}$

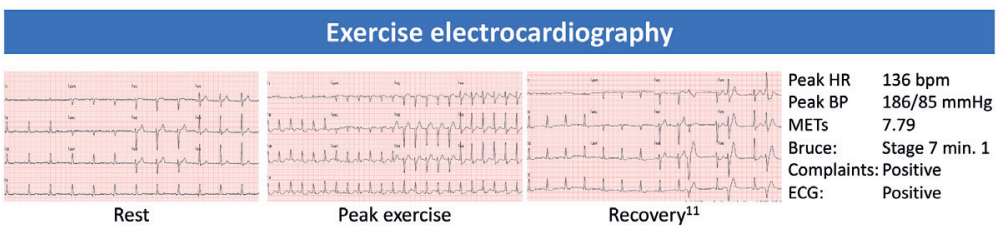

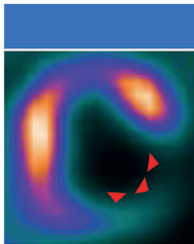

Rest SAX

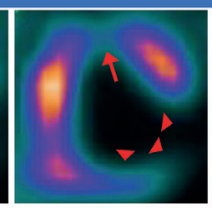

Stress SAX

Nuclear imaging

and DE-CMR (arrows), in combination with mid-wall scar in the inferolateral segment (arrowheads DE-CMR). 6. Takotsubo cardiomyopathy with apical ballooning during systole (of note, systolic images are shown, recovery of left ventricular function was observed in 2 weeks and hyperenhancement was absent on DE-CMR). 7. Post-infarction pericarditis with pericardial effusion (Dressler syndrome). 8. Dilated ascending aorta with aortic valve regurgitation. 9 . Enlarged right ventricle with septal deviation towards the left ventricle, suggestive for acute right ventricular overload in the setting of an acute pulmonary embolism. 10. Takotsubo cardiomyopathy with apical ballooning during systole (image on the right). 11. Significant ST-depression during exercise and ventricular extra systolic beats during recovery. 12. ${ }^{99 \mathrm{mTC}}$ MIBI Myocardial Perfusion Scintigraphy. Moderate myocardial ischemia in the mid and basal anterior-anteroseptal segments (arrow). A non- reversible inferolateral perfusiondefect is observed, compatible with a previous myocardial infarction (arrowheads). 
probability of disease, a patient's ability to exercise, interpretability of the electrocardiogram at rest, local availability and expertise, test duration, use of radiation, use of contrast agents, the need for additional diagnostic and prognostic information and costs. Resting echocardiography is often performed as an initial non-invasive test in patients with chest pain, as it is cheap, widely available and easily transportable to the patients' bedside. See Table 2 for the main differences in test characteristics of commonly used modalities in chest pain. Image examples of patients evaluated for chest pain are shown in Figure 1.

\section{DIAGNOSTIC EVALUATION OF ACUTE CHEST PAIN}

PART II of this thesis discusses the use of non-invasive cardiac imaging modalities in patients with acute chest pain. The initial evaluation in a patient with acute chest pain is focused on rapid exclusion of acute life-threatening conditions. Cardiac specific biomarker testing (troponin I or $\mathrm{T}$ ) is mandatory when patients are suspected of having acute myocardial injury. ${ }^{4,22}$ The sensitivity of cardiac troponin assays to detect acute myocardial infarction have been importantly improved. This development may have clinical implications for referral of patients to diagnostic testing. Earlier and more reliable rule out of acute myocardial infarction is now expected, while an accompanying decreased specificity of myocardial infarction may result in more (potentially inappropriate) referral to invasive procedures. Chapter 2 reviews the diagnostic approach in patients with acute chest pain and discusses the anticipated changing role of non-invasive cardiac imaging since the introduction of high sensitivity cardiac troponin assays.

Normal cardiac troponin values essentially rule out cardiomyocyte damage with great confidence. Advances in troponin assay technology have substantially improved the ability to exclude acute myocardial infarction in $99 \%$ of patients with acute chest pain in the emergency department. ${ }^{23-28}$ In the contemporary troponin era, additional non-invasive diagnostic testing was routinely performed to reduce the risk of missing an acute myocardial infarction. In patients with normal high-sensitive troponin levels, it becomes questionable whether routine non-invasive diagnostic testing is still needed in all patients, or that it may even increase the number of false positive test results. Therefore, in Chapter 3 , the role of additional diagnostic testing in patients with acute chest pain and normal high-sensitivity cardiac troponin levels is investigated.

Abnormal troponin levels commonly reflect myocardial injury which may have been caused by ischemic (e.g. myocardial infarction related to plaque rupture or type II infarction) or non-ischemic disease (e.g. myocarditis, pulmonary embolism). Elevated troponin levels are more commonly observed when using high sensitivity assays and the specificity for acute myocardial infarction is reduced. ${ }^{23-26}$ Still, most patients with acute chest pain and elevated troponin levels are routinely treated as acute myocardial infarction and routinely sent to invasive coronary angiography. In these patients non-obstructive coronary artery disease or normal coronaries are frequently encountered. Although obstructive coronary artery diseases has now been ruled out, the differential diagnosis remains broad and includes ischemic as well as non-ischemic disease. In Chapter 4, we review the role of imaging in these patients and propose a new diagnostic approach.

Ideally, unnecessary invasive procedures should be avoided as much as possible to prevent potential procedure-related complications, longer duration of hospitalization and health care costs. In stable angina pectoris and troponin negative acute coronary syndromes, a CMR and CTA first approach has shown to improve selection for invasive coronary angiography. ${ }^{29,30}$ Whether CMR and CTA early in the diagnostic process in patients with acute chest pain and elevated troponin levels may be beneficial is unknown. We performed a randomized controlled trial (described in Chapter $\mathbf{5}$ and $\mathbf{6}$ ) in patients with suspected non-ST elevation myocardial 


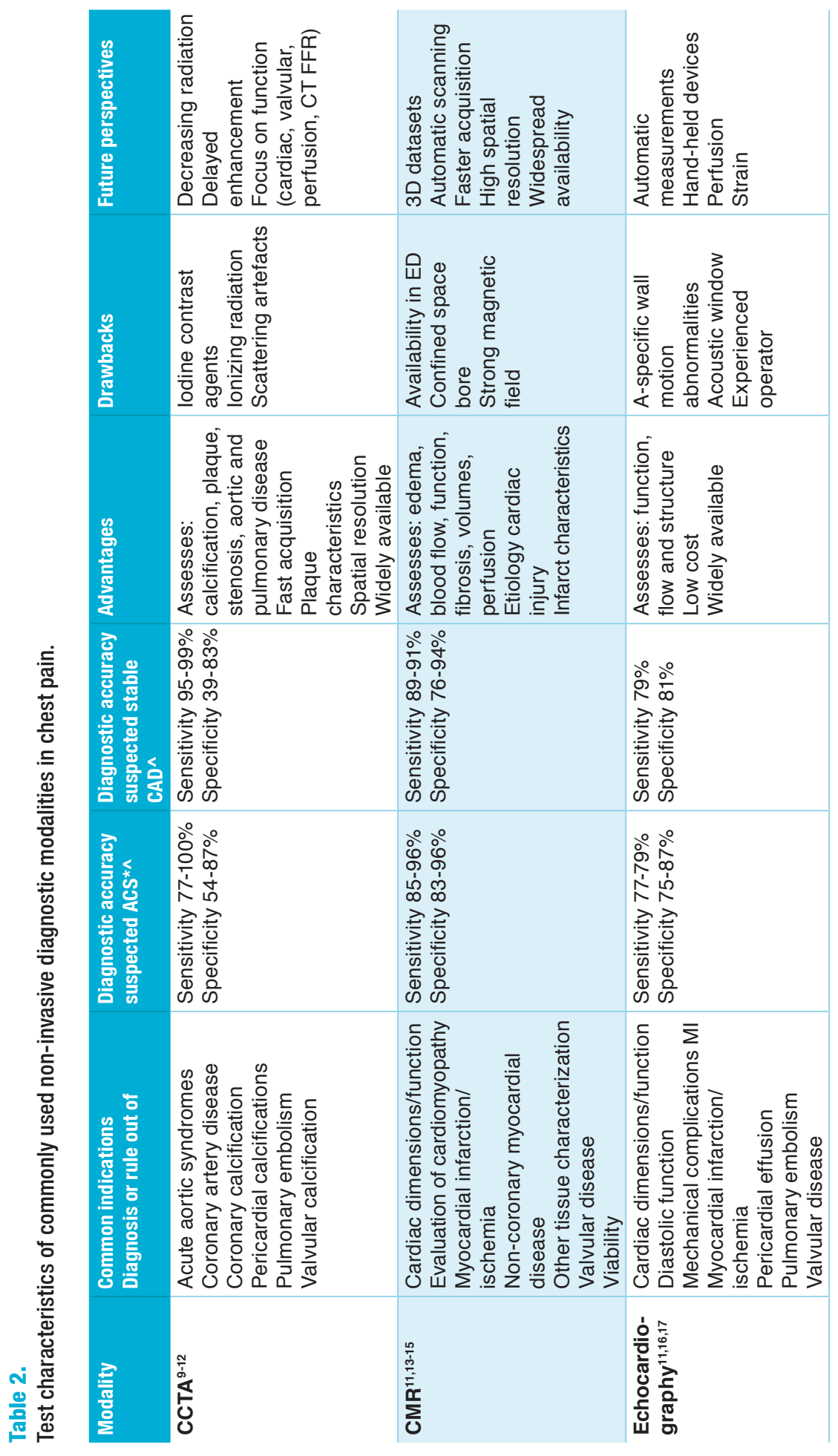




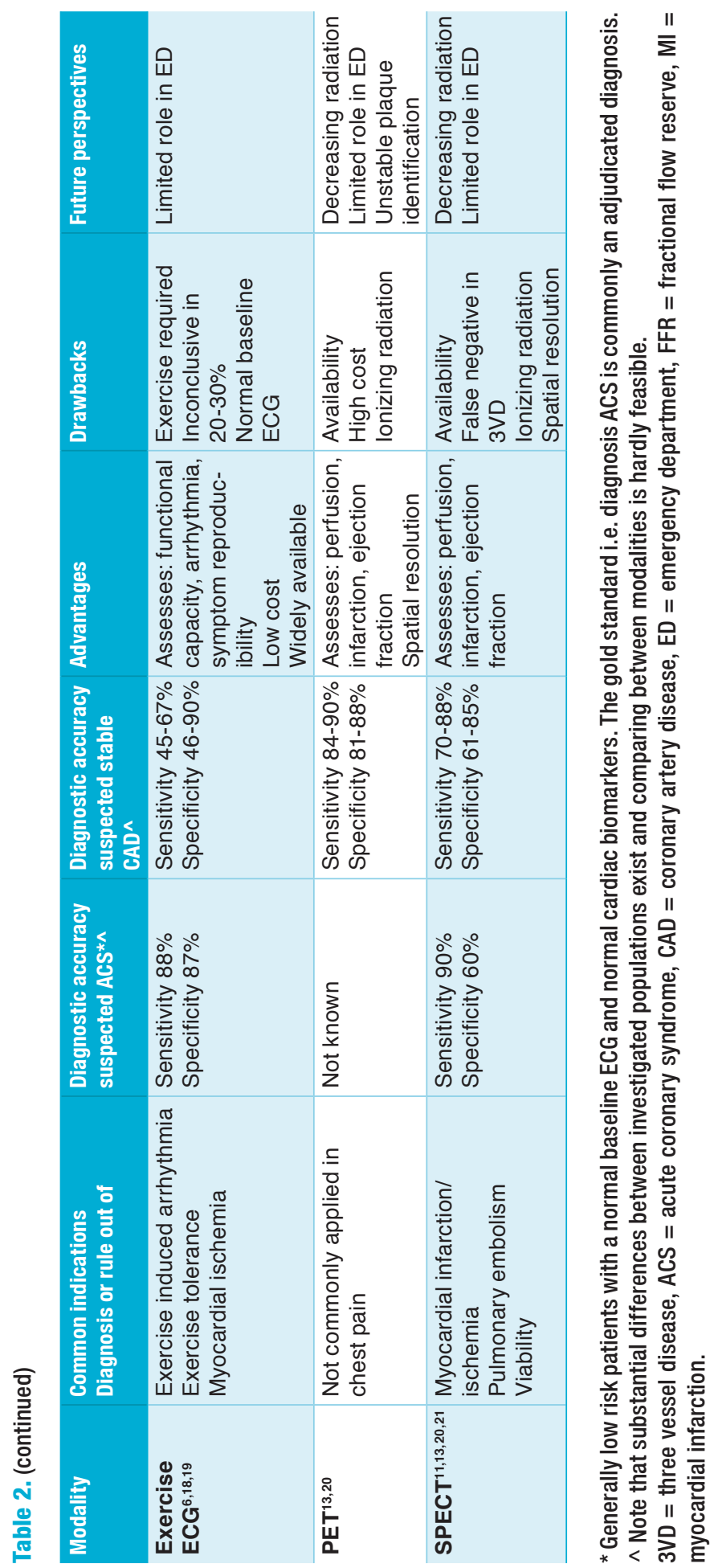


infarction to investigate the role of a CMR or CTA first approach. Ruling out myocardial infarction or diagnosing an alternative non-coronary diagnosis by using CMR or CTA may safely prevent invasive coronary angiography, improve the diagnostic yield and patient outcome.

Chapter 7 focusses on the role of CMR in patients with a definite myocardial infarction. Although myocardial infarction is usually symptomatic, causing acute chest pain and urges patients for seeking emergency care, a nontrivial proportion of patients has unrecognized myocardial infarction. ${ }^{31-33}$ These silent events may be detected with routine electrocardiography, imaging or become apparent after complications occur. Determining the age of the infarction has important clinical implications. CMR has the unique potential to characterize tissue non-invasively. As tissue characteristics change over time after infarction, due to infarct healing processes, CMR can be helpful in determining infarct age. The main purpose of our study was to investigate the performance of different CMR infarct characteristics for differentiating acute from chronic myocardial infarction.

\section{DIAGNOSTIC EVALUATION OF CHRONIC CHEST PAIN}

PART III of this thesis describes the role of non-invasive cardiac imaging modalities in patients with suspected or known stable coronary artery disease. Typical chest pain (i.e. suspected angina pectoris) usually indicates a flow limiting coronary artery atherosclerotic plaque and myocardial ischemia during stress. However, coronary artery disease is not always for the cause of chronic chest pain. Non-invasive imaging can be used to detect or rule out obstructive CAD or search for alternative diagnoses. Chapter 8 presents a case of a patient with typical angina pectoris in whom obstructive coronary artery disease was ruled out and an uncommon cause for chest pain was diagnosed using CTA.

Although the primary use for non-invasive diagnostic testing is establishing a correct diagnosis, important prognostic information is often provided simultaneously. Prognosis becomes particularly important when the test is negative. In case a negative test indicates an excellent prognosis, this test result may obviate the need for further downstream testing or therapy. Chapter 9 provides a bird's-eye overview of the literature on commonly used non-invasive cardiac tests in patients with suspected or known stable coronary artery disease. This meta-analysis pools the existing literature and is the first study to compare the prognosis after a negative test between the different modalities.

PART IV discusses and summarizes the main findings of this thesis in the light of current literature.

\section{OBJECTIVES AND OUTLINE OF THE THESIS}

The contents of this thesis are summarized in Figure 2. The aims of this thesis are:

\section{PART I: Introduction}

- The general objective of this thesis is to investigate the value of non-invasive diagnostic testing in the assessment of patients with acute and chronic chest pain. Chapter 1.

\section{PART II: Acute chest pain}

- To provide an overview of the diagnostic approach in patients with acute chest pain and to discuss a potential changing role of non-invasive cardiac imaging in the high sensitivity cardiac troponin era. Chapter 2.

- To investigate whether additional testing in patients with chest pain and normal high sensitivity cardiac troponin levels is necessary. Chapter 3. 
- To review the diagnostic challenges in patients with suspected myocardial infarction with non-obstructed coronary arteries and to propose a new diagnostic strategy. Chapter 4.

- To evaluate whether implementing CMR or CTA first in the diagnostic process safely reduces the need for invasive coronary angiography in patients with suspected myocardial infarction. Chapter 5 and 6.

- To provide insight into the prevalence of different infarct characteristics over time and to assess the performance of these characteristics for discriminating acute from chronic myocardial infarction. Chapter 7.

\section{PART III: Chronic chest pain}

- To present a case showing that non-invasive cardiac imaging is useful in narrowing down the broad differential diagnosis of chest pain. Chapter 8.

- To compare the prognostic value of a negative test result for all commonly used non-invasive cardiac imaging tests in patients with suspected or known coronary artery disease. Chapter 9.

\section{PART IV: Discussion and summary}

- To summarize and discuss the results of this thesis in the context of the current literature and to provide future perspectives for the diagnostic approach in patients with chest pain. Chapter 10.

\section{Appendices}

- To discuss the future valorization of the findings presented in this thesis, to provide a list of abbreviations commonly used throughout the thesis, information about the author and acknowledgements. 


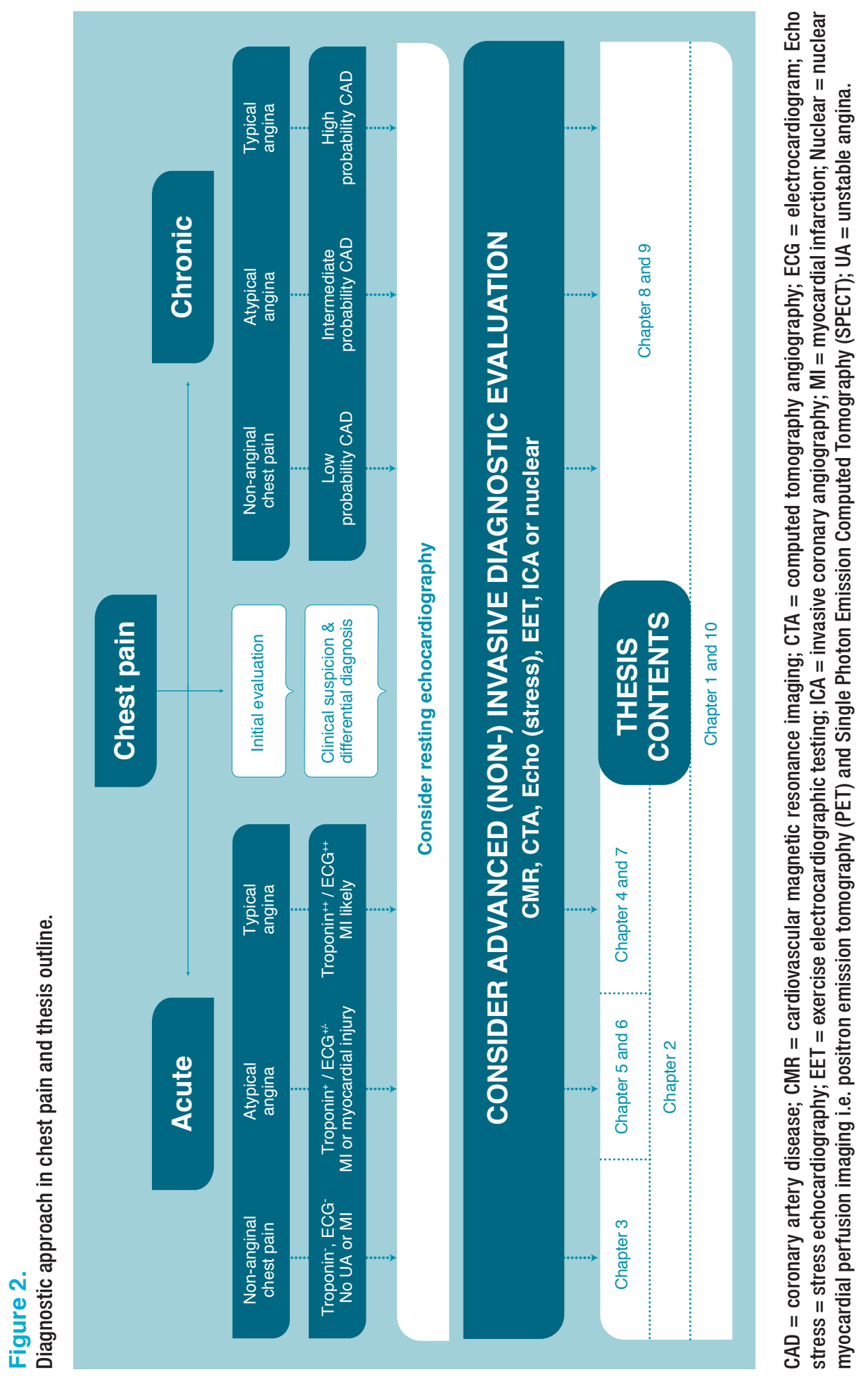




\section{REFERENCES}

1. Townsend N, Wilson L, Bhatnagar P, Wickramasinghe K, Rayner M, Nichols M. Cardiovascular disease in Europe: epidemiological update 2016. Eur Heart J 2016;37:3232-45.

2. Wilkins $E$ WL, Wickramasinghe $K$, Bhatnagar $P$, Leal $\mathrm{J}$, Luengo-Fernandez R, Burns R, Rayner M, Townsend N. European Cardiovascular Disease Statistics 2017. European Heart Network, Brussels.

3. Mockel M, Searle J, Muller R, et al. Chief complaints in medical emergencies: do they relate to underlying disease and outcome? The Charite Emergency Medicine Study (CHARITEM). European journal of emergency medicine : official journal of the European Society for Emergency Medicine 2013;20:103-8.

4. Roffi M, Patrono C, Collet JP, et al. ESC Guidelines for the management of acute coronary syndromes in patients presenting without persistent ST-segment elevation: Task Force for the Management of Acute Coronary Syndromes in Patients Presenting without Persistent ST-Segment Elevation of the European Society of Cardiology (ESC). Eur Heart J 2015;37:267-315.

5. Ibanez B, James S, Agewall S, et al. 2017 ESC Guidelines for the management of acute myocardial infarction in patients presenting with ST-segment elevation: The Task Force for the management of acute myocardial infarction in patients presenting with ST-segment elevation of the European Society of Cardiology (ESC). Eur Heart J 2017;39:119-77.

6. Montalescot G, Sechtem U, Achenbach S, et al. 2013 ESC guidelines on the management of stable coronary artery disease: the Task Force on the management of stable coronary artery disease of the European Society of Cardiology. Eur Heart J 2013;34:2949-3003.

7. Fanaroff AC, Rymer JA, Goldstein SA, Simel DL, Newby LK. Does This Patient With Chest Pain Have Acute Coronary Syndrome?: The Rational Clinical Examination Systematic Review. JAMA 2015;314:1955-65.

8. Ohman EM. Chronic Stable Angina. N Engl J Med 2016;375:293.

9. Budoff MJ, Dowe D, Jollis JG, et al. Diagnostic performance of 64-multidetector row coronary computed tomographic angiography for evaluation of coronary artery stenosis in individuals without known coronary artery disease: results from the prospective multicenter ACCURACY (Assessment by Coronary Computed Tomographic Angiography of Individuals Undergoing Invasive Coronary Angiography) trial. J Am Coll Cardiol 2008;52:1724-32.

10. Meijboom WB, Meijs MF, Schuijf JD, et al. Diagnostic accuracy of 64-slice computed tomography coronary angiography: a prospective, multicenter, multivendor study. J Am Coll Cardiol 2008;52:2135-44.

11. Danad I, Szymonifka J, Twisk JWR, et al. Diagnostic performance of cardiac imaging methods to diagnose ischaemia-causing coronary artery disease when directly compared with fractional flow reserve as a reference standard: a meta-analysis. Eur Heart J 2017;38:991-8.

12. Hoffmann U, Bamberg F, Chae CU, et al. Coronary computed tomography angiography for early triage of patients with acute chest pain: the ROMICAT (Rule Out Myocardial Infarction using Computer Assisted Tomography) trial. J Am Coll Cardiol 2009;53:1642-50.

13. Jaarsma C, Leiner T, Bekkers SC, et al. Diagnostic performance of noninvasive myocardial perfusion imaging using single-photon emission computed tomography, cardiac magnetic resonance, and positron emission tomography imaging for the detection of obstructive coronary artery disease: a meta-analysis. J Am Coll Cardiol 2012;59:1719-28.

14. Layland J, Rauhalammi S, Watkins S, et al. Assessment of Fractional Flow Reserve in Patients With Recent Non-ST-Segment-Elevation Myocardial Infarction: Comparative Study With 3-T Stress Perfusion Cardiac Magnetic Resonance Imaging. Circ Cardiovasc Interv 2015;8:e002207.

15. Nagel E, Lehmkuhl HB, Bocksch W, et al. Noninvasive diagnosis of ischemia-induced wall motion abnormalities with the use of high-dose dobutamine stress MRI: comparison with dobutamine stress echocardiography. Circulation 1999;99:763-70.

16. Jaarsma C, Schalla S, Cheriex EC, et al. Incremental value of cardiovascular magnetic resonance over echocardiography in the detection of acute and chronic myocardial infarction. J Cardiovasc Magn Reson 2013;15:5.

17. Heijenbrok-Kal MH, Fleischmann KE, Hunink MG. Stress echocardiography, stress single-photonemission computed tomography and electron beam computed tomography for the assessment of coronary artery disease: a meta-analysis of diagnostic performance. Am Heart J 2007:154:415-23.

18. Nielsen LH, Ortner N, Norgaard BL, Achenbach S, Leipsic J, Abdulla J. The diagnostic accuracy and outcomes after coronary computed tomography angiography vs. conventional functional testing in patients with stable angina pectoris: a systematic review and meta-analysis. European heart journal cardiovascular Imaging 2014;15:961-71.

19. Greenslade $\mathrm{JH}$, Parsonage W, Ho A, et al. Utility of Routine Exercise Stress Testing among Intermediate Risk Chest Pain Patients Attending an Emergency Department. Heart, lung \& circulation 2015;9:879-84.

20. Mc Ardle BA, Dowsley TF, deKemp RA, Wells GA, Beanlands RS. Does rubidium-82 PET have superior accuracy to SPECT perfusion imaging for the diagnosis of obstructive coronary disease?: A systematic review and meta-analysis. J Am Coll Cardiol 2012;60:1828-37.

21. Heller GV, Stowers SA, Hendel RC, et al. Clinical value of acute rest technetium-99m tetrofosmin tomographic myocardial perfusion imaging in patients with acute chest pain and nondiagnostic electrocardiograms. J Am Coll Cardiol 1998;31:1011-7.

22. Thygesen K, Alpert JS, Jaffe AS, et al. Third universal definition of myocardial infarction. Eur Heart J 2012;33:2551-67.

23. Reichlin T, Hochholzer W, Bassetti S, et al. Early diagnosis of myocardial infarction with sensitive cardiac troponin assays. $\mathrm{N}$ Engl $\mathrm{J}$ Med 2009;361:858-67. 
24. Keller T, Zeller T, Peetz D, et al. Sensitive troponin I assay in early diagnosis of acute myocardial infarction. N Engl J Med 2009;361:868-77.

25. Lipinski MJ, Baker NC, Escarcega RO, et al. Comparison of conventional and high-sensitivity troponin in patients with chest pain: a collaborative meta-analysis. Am Heart J 2015;169:6-16 e6.

26. Body R, Carley S, McDowell G, et al. Rapid exclusion of acute myocardial infarction in patients with undetectable troponin using a high-sensitivity assay. J Am Coll Cardiol 2011;58:1332-9.

27. Bandstein N, Ljung R, Johansson M, Holzmann MJ. Undetectable high-sensitivity cardiac troponin T level in the emergency department and risk of myocardial infarction. J Am Coll Cardiol 2014;63:2569-78.

28. Shah ASV, Anand A, Sandoval Y, et al. High-sensitivity cardiac troponin I at presentation in patients with suspected acute coronary syndrome: a cohort study. Lancet 2015;386:2481-8.

29. Greenwood JP, Ripley DP, Berry C, et al. Effect of Care Guided by Cardiovascular Magnetic Resonance, Myocardial Perfusion Scintigraphy, or NICE Guidelines on Subsequent Unnecessary Angiography Rates: The CE-MARC 2 Randomized Clinical Trial. JAMA 2016;316:1051-60.

30. Litt HI, Gatsonis C, Snyder B, et al. CT angiography for safe discharge of patients with possible acute coronary syndromes. N Engl J Med 2012;366:1393403.

31. Kim HW, Klem I, Shah DJ, et al. Unrecognized non-Q-wave myocardial infarction: prevalence and prognostic significance in patients with suspected coronary disease. PLoS Med 2009;6:e1000057.

32. de Torbal A, Boersma E, Kors JA, et al. Incidence of recognized and unrecognized myocardial infarction in men and women aged 55 and older: the Rotterdam Study. Eur Heart J 2006;27:729-36.

33. Kannel WB, Abbott RD. Incidence and prognosis of unrecognized myocardial infarction. An update on the Framingham study. N Engl J Med 1984;311:1144-7. 
PART

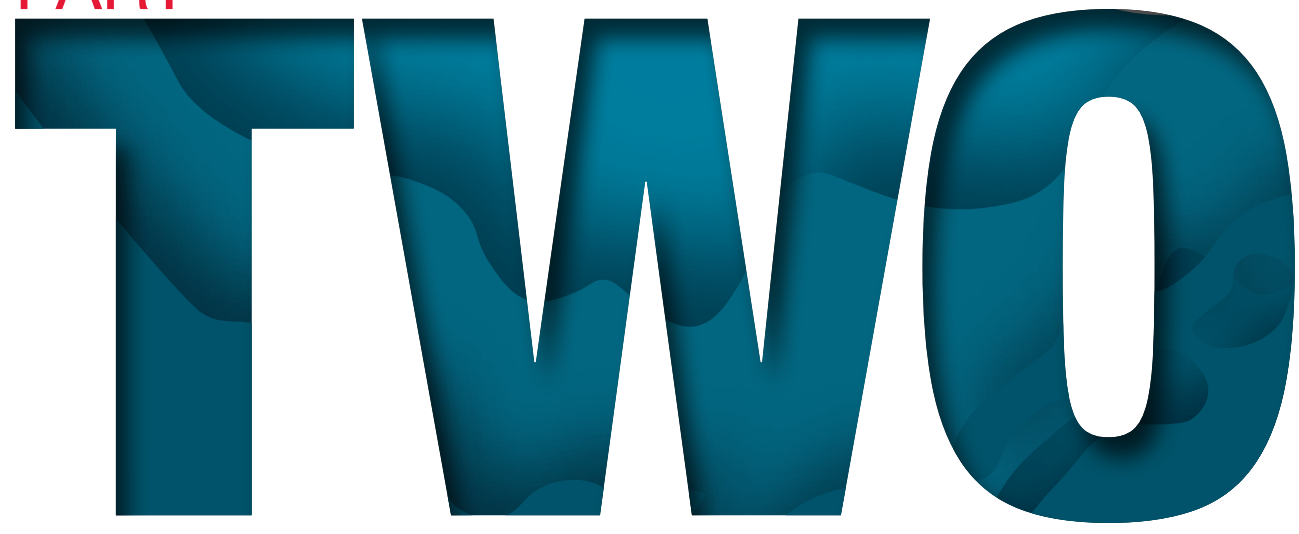


Acute chest pain 


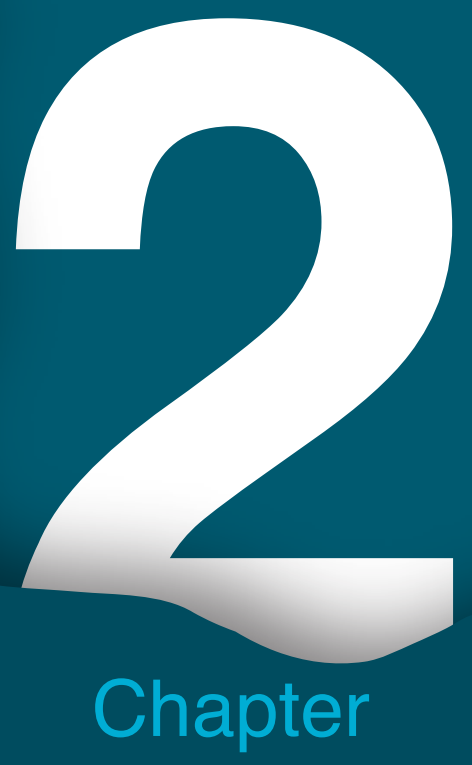




\section{Acute chest pain in the high- sensitivity cardiac troponin era: A changing role for non-invasive imaging?}

Martijn W. Smulders, MD, ${ }^{1,6}$ Bas L.J.H. Kietselaer, MD, PhD, ${ }^{1,2,6}$ Simon Schalla, MD, PhD, ${ }^{1,6}$ Jan Bucerius, MD, ${ }^{2,3,6,7}$ Caroline Jaarsma, MD, PhD, ${ }^{1,6}$ Marja P. van Dieijen-Visser, PhD, , ${ }^{4,6}$ Alma M.A. Mingels, PhD, ${ }^{4,6}$ Hans-Peter Brunner-La Rocca, MD, ${ }^{1,6}$ Mark Post, MD, PhD, ${ }^{5,6}$ Marco Das, MD, PhD, ${ }^{2,6}$ Harry J.G.M. Crijns, MD, PhD, ${ }^{1,6}$ Joachim E. Wildberger, MD, PhD, ${ }^{2,6}$ Sebastiaan C.A.M. Bekkers MD, PhD ${ }^{1,6}$

Department of ${ }^{1}$ Cardiology, ${ }^{2}$ Radiology, ${ }^{3}$ Nuclear Medicine, ${ }^{4}$ Clinical Chemistry, ${ }^{5}$ Physiology, ${ }^{6}$ Cardiovascular Research Institute Maastricht (CARIM), Maastricht University Medical Center, Maastricht, The Netherlands and department of ${ }^{7}$ Nuclear Medicine, University Hospital Aachen, Aachen, Germany 


\section{ABSTRACT}

Management of patients with acute chest pain remains challenging. Cardiac biomarker testing reduces the likelihood of erroneously discharging patients with acute myocardial infarction (AMI). Despite normal contemporary troponins, physicians have still been reluctant to discharge patients without additional testing. Nowadays, the extremely high negative predictive value of current high-sensitivity cardiac troponin (hs-cTn) assays challenges this need. However, the decreased specificity of hs-cTn assays to diagnose AMI poses a new problem as non-coronary diseases (eg, pulmonary embolism, myocarditis, cardiomyopathies, hypertension, renal failure, etc) may also cause elevated hs-cTn levels. Subjecting patients with non-coronary diseases to unnecessary pharmacological therapy or invasive procedures must be prevented. Attempts to improve the positive predictive value to diagnose AMI by defining higher initial cutoff values or dynamic changes over time inherently lower the sensitivity of troponin assays. In this review, we anticipate a potential changing role of noninvasive imaging from ruling out myocardial disease when troponin values are normal toward characterizing myocardial disease when hs-cTn values are (mildly) abnormal. 


\section{INTRODUCTION}

Acute chest pain is one of the most common reasons for emergency department (ED) presentation, accounting for $10 \%$ of all visits. ${ }^{1}$ Diagnostic evaluation of patients with acute chest pain remains challenging due to the heterogeneous spectrum of underlying etiologies that can be of cardiovascular or non-cardiovascular origin, and pernicious or benign. ${ }^{2,3}$ Although most patients have a non-life-threatening disorder, approximately $15 \%$ are diagnosed as having acute myocardial infarction (AMI) and in rare cases with acute aortic dissection (AAD) or pulmonary embolism (PE). ${ }^{2,4}$ Even after thorough evaluation, a firm diagnosis remains uncertain in a subset of patients that can unsettle patients and physicians. Particularly in those with atypical chest pain, the pain can be musculoskeletal, gastrointestinal, or respiratory in origin and the yield of additional investigations is generally low. ${ }^{3,5}$ Nevertheless, informing patients about their very low probability of future adverse cardiac events when additional noninvasive test results in the ED are negative is often sufficient for reassurance.

For decades, biomarker testing has been playing a central role in the evaluation of patients with acute chest pain and cardiac troponin (cTn) testing has substantially reduced the likelihood of erroneously discharging patients with AMI. An elevated cTn concentration is defined as a measurement exceeding the 99th percentile upper reference limit (URL) of an apparently healthy reference population. ${ }^{6}$ Contemporary cTn assays (ie, non-high-sensitive) do not have optimal precision at the recommended 99th percentile. Although serial sampling improves sensitivity, ED physicians are often still reluctant to discharge patients without ordering additional noninvasive (imaging) tests.

Current high-sensitivity (hs) cTn assays measure cTn concentrations above the limit of detection in $\geq 50 \%$ of normal individuals with $\leq 10 \%$ coefficient of variation at the recommended 99th percentile, thereby increasing the ability to determine small changes in cTn. ${ }^{7-9}$ Because of the extremely high negative predictive value (NPV) of hs-cTn assays for the diagnosis of AMI, the need for additional testing to rule out $\mathrm{AMI}$ is challenged..$^{10-12}$

Instead, because of a substantially lower specificity to diagnose AMI, ED physicians are increasingly confronted with abnormal hs-cTn values that may be related to various acute or chronic conditions other than AMI (ie, myocarditis, stress [takotsubo] cardiomyopathy, severe hypertension, tachycardia, renal failure, non-acute structural myocardial disease, AAD, PE, or even stable coronary artery disease [CAD]). ${ }^{13,14}$

Thus, abnormal hs-cTn levels (ie, above the 99th percentile) in patients presenting with acute chest pain and non-diagnostic electrocardiograms (ECGs) do not automatically equate $\mathrm{AMI}$ and warrant a more sophisticated approach. Thorough history taking, determination of risk factors, physical examination, and (serial) ECGs remain important tools but lack specificity for a certain diagnosis. Additional noninvasive imaging techniques may be useful to further characterize myocardial disease and prevent unnecessary invasive procedures or aggressive treatments. This review is intended to create a different mindset how noninvasive cardiac imaging in patients presenting with acute chest pain can be useful in the hs-cTn era. It does not come down on the side of any particular imaging strategy as evidence is still building up on this topic.

\section{INITIAL EVALUATION}

Patients with acute chest pain may have a life-threatening condition, necessitating a rapid evaluation by an experienced physician. ${ }^{15,16}$ The ED evaluation primarily focuses on the early exclusion of acute life-threatening conditions and risk stratification to identify patients who can be discharged early or might benefit from tailored treatment, rather than anatomically detecting CAD. ${ }^{17}$ For instance, CAD may just be coincidental and an unrelated finding in patients with musculoskeletal 
chest pain. Hospital admission is usually indicated in case of an acute coronary syndrome, perimyocarditis, stress cardiomyopathy, or certain "malignant" arrhythmias, and may also be appropriate for certain patients with pneumonia or pneumothorax. The acceptable miss rate regarding major adverse cardiac events (mostly AMI, death, or life-threatening arrhythmia) within 30 days of ED presentation for acute chest pain must be $<1 \% .^{18}$

Although medical history taking is subjective, the absence of typical angina pectoris characteristics and cardiovascular risk factors decreases the probability of AMI substantially, but conversely increases with an increasing number of risk factors. ${ }^{19,20}$ Physical examination is often unremarkable, but may be supportive of both coronary and non-coronary causes (eg, PE, acute aortic syndromes, perimyocarditis, valvular disease), as well as extra-cardiac causes of acute chest pain (eg, pneumothorax, pneumonia). Moreover, reproducible chest wall tenderness on palpation of the thorax substantially reduces the likelihood of AMI or unstable angina pectoris (UA)..$^{20,21}$

The ECG remains an essential, first noninvasive test in suspected AMI patients and should be assessed within 10 minutes after ED arrival. ${ }^{15,16}$ The likelihood of AMI is lower when the ECG is normal or non-diagnostic but substantially increases in the presence of marked ST-segment deviations. ${ }^{20,22}$ Because a single normal ECG does not rule out $\mathrm{AMI}$, it is recommended to obtain serial ECGs or perform continuous ECG monitoring. ${ }^{23}$

Although the prevalence of acute life-threatening non-cardiac causes of acute chest pain requiring admission (eg, AAD, PE, and certain patients with pneumothorax or pneumonia) is low, additional testing (ie, D-dimers, chest X-ray, or computed tomographic angiography [CTA]) is useful when clinical suspicion is high.

The initial evaluation remains the cornerstone of risk stratification, but lacks sufficient NPV to exclude all patients with $\mathrm{AMI}$ and positive predictive value (PPV) to diagnose AMI or other (myocardial) diseases. ${ }^{20}$ Although decision making is usually straightforward in patients presenting with typical cardiac symptoms and pronounced ST-segment deviation, this can be troublesome in patients with atypical symptoms and non-diagnostic ECGs. In these patients, biomarker testing is decisive but elevated biomarkers must always be considered in the clinical context.

\section{CARDIAC BIOMARKERS}

Cardiac biomarkers are proteins that are released after cardiomyocyte injury. Until 2000, creatine kinase-MB was the most frequently used cardiac biomarker and the frequency of mistakenly discharging patients with AMI was approximately $2 \% .{ }^{24,25}$ After the year 2000, cTns (cTnl and cTnT [ie, contemporary troponin assays]) became the preferred biomarkers to diagnose myocardial injury because of their cardiac specificity and superior sensitivity to detect myocardial damage. ${ }^{26}$ However, the risk for adverse cardiac events is still considered non-negligible in patients with acute chest pain and normal contemporary troponins. Therefore, ED physicians still seek for a higher level of confidence to exclude AMI and often order additional noninvasive and sometimes even invasive tests before discharging a patient. The NPV of distinct noninvasive modalities for adverse cardiac events ranges from $95 \%$ to $100 \%$ and is shown in Supplemental Table 1.

\section{High sensitivity cardiac troponin assays}

The improved analytical performance of the current hs-cTn assays has enabled the detection of troponins at almost 10-fold lower concentrations and with higher precision. Hs-cTn levels below the 99th percentile URL rule out AMI with extremely high confidence (NPV 99\%). 6,10-12 Undetectable hs-cTn levels rule out AMI with even higher confidence and indicate an excellent prognosis (NPV >99.5\%)..$^{12,27}$ Together with a considerable shorter period after symptom onset to detect 
increased serum troponin levels, hs-cTn assays have shown superior ability to exclude AMI in comparison with the contemporary cTn assays. ${ }^{10,11}$ Of note, serial testing should still be considered in patients with normal initial hs-cTn levels presenting very early after symptom onset.

Inversely, the incidence of AMI increases with increasingly higher hs-cTn values at presentation. ${ }^{28,29}$ It follows that rather sharply defined lower range hs-cTn cutoff values can be used to achieve an extremely high NPV but that defining the upper hs-cTn cutoff values to diagnose AMI is more gradual and less absolute. Studies to define the optimal upper hs-cTn cutoff to rule-in AMI are unique for each hs-cTn assay. For the purpose of this review, mildly elevated hs-cTn levels refer to hs-cTn levels $>$ URL and cTn levels that were previously not captured by contemporary cTn-assays without providing specific values.

\section{Low specificity and positive predictive value of hs-cTn assays}

The increased diagnostic sensitivity of hs-cTn assays comes at the expense of a lower specificity and PPV to diagnose AMI.10,11,13,30 This applies to both type $1 \mathrm{MI}$ (ie, related to plaque rupture or thrombotic occlusion) and type $2 \mathrm{Ml}$ (ie, secondary to supply-demand mismatch with or without $\mathrm{CAD}){ }^{31}$ Type $2 \mathrm{Ml}$ is becoming increasingly recognized but is poorly defined, making differentiation from type $1 \mathrm{Ml}$ often clinically difficult. ${ }^{32,33}$ Differentiation is based on clinical judgment that takes into account various coexisting factors (tachycardia's, anemia, hypertension, sepsis, renal failure, etc).

Using the currently set diagnostic cutoff value for AMI, the PPV to diagnose AMI is only $50 \%$ to $70 \% .6,10,11$ The PPV for AMI is even lower (approximately $20 \%$ ) when hs-cTn levels are mildly abnormal. ${ }^{28}$ Abnormal hs-cTn levels may indicate myocardial injury, but are not specific for type $1 \mathrm{Ml}$ and can be due to type $2 \mathrm{MI}$ (tachycardia, hypertension, sepsis, anemia, etc), non-ischemic (perimyocarditis, stress cardiomyopathy) or extra-cardiac diseases (AAD or PE). Moreover, hs-cTn assays allow for the detection of very low troponin values as seen also in patients with (asymptomatic) "stable" CAD and patients with structural heart disease (ie, congestive heart failure, cardiomyopathies, or hypertensive heart disease) ${ }^{14,34}$ Regardless, even in asymptomatic patients, mildly elevated hs-cTn levels provide incremental prognostic information..$^{14,34}$

Finally, higher baseline hs-cTn levels are observed in male and elderly patients that may exceed the URL of normal. It has therefore been suggested that age- and gender-specific cutoffs should be applied. ${ }^{8,35,36}$ Currently, uniform hs-cTn cutoff levels are used for all patients irrespective of age and sex, resulting in more positive test results in male and elderly patients and potentially missed myocardial disease in female patients. ${ }^{37}$

\section{Attempts to improve the specificity of hs-cTn assays}

It is becoming increasingly clear that hs-cTn levels should be interpreted as quantitative rather than qualitative values, and that the terms positive and negative troponin should be avoided. Several algorithms have been suggested and validated to improve the diagnostic specificity of hs-cTn assays to diagnose AMI. A common method is using predefined relative or absolute dynamic changes in hs-cTn levels quantified as the delta troponin over a specified period rather than a single baseline value. This is in accordance with the Third Universal Definition of MI that requires a rise and/or fall pattern of hs-cTn levels. ${ }^{6}$ Although the hs-cTn change must be at least above the reference change value that is based on the analytical variation of the respective assay and the biological variation, the magnitude and the time frame of this change are still debated.

Several relative and absolute changes (eg, 20-50\% and for hs-cTnT 7-9 ng/L) have been suggested but are dependent on the patient population and the immunoassay used. ${ }^{38,39}$ Moreover, many of these suggested dynamic changes have been determined retrospectively with an 
adjudicated AMI diagnosis that was based often on contemporary cTn assays. A recent study demonstrated that relative hs-cTnT changes $<20 \%$ and absolute changes $<9 \mathrm{ng} / \mathrm{L}$ are not uncommon ( $26 \%$ and $12 \%$, respectively) in non-ST-elevation myocardial infarction. ${ }^{40}$ An editorial comment to that study suggested that for using different delta values, $5-67 \%$ of AMI may be missed. ${ }^{41}$ This raises caution against the strict use of delta values to exclude AMI in patients with an otherwise high clinical probability of AMI. Moreover, dynamic changes are also not exclusive to AMI but rather indicative of acute myocardial injury.

Nevertheless, the European Society of Cardiology has recommended an algorithm for clinical use that incorporates hs-cTn baseline values and 1-hour absolute changes (hs-cTn 0-h/1-h algorithm).$^{16}$ This algorithm assigns patients into 3 groups: (1) a rule-out group (60\% of patients), (2) a rule-in group (17\% of patients), and (3) an observe group with substantial diagnostic uncertainty $\left(23 \%\right.$ of remaining patients). ${ }^{29}$ Although this algorithm improves clinical decision making, still $22 \%$ in the rule-in group and $81 \%$ in the observe group eventually do not have AMI. Most patients in the observe group are diagnosed as having non-coronary myocardial or non-cardiac disease, although preexisting CAD may be frequently present. ${ }^{29,42,43}$

Increased biomarker levels should always be evaluated in light of the clinical scenario, patient characteristics, and pretest probabilities because isolated (mildly) abnormal hs-cTn levels are insufficient to diagnose AMI. ${ }^{6}$ On the other hand, higher baseline hs-cTn and delta values may be indicative of acute (ongoing) myocardial injury and increase the probability of AMI. ${ }^{29,38}$

In summary, current clinical interpretation of abnormal hs-cTn levels in acute chest pain is useful but lacks sufficient specificity for a certain myocardial disease and methods to improve the diagnostic specificity inherently lower sensitivity.

\section{USEFULNESS OF ADDITIONAL NON-INVASIVE CARDIOVASCULAR TESTING}

Based on the initial hs-cTn values and repeated measures, the European Society of Cardiology guidelines support the classification of patients into 3 groups. ${ }^{16}$ Figure 1 shows a modification of this algorithm and provides suggestions for the usefulness of additional testing or noninvasive imaging: (1) rule-out group: in patients with hs-cTn levels $\leq U R L$ or undetectable levels, AMI can be ruled out confidently (ie, prognosis is excellent and the rate of missing AMI is extremely low) and additional testing is generally discouraged to prevent false-positive test results; (2) observe group: in patients with (mildly) abnormal (>URL) hs-cTn levels but without a substantial rise and/ or fall, additional testing and characterization of myocardial injury is often necessary (to differentiate between coronary and non-coronary myocardial disease or even extra-cardiac disease); and (3) rule-in group: patients with markedly elevated and/or substantially rising hs-cTn levels and the appropriate clinical setting have a high likelihood for AMI and should undergo invasive testing when indicated. With the exception of indicated echocardiography, additional noninvasive tests should not unnecessarily delay invasive management in the rule-in group.

In cohort studies comparing 2 sequential periods, introducing the hs-cTn assay significantly increased the prevalence of AMI, use of ACS medications, invasive coronary angiograms, revascularization procedures, and length of hospital stay as compared with the contemporary assay period. Whether this more aggressive approach improves outcome is still unknown because studies have been conflicting. ${ }^{44-46}$ Although abnormal hs-cTn values should always be interpreted in the light of symptoms and pretest probability, a certain diagnosis cannot be reliably ruled in or out at this time. Therefore, careful clinical evaluation and diagnostic workup should precede routine invasive management and may be particularly useful in the "observe" group with most considerable diagnostic uncertainty. ${ }^{42}$ 
Figure 1.

Risk stratification algorithm in patients with acute chest pain suspected for myocardial ischemia.

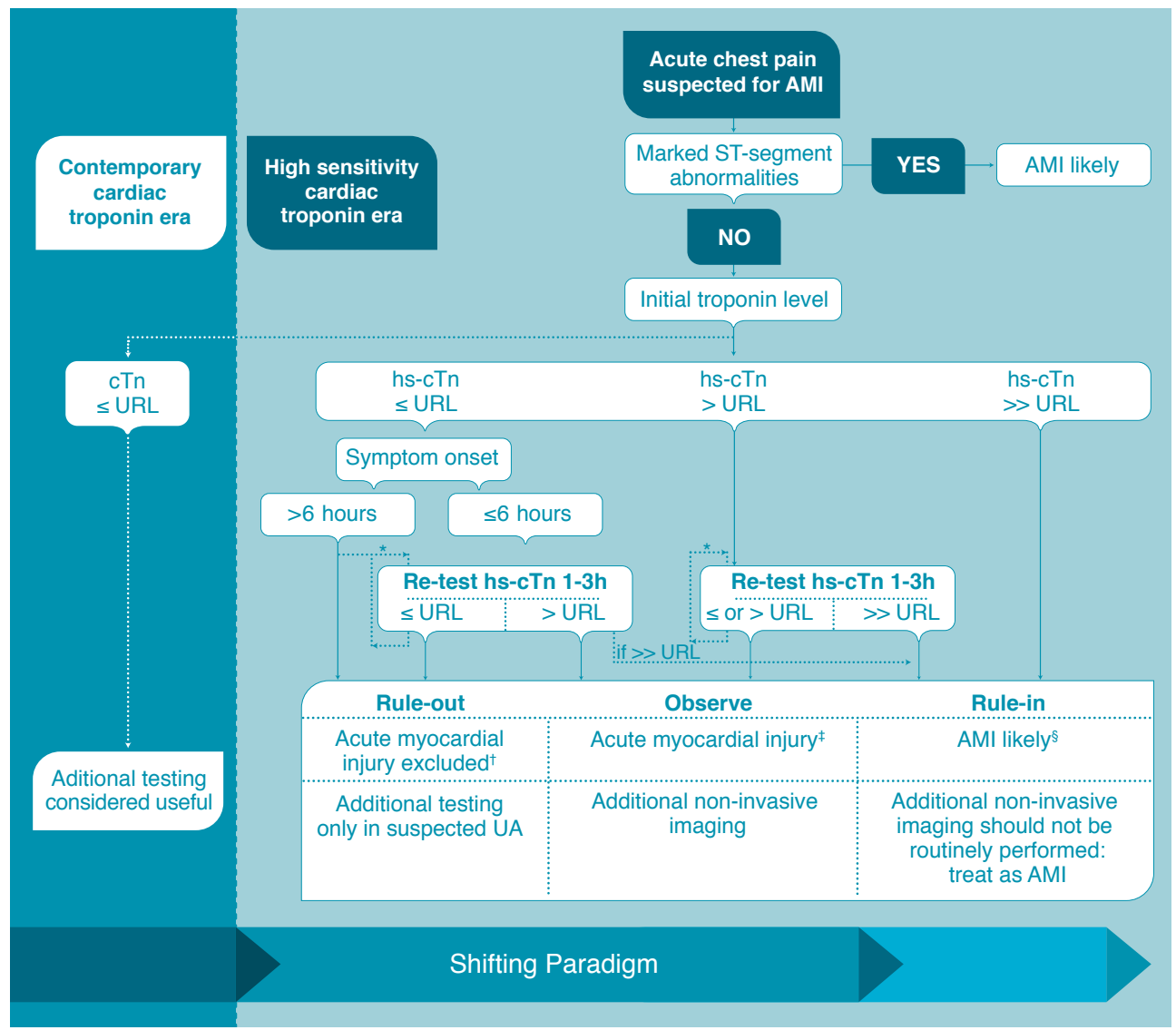

${ }^{\dagger}$ Acute myocardial injury can be ruled out confidently and prognosis is excellent. Of note: UA may still be present in a small subset of these patients. ${ }^{\ddagger}$ Acute myocardial injury: both coronary and non-coronary causes (myocarditis, cardiomyopathies [stress, hypertrophic, dilated], PE) may be responsible. ${ }^{\S} \mathrm{AMI}$ highly likely. ${ }^{*}$ Reassess hs-cTn if clinical suspicion for AMI is high and/or symptom-onset uncertain. cTn, contemporary troponin assay (ie, non-high-sensitive); STEMI, ST-elevation myocardial infarction. ">>" means markedly elevated and/or substantially rising hs-cTn level.

Furthermore, studies are needed that optimally define "markedly elevated and/or substantially rising hs-cTn levels." These studies should ideally include imaging end points to more accurately define AMI (to identify new loss of viable myocardium or new regional wall motion abnormalities), rather than an adjudicated diagnosis based on clinical parameters only.

\section{In patients with normal and undetectable hs-cTn levels}

In the contemporary cTn era (ie, non-high-sensitive) and supported by guidelines, additional noninvasive testing was often performed before discharging patients with normal troponin levels 
with increased certainty. High-sensitivity cTn assays now rule out AMI with an NPV of $99 \%$, and even $>99.5 \%$ when hs-cTn levels are undetectable..$^{10-12,27}$ In combination with a much shorter time to rule out AMI after presentation, this may obviate the need for additional noninvasive testing at all or at least in the ED in these patients. Additional testing in extremely low-risk patients may even cause harm because of an increased number of false positive test results (according to Bayes' theorem). Regardless, clinical judgment by an experienced ED physician remains crucial. Typical angina symptoms, acceleration of previously stable angina, presence of cardiovascular risk factors, signs of atherosclerosis on physical examination, preexisting coronary artery stenosis $\geq 70 \%$, or positive cardiac exercise test result may still require admission for suspected UA or discharge with additional testing in the outpatient clinic. It should be noted that the prevalence of UA declines when using hs-cTn assays because many patients diagnosed as having UA using contemporary cTn assays can be reclassified as AMI. ${ }^{44,47}$

Although AMI can be ruled out reliably, normal hs-cTn levels ( $\angle U R L)$ or stable hs-cTn elevations not fulfilling the criteria for AMI obviously do not rule out the presence of CAD or UA. Unstable angina pectoris is suspected on the basis of clinical judgment (pretest probability, risk factors, typical angina) and warrants in-hospital management. On the other hand, systematically searching for CAD (using CTA) and initiating preventive medication in a low-risk population has not yet shown to improve outcome or to be cost-effective thus far. ${ }^{48} \mathrm{~A}$ systematic search for CAD in the $\mathrm{ED}$ is not recommended and the detection of CAD might rather be a finding unrelated to current symptoms. ${ }^{17}$

In summary, the high NPV of current hs-cTn assays questions the need for urgent additional noninvasive testing before patients can be safely discharged from the ED. ${ }^{49,50}$ Conversely, additional noninvasive testing remains necessary in suspected UA.

\section{In patients with mildly abnormal hs-cTn levels}

The challenge now lies in the clinical interpretation of mildly abnormal hs-cTn levels (patients in the observe group) because this may reflect AMI or acute non-coronary (structural) myocardial disease, or may be associated with chronic stable CAD, renal dysfunction, or even be a variation of normal (in the elderly and men). Clearly, patients not having AMI should not be subjected to unnecessary aggressive antithrombotic, antiplatelet therapy, or invasive coronary angiography. Although symptoms, physical examination, serial ECGs, and height of initial hs-cTn levels contain pivotal information, the initial evaluation is often not specific for a certain diagnosis. This is even more difficult when hs-cTn levels are only mildly abnormal. Noninvasive cardiovascular imaging early in the diagnostic process could therefore be particularly useful to further characterize myocardial disease and hence serve as a gatekeeper to prevent unnecessary invasive procedures or aggressive therapy.

Exercise testing is generally considered contraindicated in patients with suspected AMI. ${ }^{51}$ Apart from this, it does not provide structural information and does not allow for differentiating between myocardial diseases. Two-dimensional (2D) echocardiography by a trained physician can be very helpful for the initial assessment of certain patients with acute chest pain, especially when patients are hemodynamically compromised. Current guidelines recommend 2D echo- cardiography to detect AMI or other acute pathologies, such as AAD or PE. ${ }^{16}$ However, recent studies challenge the generally believed high accuracy of $2 \mathrm{D}$ echocardiography to detect AMI based on the visual assessment of segmental wall motion abnormalities (SWMAs). ${ }^{52}$ Importantly, SWMAs are not specific for AMI and can be found in myocarditis as well. ${ }^{53}$ Myocardial contrast echocardiography accurately reflects decreased myocardial perfusion and has been shown to increase the diagnostic accuracy to detect AMI over visual assessment of SWMA. ${ }^{54}$ 
Strain analysis using speckle-tracking echocardiography appears promising to detect AMI but still needs additional validation. ${ }^{55}$ Moreover, suboptimal acoustic windows in a substantial number of patients hinder all echocardiographic techniques. Therefore, its usefulness in patients with mildly abnormal hs-cTn levels is limited.

Alternative noninvasive imaging tests include nuclear cardiovascular imaging, cardiovascular magnetic resonance imaging (CMR), and cardiac CTA. Although they visualize different aspects of disease, each modality can be used uniquely to differentiate between coronary and non-coronary myocardial disease.

Resting myocardial perfusion can be assessed with single-photon emission computed tomographic (SPECT) using ${ }^{99 m}$ Technetium-Sestamibi or, less frequently nowadays, ${ }^{201}$ Thallium. The sensitivity to detect AMI ranges from 90\% to 100\% (NPV 99-100\%). ${ }^{56,57}$ Patients with acute chest pain and normal rest myocardial perfusion have an excellent prognosis. ${ }^{56,57}$ In addition to detecting myocardial perfusion, gated SPECT allows determining global and regional ventricular function. ${ }^{58}$ However, SPECT has not gained widespread clinical acceptance for use in patients with acute chest pain, because smaller defects remain undetected and there are logistic restraints in the ED setting. ${ }^{59}$ Although positron emission tomography (PET) myocardial perfusion more accurately detects CAD in comparison to SPECT in an outpatient setting, its usefulness is less well studied in the ED. ${ }^{60}$ Increased uptake of ${ }^{18} \mathrm{~F}$-fluorodeoxyglucose can be observed in active myocardial inflammation, whereas uptake is decreased in AMI and ischemic myocardium. ${ }^{61}{ }^{18} \mathrm{~F}$-fluorodeoxyglucose PET has also been used to image plaque instability and inflammation, but accurate interpretation of the coronary arteries is often hindered by interference with background myocardial uptake as well as the rather low spatial and temporal resolution. ${ }^{62}$ ${ }^{18} \mathrm{~F}$-sodium fluoride PET imaging is promising and abnormal coronary artery uptake strongly suggests acute coronary pathology..$^{62}$ However, ${ }^{18} \mathrm{~F}$-sodium fluoride PET imaging is at this time not feasible in the ED. Other PET tracers, such as rubidium-82 and the novel tracer flurpiridaz F-18, provide information on myocardial perfusion. However, for both tracers but mainly for flurpiridaz, data on their performance in detecting perfusion defects on rest images are rare and require further evaluation in larger clinical trials. ${ }^{63}$ Furthermore, flurpiridaz is not yet available for clinical use. A major drawback of nuclear imaging (both SPECT and PET) is the inability to exclude or diagnose more than one disease, whereas the differential diagnosis in patients with mildly abnormal hs-cTn levels is broad. Hence, "one-stop-shop" imaging to identify the underlying cause cannot be expected because nuclear medicine tracers are more or less specifically usable for one clinical indication, and therefore, different radiotracers are required to exclude different potential causes. A hybrid approach of PET with CT or CMR may increase the clinical potential of nuclear imaging in the cardiac ED, but availability of these hybrid scanners is very limited. Currently, it seems unlikely that PET or SPECT will play an important role in the emergency setting as a tool to differentiate between myocardial diseases when hs-cTn levels are abnormal. Finally, nuclear imaging exposes patients to ionizing radiation and imaging protocols can be time-consuming.

Several CMR techniques can be used to comprehensively assess patients with acute chest pain and abnormal hs-cTn levels. A CMR protocol, including cine, T2-weighted, rest perfusion and delayed enhancement (DE) CMR, has been shown to be highly accurate to diagnose AMI. ${ }^{64,65}$ Delayed enhancement CMR is a well-validated technique to assess the presence, location, etiology, size, and transmural extent of myocardial scarring. ${ }^{66}$ Delayed enhancement CMR can detect a very small amount of injury ( $<1$ gram myocardial tissue). ${ }^{67}$ The pattern of hyperenhancement on delayed enhancement CMR provides important information regarding the underlying etiology. ${ }^{68}$ In particular, a subendocardial or transmural hyperenhancement pattern 
is most frequently observed in ischemic injury, based on the wave front phenomenon of ischemic myocardial injury, whereas a mid- to epicardial hyperenhancement pattern suggests non-ischemic pathology (eg, myocarditis). ${ }^{68} \mathrm{~A}$ comprehensive CMR investigation has been shown to provide a final diagnosis in $70 \%$ of patients with acute chest pain, with normal or insignificant coronary artery stenosis $(<50 \%)$ on invasive coronary angiography. ${ }^{69,70}$ Absence of significant obstructive CAD or angiographic evidence of acute plaque rupture is part of the proposed criteria for diagnosing takotsubo cardiomyopathy. Cardiovascular magnetic resonance imaging typically shows left ventricular wall motion abnormalities extending beyond a single coronary perfusion bed, high signal on T2-weighted sequences, and absence of scar on delayed enhancement CMR. ${ }^{71,72}$ In the presence of an appropriate clinical setting, these typical CMR findings may be diagnostic and eliminate the need for invasive coronary angiography. Cardiovascular magnetic resonance imaging is highly accurate to detect structural heart disease that may be responsible for stable and mildly abnormal hs-cTn levels (eg, dilated, hypertrophic, or infiltrative cardiomyopathy). Although generally considered less accurate than CTA, CMR may also be useful to exclude AAD or PE. ${ }^{73,74}$ Although a normal CMR study including stress-rest perfusion imaging does not provide a final diagnosis in patients with acute chest pain, it does indicate an excellent prognosis. ${ }^{70,75}$ Disadvantages of CMR are limited availability, need for specialized equipment and personnel, time-consuming scanning protocols that can be strenuous for patients, and restricted applicability in patients with ferromagnetic implants.

Computed tomographic angiography is a relatively straightforward technique and available in many centers on a $24 / 7$ basis, but inevitably requires exposure to ionizing radiation and iodine contrast agents. This noninvasive imaging modality provides insight in coronary and non-coronary causes of acute chest pain. Administration of iodinated contrast agents is required because a native CT scan (without angiography) is insufficient to exclude AMI and other disease (ie, AAD or $\mathrm{PE}){ }^{76}$ Although a "triple rule-out" protocol may be useful to rule out $A A D, P E$, and CAD, the overall diagnostic yield of this strategy has not yet shown to be superior to coronary CTA alone. ${ }^{4,77,78}$ Besides assessing the severity of coronary stenosis, several plaque characteristics associated with AMI can be assessed including outward remodeling, spotty calcifications, and a low-density lipid core..$^{79}$ Although $a \geq 50 \%$ coronary stenosis on CTA is suspicious for a coronary etiology of chest pain and elevated hs-cTn levels, it may merely be a coincidental and unrelated finding. ${ }^{80}$ Computed tomographic angiography may erroneously exclude AMI or UA in up to $20 \%$ of patients with no or mild CAD, whereas they remain at high risk for long-term recurrent ischemic events and may benefit from antiplatelet therapy. ${ }^{81,82}$ Rest myocardial perfusion CT and fractional flow reserve CT appear promising to further improve the diagnostic yield by evaluating the functional consequence of a stenosis. ${ }^{83,84} \mathrm{~A}$ fractional flow reserve CT-guided strategy has been associated with fewer unnecessary invasive coronary angiograms in patients with new-onset chest pain. ${ }^{85}$ Delayed enhancement CT may be used to visualize scar similar to delayed enhancement CMR. ${ }^{86,87}$ Whether these CT technologies also allow for characterizing myocardial disease in patients with mildly elevated hs-cTn levels is unknown. Some studies suggest that CTA may be useful to detect extra-cardiac disease in highly selected patients with acute chest pain and mildly abnormal cTn levels, but whether these findings are related to symptoms is disputable. ${ }^{88}$

Although patients should be diagnosed as early as possible to prevent erroneous or delayed therapy, the relatively low-risk profile allows for deferral of additional noninvasive imaging for at least 24 hours. ${ }^{16}$ Which noninvasive imaging modality is most useful in these patients is currently unknown but dependent on several factors. Nevertheless, the current hs-cTn era will change the deployment of noninvasive imaging, from ruling out acute myocardial disease toward characterizing 
myocardial disease. The ongoing CARMENTA trial (NCT01559467) investigates whether implementing CTA or CMR early in the diagnostic process in patients presenting with acute chest pain, non-diagnostic ECGs, and abnormal hs-cTnT levels can prevent invasive procedures in comparison to routine clinical management without adversely affecting outcome. ${ }^{89}$ Computed tomographic angiography and CMR have their own and unique ways to prevent invasive coronary angiography by excluding (significant) CAD and to detect other diseases such as AAD and PE (CTA and CMR) or myocarditis and stress cardiomyopathy (CMR). Furthermore, this trial may help to determine the preferential imaging modality in this setting, to better define hs-cTn cutoff levels that rule in AMI and to improve the differentiation between types 1 and $2 \mathrm{MI}$. Especially patients who have undergone both (non-) invasive coronary angiography and CMR will be suitable to investigate the latter.

\section{Patients with markedly abnormal hs-cTn levels}

An (early, within 24 hours) invasive approach is usually recommended in patients with high risk clinical features and markedly elevated or rising and/or falling troponin levels. ${ }^{15,16}$ Although the extent of these values has not been properly defined yet, the probability of AMI increases substantially when initial hs-cTn values and "delta" values changes are higher. ${ }^{28,29,38}$ Patients with persistent ST-elevation or ST-depression and other high-risk features (cardiogenic shock, ventricular tachycardias) should undergo immediate invasive coronary angiography that should not be delayed by routine pre-procedural advanced noninvasive imaging. Despite this, echocardiography can occasionally be extremely valuable to assess ventricular function, complications (myocardial rupture, pericardial effusion), valvular disease, or other life-threatening diagnoses (AAD, PE).

Nonetheless, in up to $20 \%$ of patients suspected for AMI no or non-obstructed $(<50 \%)$ CAD is found after invasive coronary angiography. ${ }^{90,91}$ The differential diagnosis includes AMI caused by a temporary coronary artery occlusion (spontaneous recanalization, embolism with spontaneous thrombolysis, or spasm), myocarditis, stress cardiomyopathy, PE, or AAD. Evidence for certain diagnoses can already be obtained during invasive coronary angiography and include testing for vasospasm or searching for vulnerable plaques with intravascular ultrasound or optical coherence tomography. Cardiovascular magnetic resonance imaging is a very useful secondary diagnostic step in patients with "normal" coronary arteries, to differentiate between coronary and non-coronary myocardial disease..$^{68-70}$ In the presence of a typical MI pattern (ie, subendocardial or transmural scar), the coronary angiogram should be reassessed to search for small-occluded side branches that initially may have been overlooked. Additional CTA may detect outward remodeled vulnerable plaques that were initially not apparent, or detect AAD or PE. In the presence of a typical CMR pattern of MI but normal coronary arteries on CTA, patients can be tested for a hypercoagulable state (spontaneous coronary thrombosis) or paradoxical embolism (patent foramen ovale or atrial septal defect).

\section{CONCLUSION}

Despite normal contemporary cTn levels in patients with acute chest pain, ED physicians often needed additional noninvasive tests to achieve a higher level of confidence before safely discharging patients. Current hs-cTn assays now rule out AMI with high confidence and challenge this need for additional testing. This does not apply for UA, because hs-cTn assays do not rule out UA. However, the reduced specificity of the hs-cTn assays for AMI confronts ED physicians with a new problem because (mildly) abnormal hs-cTn values are increasingly being encountered and may reflect an underlying coronary, non-coronary myocardial disease, or even 
non-cardiac disease. Consequently, a shifting paradigm of the deployment of noninvasive imaging is anticipated from ruling out toward characterizing myocardial disease and prevent that patients are subjected to unnecessary aggressive antithrombotic treatment and invasive procedures. As evidence is still building up, the most appropriate imaging modality or even multicomponent strategy is currently unknown, but an individualized approach of "tailored diagnostics" seems plausible. Prospective studies are required that not only investigate the diagnostic accuracy of imaging modalities, but also the therapeutic consequences related to the diagnostic findings. 


\section{REFERENCES}

1. Mockel M, Searle J, Muller R, et al. Chief complaints in medical emergencies: do they relate to underlying disease and outcome? The Charite Emergency Medicine Study (CHARITEM). European journal of emergency medicine: official journal of the European Society for Emergency Medicine 2013;20:103-8.

2. Lee TH, Goldman L. Evaluation of the patient with acute chest pain. N Engl J Med 2000;342:1187-95.

3. Fruergaard P, Launbjerg J, Hesse B, et al. The diagnoses of patients admitted with acute chest pain but without myocardial infarction. Eur Heart J 1996;17:1028-34.

4. Burris $A C, 2^{\text {nd }}$, Boura JA, Raff GL, Chinnaiyan KM. Triple Rule Out Versus Coronary CT Angiography in Patients With Acute Chest Pain: Results From the ACIC Consortium. JACC Cardiovasc Imaging 2015;8:817-25.

5. Spalding L, Reay E, Kelly C. Cause and outcome of atypical chest pain in patients admitted to hospital. Journal of the Royal Society of Medicine 2003;96:122-5.

6. Thygesen K, Alpert JS, Jaffe AS, et al. Third universal definition of myocardial infarction. J Am Coll Cardiol 2012;60:1581-98.

7. Apple FS, Collinson PO, Biomarkers ITFoCAoC. Analytical characteristics of high-sensitivity cardiac troponin assays. Clin Chem 2012;58:54-61.

8. Apple FS, Jaffe AS, Collinson P, et al. IFCC educational materials on selected analytical and clinical applications of high sensitivity cardiac troponin assays. Clin Biochem 2015;48:201-3.

9. Sandoval Y, Smith SW, Apple FS. Present and Future of Cardiac Troponin in Clinical Practice: A Paradigm Shift to High-Sensitivity Assays. Am J Med 2016;129:354-65.

10. Reichlin T, Hochholzer W, Bassetti S, et al. Early diagnosis of myocardial infarction with sensitive cardiactroponin assays. NEnglJ Med 2009;361:858-67.

11. Body R, Carley S, McDowell G, et al. Rapid exclusion of acute myocardial infarction in patients with undetectable troponin using a high-sensitivity assay. J Am Coll Cardiol 2011;58:1332-9.

12. Shah ASV, Anand A, Sandoval Y, et al. High-sensitivity cardiac troponin I at presentation in patients with suspected acute coronary syndrome: a cohort study. Lancet 2015;386:2481-8.

13. Mueller C. Biomarkers and acute coronary syndromes: an update. Eur Heart J 2014;35:552-6.

14. de Lemos JA, Drazner MH, Omland T, et al. Association of troponin $\mathrm{T}$ detected with a highly sensitive assay and cardiac structure and mortality risk in the general population. JAMA 2010;304:2503-12.

15. Amsterdam EA, Wenger NK, Brindis RG, et al. 2014 AHA/ACC Guideline for the Management of Patients With Non-ST-Elevation Acute Coronary Syndromes: A Report of the American College of Cardiology/ American Heart Association Task Force on Practice Guidelines. J Am Coll Cardiol 2014;24:e139-e228.

16. Roffi M, Patrono C, Collet JP, et al. ESC Guidelines for the management of acute coronary syndromes in patients presenting without persistent ST-segment elevation: Task Force for the Management of Acute Coronary Syndromes in Patients Presenting without Persistent ST-Segment Elevation of the European Society of Cardiology (ESC). Eur Heart J 2015; 37:267-315.
17. Amsterdam EA, Kirk JD, Bluemke DA, et al. Testing of low-risk patients presenting to the emergency department with chest pain: a scientific statement from the American Heart Association. Circulation 2010;122:1756-76.

18. Than $M$, Herbert M, Flaws $D$, et al. What is an acceptable risk of major adverse cardiac event in chest pain patients soon after discharge from the Emergency Department?: a clinical survey. Int $\mathrm{J}$ Cardiol 2013;166:752-4.

19. Swap CJ, Nagurney JT. Value and limitations of chest pain history in the evaluation of patients with suspected acute coronary syndromes. JAMA 2005;294:2623-9.

20. Fanaroff AC, Rymer JA, Goldstein SA, Simel DL, Newby LK. Does This Patient With Chest Pain Have Acute Coronary Syndrome?: The Rational Clinical Examination Systematic Review. JAMA 2015;314:1955-65

21. Grani C, Senn O, Bischof M, et al. Diagnostic performance of reproducible chest wall tenderness to rule out acute coronary syndrome in acute chest pain: a prospective diagnostic study. BMJ Open 2015;5:e007442.

22. American College of Emergency Physicians; Society for Cardiovascular Angiography and Interventions, O'Gara PT, et al. 2013 ACCF/AHA guideline for the management of ST-elevation myocardial infarction: a report of the American College of Cardiology Foundation/American Heart Association Task Force on Practice Guidelines. J Am Coll Cardiol 2013;61:e78-140.

23. Fesmire FM, Percy RF, Bardoner JB, Wharton DR, Calhoun FB. Usefulness of automated serial 12-lead ECG monitoring during the initial emergency department evaluation of patients with chest pain. Ann Emerg Med 1998;31:3-11.

24. McCarthy BD, Beshansky JR, D'Agostino RB, Selker HP. Missed diagnoses of acute myocardial infarction in the emergency department: results from a multicenter study. Ann Emerg Med 1993;22:579-82.

25. Pope JH, Aufderheide TP, Ruthazer R, et al. Missed diagnoses of acute cardiac ischemia in the emergency department. $\mathrm{N}$ Engl $\mathrm{J}$ Med 2000;342:1163-70.

26. Alpert JS, Thygesen K, Antman E, Bassand JP. Myocardial infarction redefined--a consensus document of The Joint European Society of Cardiology/American College of Cardiology Committee for the redefinition of myocardial infarction. J Am Coll Cardiol 2000;36:959-69.

27. Bandstein N, Ljung R, Johansson M, Holzmann MJ. Undetectable high-sensitivity cardiac troponin $\mathrm{T}$ level in the emergency department and risk of myocardial infarction. J Am Coll Cardiol 2014;63:2569-78.

28. Melki D, Lugnegård J, Alfredsson J, et al. Implications of Introducing High-Sensitivity Cardiac Troponin T Into Clinical Practice. J Am Coll Cardiol 2015;65:1655-64.

29. Reichlin T, Schindler C, Drexler B, et al. One-hour rule-out and rule-in of acute myocardial infarction using high-sensitivity cardiac troponin T. Arch Intern Med 2012;172:1211-8. 
30. Lipinski MJ, Baker NC, Escarcega RO, et al. Comparison of conventional and high-sensitivity troponin in patients with chest pain: a collaborative meta-analysis. Am Heart J 2015;169:6-16 e6.

31. Sandoval Y, Smith SW, Thordsen SE, Apple FS. Supply/demand type 2 myocardial infarction: should we be paying more attention? J Am Coll Cardiol 2014;63:2079-87.

32. Korley FK, Jaffe AS. Preparing the United States for high-sensitivity cardiac troponin assays. J Am Coll Cardiol 2013;61:1753-8.

33. Sandoval Y, Smith SW, Schulz KM, et al. Diagnosis of type 1 and type 2 myocardial infarction using a high-sensitivity cardiac troponin I assay with sex-specific 99th percentiles based on the third universal definition of myocardial infarction classification system. Clin Chem 2015;61:657-63.

34. Omland T, de Lemos JA, Sabatine MS, et al. A sensitive cardiac troponin $\mathrm{T}$ assay in stable coronary artery disease. N Engl J Med 2009;361:2538-47.

35. Cardinaels EP, Mingels AM, Jacobs LH, Meex SJ, Bekers O, van Dieijen-Visser MP. A comprehensive review of upper reference limits reported for (high-) sensitivity cardiac troponin assays: the challenges that lie ahead. Clin Chem Lab Med 2012;50:791-806.

36. Gore MO, Seliger SL, Defilippi CR, et al. Age- and sex-dependent upper reference limits for the highsensitivity cardiac troponin T assay. J Am Coll Cardiol 2014;63:1441-8.

37. Shah AS, Griffiths M, Lee KK, et al. High sensitivity cardiac troponin and the under-diagnosis of myocardial infarction in women: prospective cohort study. BMJ 2015;350:g7873.

38. Mueller M, Biener M, Vafaie M, et al. Absolute and relative kinetic changes of high-sensitivity cardiac troponin $\mathrm{T}$ in acute coronary syndrome and in patients with increased troponin in the absence of acute coronary syndrome. Clin Chem 2012;58:209-18.

39. Reichlin T, Irfan A, Twerenbold R, et al. Utility of absolute and relative changes in cardiac troponin concentrations in the early diagnosis of acute myocardial infarction. Circulation 2011;124:136-45.

40. Bjurman C, Larsson M, Johanson P, et al. Small changes in troponin $T$ levels are common in patients with non-ST-segment elevation myocardial infarction and are linked to higher mortality. J Am Coll Cardiol 2013;62:1231-8.

41. Morrow DA, Bonaca MP. Real-world application of "delta" troponin: diagnostic and prognostic implications. J Am Coll Cardiol 2013;62:1239-41.

42. Nestelberger T, Wildi $\mathrm{K}$, Boeddinghaus $\mathrm{J}$, et al. Characterization of the observe zone of the ESC 2015 high-sensitivity cardiac troponin 0h/1halgorithm for the early diagnosis of acute myocardial infarction. Int J Cardiol 2016;207:238-45.

43. Reichlin T, Twerenbold R, Wildi K, et al. Prospective validation of a 1-hour algorithm to rule-out and rule-in acute myocardial infarction using a highsensitivity cardiac troponin T assay. CMAJ : Canadian Medical Association journal = journal de l'Association medicale canadienne 2015;187:E243-52.

44. Eggers KM, Lindahl B, Melki D, Jernberg T. Consequences of implementing a cardiac troponin assay with improved sensitivity at Swedish coronary care units: an analysis from the SWEDEHEART registry. Eur Heart J 2016; 37:2417-24.
45. Mills NL, Churchhouse AM, Lee KK, et al. Implementation of a sensitive troponin I assay and risk of recurrent myocardial infarction and death in patients with suspected acute coronary syndrome. JAMA 2011;305:1210-6.

46. Sanchis J, Garcia-Blas S, Mainar L, et al. Highsensitivity versus conventional troponin for management and prognosis assessment of patients with acute chest pain. Heart 2014;100:1591-6.

47. Braunwald E, Morrow DA. Unstable angina: is it time for a requiem? Circulation 2013;127:2452-7.

48. Litt HI, Gatsonis C, Snyder B, et al. CT angiography for safe discharge of patients with possible acute coronary syndromes. N Engl J Med 2012;366:1393-403.

49. Redberg RF. Coronary CT angiography for acute chest pain. N Engl J Med 2012;367:375-6.

50. Prasad V, Cheung M, Cifu A. Chest pain in the emergency department: the case against our current practice of routine noninvasive testing. Arch Intern Med 2012;172:1506-9.

51. Gibbons RJ, Balady GJ, Beasley JW, et al. ACC/ AHA Guidelines for Exercise Testing. A report of the American College of Cardiology/American Heart Association Task Force on Practice Guidelines (Committee on Exercise Testing). J Am Coll Cardiol 1997;30:260-311.

52. Jaarsma C, Schalla S, Cheriex EC, et al. Incremental value of cardiovascular magnetic resonance over echocardiography in the detection of acute and chronic myocardial infarction. J Cardiovasc Magn Reson 2013;15:5.

53. Pinamonti B, Alberti E, Cigalotto A, et al. Echocardiographic findings in myocarditis. Am J Cardiol 1988;62:285-91.

54. Rinkevich D, Kaul S, Wang XQ, et al. Regional left ventricular perfusion and function in patients presenting to the emergency department with chest pain and no ST-segment elevation. Eur Heart $\mathrm{J}$ 2005;26:1606-11.

55. Sjoli B, Orn S, Grenne B, Ihlen H, Edvardsen T, Brunvand H. Diagnostic capability and reproducibility of strain by Doppler and by speckle tracking in patients with acute myocardial infarction. JACC Cardiovasc Imaging 2009;2:24-33.

56. Heller GV, Stowers SA, Hendel RC, et al. Clinical value of acute rest technetium-99m tetrofosmin tomographic myocardial perfusion imaging in patients with acute chest pain and nondiagnostic electrocardiograms. J Am Coll Cardiol 1998;31:1011-7.

57. Iskander $\mathrm{S}$, Iskandrian AE. Risk assessment using single-photon emission computed tomographic technetium-99m sestamibi imaging. J Am Coll Cardiol 1998;32:57-62.

58. Anagnostopoulos C, Gunning MG, Pennell DJ, Laney R, Proukakis H, Underwood SR. Regional myocardial motion and thickening assessed at rest by ECG-gated $99 \mathrm{mTC}-\mathrm{MIBI}$ emission tomography and by magnetic resonance imaging. European journal of nuclear medicine 1996;23:909-16.

59. Wagner A, Mahrholdt H, Holly TA, et al. Contrastenhanced MRI and routine single photon emission computed tomography (SPECT) perfusion imaging for detection of subendocardial myocardial infarcts: an imaging study. Lancet 2003;361:374-9.

60. Jaarsma C, Leiner T, Bekkers SC, et al. Diagnostic performance of noninvasive myocardial perfusion 
imaging using single-photon emission computed tomography, cardiac magnetic resonance, and positron emission tomography imaging for the detection of obstructive coronary artery disease: a meta-analysis. J Am Coll Cardiol 2012;59:1719-28.

61. Rischpler C, Nekolla SG, Kunze KP, Schwaiger M. $\mathrm{PET} / \mathrm{MRI}$ of the Heart. Seminars in nuclear medicine 2015;45:234-47.

62. Joshi NV, Vesey AT, Williams MC, et al. 18F-fluoride positron emission tomography for identification of ruptured and high-risk coronary atherosclerotic plaques: a prospective clinical trial. Lancet 2014;383:705-13.

63. Maddahi J, Packard RR. Cardiac PET perfusion tracers: current status and future directions. Seminars in nuclear medicine 2014;44:333-43.

64. Kwong RY, Schussheim AE, Rekhraj S, et al. Detecting acute coronary syndrome in the emergency department with cardiac magnetic resonance imaging. Circulation 2003;107:531-7.

65. Cury RC, Shash K, Nagurney JT, et al. Cardiac magnetic resonance with T2-weighted imaging improves detection of patients with acute coronary syndrome in the emergency department. Circulation 2008; 118:837-44.

66. Kim RJ, Fieno DS, Parrish TB, et al. Relationship of $\mathrm{MRI}$ delayed contrast enhancement to irreversible injury, infarct age, and contractile function. Circulation 1999;100:1992-2002.

67. Ricciardi MJ, Wu E, Davidson CJ, et al. Visualization of discrete microinfarction after percutaneous coronary intervention associated with mild creatine kinase-MB elevation. Circulation 2001;103:2780-3.

68. Mahrholdt H, Wagner A, Judd RM, Sechtem U, Kim RJ. Delayed enhancement cardiovascular magnetic resonance assessment of non-ischaemic cardiomyopathies. Eur Heart J 2005;26:1461-74.

69. Assomull RG, Lyne JC, Keenan N, et al. The role of cardiovascular magnetic resonance in patients presenting with chest pain, raised troponin, and unobstructed coronary arteries. Eur Heart $J$ 2007;28:1242-9.

70. Gerbaud E, Harcaut E, Coste P, et al. Cardiac magnetic resonance imaging for the diagnosis of patients presenting with chest pain, raised troponin, and unobstructed coronary arteries. Int $\mathrm{J}$ Cardiovasc Imaging 2012;28:783-94.

71. Eitel I, von Knobelsdorff-Brenkenhoff F, Bernhardt $\mathrm{P}$, et al. Clinical characteristics and cardiovascular magnetic resonance findings in stress (takotsubo) cardiomyopathy. JAMA 2011;306:277-86.

72. Prasad A, Lerman A, Rihal CS. Apical ballooning syndrome (Tako-Tsubo or stress cardiomyopathy): a mimic of acute myocardial infarction. Am Heart $\mathrm{J}$ 2008:155:408-17.

73. Stein PD, Chenevert TL, Fowler SE, et al. Gadoliniumenhanced magnetic resonance angiography for pulmonary embolism: a multicenter prospective study (PIOPED III). Ann Intern Med 2010;152:434-43, W142-3.

74. Moore AG, Eagle KA, Bruckman D, et al. Choice of computed tomography, transesophageal echocardiography, magnetic resonance imaging, and aortography in acute aortic dissection: International Registry of Acute Aortic Dissection (IRAD). Am J Cardiol 2002;89:1235-8.
75. Chopard R, Jehl J, Dutheil J, et al. Evolution of acute coronary syndrome with normal coronary arteries and normal cardiac magnetic resonance imaging. Arch Cardiovasc Dis 2011;104:509-17.

76. Dedic A, Ten Kate GJ, Neefjes LA, et al. Coronary CT angiography outperforms calcium imaging in the triage of acute coronary syndrome. Int $\mathrm{J}$ Cardio 2013;167:1597-602.

77. Takakuwa KM, Halpern EJ. Evaluation of a "triple rule-out" coronary CT angiography protocol: use of 64-Section CT in low-to-moderate risk emergency department patients suspected of having acute coronary syndrome. Radiology 2008;248:438-46.

78. Ayaram D, Bellolio MF, Murad MH, et al. Triple rule-out computed tomographic angiography for chest pain: a diagnostic systematic review and meta-analysis. Acad Emerg Med 2013;20:861-71.

79. Puchner SB, Liu T, Mayrhofer T, et al. High-risk plaque detected on coronary CT angiography predicts acute coronary syndromes independent of significant stenosis in acute chest pain: results from the ROMICAT-II trial. J Am Coll Cardiol 2014;64:684-92.

80. Ferencik M, Liu T, Mayrhofer T, et al. hs-Troponin I Followed by CT Angiography Improves Acute Coronary Syndrome Risk Stratification Accuracy and Work-Up in Acute Chest Pain Patients: Results From ROMICAT II Trial. JACC Cardiovasc Imaging 2015.

81. Lindholm D, Varenhorst C, Cannon CP, et al. Ticagrelor vs. clopidogrel in patients with non-ST-elevation acute coronary syndrome with or without revascularization: results from the PLATO trial. Eur Heart J 2014;35:2083-93.

82. Rossini R, Capodanno D, Lettieri $C$, et al. Long-term outcomes of patients with acute coronary syndrome and nonobstructive coronary artery disease. Am J Cardiol 2013;112:150-5.

83. Pursnani A, Lee AM, Mayrhofer T, et al. Early resting myocardial computed tomography perfusion for the detection of acute coronary syndrome in patients with coronary artery disease. Circ Cardiovasc Imaging 2015;8:e002404.

84. Norgaard BL, Leipsic J, Gaur S, et al. Diagnostic performance of noninvasive fractional flow reserve derived from coronary computed tomography angiography in suspected coronary artery disease: the NXT trial (Analysis of Coronary Blood Flow Using CT Angiography: Next Steps). J Am Coll Cardiol 2014;63:1145-55

85. Douglas PS, Pontone G, Hlatky MA, et al. Clinical outcomes of fractional flow reserve by computed tomographic angiography-guided diagnostic strategies vs. usual care in patients with suspected coronary artery disease: the prospective longitudinal trial of FFRCT: outcome and resource impacts study. Eur Heart J 2015:36:3359-67.

86. Lardo AC, Cordeiro MA, Silva C, et al. Contrast-enhanced multidetector computed tomography viability imaging after myocardial infarction: characterization of myocyte death, microvascular obstruction, and chronic scar. Circulation 2006;113:394-404.

87. Gerber BL, Belge B, Legros GJ, et al. Characterization of acute and chronic myocardial infarcts by multidetector computed tomography: comparison with contrast-enhanced magnetic resonance. Circulation 2006;113:823-33. 
88. Gruettner J, Fink C, Walter T, et al. Coronary computed tomography and triple rule out CT in patients with acute chest pain and an intermediate cardiac risk profile. Part 1: impact on patient management. Eur J Radiol 2013;82:100-5.

89. Smulders MW, Kietselaer BL, Das M, et al. The role of cardiovascular magnetic resonance imaging and computed tomography angiography in suspected non-ST-elevation myocardial infarction patients: Design and rationale of the CARdiovascular Magnetic rEsoNance imaging and computed Tomography Angiography (CARMENTA) trial. Am Heart J 2013;166:968-75.

90. Collste O, Sorensson P, Frick M, et al. Myocardial infarction with normal coronary arteries is common and associated with normal findings on cardiovascular magnetic resonance imaging: results from the Stockholm Myocardial Infarction with Normal Coronaries study. Journal of internal medicine 2013;273:189-96.

91. Patel MR, Chen AY, Peterson ED, et al. Prevalence, predictors, and outcomes of patients with non-ST-segment elevation myocardial infarction and insignificant coronary artery disease: results from the Can Rapid risk stratification of Unstable angina patients Suppress ADverse outcomes with Early implementation of the ACC/AHA Guidelines (CRUSADE) initiative. Am Heart J 2006;152:641-7. 
Supplemental Table 1.

Negative predictive value of different tests, available to evaluate patients with acute chest pain, normal electrocardiogram and troponin value.

\begin{tabular}{|c|c|c|c|c|c|}
\hline $\begin{array}{l}\text { SPECT/PET } \\
\text { Reference }\end{array}$ & \begin{tabular}{|l} 
Number of \\
patients
\end{tabular} & \begin{tabular}{|l} 
Follow up \\
(years)
\end{tabular} & Study protocol & Endpoint & NPV (\%) \\
\hline Amsterdam et al. ${ }^{1}$ & 888 & $0.1 \pm N S$ & ST depression $<1 \mathrm{~mm}$ & Death, MI, PCI/CABG & 100 \\
\hline Conti et al. $^{2}$ & 188 & $0.3 \pm N S$ & ST depression $<1 \mathrm{~mm}$ & $\begin{array}{l}\text { Cardiac death, MI, } \\
\text { PCl/CABG, CAD }>50 \%\end{array}$ & 93 \\
\hline Jeetley et al. ${ }^{3}$ & 148 & $0.7 \pm 0.3$ & ST depression $<1 \mathrm{~mm}$ & Death, MI, PCI/CABG & 95 \\
\hline Greenslade et al. ${ }^{4}$ & 777 & $0.1 \pm N S$ & ST depression $<1 \mathrm{~mm}$ & MI, UA & 100 \\
\hline Nucifora et al. ${ }^{5}$ & 89 & $0.2 \pm N S$ & ST depression $<1 \mathrm{~mm}$ & $\begin{array}{l}\text { Cardiac death, MI, } \\
\text { PCI/CABG }\end{array}$ & 93 \\
\hline Meyer et al. ${ }^{6}$ & 871 & $0.5 \pm N S$ & ST depression $<1 \mathrm{~mm}$ & Death, MI & 100 \\
\hline Sanchis et al. ${ }^{7}$ & 283 & $0.5 \pm N S$ & ST depression $<1 \mathrm{~mm}$ & Cardiac death, MI & 100 \\
\hline Sanchis et al. ${ }^{8}$ & 340 & $1.0 \pm N S$ & ST depression $<1 \mathrm{~mm}$ & Death, MI & 98 \\
\hline Sarullo et al. ${ }^{9}$ & 190 & $1.4 \pm 0.5$ & ST depression $<1 \mathrm{~mm}$ & $\begin{array}{l}\text { Death, MI, PCl/CABG, } \\
\text { UA }\end{array}$ & 93 \\
\hline $\begin{array}{l}\text { Echocardiography } \\
\text { Reference }\end{array}$ & $\begin{array}{l}\text { Number of } \\
\text { patients }\end{array}$ & $\begin{array}{l}\text { Follow up } \\
\text { (years) }\end{array}$ & Study protocol & Endpoint & NPV (\%) \\
\hline Bedetti et al. ${ }^{10}$ & 552 & $1.1 \pm 1.0$ & Stress induced WMA & $\begin{array}{l}\text { Cardiac death, MI, } \\
\text { PCI/CABG, UA }\end{array}$ & 99 \\
\hline Bholasingh et al. ${ }^{11}$ & 377 & $0.5 \pm N S$ & Stress induced WMA & $\begin{array}{l}\text { Cardiac death, MI, } \\
\text { PCI/CABG, UA }\end{array}$ & 96 \\
\hline Conti et al. ${ }^{2}$ & 188 & $0.3 \pm N S$ & Stress induced WMA & $\begin{array}{l}\text { Cardiac death, MI, } \\
\text { PCl/CABG, CAD }>50 \%\end{array}$ & 96 \\
\hline Gaibazzi et al..$^{12}$ & 545 & $\begin{array}{l}1.0 \\
\text { (NS-NS) }\end{array}$ & $\begin{array}{l}\text { Stress contrast } \\
\text { perfusion and WMA }\end{array}$ & Cardiac death, MI, UA & 99 \\
\hline Hartlage et al..$^{13}$ & 166 & $\begin{array}{l}0.9 \\
\text { (NS-NS) }\end{array}$ & Stress induced WMA & $\begin{array}{l}\text { Cardiac death, MI, } \\
\text { CAD }>50 \%, \text { UA }\end{array}$ & 98 \\
\hline Heitner et al. ${ }^{14}$ & 60 & $1.2 \pm 0.4$ & Stress induced WMA & Death, MI, CAD>50\% & 94 \\
\hline Lerakis et al. $^{15}$ & 204 & $\begin{array}{l}0.9 \\
(0.5-1.2)\end{array}$ & Stress induced WMA & Death, MI, UA & 99 \\
\hline Jeetley et al. ${ }^{3}$ & 145 & $0.8 \pm 0.4$ & Stress induced WMA & Death, MI, PCI/CABG & 97 \\
\hline Jeetley et al. ${ }^{16}$ & 145 & $0.7 \pm 0.4$ & $\begin{array}{l}\text { Stress contrast } \\
\text { perfusion }\end{array}$ & $\begin{array}{l}\text { Cardiac death, MI, } \\
\text { PCI/CABG }\end{array}$ & 93 \\
\hline Nucifora et al. ${ }^{5}$ & 110 & $0.2 \pm N S$ & Stress induced WMA & $\begin{array}{l}\text { Cardiac death, MI, } \\
\text { PCI/CABG }\end{array}$ & 100 \\
\hline $\begin{array}{l}\text { SPECT/PET } \\
\text { Reference }\end{array}$ & $\begin{array}{l}\text { Number of } \\
\text { patients }\end{array}$ & $\begin{array}{l}\text { Follow up } \\
\text { (years) }\end{array}$ & Study protocol & Endpoint & NPV (\%) \\
\hline Better et al. ${ }^{17}$ & 356 & $0.1 \pm N S$ & $\begin{array}{l}\text { SPECT Rest } \\
\text { perfusion }\end{array}$ & Cardiac death, MI & 99 \\
\hline Einstein et al. ${ }^{18}$ & 100 & $1.0 \pm N S$ & $\begin{array}{l}\text { SPECT Stress } \\
\text { perfusion }\end{array}$ & Death, MI, UA & 100 \\
\hline Forberg et al. ${ }^{19}$ & 40 & $0.5 \pm N S$ & $\begin{array}{l}\text { SPECT Rest } \\
\text { perfusion }\end{array}$ & MI, UA & 100 \\
\hline Gallagher et al..$^{20}$ & 85 & $0.1 \pm N S$ & $\begin{array}{l}\text { SPECT Stress } \\
\text { perfusion }\end{array}$ & $\begin{array}{l}\text { Cardiac death, MI, } \\
\text { UA, heart failure }\end{array}$ & 97 \\
\hline
\end{tabular}


Supplemental Table 1. (continued)

\begin{tabular}{|c|c|c|c|c|c|}
\hline $\begin{array}{l}\text { SPECT/PET } \\
\text { Reference }\end{array}$ & \begin{tabular}{|l} 
Number of \\
patients
\end{tabular} & $\begin{array}{l}\text { Follow up } \\
\text { (years) }\end{array}$ & Study protocol & Endpoint & NPV (\%) \\
\hline Goldstein et al. ${ }^{21}$ & 98 & $0.5 \pm N S$ & $\begin{array}{l}\text { SPECT Stress } \\
\text { perfusion }\end{array}$ & Cardiac death, MI, UA & 100 \\
\hline Goldstein et al. ${ }^{22}$ & 266 & $0.5 \pm N S$ & $\begin{array}{l}\text { SPECT Stress } \\
\text { perfusion }\end{array}$ & $\begin{array}{l}\text { Cardiac death, MI, } \\
\text { PCI/CABG }\end{array}$ & 100 \\
\hline Nabi et al. ${ }^{23}$ & 1561 & $0.6 \pm 0.2$ & $\begin{array}{l}\text { SPECT Stress } \\
\text { perfusion }\end{array}$ & Cardiac death, MI, UA & 98 \\
\hline Nabi et al. ${ }^{24}$ & 1031 & $0.6 \pm 0.3$ & $\begin{array}{l}\text { SPECT Stress } \\
\text { perfusion }\end{array}$ & Cardiac death, MI, UA & 99 \\
\hline Peix et al. ${ }^{25}$ & 44 & $1.0 \pm N S$ & $\begin{array}{l}\text { SPECT Stress } \\
\text { perfusion }\end{array}$ & $\begin{array}{l}\text { Death, MI, UA, PCl/ } \\
\text { CABG }\end{array}$ & 100 \\
\hline $\begin{array}{l}\text { CMR } \\
\text { Reference }\end{array}$ & $\begin{array}{l}\text { Number of } \\
\text { patients }\end{array}$ & \begin{tabular}{|l} 
Follow up \\
(years)
\end{tabular} & Study protocol & Endpoint & NPV (\%) \\
\hline Cury et al. ${ }^{26}$ & 62 & 0 & $\begin{array}{l}\text { Cine, T2w, DE, stress } \\
\text { perfusion }\end{array}$ & MI, UA & 96 \\
\hline Hartlage et al. ${ }^{13}$ & 89 & $\begin{array}{l}0.8 \\
\text { (NS-NS) }\end{array}$ & $D E$, stress perfusion & $\begin{array}{l}\text { Cardiac death, MI, } \\
\text { UA, CAD }>50 \%\end{array}$ & 100 \\
\hline Heitner et al. ${ }^{14}$ & 60 & $1.2 \pm 0.4$ & Stress perfusion & Death, MI, CAD>50\% & 98 \\
\hline $\begin{array}{l}\text { Ingkanisorn et } \\
\text { al. }^{27}\end{array}$ & 135 & $\begin{array}{l}1.3 \\
\text { (NS-NS) }\end{array}$ & Stress perfusion & Death, MI, CAD>50\% & 100 \\
\hline Lerakis et al. ${ }^{28}$ & 103 & $0.8 \pm N S$ & $\begin{array}{l}\text { Cine, DE, stress } \\
\text { perfusion }\end{array}$ & $\begin{array}{l}\text { Cardiac death, MI, } \\
\text { UA, PCI/CABG, } \\
\text { CAD }>50 \%\end{array}$ & 100 \\
\hline $\begin{array}{l}\text { CTA } \\
\text { Reference }\end{array}$ & $\begin{array}{l}\text { Number of } \\
\text { patients }\end{array}$ & $\begin{array}{l}\text { Follow up } \\
\text { (years) }\end{array}$ & Study protocol & Endpoint & NPV (\%) \\
\hline Christiaens et al. ${ }^{29}$ & 175 & $0.5 \pm 0.2$ & Stenosis $<50 \%$ & MACE & 100 \\
\hline Cury et al. ${ }^{30}$ & 529 & $0.1 \pm N S$ & Stenosis $<50 \%$ & Death, MI, UA & 100 \\
\hline Gallagher et al. ${ }^{20}$ & 85 & $0.1 \pm N S$ & Stenosis $<50 \%$ & $\begin{array}{l}\text { Cardiac death, MI, } \\
\text { UA, heart failure }\end{array}$ & 99 \\
\hline Goldstein et al. ${ }^{21}$ & 99 & $0.5 \pm N S$ & $\begin{array}{l}\text { Stenosis } \leq 25 \% \text { and } \\
\text { calcium score } \leq 100\end{array}$ & Cardiac death, MI, UA & 100 \\
\hline Goldstein et al. ${ }^{22}$ & 268 & $0.5 \pm N S$ & $\begin{array}{l}\text { Stenosis } \leq 25 \% \text { and } \\
\text { calcium score } \leq 100\end{array}$ & $\begin{array}{l}\text { Cardiac death, MI, } \\
\text { PCI/CABG }\end{array}$ & 99 \\
\hline Hansen et al. ${ }^{31}$ & 85 & $1.0 \pm 0.2$ & Stenosis $<50 \%$ & Death, MI, PCI/CABG & 100 \\
\hline Hoffmann et al. ${ }^{32}$ & 368 & $0.5 \pm 0.2$ & Stenosis $<50 \%$ & $\begin{array}{l}\text { Death, MI, PCI/CABG, } \\
\text { UA }\end{array}$ & 98 \\
\hline Hollander et al. ${ }^{33}$ & 568 & $0.1 \pm N S$ & Stenosis $<50 \%$ & Cardiac death, MI & 100 \\
\hline Linde et al. ${ }^{34}$ & 272 & $0.3 \pm N S$ & Stenosis $<50 \%$ & Cardiac death, MI & 100 \\
\hline Litt et al. ${ }^{35}$ & 908 & $0.1 \pm N S$ & Stenosis $<50 \%$ & Cardiac death, MI & 100 \\
\hline Nabi et al. ${ }^{24}$ & 1031 & $0.6 \pm 0.3$ & Calcium score 0 & Cardiac death, MI, UA & 100 \\
\hline Nance et al. ${ }^{36}$ & 458 & $\begin{array}{l}1.1 \\
(0.8-1.5)\end{array}$ & No plaque & $\begin{array}{l}\text { Cardiac death, MI, } \\
\text { UA, PCI/CABG }\end{array}$ & 100 \\
\hline Nasis et al. ${ }^{37}$ & 203 & $1.2 \pm N S$ & Stenosis $<50 \%$ & Death, MI, PCI/CABG & 100 \\
\hline $\begin{array}{l}\text { Rubinshtein et } \\
\text { al. }^{38}\end{array}$ & 58 & $1.3 \pm N S$ & Stenosis $<50 \%$ & $\begin{array}{l}\text { Death, MI, PCl/CABG, } \\
\text { UA }\end{array}$ & 97 \\
\hline
\end{tabular}


Supplemental Table 1. (continued)

\begin{tabular}{l|l|l|l|l|l}
$\begin{array}{l}\text { CTA } \\
\text { Reference }\end{array}$ & $\begin{array}{l}\text { Number of } \\
\text { patients }\end{array}$ & $\begin{array}{l}\text { Follow up } \\
\text { (years) }\end{array}$ & Study protocol & Endpoint & NPV (\%) \\
\hline Schlett et al. ${ }^{39}$ & 333 & $\begin{array}{l}1.9 \\
\text { (NS-NS) }\end{array}$ & Stenosis $<50 \%$ & $\begin{array}{l}\text { Cardiac death, MI, } \\
\text { PCI/CABG }\end{array}$ & 98 \\
\hline Singer et al. ${ }^{40}$ & 507 & $0.5 \pm$ NS & Stenosis $<50 \%$ & Death, MI, PCl/CABG & 100 \\
\hline${\text { Takakuwa et al. }{ }^{41}}$ & 197 & $0.1 \pm$ NS & Stenosis $<50 \%$ & MI, PCl/CABG, UA & 99 \\
\hline Ueno et al. ${ }^{42}$ & 36 & $0.5 \pm$ NS & Stenosis $<50 \%$ & MI, UA & 95 \\
\hline
\end{tabular}

$\mathrm{CABG}=$ coronary artery bypass grafting, $\mathrm{CAD}=$ coronary artery disease, $\mathrm{CMR}=$ cardiovascular magnetic resonance imaging, $\mathrm{CTA}=$ computed tomography angiography, $\mathrm{DE}=$ delayed enhancement, $\mathrm{MI}=$ myocardial infarction, NPV = negative predictive value, $\mathrm{NS}=$ not specified, $\mathrm{PCI}=$ percutaneous coronary intervention, SPECT = single-photon emission computed tomography, $\mathrm{T} 2 \mathrm{w}=\mathrm{T} 2$ weighted, $\mathrm{UA}=$ unstable angina pectoris, $W M A=$ wall motion abnormality. 


\section{TABLE REFERENCES}

1. Amsterdam EA, Kirk JD, Diercks DB, Lewis WR, Turnipseed SD. Immediate exercise testing to evaluate low-risk patients presenting to the emergency department with chest pain. J Am Coll Cardiol 2002;40:251-6.

2. Conti A, Alesi A, Aspesi G, et al. Comparison of exercise electrocardiogram and exercise echocardiography in intermediate-risk chest pain patients. Am J Emerg Med 2015;33:7-13.

3. Jeetley P, Burden L, Senior R. Stress echocardiography is superior to exercise ECG in the risk stratification of patients presenting with acute chest pain with negative Troponin. Eur J Echocardiogr 2006;7:155-64.

4. Greenslade JH, Parsonage W, Ho A, et al. Utility of Routine Exercise Stress Testing among Intermediate Risk Chest Pain Patients Attending an Emergency Department. Heart, lung \& circulation 2015;9: 879-84.

5. Nucifora G, Badano LP, Sarraf-Zadegan N, et al. Comparison of early dobutamine stress echocardiography and exercise electrocardiographic testing for management of patients presenting to the emergency department with chest pain. Am J Cardiol 2007;100:1068-73.

6. Meyer MC, Mooney RP, Sekera AK. A critical pathway for patients with acute chest pain and low risk for short-term adverse cardiac events: role of outpatient stress testing. Ann Emerg Med 2006;47:427-35.

7. Sanchis J, Bodi V, Llacer A, et al. Risk stratification of patients with acute chest pain and normal troponin concentrations. Heart 2005;91:1013-8.

8. Sanchis J, Bodi V, Nunez J, et al. Usefulness of early exercise testing and clinical risk score for prognostic evaluation in chest pain units without preexisting evidence of myocardial ischemia. Am J Cardiol 2006;97:633-5.

9. Sarullo FM, Di Pasquale P, Orlando G, et al. Utility and safety of immediate exercise testing of low-risk patients admitted to the hospital with acute chest pain. Int J Cardiol 2000;75:239-43.

10. Bedetti G, Pasanisi EM, Tintori G, et al. Stress echo in chest pain unit: the SPEED trial. Int $\mathrm{J}$ Cardiol 2005;102:461-7.

11. Bholasingh R, Cornel JH, Kamp O, et al. Prognostic value of predischarge dobutamine stress echocardiography in chest pain patients with a negative cardiac troponin T. Journal of the American College of Cardiology 2003;41:596-602.

12. Gaibazzi N, Squeri A, Reverberi $C$, et al. Contrast stress-echocardiography predicts cardiac events in patients with suspected acute coronary syndrome but nondiagnostic electrocardiogram and normal 12-hour troponin. J Am Soc Echocardiogr 2011;24:1333-41

13. Hartlage $\mathrm{G}$, Janik M, Anadiotis A, et al. Prognostic value of adenosine stress cardiovascular magnetic resonance and dobutamine stress echocardiography in patients with low-risk chest pain. Int J Cardiovasc Imaging 2012;28:803-12.

14. Heitner JF, Klem I, Rasheed D, et al. Stress Cardiac MR Imaging Compared with Stress Echocardiography in the Early Evaluation of Patients Who Present to the Emergency Department with Intermediate-Risk Chest Pain. Radiology 2014;271:56-64.

15. Lerakis S, Aznaouridis K, Synetos A, et al. Predictive value of normal dobutamine stress echocardiogram in patients with low-risk acute chest pain. Int J Cardiol 2010;144:289-91.

16. Jeetley P, Burden L, Greaves K, Senior R. Prognostic value of myocardial contrast echocardiography in patients presenting to hospital with acute chest pain and negative troponin. Am J Cardiol 2007;99:1369-73.

17. Better N, Karthikeyan G, Vitola J, et al. Performance of rest myocardial perfusion imaging in the management of acute chest pain in the emergency room in developing nations (PREMIER trial). J Nucl Cardiol 2012;19:1146-53.

18. Einstein AJ, Johnson LL, DeLuca AJ, et al. Radiation dose and prognosis of ultra-low-dose stress-first myocardial perfusion SPECT in patients with chest pain using a high-efficiency camera. J Nucl Med 2015;56:545-51.

19. Forberg JL, Hilmersson $\mathrm{CE}$, Carlsson $\mathrm{M}$, et al. Negative predictive value and potential cost savings of acute nuclear myocardial perfusion imaging in low risk patients with suspected acute coronary syndrome: a prospective single blinded study. BMC emergency medicine 2009;9:12.

20. Gallagher MJ, Ross MA, Raff GL, Goldstein JA, O'Neill WW, O'Neil B. The diagnostic accuracy of 64-slice computed tomography coronary angiography compared with stress nuclear imaging in emergency department low-risk chest pain patients. Ann Emerg Med 2007;49:125-36.

21. Goldstein JA, Gallagher MJ, O'Neill WW, Ross MA, O'Neil BJ, Raff GL. A randomized controlled trial of multi-slice coronary computed tomography for evaluation of acute chest pain. J Am Coll Cardiol 2007;49:863-71.

22. Goldstein JA, Chinnaiyan KM, Abidov A, et al. The CT-STAT (Coronary Computed Tomographic Angiography for Systematic Triage of Acute Chest Pain Patients to Treatment) trial. J Am Coll Cardiol 2011;58:1414-22.

23. Nabi F, Chang SM, Xu J, Gigliotti E, Mahmarian JJ. Assessing risk in acute chest pain: The value of stress myocardial perfusion imaging in patients admitted through the emergency department. $\mathrm{J} \mathrm{Nucl}$ Cardiol 2012;19:233-43.

24. Nabi F, Chang SM, Pratt CM, et al. Coronary artery calcium scoring in the emergency department: identifying which patients with chest pain can be safely discharged home. Ann Emerg Med 2010;56:220-9

25. Peix A, Batista E, Cabrera LO, et al. Gated-SPECT myocardial perfusion imaging and coronary calcium score for evaluation of patients with acute chest pain and a normal or nondiagnostic electrocardiogram. Coronary artery disease 2012;23:438-44.

26. Cury RC, Shash K, Nagurney JT, et al. Cardiac magnetic resonance with T2-weighted imaging improves detection of patients with acute coronary syndrome in the emergency department. Circulation 2008;118:837-44.

27. Ingkanisorn WP, Kwong RY, Bohme NS, et al. Prognosis of negative adenosine stress magnetic resonance in patients presenting to an emergency department with chest pain. J Am Coll Cardiol 2006; 47:1427-32. 
28. Lerakis S, McLean DS, Anadiotis AV, et al. Prognostic value of adenosine stress cardiovascular magnetic resonance in patients with low-risk chest pain. J Cardiovasc Magn Reson 2009;11:37.

29. Christiaens L, Duchat F, Boudiaf M, et al. Impact of 64-slice coronary CT on the management of patients presenting with acute chest pain: results of a prospective two-centre study. Eur Radiol 2012;22:1050-8.

30. Cury RC, Feuchtner GM, Batlle JC, et al. Triage of patients presenting with chest pain to the emergency department: implementation of coronary CT angiography in a large urban health care system. AJR Am J Roentgenol 2013;200:57-65.

31. Hansen M, Ginns J, Seneviratne S, et al. The value of dual-source 64-slice CT coronary angiography in the assessment of patients presenting to an acute chest pain service. Heart, lung \& circulation 2010;19:213-8.

32. Hoffmann U, Bamberg F, Chae CU, et al. Coronary computed tomography angiography for early triage of patients with acute chest pain: the ROMICAT (Rule Out Myocardial Infarction using Computer Assisted Tomography) trial. J Am Coll Cardiol 2009;53:1642-50.

33. Hollander JE, Chang AM, Shofer FS, et al. One-year outcomes following coronary computerized tomographic angiography for evaluation of emergency department patients with potential acute coronary syndrome. Acad Emerg Med 2009;16:693-8.

34. Linde JJ, Kofoed KF, Sorgaard M, et al. Cardiac computed tomography guided treatment strategy in patients with recent acute-onset chest pain: results from the randomised, controlled trial: CArdiac $\mathrm{cT}$ in the treatment of acute $\mathrm{CHest}$ pain $(\mathrm{CATCH})$. Int $\mathrm{J}$ Cardiol 2013;168:5257-62.

35. Litt HI, Gatsonis C, Snyder B, et al. CT angiography for safe discharge of patients with possible acute coronary syndromes. N Engl J Med 2012;366:1393-403.

36. Nance JW, Jr., Schlett CL, Schoepf UJ, et al. Incremental prognostic value of different components of coronary atherosclerotic plaque at cardiac CT angiography beyond coronary calcification in patients with acute chest pain. Radiology 2012;264:679-90.

37. Nasis A, Meredith IT, Nerlekar N, et al. Acute chest pain investigation: utility of cardiac CT angiography in guiding troponin measurement. Radiology 2011;260:381-9.

38. Rubinshtein R, Halon DA, Gaspar T, et al. Usefulness of 64-slice cardiac computed tomographic angiography for diagnosing acute coronary syndromes and predicting clinical outcome in emergency department patients with chest pain of uncertain origin. Circulation 2007;115:1762-8.

39. Schlett CL, Banerji D, Siegel E, et al. Prognostic value of CT angiography for major adverse cardiac events in patients with acute chest pain from the emergency department: 2-year outcomes of the ROMICAT trial. JACC Cardiovasc Imaging 2011;4:481-91.

40. Singer AJ, Domingo A, Thode HC, Jr., et al. Utilization of coronary computed tomography angiography for exclusion of coronary artery disease in ED patients with low- to intermediate-risk chest pain: a 1-year experience. Am J Emerg Med 2012;30:1706-11.
41. Takakuwa KM, Halpern EJ. Evaluation of a "triple rule-out" coronary CT angiography protocol: use of 64-Section CT in low-to-moderate risk emergency department patients suspected of having acute coronary syndrome. Radiology 2008;248:438-46.

42. Ueno K, Anzai T, Jinzaki M, et al. Diagnostic capacity of 64-slice multidetector computed tomography for acute coronary syndrome in patients presenting with acute chest pain. Cardiology 2009;112:211-8. 


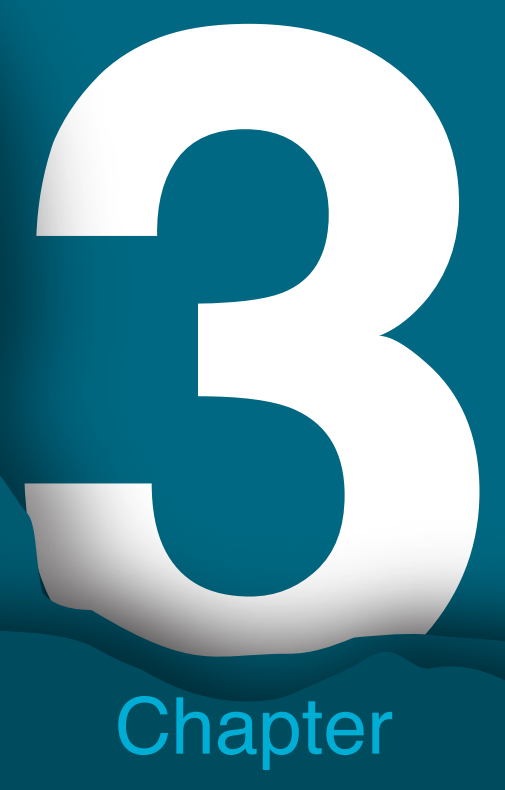




\section{Risk stratification and role for additional diagnostic testing in patients with acute chest pain and normal high-sensitivity cardiac troponin levels}

Martijn W. Smulders, MD, ${ }^{1,5}$ Sebastiaan C.A.M. Bekkers, MD, PhD, ${ }^{1,2,5}$ Yvonne J.M. van Cauteren, MD, ${ }^{1,2,5}$ Anna Liefhebber, MD, ${ }^{1}$ Jasper R. Vermeer, MD, ${ }^{1}$ Juliette Vervuurt, MD, ${ }^{1}$ Marja P. van Dieijen-Visser, PhD, ${ }^{3,5}$ Alma M.A. Mingels, PhD, ${ }^{3,5}$ Hans-Peter Brunner-La Rocca, MD, 1,5 Pieter C. Dagnelie, PhD, ${ }^{4,5,6}$ Joachim E. Wildberger, MD, PhD, ${ }^{2,5}$ Harry J.G.M. Crijns, MD, PhD, ${ }^{1,5}$ Bas L.J.H. Kietselaer, MD, PhD ${ }^{1,2,5,7}$

Department of ${ }^{1}$ Cardiology, ${ }^{2}$ Radiology, ${ }^{3}$ Clinical Chemistry, ${ }^{4}$ Epidemiology, ${ }^{5}$ Cardiovascular Research Institute Maastricht (CARIM), ${ }^{6}$ School for Public Health and Primary Care (CAPHRI), Maastricht University Medical Center, Maastricht, The Netherlands and department of ${ }^{7}$ Cardiology, Zuyderland Medical Center, Heerlen, The Netherlands 


\section{ABSTRACT}

\section{Background}

Normal high sensitivity cardiac troponin (hs-cTn) assays rule out acute myocardial infarction (AMI) with great accuracy, but additional non-invasive testing is frequently ordered. This observational study evaluates whether clinical characteristics can contribute to risk stratification and could guide referral for additional testing.

\section{Methods}

918 serial patients with acute chest pain and normal hs-cTnT levels were prospectively included. Major adverse cardiac events (MACE) and non-invasive test results were assessed during one-year follow-up. Patients were classified as low and high risk based on clinical characteristics.

\section{Results}

MACE occurred in $6.4 \%$ of patients and mainly comprised revascularizations (86\%). A recent abnormal stress test, suspicious history, a positive family history and higher baseline hs-cTnT levels were independent predictors of MACE with odds ratios of 16.00 (95\%Cl:6.25-40.96), 16.43 (6.36-42.45), 2.33 (1.22-4.42) and 1.10 (1.01-1.21), respectively. Absence of both recent abnormal stress test and suspicious history identified $86 \%$ of patients. These patients were at very low risk for MACE $(0.4 \%$ in 30 -days and $2.3 \%$ in one-year). Despite this, the majority $(287 / 345=83 \%)$ of additional tests were performed in low risk patients, with $<10 \%$ abnormal test findings. The diagnostic yield was significantly higher in the remaining higher risk patients, $40 \%$ abnormal test findings and a positive predictive value of $70 \%$ for MACE. Similar results were observed in patients without known coronary artery disease.

\section{Conclusions}

Clinical characteristics can be used to identify low risk patients with acute chest pain and normal hs-cTnT levels. Current strategies in the emergency department result in numerous additional tests, which are mostly ordered in patients at very low risk and have a low diagnostic yield. 


\section{INTRODUCTION}

Acute chest pain is one of the most common reasons for emergency department (ED) visits and is a symptom of a wide variety of diseases, ranging from a trivial ailment to life-threatening disorders. Despite advances in risk stratification, differentiating acute myocardial infarction (AMI) from non-cardiac causes remains challenging. Although only a minority of patients is ultimately diagnosed with $\mathrm{AMI}$, excluding $\mathrm{AMI}$ is crucial for appropriate treatment and reducing mortality. ${ }^{1-6}$

The initial evaluation of patients with chest pain is based on clinical history taking, a physical examination and an electrocardiogram (ECG). Although generally regarded as subjective, a combination of these elements may help identifying patients at higher risk. ${ }^{7}$ However, sensitivity of the initial evaluation is insufficient to reliably detect all patients with AMI and therefore cardiac biomarker testing (cardiac troponin) is often decisive in the diagnostic approach of patients with acute chest pain., ${ }^{1,3}$

High sensitivity cardiac troponin (hs-cTn) assays allow ruling out of AMI at presentation with high confidence (negative predictive value 99\%) and normal hs-cTn levels indicate an excellent prognosis. $^{8-11}$ Despite this and endorsed by current guidelines, patients with normal troponin levels are frequently referred for additional non-invasive testing to further reduce the risk of (acute and/or subsequent) AMI and for reassurance of both treating physician and patient., ${ }^{1,3,12}$ However, this approach has been questioned, as it is associated with a low diagnostic yield, many false positive test results, higher healthcare costs, increased radiation exposure and no clear benefit in clinical outcome..$^{13,14}$

We hypothesize that commonly available clinical characteristics can reliably risk stratify patients with acute chest pain and normal hs-cTnT levels. Secondly, routine use of non-invasive testing may not be useful in all patients, for the detection of unstable angina, predicting future cardiac events and need for coronary revascularization.

\section{MATERIAL AND METHODS}

\section{Study population and objectives}

Consecutive patients presenting with acute chest pain at the ED of the Maastricht University Medical Center (MUMC) were prospectively enrolled from April 11, 2012 to April 10, 2013 in this observational cohort trial. The MUMC is a university hospital with a catchment area of 250.000 inhabitants in the South-eastern part of the Netherlands. Although the MUMC is a university hospital, it serves as the sole hospital for patients within the municipality of Maastricht and several surrounding municipalities. Therefore, over $95 \%$ of patients are local residents. During the study period, the MUMC was the only hospital with a primary percutaneous coronary intervention $(\mathrm{PCl})$ service in the South-eastern part of the Netherlands and may therefore explain the high rate of patient with ST-elevation MI.

Patients were included if they presented with acute chest pain suggestive of cardiac ischemia and had normal hs-cTnT levels $\left(\leq 14 \mathrm{ng} / \mathrm{L}, 5^{\text {th }}\right.$ generation troponin assay, Roche Diagnostics, Basel, Switzerland) at presentation and, if re-testing was clinically indicated, 3 hours after presentation. ${ }^{1,3}$ Patients with ST-elevation MI were excluded. All patients in this study received standard care in the work-up for suspected AMI, including a thorough medical history, physical examination, 12-lead ECG, biomarker testing and additional cardiac testing when indicated. This work-up was left at discretion of the attending cardiologist, and based on institutional and European guidelines. The study was approved by the Ethical Committee of the Maastricht University Hospital and Maastricht University (METC identifier 14-4-009). The study was performed and reported in compliance with the STROBE guidelines. 
The primary study objective was to identify clinical characteristics that allowed stratification of patients to low and high risk for 30-day and one-year major adverse cardiac events (MACE). Secondly, the result and outcome of additional cardiac tests on admission and during one-year follow-up were evaluated and compared between low and high risk patients.

\section{Outcome data and definitions}

The number of cardiac deaths and spontaneous AMI during 30-day and one-year follow-up were scored as hard cardiac events. MACE was defined as a composite of cardiac death, AMI, previously unplanned revascularization ( $\mathrm{PCl}$ or $\mathrm{CABG}$ ) and admission for congestive heart failure during 30-day and one-year follow-up. Cardiac death was a combined endpoint of cardiac deaths and unknown deaths, thus all deaths were considered as being cardiac in origin, unless a clear non-cardiac cause of death was present. AMI was defined as AMI type 1 based on the Universal Definition of AMI, thus related to atherosclerotic plaque rupture resulting in decreased blood flow and myocardial necrosis. ${ }^{15}$ Coronary revascularizations planned before index presentation were not counted as an event $(n=12)$. Congestive heart failure was scored when patients were admitted and treated for decompensated heart failure. In case of multiple events, the first event that occurred in an individual patient was considered as the patient outcome and time to event.

The number of non-invasive tests during index presentation and during the one-year follow-up period were recorded. Tests performed after a MACE occurred were not considered. For the purpose of the current study, a positive test result was defined as 1) a reversible perfusion defect on single-photon emission tomography (SPECT [summed difference score $>4 \%$ ]), 2) $\geq 1 \mathrm{~mm}$ ST-segment depression on an electrocardiographic exercise test (EET), 3) extensive coronary calcifications with an Agatston score $\geq 1000$ on CT, 4) a (new) luminal narrowing of $\geq 70 \%$ on cardiac computed tomography angiography (CCTA) and/or invasive coronary angiography (ICA) or abnormal fractional flow reserve $(\leq 0.80)^{16}$. As no stress echocardiography was being performed during the study period, echocardiograms were not counted as positive or negative for ischemic coronary artery disease (CAD). A test was considered non-diagnostic if the images were uninterpretable or in case of a negative EET at submaximal exercise $(<85 \%$ of the maximum predicted target heart rate).

\section{Data analysis and patient chart review}

Admission and follow-up data were retrieved from the electronic patient record system by two reviewers. The general practitioner was contacted in case additional information was necessary. A detailed assessment of the medical history including traditional risk factors for CAD, interpretation of the ECG, cardiac biomarkers, additional testing on admission and during follow-up (e.g. EET, echocardiography, CCTA, SPECT, ICA), final diagnosis at discharge from the ED or patient ward, patient treatment and adverse cardiac events were obtained. An independent cardiologist was available to resolve any discrepancies.

The history taking was classified as follows and based on the traditional clinical classification of chest pain: ${ }^{17} 1$ ) Highly suspicious: typical angina (i.e. substernal chest discomfort, exacerbation of symptoms by physical exertion or stress, relief of symptoms by rest or nitrates) and/or chest pain that was recognized from prior myocardial ischemic episodes, 2) moderately suspicious: atypical angina meeting two of three criteria for typical angina, and 3) slightly suspicious: non-anginal chest pain that meets maximally only one of the criteria for typical angina. This categorization of patients was based on the documentation by the attending cardiologist and review of the patient records. 
A history of coronary disease was defined as known coronary artery disease ( $\geq 50 \%$ stenosis), previous $\mathrm{MI}$ or coronary revascularization (PCI or CABG). Traditional risk factors for CAD were scored: 1) hypertension, 2) hypercholesterolemia, 3) diabetes, 4) smoking and a 5) family history of CAD at age $\leq 65$ years old. A stress test (e.g. EET or SPECT) was considered recent if the stress test was performed within 3 months before ED presentation. The diagnosis at discharge (e.g. acute MI, unstable angina, arrhythmia, no acute cardiac pathology) was based on the documentation by the attending cardiologist. The diagnosis "unknown but no acute cardiac pathology" was a combination of the following: 1) acute myocardial injury was excluded, 2) gastro-oesophageal symptoms, 3) musculoskeletal complaints, 4) pleuritis and pneumonia, or 5) hyperventilation syndrome.

Scoring of ECG parameters was based on the interpretation of the ECG by the attending cardiologist at the time of presentation. Cardiac biomarker testing was performed on clinical indication and troponin results at presentation were considered as continuous and commonly accepted dichotomous values: undetectable hs-cTnT level ( $<5 \mathrm{ng} / \mathrm{L})$ and detectable hs-cTnT levels (5-14 ng/L).

\section{Statistical analyses}

Statistical analysis was performed with SPSS statistics 23 (SPSS Inc., Chicago, Illinois). Categorical data are expressed as frequencies and percentages. Differences in categorical data were evaluated using a Chi-square or in cases where the expected cell count was $<5 \mathrm{a}$ Fisher's Exact Test was used. Continuous variables with normally distributed data are expressed as mean $\pm S D$ and differences between groups were compared using an independent $t$-test or one-way ANOVA when more than two groups were compared. Non-normally distributed continuous data were presented as a median with interquartile range (IQR) and differences between groups were tested with the Mann-Whitney $U$ test or independent samples KruskalWallis test when more than two groups were compared. A two-tailed $p$-value of $<0.05$ was considered statistically significant.

Univariable binary logistic regression was performed to explore the effect of patient characteristics at baseline on the occurrence of MACE during 1-year follow-up. Each characteristic was tested independently in a univariable logistic regression model. For continuous data, odds ratios were expressed per unit of the determinant. Independent variables that were significantly associated with MACE during follow-up were included in the multivariable analysis. Missing data was excluded from the analysis. A variable was selected for a stepwise backward multivariate binary logistic regression based on: 1) a univariable $p$-value $<0.01,2$ ) a favourable univariable odds ratio, and 3) clinical relevance. Variables associated with a $p$-value $<0.10$ in the multivariable binary logistic regression model were retained in the model. For variables independently associated with MACE, the cumulative event rate was estimated by a Kaplan-Meier analysis and a log-rank test was used to test for differences between groups.

Patients were classified as low and high risk based on clinical characteristics independently associated with MACE. The number and outcome of additional non-invasive testing was scored and compared between low and high risk patients. A subgroup analysis was performed in patients without known coronary disease.

\section{RESULTS}

In total, 2170 patients with acute chest pain suspected for myocardial ischemia were evaluated on the ED during the one-year inclusion period. Patients with ST-elevation AMI $(n=583)$ or patients with elevated hs-cTnT concentration $(n=590)$ were excluded from the analysis. An 
additional 73 patients were excluded because no hs-cTnT measurement was performed. During one-year follow-up, 6 patients died of non-cardiac causes (4 cancer, 1 cerebral haemorrhage, 1 ruptured abdominal aortic aneurysm) and were excluded. The final study population consisted of 918 patients (Figure 1). Baseline characteristics of the study population are shown in Table 1. Mean age was 59 years and $50 \%$ were men. A total of 291 patients $(32 \%)$ had known coronary disease. Mean hs-cTnT level was $6.9 \pm 3.6 \mathrm{ng} / \mathrm{L}$ (median $7.0 \mathrm{ng} / \mathrm{L}$ [IQR 5-10]). The majority of patients did not have ST-deviations or T-wave inversions on the ECG. A total of 832 patients $(91 \%)$ were immediately discharged from the ED and had in general a lower clinical risk profile (e.g. atypical history, less frequent history of cardiovascular disease and ECG changes, and lower hs-cTnT levels). No patient was admitted or discharged with a diagnosis of AMI during the initial admission. The most common diagnosis at discharge (88\%) was no acute cardiac pathology (Supplemental Table 1).

A total of 8 patients experienced cardiac death or AMI (2 unknown deaths and 6 AMI, median time to event was 167 days [IQR 50-302]) resulting in a one-year hard cardiac event rate of $0.9 \%$.

\section{Figure 1.}

Patient selection flow chart.

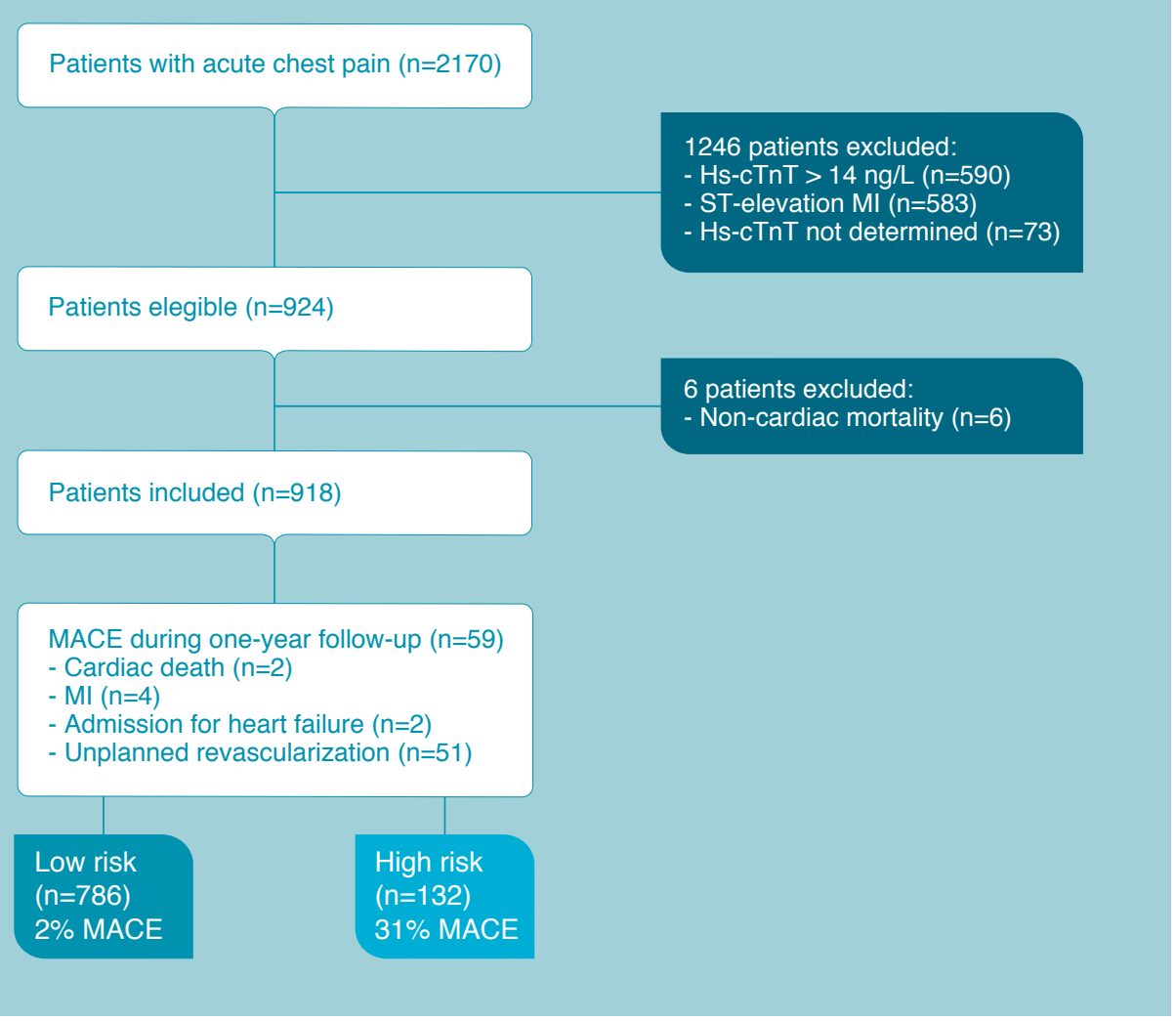

Hs-cTnT = high sensitivity cardiac troponin $\mathrm{T} ; \mathrm{Ml}=$ myocardial infarction . 
Table 1.

Baseline patient characteristics and univariable predictors for MACE.

\begin{tabular}{|c|c|c|c|c|c|}
\hline Characteristic & $\begin{array}{l}\text { All Patients } \\
(n=918)\end{array}$ & $\begin{array}{l}\text { MACE } \\
(\mathrm{n}=59)\end{array}$ & $\begin{array}{l}\text { No MACE } \\
(\mathrm{n}=859)\end{array}$ & \begin{tabular}{|l|}
$\boldsymbol{P}-$ \\
value $^{*}$
\end{tabular} & \begin{tabular}{|l|} 
Univariable \\
OR $(95 \%$ CI)
\end{tabular} \\
\hline \multicolumn{6}{|l|}{ General } \\
\hline Age (years) & $59.1 \pm 12.8$ & $63.2 \pm 9.4$ & $58.8 \pm 13.0$ & 0.012 & $1.03(1.01-1.05)$ \\
\hline Male gender & $454(49.5 \%)$ & $35(59.3 \%)$ & $419(48.8 \%)$ & 0.117 & $1.53(0.90-2.62)$ \\
\hline BMI & $27.9 \pm 5.2$ & $27.6 \pm 4.7$ & $27.9 \pm 5.3$ & 0.691 & $0.99(0.93-1.04)$ \\
\hline \multicolumn{6}{|l|}{ Clinical history } \\
\hline \multicolumn{6}{|l|}{ Known cardiovascular disease } \\
\hline - History of revascularization & $238(25.9 \%)$ & $30(50.8 \%)$ & $208(24.2 \%)$ & $<0.001$ & $3.24(1.90-5.52)$ \\
\hline - History of MI & $153(16.7 \%)$ & $13(22.0 \%)$ & $140(16.3 \%)$ & 0.253 & $1.45(0.76-2.76)$ \\
\hline \multicolumn{6}{|l|}{ Risk factors for $C A D^{*}$} \\
\hline - Hypertension & $414(45.1 \%)$ & $33(55.9 \%)$ & $381(44.4 \%)$ & 0.115 & $1.53(0.90-2.60)$ \\
\hline - Diabetes mellitus & $124(13.5 \%)$ & $17(28.8 \%)$ & $107(12.5 \%)$ & 0.001 & $2.77(1.52-5.05)$ \\
\hline - Hypercholesterolemia & $330(35.9 \%)$ & $34(57.6 \%)$ & 296 (34.5\%) & 0.001 & $2.27(1.33-3.87)$ \\
\hline - Positive family history & $349(38.0 \%)$ & $34(57.6 \%)$ & $315(36.7 \%)$ & 0.002 & $2.59(1.49-4.51)$ \\
\hline - Smoking & $412(44.9 \%)$ & $28(47.5 \%)$ & $384(44.7 \%)$ & 0.795 & $1.07(0.63-1.82)$ \\
\hline \multicolumn{6}{|l|}{$\begin{array}{l}\text { Emergency department } \\
\text { presentation }\end{array}$} \\
\hline Patient history classification & & & & $<0.001$ & \\
\hline - Slightly suspicious & $482(52.5 \%)$ & $6(10.2 \%)$ & $476(55.4 \%)$ & & - \\
\hline - Moderately suspicious & $318(34.6 \%)$ & $18(30.5 \%)$ & 300 (34.9\%) & & $4.76(1.87-12.13)$ \\
\hline - Highly suspicious & $118(12.9 \%)$ & $35(59.3 \%)$ & $83(9.7 \%)$ & & $\begin{array}{l}33.45 \\
(13.64-82.03)\end{array}$ \\
\hline Recent abnormal stress test & 30 (3.3\%) & $18(30.5 \%)$ & $12(1.4 \%)$ & $<0.001$ & $\begin{array}{l}30.99 \\
(14.00-68.61)\end{array}$ \\
\hline \multicolumn{6}{|l|}{ Electrocardiogram } \\
\hline ST-T segment changes & 85 (9.3\%) & $8(13.6 \%)$ & 77 (9.0\%) & 0.239 & $1.59(0.73-3.48)$ \\
\hline Negative T-wave & $102(11.1 \%)$ & $13(22.0 \%)$ & $89(10.4 \%)$ & 0.006 & $2.45(1.27-4.70)$ \\
\hline Normal ECG & $685(74.6 \%)$ & $40(67.8 \%)$ & $645(75.1 \%)$ & 0.213 & $0.70(0.40-1.23)$ \\
\hline \multicolumn{6}{|l|}{ Laboratory Testing } \\
\hline Hs-cTnT at baseline (ng/L) & $6.9 \pm 3.6$ & $8.6 \pm 3.0$ & $6.8 \pm 3.6$ & $<0.001$ & $1.16(1.07-1.26)$ \\
\hline $\begin{array}{l}\text { Undetectable hs-cTnT at } \\
\text { baseline }\end{array}$ & $205(22.3 \%)$ & $5(8.5 \%)$ & $200(23.3 \%)$ & 0.008 & $0.31(0.12-0.77)$ \\
\hline Delta hs-cTnT (ng/L)^ & $1.0(0.0-1.0)$ & $1.0(0.0-1.3)$ & $1.0(0.0-1.0)$ & 0.237 & $1.01(0.74-1.38)$ \\
\hline CK (U/L) & $87(64-120)$ & $79(68-114)$ & $88(64-120)$ & 0.610 & $1.00(0.99-1.00)$ \\
\hline Creatinine (mol/L) & $78.0 \pm 21.4$ & $74.1 \pm 15.3$ & $78.3 \pm 21.8$ & 0.265 & $0.99(0.97-1.01)$ \\
\hline
\end{tabular}

Continuous data are expressed as mean \pm standard deviation or median (interquartile range) and given odds ratios are expressed per unit of the determinant. Categorical data are expressed as frequencies with (percentages). 
Legend Table 1. (continued)

\# $P$-values are shown for the comparison of patients without a MACE and patients experiencing a MACE during 1-year follow-up. Significance was calculated by Chi-square test, Fisher's Exact test, independent $t$-test or Mann-Whitney $\mathrm{U}$ test when appropriate.

$\wedge$ A second hs-cTnT measurement after 3 hours to calculate the change in hs-cTnT level was available in $178(19 \%)$ patients.

*Data on cardiovascular risk factors were missing for 19 patients.

$\mathrm{BMI}=$ body mass index; $\mathrm{CAD}=$ coronary artery disease; $\mathrm{Cl}=$ confidence interval; $\mathrm{CK}=$ creatine kinase; $\mathrm{ECG}=$ electrocardiogram; hs-cTnT = high sensitivity cardiac Troponin-T; MACE = major adverse cardiac events; $\mathrm{Ml}=$ myocardial infarction; $\mathrm{ng} / \mathrm{L}=$ nanograms per liter; $\mathrm{OR}=$ odds ratio; $\mu \mathrm{mol} / \mathrm{L}=$ micromol per liter; $\mathrm{U} / \mathrm{L}=$ units per liters.

One event occurred within the first month after presentation of acute chest pain (death of unknown cause, 6 days after index presentation), resulting in a 30-day hard cardiac event-free survival of 99.9\%. MACE occurred in 59 patients (6.4\%) during one-year follow-up: 2 cardiac deaths (unknown cause for both), 4 AMI, 2 admissions for heart failure and 51 unplanned revascularizations. The 30-day MACE-free survival was $97.6 \%, 1$ cardiac death and 21 revascularizations.

Notably, undetectable hs-cTnT levels (i.e. $<5 \mathrm{ng} / \mathrm{L}$ ) were observed in 205 patients ( $22 \%$ of the population). Patients with undetectable hs-cTnT levels had an excellent prognosis with a cardiac death and AMI-free survival of $100 \%$ and MACE free survival of $97.6 \%$ during one-year follow-up.

\section{Clinical predictors of MACE and risk stratification}

Patients with MACE during follow-up were older, had more frequently a history of coronary revascularization, diabetes mellitus, hypercholesterolemia, family history, suspicious patient history, recent abnormal stress test and higher hs-cTnT levels than patients without MACE (Table 1). Multivariable logistic regression analysis demonstrated that a recent abnormal stress test, a more suspicious history, a positive family history and higher hs-cTnT concentrations were independently associated with MACE (Table 2 and Figure 2).

A recent abnormal stress test and highly suspicious history independently predicted MACE with high odds ratios of 16.00 (6.25-40.96) and 16.43 (6.36-42.45), respectively. A simple clinical rule based on the absence (low risk) or presence of at least one of these two variables (high risk) allowed us to risk stratify patients. The vast majority of patients $(86 \%)$ did not have a recent abnormal stress test or highly suspicious history and were classified as low risk. These patients had an overall 30-day MACE rate of $0.4 \%$ and a one-year MACE rate of $2.3 \%$ (1.7\% revascularizations). The remaining patients (14\%) were classified as high risk, having a one-year MACE rate of $31.1 \%$ ( $28.8 \%$ revascularizations). Moreover, the one-year event rate for cardiac death and AMI was significantly different between very low and higher risk patients $(0.5 \%$ vs. $3.0 \%, p=0.018)$.

\section{Frequency and usefulness of additional non-invasive testing}

Over one third of patients underwent at least one non-invasive diagnostic test to detect ischemia or CAD (Table 3A). EET was performed in $30 \%$ of patients and comprised the largest proportion of all non-invasive tests applied. The number of patients undergoing additional testing increased to $51 \%$ if echocardiography was included as well. Over one third of these patients underwent more than one non-invasive test. Patients with at least one non-invasive diagnostic test had rather similar baseline characteristics in comparison with those without additional testing, except for mild variations in the number of patients with hypercholesterolemia ( $32.1 \%$ vs. $42.3 \%, p=0.003)$, a positive family history $(35.3 \%$ vs. $42.6 \%, p=0.039)$ and an atypical history $(45.8 \%$ vs. $56.5 \%$, 
Figure 2.

Kaplan-Meier survival curves for variables that were independently associated with MACE-free survival.
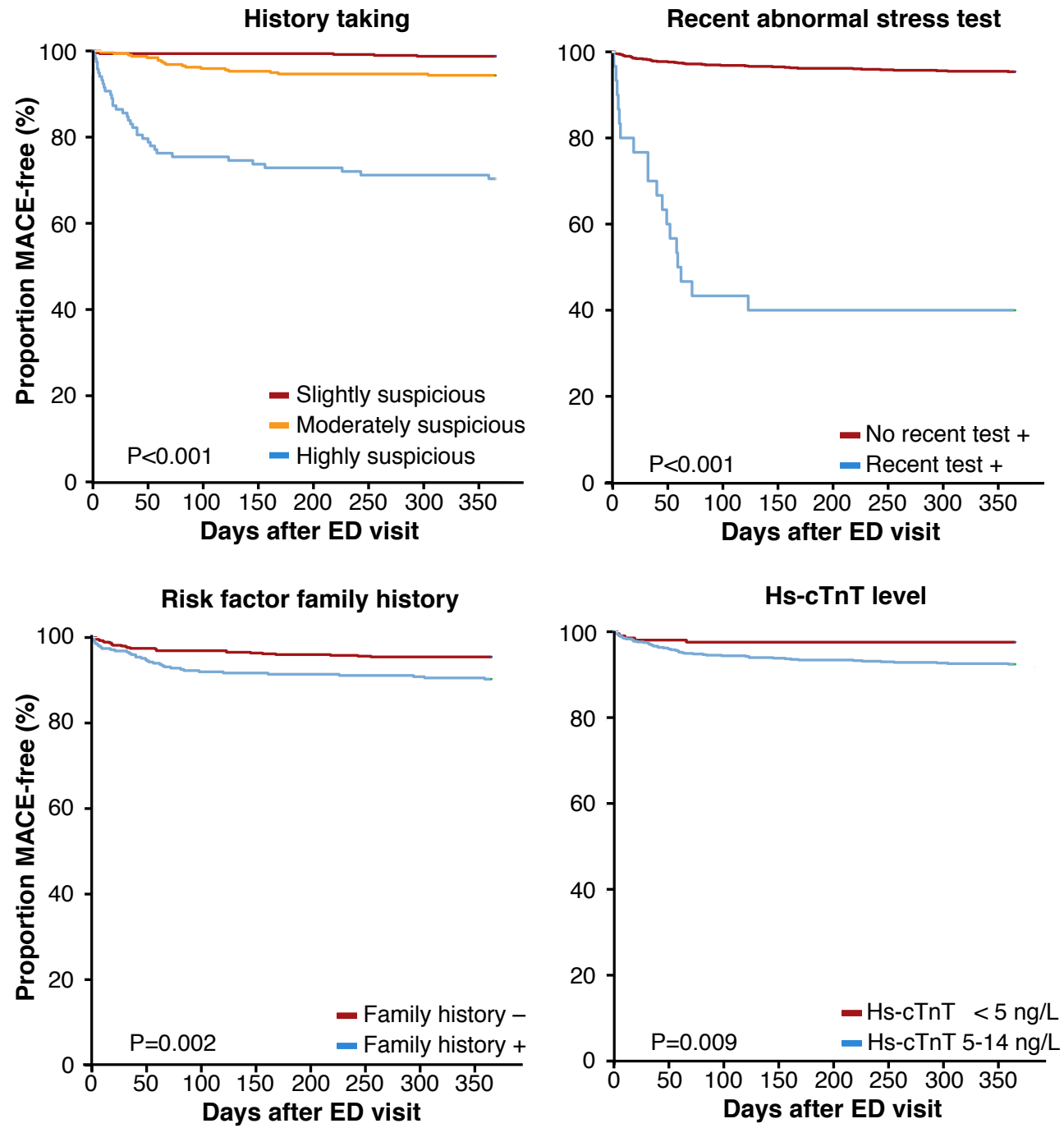

$\mathrm{ED}=$ emergency department; hs-cTnT = high sensitivity cardiac troponin $\mathrm{T} ; \mathrm{MACE}=$ major adverse cardiac events. Note, for clarification of the image is chosen for hs-cTnT detectable vs. undetectable instead of showing the continuous characteristics.

$\mathrm{p}=0.007$, Supplemental Table 2). The proportion of patients with cardiac death and AMI during follow-up did not significantly differ between patients with and without additional non-invasive testing $(0.9 \%$ vs. $0.9 \%, p=0.996)$. Referral to a specific non-invasive test mostly depended on the presence of known cardiovascular disease. Patients referred to SPECT tend to have a 
higher clinical risk profile than patients referred for EET and CCTA (Supplemental Table 3).

The majority of tests (83\%) were performed in patients identified as low risk by our simple clinical rule (Tabel 3B). A severe coronary stenosis or detection of myocardial ischemia (by CCTA or EET/SPECT, respectively) was found in $8 \%$ of low risk patients and in $40 \%$ of high risk patients, $p<0.001$. The positive predictive value of non-invasive testing to predict MACE was $17 \%$ for patients classified as low risk and $70 \%$ for patients at high risk, $p<0.001$. Patients in the high-risk category were more frequently referred for ICA and the proportion of patients with obstructive CAD was higher ( $10 \%$ versus $58 \%$, respectively, $p<0.001$ ).

In low risk patients $(n=786)$, suspicion of obstructive CAD on non-invasive testing $(n=23)$ was confirmed by ICA in 6 patients of whom 4 underwent revascularization. Furthermore, anti-platelet therapy was initiated or intensified in 10 patients. Another 39 patients were directly referred to ICA (i.e. without non-invasive testing first) and obstructive CAD was found in 4 patients. One of these 4 was revascularized, which was complicated by an ST-elevation MI due to an in-stent thrombus two weeks after the intervention. In summary, 326 tests in 786 low risk patients led to 5 revascularization procedures and 6 other patients received optimized medical therapy (3\% of low risk patients undergoing testing). The characteristics and test details of all patients at low risk with a positive non-invasive or primary invasive test result are presented in Supplemental Table 4.

Table 2.

Multivariable logistic regression analysis of characteristics associated with the prospective occurrence of MACE.

\begin{tabular}{l|l|l}
\hline Variable & $\begin{array}{l}\text { Multivariable } \\
\text { OR }(95 \% \text { CI) }\end{array}$ & P-value \\
\hline Recent abnormal stress test & $16.00(6.25-40.96)$ & $<0.001$ \\
\hline Highly suspicious history & $16.43(6.36-42.45)$ & $<0.001$ \\
\hline Moderately suspicious history & $2.89(1.09-7.63)$ & 0.033 \\
\hline Positive family history & $2.32(1.22-4.42)$ & 0.010 \\
\hline Hs-cTnT level & $1.10(1.01-1.21)$ & 0.034 \\
\hline Risk factor diabetes mellitus & - & - \\
\hline Risk factor hypercholesterolemia & - & - \\
\hline History of revascularization & - & - \\
\hline Negative T-wave on ECG & - & - \\
\hline
\end{tabular}

$\mathrm{Cl}=$ confidence interval; hs-cTnT = high sensitivity cardiac Troponin-T; MACE = major adverse cardiac events; $\mathrm{ng} / \mathrm{L}=$ nanograms per liter; $\mathrm{OR}=$ odds ratio.

Risk factor diabetes mellitus, negative T-wave on the ECG, risk factor hypercholesterolemia and history of revascularization were eliminated in a backward multivariable logistic regression analysis as it did not significantly contribute to the model.

\section{Observations in patients without known coronary disease}

In total 627 patients did not have a history of myocardial infarction, revascularization or obstructive CAD. One-year MACE-rate was significantly lower in these patients $(n=26$ [4.1\%] of whom 3 experienced cardiac death or acute MI) compared with patients with a history of 
Table 3.

Additional tests during index presentation and one-year follow-up in all patients $(A)$ and stratified for risk profile as identified by the new simple clinical rule based on the absence of a recent abnormal stress test and highly suspicious history (low risk) or presence of at least one of these characteristics (B).

\begin{tabular}{ll|l|l|}
\hline A & \multicolumn{2}{l}{ Total population (n=918 - 59 MACE) } \\
\hline Test & $\begin{array}{l}\text { Number of } \\
\text { tests } \\
(\%)\end{array}$ & $\begin{array}{l}\text { Abnormal } \\
\text { tests } \\
(\%)\end{array}$ & $\begin{array}{l}\text { PPV MACE } \\
(\%)\end{array}$ \\
\hline EET & $271(30 \%)$ & $17(6 \%)$ & $59 \%$ \\
\hline CCTA & $86(9 \%)$ & $17(20 \%)$ & $41 \%$ \\
\hline SPECT & $45(5 \%)$ & $13(29 \%)$ & $23 \%$ \\
\hline$\geq 1$ CCTA, EET or SPECT & $345(38 \%)$ & $46(13 \%)$ & $43 \%$ \\
\hline Echo & $251(27 \%)$ & & \\
\hline$\geq 1$ CCTA, EET, SPECT or Echo & $465(51 \%)$ & & \\
\hline \begin{tabular}{l} 
Primary ICA \\
\hline 1 CCTA, EET, SPECT or
\end{tabular} & $91(10 \%)$ & $34(37 \%)$ & $68 \%$ \\
\hline primary ICA & $431(47 \%)$ & $78(18 \%)$ & $54 \%$ \\
\hline
\end{tabular}

\begin{tabular}{|c|c|c|c|c|c|c|}
\hline B & \multicolumn{3}{|c|}{ Low risk ( $n=786-18$ MACE) } & \multicolumn{3}{|c|}{ High risk ( $n=132-41$ MACE) } \\
\hline Test & $\begin{array}{l}\text { Number of } \\
\text { tests } \\
(\%)\end{array}$ & $\begin{array}{l}\text { Abnormal } \\
\text { tests } \\
(\%)\end{array}$ & $\begin{array}{l}\text { PPV MACE } \\
(\%)\end{array}$ & $\begin{array}{l}\text { Number of } \\
\text { tests } \\
(\%)\end{array}$ & $\begin{array}{l}\text { Abnormal } \\
\text { tests } \\
(\%)\end{array}$ & $\begin{array}{l}\text { PPV MACE } \\
(\%)\end{array}$ \\
\hline EET & $222(28 \%)$ & $4(2 \%)$ & $0 \%$ & 49 (37\%) & $13(10 \%)$ & $77 \%$ \\
\hline CCTA & $78(10 \%)$ & $12(15 \%)$ & $25 \%$ & $8(7 \%)$ & $5(63 \%)$ & $80 \%$ \\
\hline SPECT & $33(4 \%)$ & $8(24 \%)$ & $13 \%$ & $12(9 \%)$ & $5(42 \%)$ & $40 \%$ \\
\hline$\geq 1$ CCTA, EET or SPECT & $287(37 \%)$ & $23(8 \%)$ & $17 \%$ & $58(44 \%)$ & $23(40 \%)$ & $70 \%$ \\
\hline Echo & $207(26 \%)$ & & & $44(33 \%)$ & & \\
\hline $\begin{array}{l}\geq 1 \text { CCTA, EET, SPECT or } \\
\text { Echo }\end{array}$ & 385 (49\%) & & & $80(61 \%)$ & & \\
\hline Primary ICA & $39(5 \%)$ & $4(10 \%)$ & $25 \%$ & $52(39 \%)$ & $30(58 \%)$ & $73 \%$ \\
\hline $\begin{array}{l}\geq 1 \text { CCTA, EET, SPECT or } \\
\text { primary ICA }\end{array}$ & $326(41 \%)$ & $27(8 \%)$ & $19 \%$ & $105(80 \%)$ & $51(49 \%)$ & $73 \%$ \\
\hline
\end{tabular}

Categorical data are expressed as frequencies (percentages). CCTA = computed tomography angiography; Echo = echocardiography; EET = electrocardiographic exercise test; ICA = invasive coronary angiography; MACE = major adverse cardiac events; SPECT = single-photon emission computed tomography. Primary ICA means immediate referral to ICA without performing non-invasive cardiac imaging first. $\geq 1$ CCTA, EET or SPECT means: at least one CCTA, EET or SPECT scan was performed in a single patient.

coronary disease $(n=33[11.3 \%], p<0.001)$. Undetectable troponin levels implied an excellent prognosis as 1 out of 161 experienced MACE (0.6\%). Multivariable logistic regression analysis demonstrated that a recent abnormal stress test, a more suspicious history, a positive family history, a negative T wave and higher hs-cTnT concentrations were independently associated with MACE. The simple clinical rule identified 591 patients (94\%) as low risk having a 30-day MACE rate of $0.3 \%$ and a one-year MACE rate of $1.7 \%$ (1.4\% revascularizations). High risk 
patients had a one-year MACE rate of $44.4 \%$.

Patients with traditional cardiovascular risk factors present tended to undergo non-invasive diagnostic testing more frequently. Of 226 patients (36\%) referred for additional testing, 211 patients (93\%) were performed in patients classified as low risk and 26 of 226 tests (12\%) were abnormal. The diagnostic yield was considerably higher in patients classified as high risk $(67 \%$ abnormal test results) versus patients classified as low risk ( $8 \%$ abnormal test results, $p<0.001$ ).

\section{DISCUSSION}

This study identifies low and high risk patients based on clinical characteristics in a real-world acute chest pain population with normal hs-cTnT levels and evaluates the value of additional testing in relation to patient outcome. The vast majority of patients can be classified as low risk $(86 \%)$ with a 30 -day MACE rate of $0.4 \%$. Despite this very low risk of events, additional testing was commonly performed. Low risk patients are unlikely to benefit from additional testing, as abnormal test findings and therapeutic interventions are infrequent and the predictive value for MACE is low. Our results open the discussion for restricting downstream testing in patients with normal hs-cTnT levels, especially in those identified as low risk.

The incremental value of non-invasive cardiac testing in acute chest pain with normal cardiac troponins has been questioned..$^{13,14}$ Concerns on routine use of non-invasive imaging are fuelled by the lack of improvement in patient outcome, increased ionizing radiation exposure, increase in potential harmful downstream invasive procedures and higher health care costs. ${ }^{18}$

Our results confirm the excellent negative predictive value of hs-cTnT assays to rule out acute $\mathrm{MI}$, as none of the patients was initially admitted or discharged with an AMI. ${ }^{8-11}$ However, we extend prior research with the finding of adverse events (including revascularizations) in $6 \%$ of the population during one-year follow-up. Risk scores may aid in identifying those patients with adverse outcome. An overwhelming number of risk scores and pathways have been proposed for risk stratification over the last years, such as GRACE, TIMI, ADAPT, HEART, No Objective Testing rule, ESC 0h/1h, High-STEACS. ${ }^{3,19-27}$ Similar to our clinical rule are most of these scores highly accurate in identifying patients at low risk for adverse outcome. Different from these scores, our clinical rule requires only 2 variables (i.e. recent abnormal stress test result and highly suspicious clinical history) that are either present (high risk) or absent (low risk if both are absent).

Despite that some studies suggest that additional testing may not be necessary in patients classified as low risk, such as the No Objective Testing rule, only very little data is available on the diagnostic yield of additional testing in patients identified as low risk. ${ }^{23}$ One of the few available studies is by Mahler et al. investigating the HEART Pathway, which recommended discharge without additional testing in patients with a low HEART score and negative serial troponin levels. The HEART Pathway resulted in a reduction of additional testing (minus $12 \%$ ), but was not powered to test differences in MACE. ${ }^{28}$ The proposed simple clinical rule in the current manuscript identifies $86 \%$ of patients at such a low risk that additional testing may not be necessary, reducing the number of additional tests substantially.

The current study uniquely combines the role of a clinical rule in risk stratification of patients with acute chest pain and normal high-sensitivity troponin levels and the diagnostic yield of additional testing based on this risk stratification. Others have shown that additional testing does not improve outcome in low risk chest pain patients. ${ }^{29,30}$ In a large health insurance claim data cohort additional testing was associated with an increased number of invasive coronary angiography and revascularization, while number of $\mathrm{Ml}$ remained similar. ${ }^{30}$ These findings were confirmed in a retrospective study in almost 1 million patients. ${ }^{31}$ This suggests that overdiagnosing 
may trigger overtreatment with no benefit on patient outcome. Another large observational study in over 200 hospitals showed that hospitals with higher rates of additional cardiac imaging, did not have fewer readmissions for AMI. ${ }^{32}$ In addition, systematically using CCTA in patients with low risk acute chest pain did not improve patient outcome, but resulted in more invasive procedures and higher costs. ${ }^{33-36} \mathrm{~A}$ large multi-centre controlled trial confirming all these observational and retrospective findings could fill the unmet clinical need for effective referral for downstream testing.

The rational of performing additional testing in patients with acute chest pain is to detect obstructive CAD as early as possible, which may trigger adequate treatment and hereby reduce the number of acute $\mathrm{Ml}$ and cardiac death. However, as described above there is no evidence that applying routine non-invasive testing improves prognosis, although arguably a higher risk subgroup might benefit from this approach. Besides no evidence for improvement in prognosis, the diagnostic yield of routine additional cardiac imaging is generally low and many false positive test results are encountered. ${ }^{37-40}$ The current study shows the diagnostic yield of additional testing could improve when selecting high risk patients. However, one should keep in mind that even in case obstructive CAD is found, it is not yet clear whether this should be treated with medication alone or in combination with coronary revascularization. ${ }^{41}$

Some limitations of the current study should be considered. Firstly, this is a single centre observational study in an unselected population with acute chest pain and clinical decisions were made irrespective of our findings. The description of real world data has important merits in terms of generalizability of results. But no patient was discharged or tested based on our findings, thus the efficacy of our protocol remains unknown. Our hypothesis that low risk patients may be discharged without further testing requires further investigation preferably in a multicentre randomized clinical setting using multiple hs-cTn assays. Secondly, patients who were not hospitalized were not routinely scheduled for re-evaluation. Therefore potentially, although unlikely, an AMI may have been missed. Thirdly, a number of revascularizations might be driven by patient symptoms and an anatomical stenosis, not by evidence of myocardial ischemia. In addition, progression of known CAD (i.e. rather stable CAD) may have triggered ED presentation or even revascularization. To exclude confounding of known CAD, a separate subgroup analysis in patients without known CAD was performed. The results regarding variables independently predicting MACE, risk stratification using the simple clinical rule and additional diagnostic testing and test results were relatively analogous to the unselected acute chest pain population including patients with a known history of CAD.

\section{CONCLUSIONS}

Patients with acute chest pain and normal hs-cTnT levels have an excellent prognosis. Based on clinical characteristics can majority of patients be considered as extremely low risk. In such low risk patients, has additional testing a very limited yield. Based on clinical characteristics, a smaller subset of patients may be considered as higher risk for MACE with potential benefit of additional testing. This clear-cut and easy to implant approach could significantly reduce the number of often unnecessary additional tests, potentially reduce the number of hospital admissions and result in a more cost-effective approach in these patients. 


\section{REFERENCES}

1. Amsterdam EA, Wenger NK, Brindis RG, et al. 2014 AHA/ACC Guideline for the Management of Patients With Non-ST-Elevation Acute Coronary Syndromes: A Report of the American College of Cardiology/ American Heart Association Task Force on Practice Guidelines. J Am Coll Cardiol 2014;24:e139-e228.

2. Lee TH, Goldman L. Evaluation of the patient with acute chest pain. N Engl J Med 2000;342:1187-95.

3. Roffi M, Patrono C, Collet JP, et al. ESC Guidelines for the management of acute coronary syndromes in patients presenting without persistent ST-segment elevation: Task Force for the Management of Acute Coronary Syndromes in Patients Presenting without Persistent ST-Segment Elevation of the European Society of Cardiology (ESC). Eur Heart $J$ 2015;37:267-315.

4. Fruergaard P, Launbjerg J, Hesse B, et al. The diagnoses of patients admitted with acute chest pain but without myocardial infarction. Eur Heart $\mathrm{J}$ 1996;17:1028-34.

5. Kohn MA, Kwan E, Gupta M, Tabas JA. Prevalence of acute myocardial infarction and other serious diagnoses in patients presenting to an urban emergency department with chest pain. J Emerg Med 2005;29:383-90.

6. Pope JH, Aufderheide TP, Ruthazer R, et al. Missed diagnoses of acute cardiac ischemia in the emergency department. N Engl J Med 2000;342:1163-70.

7. Fanaroff AC, Rymer JA, Goldstein SA, Simel DL, Newby LK. Does This Patient With Chest Pain Have Acute Coronary Syndrome?: The Rational Clinical Examination Systematic Review. JAMA 2015;314:1955-65.

8. Bandstein N, Ljung R, Johansson M, Holzmann MJ. Undetectable high-sensitivity cardiac troponin T level in the emergency department and risk of myocardial infarction. J Am Coll Cardiol 2014;63:2569-78.

9. Body R, Carley S, McDowell G, et al. Rapid exclusion of acute myocardial infarction in patients with undetectable troponin using a high-sensitivity assay. J Am Coll Cardiol 2011;58:1332-9.

10. Reichlin T, Hochholzer W, Bassetti S, et al. Early diagnosis of myocardial infarction with sensitive cardiac troponin assays. $N$ Engl $J$ Med 2009;361:858-67.

11. Shah ASV, Anand A, Sandoval Y, et al. High-sensitivity cardiac troponin I at presentation in patients with suspected acute coronary syndrome: a cohort study. Lancet 2015;386:2481-8.

12. Smeeth L, Skinner JS, Ashcroft J, Hemingway H, Timmis A, Chest Pain Guideline Development G. NICE clinical guideline: chest pain of recent onset. The British journal of general practice : the journal of the Royal College of General Practitioners 2010;60:607-10.

13. Prasad V, Cheung M, Cifu A. Chest pain in the emergency department: the case against our current practice of routine noninvasive testing. Arch Intern Med 2012;172:1506-9.

14. Redberg RF. Coronary CT angiography for acute chest pain. N Engl J Med 2012;367:375-6.

15. Thygesen K, Alpert JS, Jaffe AS, et al. Third universal definition of myocardial infarction. Eur Heart J 2012;33:2551-67.
16. De Bruyne B, Fearon WF, Pijls NH, et al. Fractional flow reserve-guided $\mathrm{PCl}$ for stable coronary artery disease. N Engl J Med 2014;371:1208-17.

17. Task Force M, Montalescot G, Sechtem U, et al. 2013 ESC guidelines on the management of stable coronary artery disease: the Task Force on the management of stable coronary artery disease of the European Society of Cardiology. Eur Heart $J$ 2013;34:2949-3003.

18. Smulders MW, Kietselaer BL, Schalla S, et al. Acute chest pain in the high-sensitivity cardiac troponin era: A changing role for noninvasive imaging? Am Heart J 2016;177:102-11.

19. Antman EM, Cohen M, Bernink PJ, et al. The TIMI risk score for unstable angina/non-ST elevation $\mathrm{Ml}$ : A method for prognostication and therapeutic decision making. JAMA 2000;284:835-42.

20. Backus BE, Six AJ, Kelder JC, et al. Chest pain in the emergency room: a multicenter validation of the HEART Score. Crit Pathw Cardiol 2010;9:164-9.

21. Cullen L, Mueller C, Parsonage WA, et al. Validation of high-sensitivity troponin I in a 2-hour diagnostic strategy to assess 30-day outcomes in emergency department patients with possible acute coronary syndrome. J Am Coll Cardiol 2013;62:1242-9.

22. Fox KA, Dabbous OH, Goldberg RJ, et al. Prediction of risk of death and myocardial infarction in the six months after presentation with acute coronary syndrome: prospective multinational observational study (GRACE). BMJ 2006;333:1091.

23. Greenslade $\mathrm{JH}$, Parsonage $\mathrm{W}$, Than $\mathrm{M}$, et al. A Clinical Decision Rule to Identify Emergency Department Patients at Low Risk for Acute Coronary Syndrome Who Do Not Need Objective Coronary Artery Disease Testing: The No Objective Testing Rule. Ann Emerg Med 2016;67:478-89 e2.

24. Reichlin T, Schindler C, Drexler B, et al. One-hour rule-out and rule-in of acute myocardial infarction using high-sensitivity cardiac troponin T. Arch Intern Med 2012;172:1211-8.

25. Chapman AR, Anand A, Boeddinghaus J, et al. Comparison of the Efficacy and Safety of Early Rule-Out Pathways for Acute Myocardial Infarction. Circulation 2017;135:1586-96.

26. Mahler SA, Hiestand BC, Goff DC, Jr., Hoekstra JW, Miller $\mathrm{CD}$. Can the HEART score safely reduce stress testing and cardiac imaging in patients at low risk for major adverse cardiac events? Crit Pathw Cardiol 2011;10:128-33.

27. Ferencik M, Mayrhofer T, Lu MT, et al. High-Sensitivity Cardiac Troponin I as a Gatekeeper for Coronary Computed Tomography Angiography and Stress Testing in Patients with Acute Chest Pain. Clin Chem 2017

28. Mahler SA, Riley RF, Hiestand BC, et al. The HEART Pathway randomized trial: identifying emergency department patients with acute chest pain for early discharge. Circ Cardiovasc Qual Outcomes 2015;8:195-203.

29. Chan GW, Sites FD, Shofer FS, Hollander JE. Impact of stress testing on 30-day cardiovascular outcomes for low-risk patients with chest pain admitted to floor telemetry beds. The American Journal of Emergency Medicine 2003;21:282-7. 
30. Foy AJ, Liu G, Davidson WR, Jr., Sciamanna C, Leslie DL. Comparative effectiveness of diagnostic testing strategies in emergency department patients with chest pain: an analysis of downstream testing, interventions, and outcomes. JAMA internal medicine 2015;175:428-36.

31. Sandhu AT, Heidenreich PA, Bhattacharya J, Bundorf MK. Cardiovascular Testing and Clinical Outcomes in Emergency Department Patients With Chest Pain. JAMA internal medicine 2017;177:1175-82.

32. Safavi KC, Li SX, Dharmarajan K, et al. Hospital variation in the use of noninvasive cardiac imaging and its association with downstream testing, interventions, and outcomes. JAMA internal medicine 2014; 174:546-53.

33. Hoffmann U, Truong QA, Schoenfeld DA, et al. Coronary CT angiography versus standard evaluation in acute chest pain. N Engl J Med 2012;367:299308.

34. Litt HI, Gatsonis C, Snyder B, et al. CT angiography for safe discharge of patients with possible acute coronary syndromes. N Engl J Med 2012;366:1393-403.

35. Hulten E, Pickett C, Bittencourt MS, et al. Outcomes after coronary computed tomography angiography in the emergency department: a systematic review and meta-analysis of randomized, controlled trials. J Am Coll Cardiol 2013;61:880-92.

36. Reinhardt SW, Lin CJ, Novak E, Brown DL. Noninvasive Cardiac Testing vs Clinical Evaluation Alone in Acute Chest Pain: A Secondary Analysis of the ROMICAT-II Randomized Clinical Trial. JAMA internal medicine 2018;178:212-9.

37. Hermann LK, Newman DH, Pleasant WA, et al. Yield of routine provocative cardiac testing among patients in an emergency department-based chest pain unit. JAMA internal medicine 2013;173:1128-33.

38. Penumetsa SC, Mallidi J, Friderici JL, Hiser W, Rothberg MB. Outcomes of patients admitted for observation of chest pain. Arch Intern Med 2012;172:873-7.

39. Kelly AM, Klim S. What is the Yield of Testing for Coronary Artery Disease after an Emergency Department Attendance with Chest Pain? Heart, lung \& circulation 2016;25:12-8.

40. Winchester DE, Brandt J, Schmidt C, Allen B, Payton T, Amsterdam EA. Diagnostic yield of routine noninvasive cardiovascular testing in low-risk acute chest pain patients. Am J Cardiol 2015;116:204-7.

41. Sedlis SP, Hartigan PM, Teo KK, et al. Effect of PCl on Long-Term Survival in Patients with Stable Ischemic Heart Disease. $N$ Engl $J$ Med 2015;373:1937-46. 
Supplemental Table 1.

Diagnosis at discharge from the emergency department.

\begin{tabular}{l|l}
\hline Diagnosis at discharge & \\
\hline Unknown but no acute cardiac pathology & $87.8 \%$ \\
\hline Unstable angina pectoris & $5.7 \%$ \\
\hline Pericarditis & $1.9 \%$ \\
\hline Arrhythmia & $1.8 \%$ \\
\hline Hypertension & $1.7 \%$ \\
\hline Variant angina & $0.4 \%$ \\
\hline Other & $0.5 \%$ \\
\hline
\end{tabular}

The final diagnosis in patients with "no acute cardiac pathology" includes gastro-esophageal disease and musculoskeletal pathology.

Supplemental Table 2.

Baseline patient characteristics for scheduling additional testing.

\begin{tabular}{|c|c|c|c|c|}
\hline Characteristic & $\begin{array}{l}\text { All Patients } \\
(n=918)\end{array}$ & $\begin{array}{l}\text { Patients without a } \\
\text { test }(n=573)\end{array}$ & \begin{tabular}{|l|} 
Patients with $\geq 1$ EET, \\
CCTA or SPECT $(n=345)$
\end{tabular} & $\begin{array}{l}P- \\
\text { value }\end{array}$ \\
\hline \multicolumn{5}{|l|}{ General } \\
\hline Age (years) & $59.1 \pm 12.8$ & $59.2 \pm 13.9$ & $59.0 \pm 10.8$ & 0.875 \\
\hline Male gender & $454(49.5 \%)$ & $278(48.5 \%)$ & $176(51.0 \%)$ & 0.463 \\
\hline $\mathrm{BMI}$ & $27.9 \pm 5.2$ & $27.8 \pm 5.4$ & $28.0 \pm 5.0$ & 0.732 \\
\hline \multicolumn{5}{|l|}{ Clinical history } \\
\hline \multicolumn{5}{|l|}{ Known cardiovascular disease } \\
\hline - History of revascularization & $238(25.9 \%)$ & $140(24.4 \%)$ & $98(28.4 \%)$ & 0.183 \\
\hline - History of MI & $153(16.7 \%)$ & $95(16.6 \%)$ & $58(16.8 \%)$ & 0.927 \\
\hline \multicolumn{5}{|l|}{ Risk factors for $C A D^{*}$} \\
\hline - Hypertension & $414(45.1 \%)$ & $245(42.8 \%)$ & $169(49.0 \%)$ & 0.099 \\
\hline - Diabetes & $124(13.5 \%)$ & $70(12.2 \%)$ & $54(15.7 \%)$ & 0.165 \\
\hline - Hypercholesterolemia & $330(35.9 \%)$ & $184(32.1 \%)$ & $146(42.3 \%)$ & 0.003 \\
\hline - Positive family history & $349(38.0 \%)$ & $202(35.3 \%)$ & $147(42.6 \%)$ & 0.039 \\
\hline - Smoking & 412 (44.9\%) & $259(45.2 \%)$ & $153(44.3 \%)$ & 0.651 \\
\hline
\end{tabular}

\section{Emergency department presentation}

\begin{tabular}{|c|l|l|l|l|}
\hline Patient history classification & & & & 0.007 \\
\hline $\begin{array}{c}\text { - Slightly suspicious } \\
\text { - Moderately suspicious }\end{array}$ & $482(52.5 \%)$ & $324(56.5 \%)$ & $158(45.8 \%)$ & $135(39.1 \%)$ \\
\hline $\begin{array}{c}\text { - Highly suspicious } \\
\text { Recent abnormal stress test }\end{array}$ & $118(12.9 \%)$ & $66(11.5 \%)$ & $52(15.1 \%)$ & $183(31.9 \%)$ \\
\hline
\end{tabular}


Supplemental Table 2. (continued)

\begin{tabular}{|c|c|c|c|c|}
\hline Characteristic & $\begin{array}{l}\text { All Patients } \\
(\mathrm{n}=918)\end{array}$ & $\begin{array}{l}\text { Patients without a } \\
\text { test }(\mathrm{n}=573)\end{array}$ & $\begin{array}{l}\text { Patients with } \geq 1 \text { EET, } \\
\text { CCTA or SPECT }(n=345)\end{array}$ & $\begin{array}{l}P- \\
\text { value }\end{array}$ \\
\hline \multicolumn{5}{|l|}{ Electrocardiogram } \\
\hline ST-T segment changes & 85 (9.3\%) & $57(9.9 \%)$ & $28(8.1 \%)$ & 0.354 \\
\hline Negative T-wave & $102(11.1 \%)$ & $60(10.5 \%)$ & $42(12.2 \%)$ & 0.427 \\
\hline Normal ECG & $685(74.6 \%)$ & $431(75.2 \%)$ & $254(73.6 \%)$ & 0.591 \\
\hline \multicolumn{5}{|l|}{ Laboratory Testing } \\
\hline Hs-cTnT at baseline (ng/L) & $6.9 \pm 3.6$ & $7.0 \pm 3.6$ & $6.9 \pm 3.5$ & 0.726 \\
\hline $\begin{array}{l}\text { Undetectable hs-cTnT at } \\
\text { baseline }\end{array}$ & 205 (22.3\%) & $128(22.3 \%)$ & 77 (22.3\%) & 0.994 \\
\hline Delta hs-cTnT (ng/L)^ & $1.0(0.0-1.0)$ & $1.0(0.0-1.0)$ & $1.0(0.0-1.0)$ & 0.157 \\
\hline CK (U/L) & $87(64-120)$ & $85.5(64.0-120.8)$ & $88.5(65.0-117.0)$ & 0.764 \\
\hline Creatinine ( $\mu \mathrm{mol} / \mathrm{L})$ & $78.0 \pm 21.4$ & $78.7 \pm 22.6$ & $76.7 \pm 18.7$ & 0.358 \\
\hline \multicolumn{5}{|l|}{ Outcome } \\
\hline Cardiac death or MI & $8(0.9 \%)$ & $5(0.9 \%)$ & $3(0.9 \%)$ & 0.996 \\
\hline MACE & $59(6.4 \%)$ & $29(5.1 \%)$ & 30 (8.7\%) & 0.030 \\
\hline
\end{tabular}

Continuous data are expressed as mean \pm standard deviation or median (interquartile range). Categorical data are expressed as frequencies with (percentages).

\# $P$-values are shown for the comparison of patients without a MACE and patients experiencing a MACE during 1-year follow-up. Significance was calculated by Chi-square test, Fisher's Exact test, independent $t$-test or Mann-Whitney $\mathrm{U}$ test when appropriate.

$\wedge$ A second hs-cTnT measurement after 3 hours to calculate the change in hs-cTnT level was available in $178(19 \%)$ patients.

*Data on cardiovascular risk factors were missing for 19 patients.

$\mathrm{BMI}=$ body mass index; $\mathrm{CAD}$ = coronary artery disease; $\mathrm{CCTA}=$ cardiac computed tomography angiography; $\mathrm{Cl}$ = confidence interval; $\mathrm{CK}$ = creatine kinase; $\mathrm{ECG}=$ electrocardiogram; $\mathrm{EET}=$ electrocardiographic exercise testing; hs-cTnT = high sensitivity cardiac Troponin-T; MACE = major adverse cardiac events; $\mathrm{Ml}=$ myocardial infarction; $\mathrm{ng} / \mathrm{L}=$ nanograms per liter; $\mathrm{OR}$ = odds ratio; $\mathrm{SPECT}=$ single-photon emission computed tomography; $\mu \mathrm{mol} / \mathrm{L}=$ micromol per liter; $\mathrm{U} / \mathrm{L}=$ units per liters.

Supplemental Table 3.

Baseline patient characteristics stratified for each non-invasive test performed.

\begin{tabular}{|l|l|l|l|l|}
\hline Characteristic & $\begin{array}{l}\text { EET } \\
(\mathbf{n = 2 7 1 )}\end{array}$ & $\begin{array}{l}\text { CGTA } \\
(\mathbf{n = 8 6})\end{array}$ & $\begin{array}{l}\text { SPECT } \\
(\mathrm{n=45})\end{array}$ & $\begin{array}{l}\text { P-value } \\
\text { overall" }\end{array}$ \\
\hline General & & & & \\
\hline Age (years) & $58.7 \pm 10.8$ & $57.3 \pm 9.4$ & $63.1 \pm 9.7$ & 0.008 \\
\hline Male gender & $153(56.5 \%)$ & $33(38.4 \%)$ & $23(51.1 \%)$ & 0.014 \\
\hline BMI & $27.9 \pm 5.1$ & $28.0 \pm 4.1$ & $27.8 \pm 5.3$ & 0.975 \\
\hline Clinical history & & & & \\
\hline $\begin{array}{c}\text { Known cardiovascular disease } \\
\text { - History of revascularization }\end{array}$ & $82(30.3 \%)$ & $3(3.5 \%)$ & $26(57.8 \%)$ & $<0.001$ \\
\hline
\end{tabular}


Supplemental Table 3. (continued)

\begin{tabular}{|c|c|c|c|c|}
\hline Characteristic & \begin{tabular}{|l} 
EET \\
$(n=271)$
\end{tabular} & $\begin{array}{l}\text { CCTA } \\
(\mathrm{n}=86)\end{array}$ & $\begin{array}{l}\text { SPECT } \\
(\mathrm{n}=45)\end{array}$ & $\begin{array}{l}P \text {-value } \\
\text { overall }\end{array}$ \\
\hline - History of MI & $49(18.1 \%)$ & $4(4.7 \%)$ & $11(24.4 \%)$ & 0.003 \\
\hline \multicolumn{5}{|l|}{ Risk factors for $C A D^{*}$} \\
\hline - Hypertension & $133(49.1 \%)$ & $31(36.0 \%)$ & $28(62.2 \%)$ & 0.008 \\
\hline - Diabetes & $42(15.5 \%)$ & $8(9.3 \%)$ & $11(24.4 \%)$ & 0.061 \\
\hline - Hypercholesterolemia & $117(43.2 \%)$ & $26(30.2 \%)$ & $23(51.1 \%)$ & 0.028 \\
\hline - Positive family history & $113(41.7 \%)$ & $46(53.5 \%)$ & $17(37.8 \%)$ & 0.140 \\
\hline - Smoking & $128(47.2 \%)$ & $41(47.7 \%)$ & $15(33.3 \%)$ & 0.224 \\
\hline \multicolumn{5}{|l|}{ Emergency department presentation } \\
\hline Patient history classification & & & & 0.078 \\
\hline - Slightly suspicious & $126(46.5 \%)$ & $44(51.2 \%)$ & $16(35.6 \%)$ & \\
\hline - Moderately suspicious & $101(37.3 \%)$ & $35(40.7 \%)$ & $1737.8 \%)$ & \\
\hline - Highly suspicious & $44(16.2 \%)$ & $7(8.1 \%)$ & $12(26.7 \%)$ & \\
\hline Recent abnormal stress test & $10(3.7 \%)$ & $2(2.3 \%)$ & $0(0.0 \%)$ & 0.372 \\
\hline \multicolumn{5}{|l|}{ Electrocardiogram } \\
\hline ST-T segment changes & $20(7.4 \%)$ & $4(4.7 \%)$ & $4(8.9 \%)$ & 0.595 \\
\hline Negative T-wave & $32(11.8 \%)$ & $9(10.5 \%)$ & $7(15.6 \%)$ & 0.690 \\
\hline Normal ECG & $200(73.8 \%)$ & $66(76.7 \%)$ & $32(71.1 \%)$ & 0.765 \\
\hline \multicolumn{5}{|l|}{ Laboratory testing } \\
\hline Hs-cTnT at baseline(ng/L) & $6.8 \pm 3.4$ & $6.4 \pm 3.6$ & $7.8 \pm 3.6$ & 0.068 \\
\hline Undetectable hs-cTnT at baseline & $62(22.9 \%)$ & $25(29.1 \%)$ & $7(15.6 \%)$ & 0.209 \\
\hline Delta hs-cTnT (ng/L)^ & $1.0(0.0-1.0)$ & $1.0(0.0-1.0)$ & $1.0(0.0-1.0)$ & 0.579 \\
\hline CK (U/L) & $90(66-121)$ & $86(66-113)$ & $93(66-117)$ & 0.773 \\
\hline Creatinine $(\mathrm{mmol} / \mathrm{L})$ & $78.0 \pm 18.9$ & $70.8 \pm 14.7$ & $78.0 \pm 22.9$ & 0.086 \\
\hline \multicolumn{5}{|l|}{ Outcome } \\
\hline Cardiac death or MI & $3(1.1 \%)$ & $0(0.0 \%)$ & $1(2.2 \%)$ & 0.452 \\
\hline MACE & $25(9.2 \%)$ & $8(9.3 \%)$ & $5(11.1 \%)$ & 0.922 \\
\hline
\end{tabular}

Continuous data are expressed as mean \pm standard deviation or median (interquartile range). Categorical data are expressed as frequencies with (percentages). Note that some patients did undergo multiple tests.

\# $P$-values are shown for the comparison of patients without a MACE and patients experiencing a MACE during 1-year follow-up. Significance was calculated by Chi-square test, one-way ANOVA test or independent samples Kruskal-Wallis test when appropriate.

^ A second hs-cTnT measurement after 3 hours to calculate the change in hs-cTnT level was available in 82 (20\%) patients.

*Data on cardiovascular risk factors were missing for 5 patients.

$\mathrm{BMI}=$ body mass index; $\mathrm{CAD}=$ coronary artery disease; $\mathrm{CCTA}=$ cardiac computed tomography angiography; $\mathrm{Cl}=$ confidence interval; $\mathrm{CK}$ = creatine kinase; $\mathrm{ECG}$ = electrocardiogram; $\mathrm{EET}$ = electrocardiographic exercise testing; hs-cTnT = high sensitivity cardiac Troponin-T; MACE = major adverse cardiac events; $\mathrm{MI}=$ myocardial infarction; $\mathrm{ng} / \mathrm{L}=$ nanograms per liter; $\mathrm{OR}=$ odds ratio; $\mathrm{SPECT}=$ single-photon emission computed tomography; $\mathrm{mmol} / \mathrm{L}=$ micromol per liter; $\mathrm{U} / \mathrm{L}=$ units per liters. 


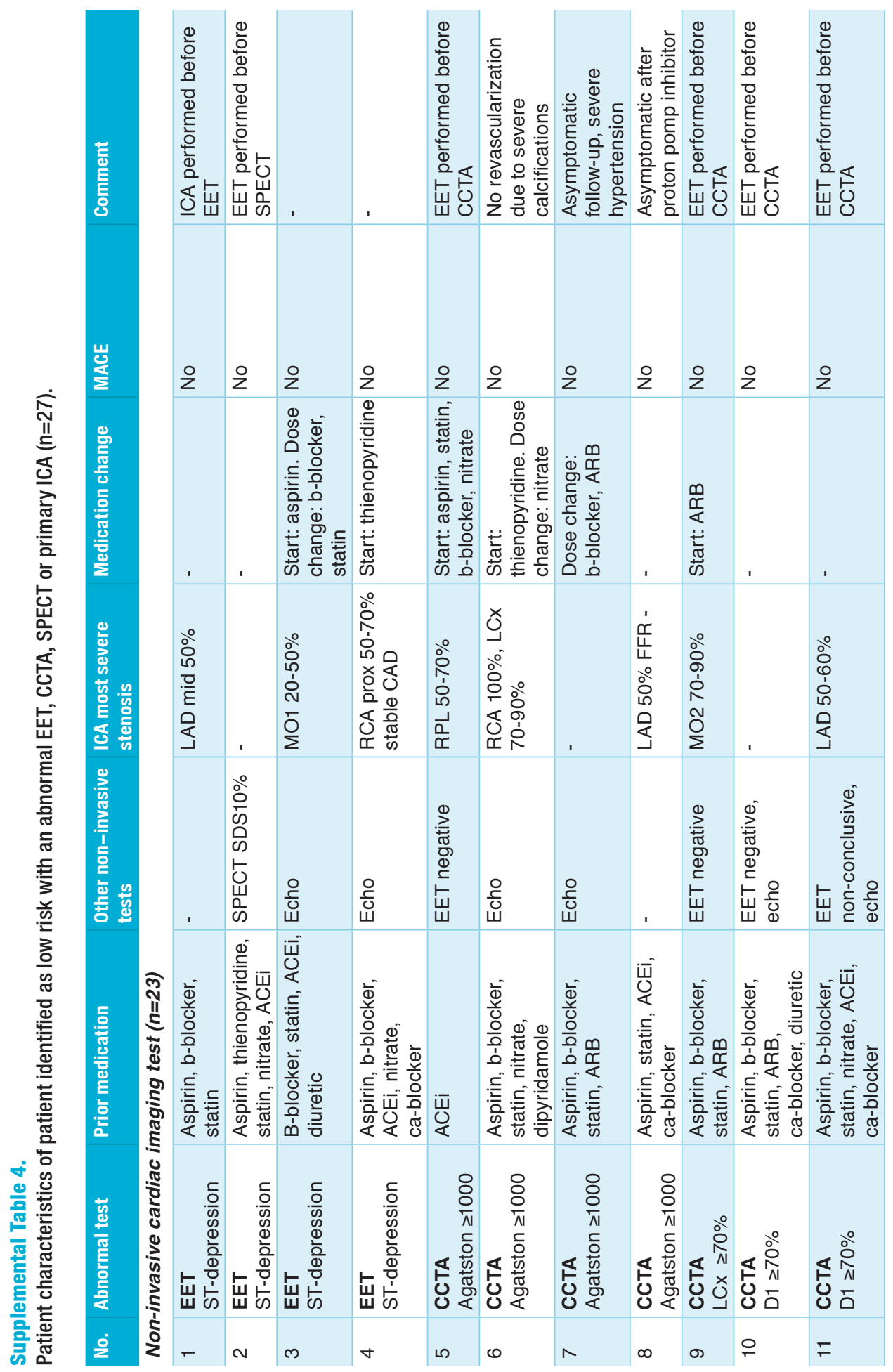




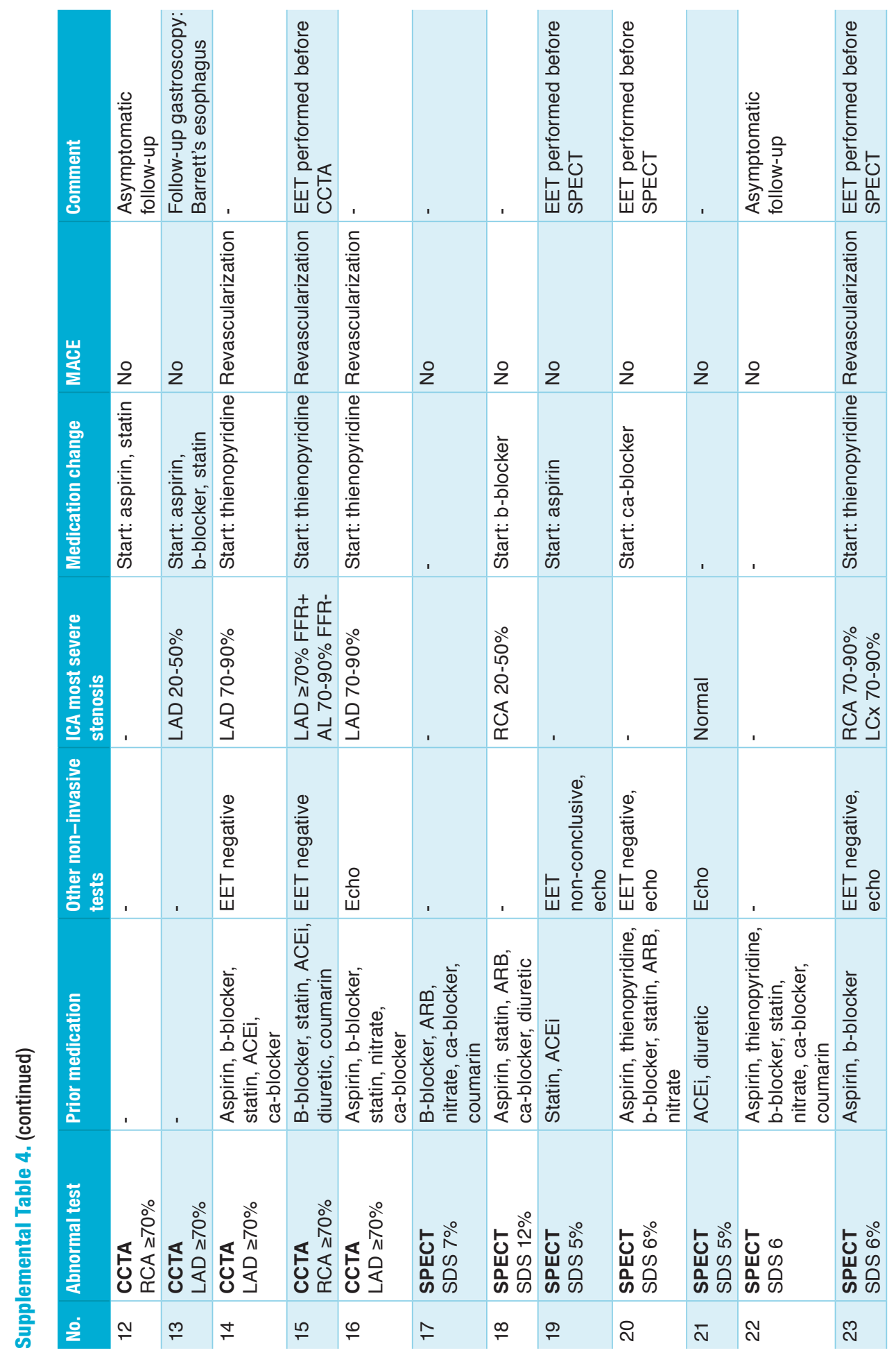




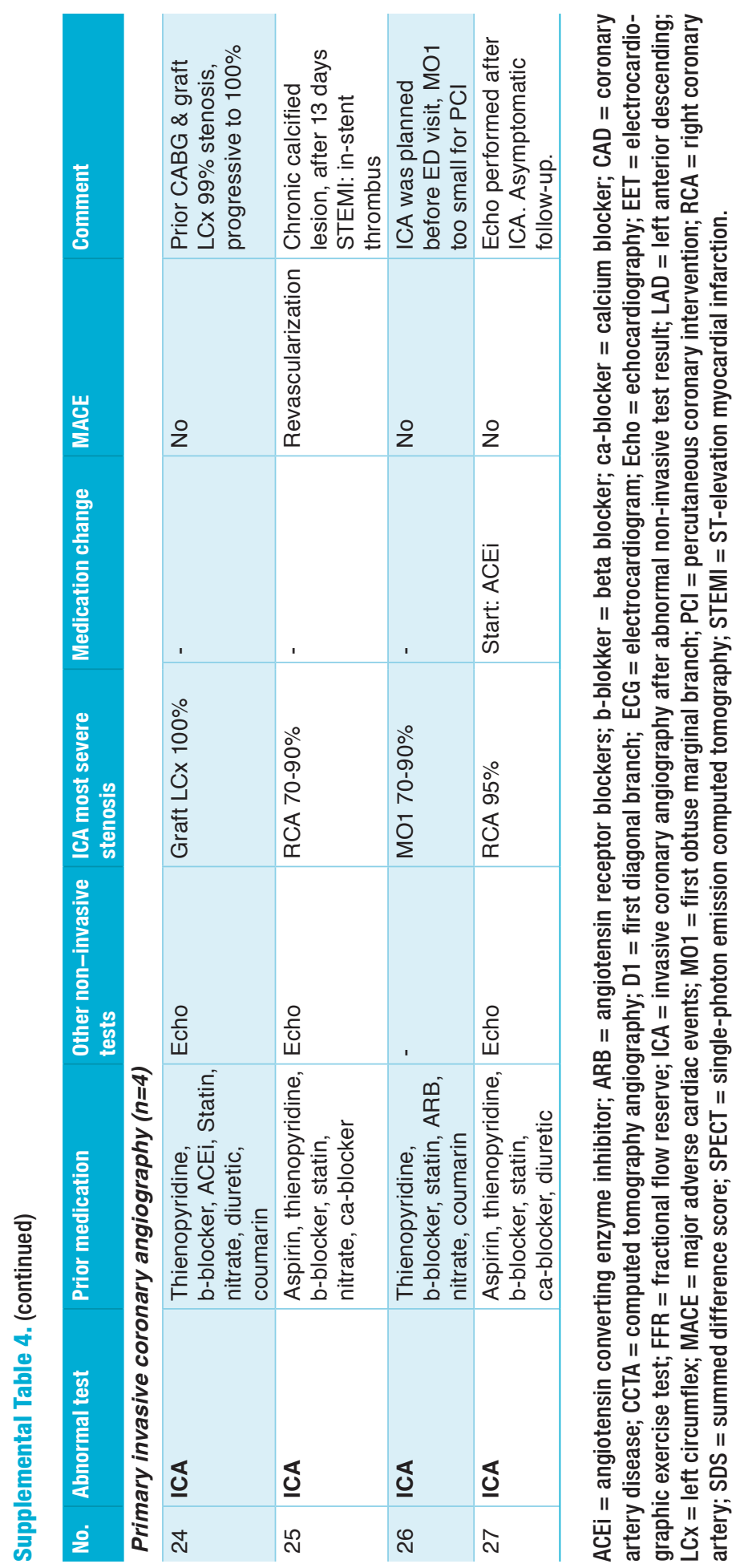




\section{Editorial Comment}




\section{Acute chest pain and normal high- sensitivity cardiac troponin levels; Is this the end of the story?}

Frans H. Rutten, MD, PhD

Afdeling Huisartsgeneeskunde, divisie Julius Centrum voor Gezondheidswetenschappen en Eerstelijns Geneeskunde, Universiteit Utrecht, Utrecht, The Netherlands

Nederlands Tijdschrift voor Geneeskunde. 2018; 162: D3540. 
Pijn op de borst komt veel voor: 1,3\% van alle huisartsenconsulten. Bij ongeveer $8 \%$ van die consulten is sprake van een levensbedreigende aandoening, zoals het acuut coronair syndroom (ACS). ${ }^{1}$ Bij patiënten die naar de Spoedeisende Hulp of de Eerste Harthulp worden verwezen vanwege acute pijn op de borst is dat percentage veel hoger: $35 \%$ van hen heeft een ACS. ${ }^{2}$ Het ACS is een verzamelterm voor ST-elevatie-myocardinfarct (STEMI), niet-ST-elevatie-myocardinfarct (NSTEMI) en instabiele angina pectoris (IAP). Van alle patiënten met een ACS heeft $50 \%$ IAP, $35 \%$ een NSTEMI en $15 \%$ een STEMI.

\section{CARDIAAL VS. NIET-CARDIAAL}

Allereerst is het van belang om een myocardinfarct (STEMI en NSTEMI) te onderscheiden van IAP en niet-cardiale aandoeningen. Een verhoogde concentratie troponine, een biomarker voor hartschade, en eventuele ST-elevatie in meerdere afleidingen van het ecg zijn suggestief voor een myocardinfarct. ${ }^{3}$ Ruim $80 \%$ van alle patiënten met acute pijn op de borst in het ziekenhuis heeft geen myocardinfarct; ongeveer $17 \%$ (0,5 x 35\%) van die patiënten heeft IAP en $65 \%$ heeft 'iets anders'.

Je verwacht dat bij patiënten uit deze 'restgroep' aanvullende diagnostiek volgt, zoals onderzoeken om een IAP-episode meer of minder waarschijnlijk te maken en onderzoeken van longen en buik. De behandeling en prognose van een patiënt met angina pectoris is tenslotte anders dan die van een patiënt met gastro-oesofageale refluxziekte. Ook kunnen ernstige pulmonale en gastro-intestinale aandoeningen acute pijn op de borst veroorzaken (Tabel 1). ${ }^{1}$ Toch gebeurt dit veelal niet in de dagelijkse cardiologische praktijk, zo blijkt uit het onderzoek dat elders in dit tijdschrift wordt beschreven. ${ }^{3}$ Bij de 'restgroep'-patiënten worden ogenschijnlijk alleen onderzoeken van het hart verricht, met als gevolg dat deze patiënten eindigen met het label 'cardiaal' of 'niet-cardiaal'.

Tabel 1.

Oorzaken van acute en niet-acute pijn op de borst

\begin{tabular}{l|l|l}
\hline $\begin{array}{l}\text { Oorzaak } \\
\begin{array}{l}\text { Cardiaal } \\
\text { levensbedreigend } \\
\text { niet-levensbedreigend }\end{array}\end{array}$ & $\begin{array}{l}\text { 8.4 } \\
8.7\end{array}$ & $\begin{array}{l}\text { Diagnose } \\
\text { myocard infarct }\end{array}$ \\
\hline Musculoskeletaal of neurogeen & 35,4 & $\begin{array}{l}\text { intercostale neuralgie, syndroom van Tietze, myogene } \\
\text { overbelasting }\end{array}$ \\
\hline Psychisch & 18,2 & angststoornis met of zonder hyperventilatiesyndroom \\
\hline Gastro-intestinaal & 14,1 & gastritis, gastro-oesofageale refluxziekte, cholelithiasis \\
\hline Pulmonaal & 7,6 & longembolie, pleuritis, pneumonie, pneumothorax \\
\hline Overig & 7,6 & \\
\hline
\end{tabular}

Maar die patiënten verwachten een verklaring voor hun klachten, evenals een bijpassende behandeling en prognose. Zij kunnen niet veel met de 'diagnose' 'niet-cardiale thoracale pijn'. $\mathrm{Na}$ een stressvolle periode en een reeks onderzoeken van het hart weten zij dan: 'het is niet van uw hart'. Deze patiënten komen binnen een week met hun partner op het spreekuur van de huisarts met vragen als: 'Wat is het dan wél dokter? De pijn moet toch ergens vandaan komen?' 


\section{TWIJFELACHTIG}

Het eerder genoemde onderzoek laat zien dat het aantal vervolgonderzoeken bij patiënten uit de 'restgroep' beperkt kan blijven. Als de anamnese niet verdacht is voor angina pectoris en een recente stresstest niet-afwijkend is, dan is er maar een kleine kans op cardiale problemen in het komende jaar. ${ }^{3}$ Dit was bij $86 \%$ van de patiënten het geval en bij hen zou sowieso beeldvormend onderzoek van het hart achterwege kunnen blijven. ${ }^{3}$

In het jaar volgend op de episode van acute pijn op de borst onderging 5,0\% van de patiënten uit de 'restgroep' een revascularisatie-ingreep, kreeg 0,4\% een myocardinfarct, werd $0,2 \%$ opgenomen in het ziekenhuis vanwege hartfalen en overleed $0,2 \% .^{3}$ Ter vergelijking: de jaarlijkse incidentie van een myocardinfarct in de algemene populatie is ongeveer $0,2 \% .{ }^{4}$ Ook weten we dat bij de meeste patiënten met stabiele angina pectoris een revascularisatie-ingreep (naast optimale medicamenteuze therapie) geen zin heeft. Een dergelijke ingreep vermindert in het eerste jaar erna wel de mate van ischemie van het hart, maar het heeft geen invloed op het aantal myocardinfarcten en het aantal patiënten dat overlijdt door een cardiale oorzaak. ${ }^{5}$

Er zijn dan ook cardiologen die stellen dat de toegevoegde waarde van beeldvormend onderzoek van het hart bij de gehele 'restgroep' van patiënten met acute pijn op de borst twijfelachtig is; het leidt alleen tot een toename van het aantal revascularisatie-ingrepen en daarmee tot hogere kosten, meer fout-positieve uitslagen en een hoger risico op iatrogene schade, terwijl de prognose van deze patiënten niet verbetert (geen vermindering van het aantal myocardinfarcten en geen sterftedaling gedurende de follow-up periode). ${ }^{6-8}$

\section{CONCLUSIE}

De diagnostiek bij patiënten met acute pijn op de borst die geen myocardinfarct blijken te hebben kan veel beter. Aanvullende onderzoeken zouden meer gericht moeten zijn op de niet-cardiale oorzaken van acute pijn op de borst, niet alleen op het in beeld brengen van het hart. Patiënten die op basis van de anamnese en de uitslag van een stresstest zeer waarschijnlijk IAP hebben, behoeven geen beeldvormend onderzoek van het hart. Wel moeten zij goed geïnstrueerd worden hoe zij moeten handelen als zij opnieuw pijn op de borst krijgen. Daarnaast is preventieve behandeling met acetylsalicylzuur en een cholesterolverlager noodzakelijk, eventueel aangevuld met een b-blokker, calciumantagonist of nitraat als aanvalsbehandeling. 


\section{REFERENCES}

1. Hoorweg BB, Willemsen RT, Cleef LE, et al. Frequency of chest pain in primary care, diagnostic tests performed and final diagnoses. Heart 2017:103:1727-32.

2. Van Severen E, Willemsen R, Vandervoort P, Sabbe M, Dinant GJ, Buntinx F. How do patients with chest pain access Emergency Department care? Eur J Emerg Med 2017;24:423-7.

3. Smulders MW, Bekkers SCAM, van Cauteren YJM, et al. Acute pijn op de borst zonder afwijkend troponine: is aanvullende niet-invasieve diagnostiek zinvol? Ned Tijdschr Geneeskd 2018;162:D3568.

4. Yeh RW, Sidney S, Chandra M, Sore IM, Selby JV, Go AS. Population trends in the incidence and outcomes of acute myocardial infarction. $\mathrm{N}$ Engl $\mathrm{J}$ Med 2010;362:2155-65.

5. Sedlis SP, Hartigan PM, Teo KK, et al; COURAGE Trial Investigators. Effect of $\mathrm{PCl}$ on long-term survival in patients with stable ischemic heart disease. N Engl J Med 2015;373:1937-46.

6. Prasad V, Cheung M, Cifu A. Chest pain in the emergency department: the case against our current practice of routine noninvasive testing. Arch Intern Med 2012;172:1506-9.

7. Redberg RF. Coronary CT angiography for acute chest pain. N Engl J Med 2012;367:375-6.

8. Hermann LK, Newman DH, Pleasant WA, et al. Yield of routine provocative cardiac testing among patients in an emergency department-based chest pain unit. JAMA Intern Med 2013;173:1128-33. 


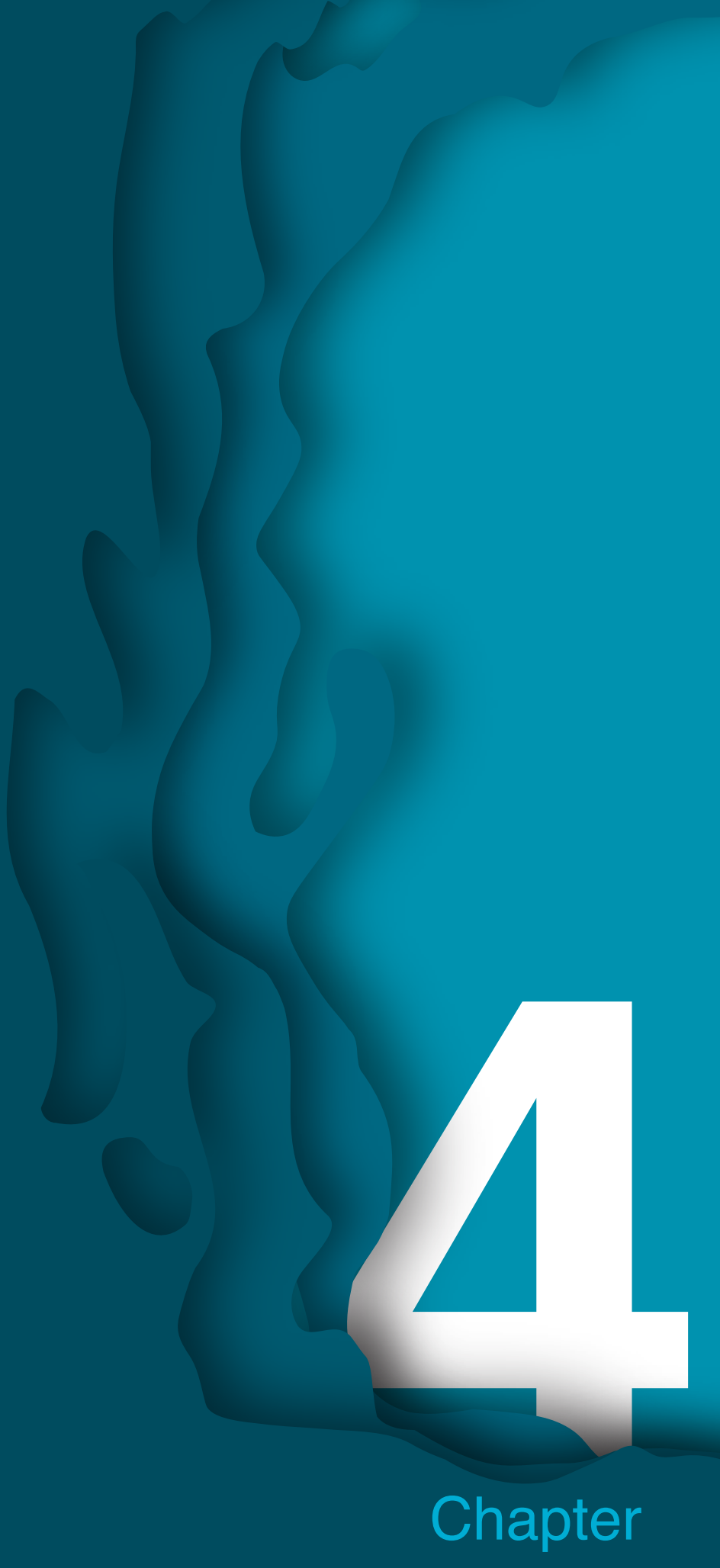




\section{High biomarkers, but normal angiogram: what next?}

Sebastiaan C.A.M. Bekkers, MD, PhD, and Martijn W. Smulders, MD

Department of Cardiology and Cardiovascular Research Institute Maastricht (CARIM), Maastricht University Medical Center, Maastricht, The Netherlands 


\section{ABSTRACT}

Myocardial infarction (MI) with nonobstructed ( $<50 \%$ stenosis) coronary arteries (MINOCA) represents a diagnostic and therapeutic dilemma. Potential diagnoses include both MI- and non-Ml-related etiologies. A diagnostic algorithm that starts in the catheterization lab and incorporates cardiovascular magnetic resonance imaging and computed tomography narrows the differential diagnosis, allowing a targeted therapeutic approach that ultimately may improve prognosis. 


\section{INTRODUCTION}

Myocardial infarction (MI) with nonobstructed ( $<50 \%$ stenosis) coronary arteries (MINOCA) occurs in approximately $6 \%$ of patients with suspected $\mathrm{Ml}$ and represents a diagnostic and therapeutic dilemma. ${ }^{1}$ The prevalence may be even higher in the era of high-sensitivity cardiac troponin (cTn) assays, because of their lower specificity to diagnose acute MI. It typically occurs in younger patients and an unsatisfying number of patients are ultimately discharged without a clear etiology for their episode of myocardial injury. Importantly, patients have an adverse outcome that may be related to inappropriate diagnosis and treatment. ${ }^{2}$

The underlying causes of MINOCA are heterogeneous and include plaque rupture with spontaneous coronary recanalization and/or distal embolization of plaque debris, coronary spasm, myocarditis, stress cardiomyopathy, pulmonary embolism, microvascular dysfunction, and others (Table 1). Given this wide spectrum of potential diagnoses, it follows that the pathology is not exclusively related to $\mathrm{MI}$, but includes non-MI diagnoses as well.

A crucial question is whether MINOCA is associated with vulnerable plaques or not. In more than half of patients with MINOCA, some degree of coronary artery disease (CAD) can be found, including outward/positively remodeled atherosclerotic plaque within a coronary artery. ${ }^{3}$ Although $\mathrm{Ml}$ is frequently triggered by atherosclerotic plaques which previously did not cause severe stenosis, holding such plaques responsible for the index event in patients with MINOCA is jumping to conclusions. ${ }^{4}$ This "smoking gun" theory is also challenged by the observation that an equal burden of CAD can be found in matched healthy controls without known cardiovascular disease and that $\mathrm{MI}$ is finally diagnosed in only $20 \%$ of patients..$^{1,5}$ The presence of minimal CAD can merely be a coincidental finding. Alternatively, microvascular disease as a result of coronary vasomotor dysfunction and/or decreased intramyocardial capillary density in hypertensive or diabetic patients or in hypertrophic cardiomyopathy, are increasingly recognized entities. ${ }^{6}$

Other non-Ml diagnoses should be taken into account and inappropriate treatment and stigmatization of patients, as having suffered an MI, should be avoided. Current guidelines do not provide recommendations on how to deal with these patients, but additional diagnostic testing is often needed to narrow the differential diagnosis.,

\section{INITIAL DIAGNOSTIC EVALUATION}

The interventional cardiologist is often the first to be confronted with MINOCA. Myocardial bridging, spontaneous coronary dissection, and missed proximally occluded side-branches should carefully be excluded. Provocative testing using intracoronary ergonovine or acetylcholine can be performed to exclude coronary vasospasm as a result of endothelial dysfunction and concealed atherosclerosis. Because coronary angiography does not allow visualization of the vessel wall, vulnerable plaques could be sought using either intravascular ultrasound (IVUS) or optical coherence tomography (OCT) while the patient is still in the catheterization lab. A thin fibrous cap, large plaque burden, large lipid core, and small lumen area are morphological characteristics of ruptured and vulnerable coronary plaques. ${ }^{9}$ However, an extensive and "blind" exploration of the complete coronary tree in search for concealed atherosclerosis is impractical, time-consuming and not without risk. Restricted availability, expertise, higher costs, and additional radiation exposure for patients further limit widespread use of OCT and IVUS. Moreover, far too many patients are sent back to the ward without further invasive testing, leaving the clinician in despair.

Clinical characteristics are not specific, but can be useful to narrow the differential diagnosis. The presence of multiple risk factors for atherosclerosis (smoking, abnormal lipid profile, positive family history, diabetes, hypertension) increases the likelihood of concealed atherosclerosis. A 
family or personal history of hypercoagulability and thromboembolism may warrant a search for hereditary thrombophilia, such as factor V Leiden, prothrombin G20210A gene mutation, protein $\mathrm{C}$, protein S, antithrombin deficiency, hyperhomocysteinemia, or the antiphospholipid antibody syndrome. Routine blood testing may reveal elevated inflammatory parameters or elevated D-dimer levels that may suggest myocarditis or pulmonary embolism, respectively. However, the information received from history or additional blood tests often lacks specificity and provides evidence too circumstantial to be clinically useful. Additional noninvasive imaging may further narrow the differential diagnosis.

Table 1.

Potential causes of myocardial infarction with nonobstructed coronary arteries (MINOCA).

\begin{tabular}{l|l}
$\begin{array}{l}\text { MI related } \\
\text { Plaque rupture or erosion and spontaneous } \\
\text { recanalization }\end{array}$ & Mon-Ml related \\
\hline Coronary spasm in setting of & Stress cardiomyopathy \\
\hline - Endothelial dysfunction & Pulmonary embolism \\
\hline - Cocaine abuse & Dilated cardiomyopathy \\
\hline - Ephedrine containing drugs abuse & Hypertrophic cardiomyopathy \\
\hline - Withdrawal from calcium antagonists & Microvascular dysfunction (syndrome X) \\
\hline (Paradoxical) coronary embolism & Pheochromocytoma \\
\hline - Myocardial tumor (myxoma) & Sarcoidosis \\
\hline - Myocardial thrombus (post-MI, atrial fibrillation) & Connective tissue disease (SLE) \\
\hline - PFO or ASD & \\
\hline Hypercoagulable status & \\
\hline - Factor V Leiden & \\
\hline - Prothrombin G20210A gene mutation & \\
\hline - Protein C deficiency & \\
\hline - Protein S deficiency & \\
\hline - Antithrombin deficiency & \\
\hline - Hyperhomocysteinaemia & \\
\hline - Anti-phospholipid antibody syndrome & \\
\hline Myocardial bridging & \\
\hline Demand ischemia & \\
\hline - Tachycardia (eg. atrial fibrillation) & \\
\hline - Severe hypertension (>200 mmHg systolic) & \\
\hline - Congestive heart failure & \\
\hline
\end{tabular}

ASD = atrial septal defect, $\mathrm{MI}=$ myocardial infarction, $\mathrm{PFO}=$ patent foramen ovale, $\mathrm{SIRS}=$ Systemic Inflammatory Response Syndrome, SLE = systemic lupus erythematosus. 


\section{NON-INVASIVE IMAGING}

\section{Cardiovascular magnetic resonance imaging}

Although a single test that untangles all different etiologies in patients with MINOCA is not available, cardiac magnetic resonance imaging (MRI) may differentiate between potential causes. A comprehensive cardiac MRI examination provides information on myocardial function (cine imaging), inflammation (T2-weighted imaging), and fibrosis (delayed enhancement imaging), and allows categorization of potential etiologies, both $\mathrm{Ml}$ - and non-Ml-related. ${ }^{10}$

Cardiac cine MRI accurately and reproducibly provides assessment of cardiac function, volumes, mass, and morphology. Consequently, regional wall motion abnormalities (WMAs) that are confined to a corresponding coronary artery territory are highly suspicious, but not diagnostic for MI. WMAs outside a single coronary artery territory or extending over multiple territories occur with either myocarditis or stress cardiomyopathy. Dilated or hypertrophic cardiomyopathy can also be suggested from cardiac cine MRI.

T2-weighted cardiac MRI enables visualization of myocardial edema (T2-hyperintensity) and may be used to detect acute MI, myocarditis, or stress cardiomyopathy. ${ }^{11}$ In acute MI, edema is typically subendocardial or transmural, and sometimes accompanied with intramyocardial hemorrhage (central hypoenhancement within hyperenhanced area) (Figure 1, case 1). In myocarditis, T2-hyperintensity is mostly patchy, mid-wall, or epicardial, and located in the septal and/or basal inferolateral segments (Figure 1, case 2). A cardinal feature of stress cardiomyopathy (also "takotsubo cardiomyopathy" or "transient apical ballooning") is reversible regional WMAs and edema that extends beyond a single coronary artery in the absence of myocardial scar and is often triggered by emotional or physical stress. ${ }^{11}$

Delayed enhancement cardiac MRI is capable of visualizing small scars that cannot be detected by other imaging techniques and allows differentiation between $\mathrm{Ml}$ - and non-MIrelated etiologies. ${ }^{10}$ Based on the concept that ischemic necrosis proceeds as a "wavefront" from the subendocardium to the epicardium with increasing occlusion time, it follows that hyperenhancement patterns that spare the subendocardium are likely to be nonischemic in origin. Thus, ischemic damage from CAD typically involves the endocardium, whereas mid-wall to epicardial scar (either patchy or linear) is consistent with myocarditis or dilated or hypertrophic cardiomyopathy. ${ }^{10}$ In such cases, the coronary angiogram should be reassessed for proximally occluded side branches that may have been missed initially.

A specific diagnosis can be provided by cardiac MRI in up to $75 \%$ of patients with MINOCA and include $\mathrm{MI}$ ( $5 \%$ to $29 \%$ ), myocarditis ( $7 \%$ to $63 \%$ ), stress cardiomyopathy ( $2 \%$ to $22 \%$ ), pericarditis ( $0 \%$ to $5 \%$ ), amyloidosis $(0 \%$ to $5 \%$ ), and hypertrophic or dilated cardiomyopathy $(0 \% \text { to } 4 \%)^{12,13}$ Nonetheless, a large subset of patients do not have any abnormalities on cardiac MRI. ${ }^{1}$ This may be explained by an insufficient resolution of cardiac MRI to detect limited myocardial damage, disease recovery (eg, stress cardiomyopathy [for this reason cardiac MRI should be performed early]), or other etiologies for MINOCA undetectable by cardiac MRI. New developments, such as T1- and T2-mapping techniques may further increase cardiac MRI's diagnostic accuracy, but validation is still awaited. ${ }^{14}$ The diagnostic role of adenosine stressperfusion cardiac MRI to detect microvascular disease is still debated. 
Figure 1.

Patient examples.

CASE 1
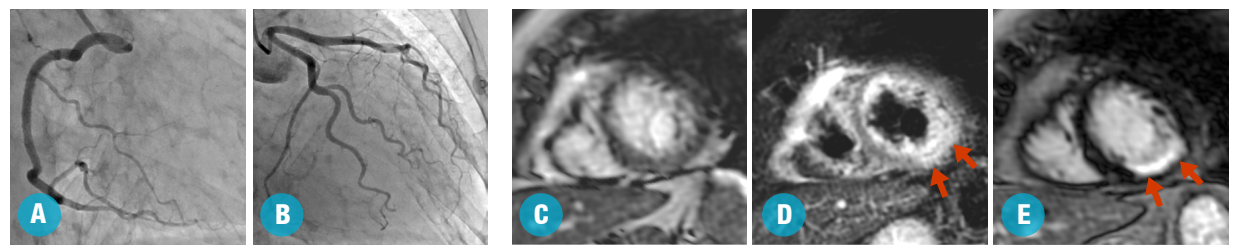

\section{CASE 2}
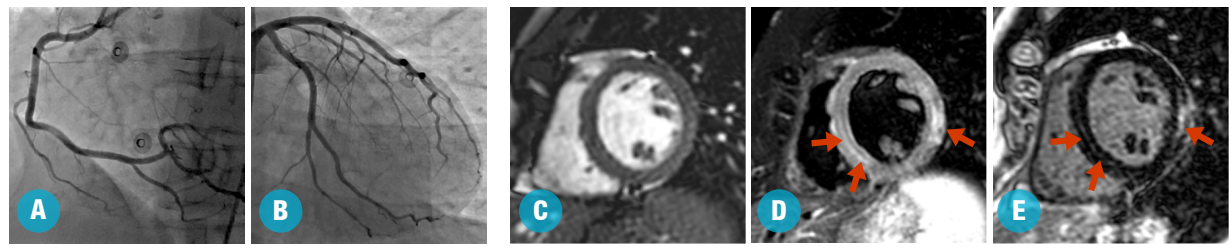

CASE 3
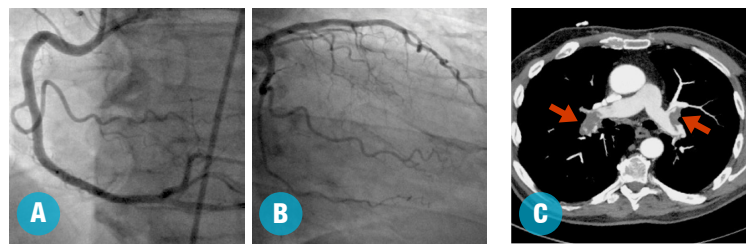

Case 1. An 82-year-old woman who presented with acute chest pain and diaphoresis. The electrocardiogram (ECG) showed ST-segment elevation in inferolateral, and ST-segment depression in anteroseptal, leads. High-sensitivity cardiac troponin T (cTnT) levels were elevated ( $40 \mathrm{ng} / \mathrm{L}$ and $317 \mathrm{ng} / \mathrm{L}$ at presentation and 3-hour follow-up, respectively). Urgent invasive coronary angiography showed vessel wall irregularities of both left and right coronary arteries (A, B). Cardiac magnetic resonance imaging (MRI) is consistent with an acute subendocardial myocardial infarction: akinesia on cardiac cine MRI (C), subendocardial increased signal intensity on the T2-weighted (edema) imaging (D), and delayed enhancement (scar) (E) in the apical mid-inferolateral segments (arrows). Case 2. A 31-year-old man who presented with acute chest pain and flulike symptoms. The ECG showed ST-segment elevation in the lateral leads and high-sensitivity cTnT level was elevated (1572 ng/L) at presentation. Invasive coronary angiography revealed normal coronary arteries (A, B). A subsequent cardiac MRI examination is consistent with myocarditis: hypokinesia on cardiac cine MRI (C), focal mid-wall to epicardial increased signal intensity on the T2-weighted (edema) (D), and the delayed enhancement images (scar) (E) in the mid- inferolateral segments (arrows). Case 3. A 66-year-old man who presented with acute chest pain. The ECG showed inverted T-waves in the anterior leads. High-sensitivity cTnT and D-dimer levels were elevated ( $34 \mathrm{ng} / \mathrm{L}$ and $>10000 \mathrm{ng} / \mathrm{mL}$, respectively). Urgent invasive coronary angiography revealed normal coronary arteries (A, B). Transthoracic echocardiography was judged as normal. A computed tomography (CT) scan was deemed more appropriate than cardiac MRI, and showed bilateral pulmonary emboli (C). 


\section{Computed tomography angiography}

Atherosclerosis may be present, but concealed on routine invasive coronary angiography because of outward remodeling of atherosclerotic plaques. Computed tomography (CT) angiography is very sensitive in detecting CAD and rules out atherosclerosis with high confidence..$^{15}$ Initial noncontrast enhanced CT scanning may identify calcified coronary plaques, but when absent, does not rule out the existence of noncalcified plaques. ${ }^{3}$ Therefore, iodine contrast agents are usually administered to visualize the coronary lumen, the vascular wall, and (noncalcified) plaques. Completely normal coronary arteries on CT angiography and a zero calcium score exclude atherosclerotic CAD as a cause for MINOCA.

In the presence of atherosclerosis, CT angiography allows characterization of plaques. In general, vulnerable plaques are noncalcified, have a large plaque area, a large lipid core, and more frequently show outward remodeling. ${ }^{3}$ The high resolution of CT angiography allows identification of ruptured plaques, but is insufficient to detect the thinned fibrous cap of eroded plaques. ${ }^{16}$ Even though there are no distinct characteristics for plaque erosion, the presence of a ruptured or vulnerable plaque may be sufficient to indicate a plaque-related etiology in a patient with MINOCA.

In addition to coronary artery evaluation, specific contrast bolus protocols allow opacification of coronary arteries, the aorta, and the pulmonary arteries in a single CT angiography scan ("triple rule out" protocol). Using this comprehensive scanning protocol may be beneficial in selected patients to quickly rule out CAD, aortic dissection, and pulmonary embolism (Figure 1, case 3$).{ }^{17}$ Furthermore, CT may identify other clinically important diagnoses such as a coronary anomaly, malignancy, or pneumonia. ${ }^{17}$

\section{CONCLUSION}

Diagnosing patients with MINOCA remains challenging and includes both $\mathrm{MI}$ - and non-MIrelated diagnoses. The diagnostic algorithm should start in the catheterization lab, followed by a staged use of non-invasive imaging techniques (Figure 2). Cardiac MRI plays a crucial role in narrowing the differential diagnosis. In combination with results from the history, and invasive (OCT or IVUS) or noninvasive techniques (CT), CAD is ruled out or becomes more plausible. In the setting of $\mathrm{MI}$ without CAD, a thorough search should be performed for (paradoxical) coronary embolism (exclude atrial fibrillation, myocardial tumor or thrombus, patent foramen ovale, or atrial septal defect) or hypercoagulability disorders. Unfortunately, in an unsatisfying number of patients, the etiology remains unknown. 
Figure 2.

Potential diagnostic strategy in patients with MINOCA.

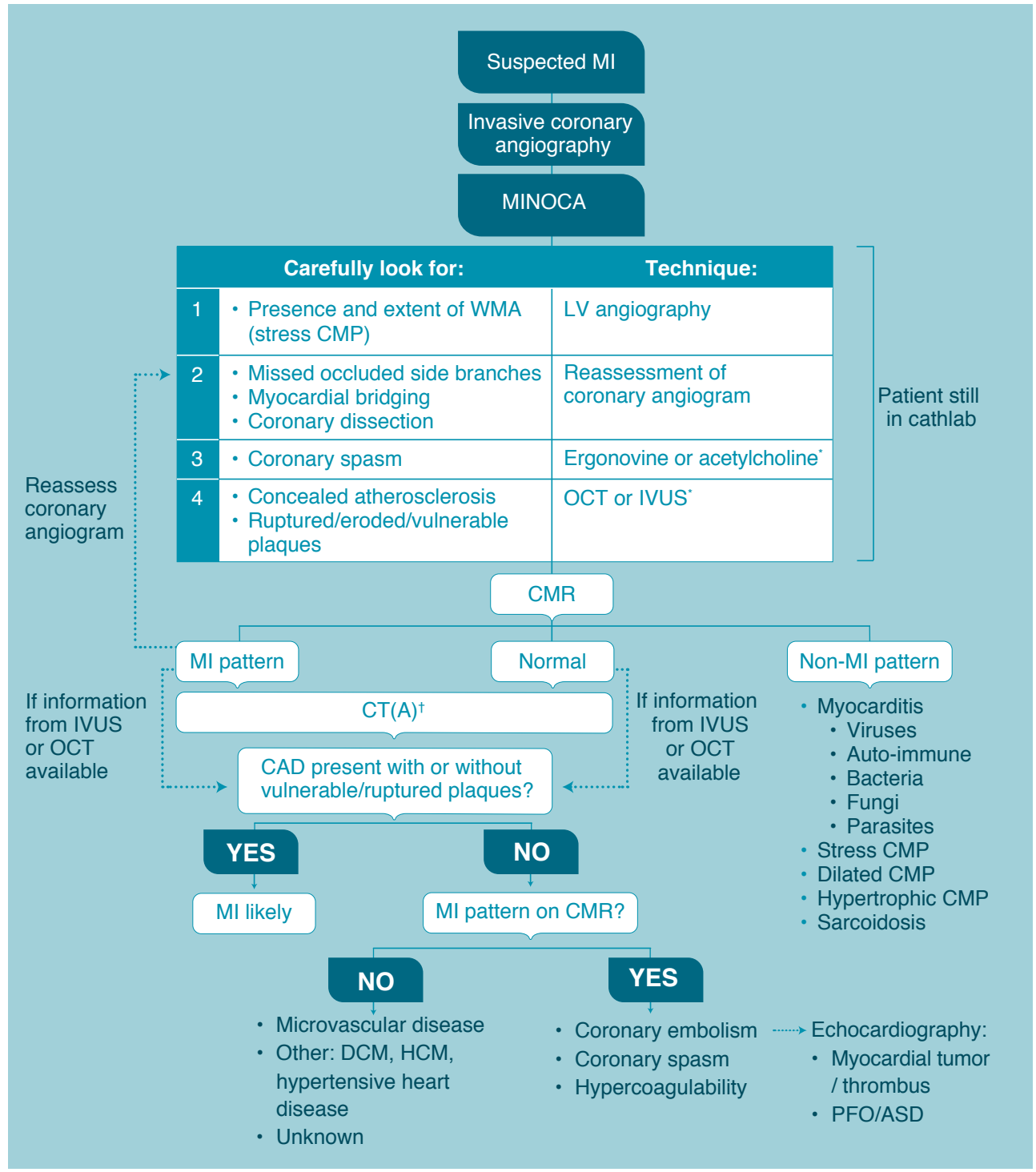

*When available. †Perform "triple rule out" CT when high suspicion for pulmonary embolism or acute aortic dissection (elevated D-dimer).

ACS $=$ acute coronary syndrome, $A S D=$ atrial septal defect, $C A D=$ coronary artery disease, $C M P=$ cardiomyopathy, $\mathrm{CMR}=$ cardiac magnetic resonance imaging, $\mathrm{CT}=$ computed tomography, $\mathrm{DCM}=$ dilated cardiomyopathy, HCM = hypertrophic cardiomyopathy, IVUS = intravascular ultrasound, LV = left ventricle, MI $=$ myocardial infarction, MINOCA = myocardial infarction with nonobstructed coronary arteries, $0 \mathrm{CT}=$ optical coherence tomography, PF0 = patent foramen ovale, WMA = wall motion abnormalities. 


\section{REFERENCES}

1. Collste $\mathrm{O}$, Sorensson P, Frick $\mathrm{M}$ et al. Myocardial infarction with normal coronary arteries is common and associated with normal findings on cardiovascular magnetic resonance imaging: results from the Stockholm Myocardial Infarction with Normal Coronaries study. Journal of internal medicine 2013;273:189-96.

2. Roe MT, Harrington RA, Prosper DM et al. Clinical and therapeutic profile of patients presenting with acute coronary syndromes who do not have significant coronary artery disease.The Platelet Glycoprotein Ilb/llla in Unstable Angina: Receptor Suppression Using Integrilin Therapy (PURSUIT) Trial Investigators. Circulation 2000;102:1101-6.

3. Aldrovandi A, Cademartiri F, Arduini D et al. Computed tomography coronary angiography in patients with acute myocardial infarction without significant coronary stenosis. Circulation 2012;126:3000-7.

4. Ambrose JA, Tannenbaum MA, Alexopoulos D et al. Angiographic progression of coronary artery disease and the development of myocardial infarction. J Am Coll Cardiol 1988;12:56-62.

5. Brolin EB, Jernberg T, Brismar TB et al. Coronary plaque burden, as determined by cardiac computed tomography, in patients with myocardial infarction and angiographically normal coronary arteries compared to healthy volunteers: a prospective multicenter observational study. Plos one 2014;9:e99783.

6. Yilmaz A, Sechtem U. Angina pectoris in patients with normal coronary angiograms: current pathophysiological concepts and therapeutic options. Heart 2012;98:1020-9.

7. Anderson JL, Adams CD, Antman EM et al. 2011 ACCF/AHA Focused Update Incorporated Into the ACC/AHA 2007 Guidelines for the Management of Patients With Unstable Angina/Non-ST-Elevation Myocardial Infarction: A Report of the American College of Cardiology Foundation/American Heart Association Task Force on Practice Guidelines. Circulation 2011;123:e426-579.

8. Hamm CW, Bassand JP, Agewall S et al. ESC Guidelines for the management of acute coronary syndromes in patients presenting without persistent ST-segment elevation: The Task Force for the management of acute coronary syndromes (ACS) in patients presenting without persistent ST-segment elevation of the European Society of Cardiology (ESC). Eur Heart J 2011;32:2999-3054.

9. Tian J, Ren X, Vergallo R et al. Distinct morphological features of ruptured culprit plaque for acute coronary events compared to those with silent rupture and thin-cap fibroatheroma: a combined optical coherence tomography and intravascular ultrasound study. J Am Coll Cardiol 2014;63:2209-16.

10. Mahrholdt H, Wagner A, Judd RM, Sechtem U, Kim RJ. Delayed enhancement cardiovascular magnetic resonance assessment of non-ischaemic cardiomyopathies. Eur Heart J 2005;26:1461-74.

11. Eitel I, von Knobelsdorff-Brenkenhoff F, Bernhardt $P$ et al. Clinical characteristics and cardiovascular magnetic resonance findings in stress (takotsubo) cardiomyopathy. JAMA 2011;306:277-86.
12. Gerbaud E, Harcaut E, Coste $P$ et al. Cardiac magnetic resonance imaging for the diagnosis of patients presenting with chest pain, raised troponin, and unobstru cted coronary arteries. Int J Cardiovasc Imaging 2012;28:783-794.

13. Assomull RG, Lyne JC, Keenan $\mathrm{N}$ et al. The role of cardiovascular magnetic resonance in patients presenting with chest pain, raised troponin, and unobstructed coronary arteries. Eur Heart $\mathrm{J}$ 2007;28:1242-9.

14. Friedrich MG, Sechtem U, Schulz-Menger $J$ et al. Cardiovascular magnetic resonance in myocarditis: A JACC White Paper. J Am Coll Cardiol 2009;53:1475-87.

15. Meijboom WB, Mollet NR, Van Mieghem CA et al. 64-Slice CT coronary angiography in patients with non-ST elevation acute coronary syndrome. Heart 2007;93:1386-92.

16. Ozaki $\mathrm{Y}$, Okumura M, Ismail TF et al. Coronary CT angiographic characteristics of culprit lesions in acute coronary syndromes not related to plaque rupture as defined by optical coherence tomography and angioscopy. Eur Heart $\mathrm{J}$ 2011;32:2814-23.

17. Takakuwa KM, Halpern EJ. Evaluation of a "triple rule-out" coronary CT angiography protocol: use of 64-Section CT in low-to-moderate risk emergency department patients suspected of having acute coronary syndrome. Radiology 2008;248:438-46. 


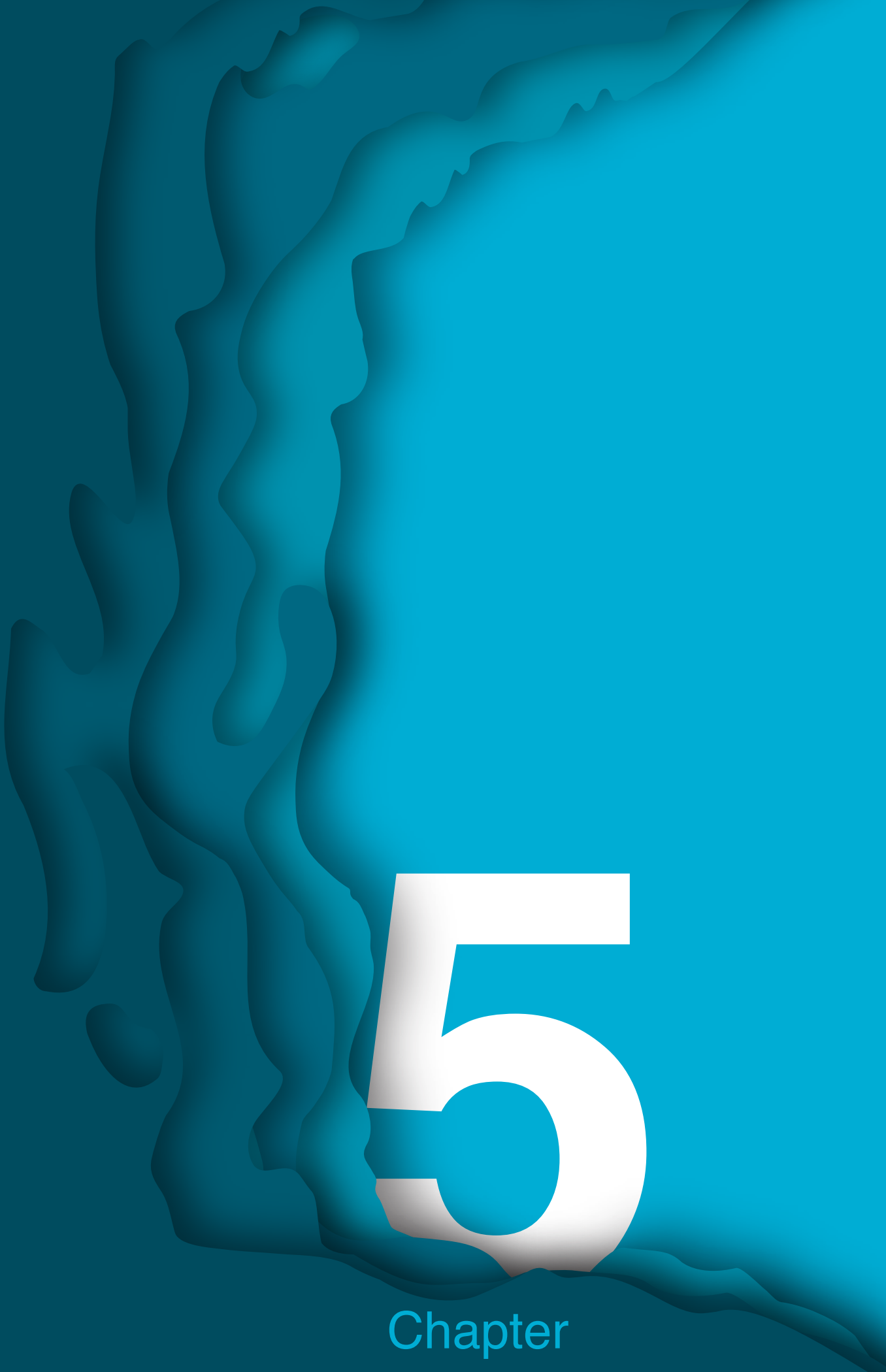




\section{The role of cardiovascular magnetic}

resonance imaging and computed tomography angiography in suspected non-ST-elevation myocardial infarction patients: Design and rationale of the CARdiovascular Magnetic rEsoNance imaging and computed Tomography Angiography (CARMENTA) trial

Martijn W. Smulders, MD, ${ }^{1,7^{*}}$ Bastiaan L.J.H. Kietselaer, MD, PhD, ${ }^{1,2,7^{*}}$ Marco Das, MD, PhD, ${ }^{2,7}$ Joachim E. Wildberger, MD, PhD, ${ }^{2,7}$ Harry J.G.M. Crijns, MD, PhD, ${ }^{1,7}$ Leo F. Veenstra, MD, ${ }^{1}$ Hans-Peter Brunner-La Rocca, MD, PhD, ${ }^{1,7}$ Marja P. van Dieijen-Visser, PhD, ${ }^{3}$ Alma M.A. Mingels, PhD, ${ }^{3}$ Pieter C. Dagnelie, PhD, ${ }^{4,8}$ Mark J. Post, MD, PhD, ${ }^{6,7}$ Anton P.M. Gorgels, MD, PhD, ${ }^{1,7}$ Antoinette D.I. van Asselt, PhD, ${ }^{5}$ Gaston Vogel, ${ }^{5}$ Simon Schalla, MD, $, 1,7$ Raymond J. Kim, MD, ${ }^{9}$ Sebastiaan C.A.M. Bekkers, MD, PhD ${ }^{1,7}$

* These authors contributed equally to this work

Department of ${ }^{1}$ Cardiology, ${ }^{2}$ Radiology, ${ }^{3}$ Clinical Chemistry, ${ }^{4}$ Epidemiology, ${ }^{5}$ Clinical Epidemiology and Medical Technology Assessment (KEMTA), ${ }^{6}$ Physiology, ${ }^{7}$ Cardiovascular Research Institute Maastricht (CARIM), ${ }^{8}$ School for Public Health and Primary Care (CAPHRI), Maastricht University Medical Center, Maastricht, The Netherlands, and department of ${ }^{9}$ Cardiology and Radiology, Duke Cardiovascular Magnetic Resonance Center, Durham, North Carolina, USA 


\section{ABSTRACT}

\section{Background}

Although high-sensitivity cardiac troponin (hs-cTn) substantially improves the early detection of myocardial injury, it lacks specificity for acute myocardial infarction (MI). In suspected nonST-elevation MI, invasive coronary angiography (ICA) remains necessary to distinguish between acute $\mathrm{MI}$ and noncoronary myocardial disease (eg, myocarditis), unnecessarily subjecting the latter to ICA and associated complications. This trial investigates whether implementing cardiovascular magnetic resonance (CMR) or computed tomography angiography (CTA) early in the diagnostic process may help to differentiate between coronary and noncoronary myocardial disease, thereby preventing unnecessary ICA.

\section{Study design}

In this prospective, single-center, randomized controlled clinical trial, 321 consecutive patients with acute chest pain, elevated hs-cTnT, and nondiagnostic electrocardiogram are randomized to 1 of 3 strategies: (1) CMR, or (2) CTA early in the diagnostic process, or (3) routine clinical management. In the 2 investigational arms of the study, results of CMR or CTA will guide further clinical management. It is expected that noncoronary myocardial disease is detected more frequently after early noninvasive imaging as compared with routine clinical management, and unnecessary ICA will be prevented. The primary end point is the total number of patients undergoing ICA during initial admission. Secondary end points are 30-day and 1-year clinical outcome (major adverse cardiac events and major procedure-related complications), time to final diagnosis, quality of life, and cost-effectiveness.

\section{Conclusion}

The CARMENTA trial investigates whether implementing CTA or CMR early in the diagnostic process in suspected non-ST-elevation MI based on elevated hs-cTnT can prevent unnecessary ICA as compared with routine clinical management, with no detrimental effect on clinical outcome. 


\section{INTRODUCTION}

As opposed to ST-elevation myocardial infarction (STEMI), electrocardiographic (ECG) changes are often nondiagnostic in non-ST-elevation MI (NSTEMI), and measuring cardiac troponin levels is an important diagnostic cornerstone., ${ }^{1,2}$ Despite being very sensitive and specific markers for myocardial injury, troponins are not specific for acute Ml.3,4 The recently introduced high-sensitivity cardiac troponin (hs-cTn) assays have substantially improved the early diagnosis of acute $\mathrm{Ml}$ in comparison with the conventional troponin (cTn) assays, but at the cost of a lower specificity. ${ }^{5,6}$ Therefore, it is often challenging to distinguish MI from other disorders that result in elevated troponin levels, such as myocarditis, pulmonary embolism (PE), or Takotsubo cardiomyopathy (ie, noncoronary myocardial disease). ${ }^{4,7}$

An important component of the universal definition of acute $\mathrm{MI}$ is a typical rise and/or fall of cardiac troponin with at least 1 value above the 99th percentile of a reference population, but the magnitude of this rise and fall has not been defined. ${ }^{1}$ Recent studies have shown that discriminating between acute $\mathrm{Ml}$ and noncoronary myocardial disease can be improved by using algorithms that combine baseline hs-cTn values with absolute or relative changes over time. Limitations of these studies are that the final diagnosis of acute MI was adjudicated based on available clinical data, including the conventional troponin assay, and routine noninvasive imaging was not used. Furthermore, these studies were designed retrospectively. ${ }^{4}$

Invasive coronary angiography (ICA) remains necessary to distinguish between acute $\mathrm{MI}$ and noncoronary myocardial disease, predisposing the latter to unnecessary ICA, aggressive antithrombotic, and antiplatelet therapy. This potentially increases the length of hospitalization, number of complications, and health care costs. Noninvasive imaging techniques can be used to differentiate between coronary and noncoronary myocardial disease and direct patient management. ${ }^{8}$

Delayed-enhancement cardiovascular magnetic resonance imaging (DE-CMR) is a well-validated technique for the diagnosis of irreversible myocardial damage, both in ischemic and in nonischemic heart disease.$^{9,10}$ An acute coronary syndrome can be accurately detected by using a CMR protocol comprising cine imaging, T2-weighted (T2), myocardial perfusion, and $\mathrm{DE}$ imaging, and distinguished from noncoronary myocardial disease. ${ }^{11-14}$

Computed tomography angiography (CTA) is a noninvasive imaging modality that rapidly determines the presence and extent of epicardial coronary artery disease (CAD). A normal CTA is associated with excellent prognosis..$^{15,16}$ Furthermore, CTA is able to detect other life-threatening noncardiac causes of chest pain such as acute aortic dissection (AAS) and PE. ${ }^{17}$

Although CMR and CTA visualize different aspects of myocardial disease, each technique can uniquely be used to distinguish between a coronary and noncoronary etiology of acute chest pain and hs-cTn rise. This study investigates whether implementing CTA or CMR early in the diagnostic process can prevent unnecessary ICA, by excluding significant CAD or establishing noncoronary myocardial disease.

It is expected that in patients with suspected NSTEMI, noncoronary myocardial disease is more frequently diagnosed when CTA or CMR is performed early in the diagnostic process as compared with routine clinical management, thereby preventing unnecessary ICA. The primary objective of the CARMENTA trial is to investigate whether this approach reduces the total number of patients undergoing ICA during initial hospitalization. A secondary objective is to compare 30-day and 1-year clinical outcome to determine safety, time to final diagnosis, cost-effectiveness, and quality of life of each strategy. 


\section{METHODS}

\section{Study design and population}

The CARMENTA trial (NCT01559467) is designed as a prospective, open-label, single-center randomized controlled clinical trial. The trial enrolls patients consecutively who present on the emergency department (ED) with acute chest pain, elevated serum hs-cTnT levels (>14 ng/L), and a nondiagnostic ECG. Enrollment will continue until 288 patients have completed the study protocol. Patients are randomized immediately after ED evaluation (comprising a detailed medical history, physical examination, serial ECGs, and serum hs-cTnT measurements) to 1) CMR (early in the diagnostic process), or (2) CTA (early in the diagnostic process), or (3) routine clinical management (without early CMR or CTA imaging). The CARMENTA trial is a comparative effectiveness trial evaluating the effectiveness of alternative clinical management strategies (CMR or CTA arm) in comparison with routine clinical care ${ }^{18}$ Besides evaluating the prespecified end points, that is, the number of patients undergoing ICA during initial hospitalization, the trial design allows evaluating the overall clinical effects of implementing noninvasive imaging early in the diagnostic strategy in suspected NSTEMI.

Before the start of the trial, physicians and nurses were profoundly familiarized with the trial purpose and design to ensure consistency in management. After CMR or CTA is performed, a diagnosis of "coronary," "noncoronary myocardial disease," or "normal/equivocal" is reported in the hospital's electronic patient record. Additional management (ECG monitoring, biomarker testing, medical therapy, downstream testing, other clinically indicated interventions) is left at the discretion of the attending cardiologist and is in accordance with current (institutional/ European Society of Cardiology/American Heart Association) NSTEMI guidelines. The study is conducted according to the principles of the Declaration of Helsinki and has been approved by the local medical ethical committee of Maastricht University Hospital and Maastricht University. Figure 1 illustrates the patient selection process and the randomization strata of the CARMENTA trial.

\section{Study endpoints and definitions}

The primary end point of the CARMENTA trial is the total number of patients with at least one ICA during initial admission in each arm. Secondary end points are 30-day and 1-year clinical outcome (a composite of major adverse cardiac events [MACEs] and major procedure-related complications), time to final diagnosis, cost-effectiveness, and quality of life. After 1 year, an independent clinical end point committee (including an interventional cardiologist, clinical cardiologist, and radiologist [both with $>5$ years' experience in CMR and CTA]), blinded for the allocated strategy, adjudicates a final diagnosis to each patient using all available clinical and imaging data.

Clinical outcome (MACE and major procedure-related complications) is defined as a composite of all-cause mortality or cardiac mortality, recurrent MI, revascularization (percutaneous coronary intervention and/or coronary artery bypass grafting) not planned after the index event or congestive heart failure requiring hospitalization, significant bleeding (fatal, intracranial, or resulting in hemodynamic compromise; need for blood transfusion or overt bleeding plus hemoglobin drop: minor bleeding $\geq 2.0 \mathrm{mmol} / \mathrm{L}$ or $[\geq 3 \mathrm{~g} / \mathrm{dL}]$ or major bleeding $\geq 3.0 \mathrm{mmol} / \mathrm{L}$ $[\geq 5 \mathrm{~g} / \mathrm{dL}]$ ), ${ }^{19} \mathrm{renal}$ failure (need for temporary or permanent hemodialysis), contrast-induced nephropathy ( $\geq 25 \%$ or $\geq 44-\mu \mathrm{mol} / \mathrm{L}$ increase in serum creatinine from baseline), nephrogenic systemic fibrosis, allergic reaction requiring urgent therapy, dissection/perforation/rupture after puncture of a vessel, stroke (ischemic or hemorrhagic), or transient ischemic attack diagnosed 
Figure 1.

Study design - flow chart patient selection.

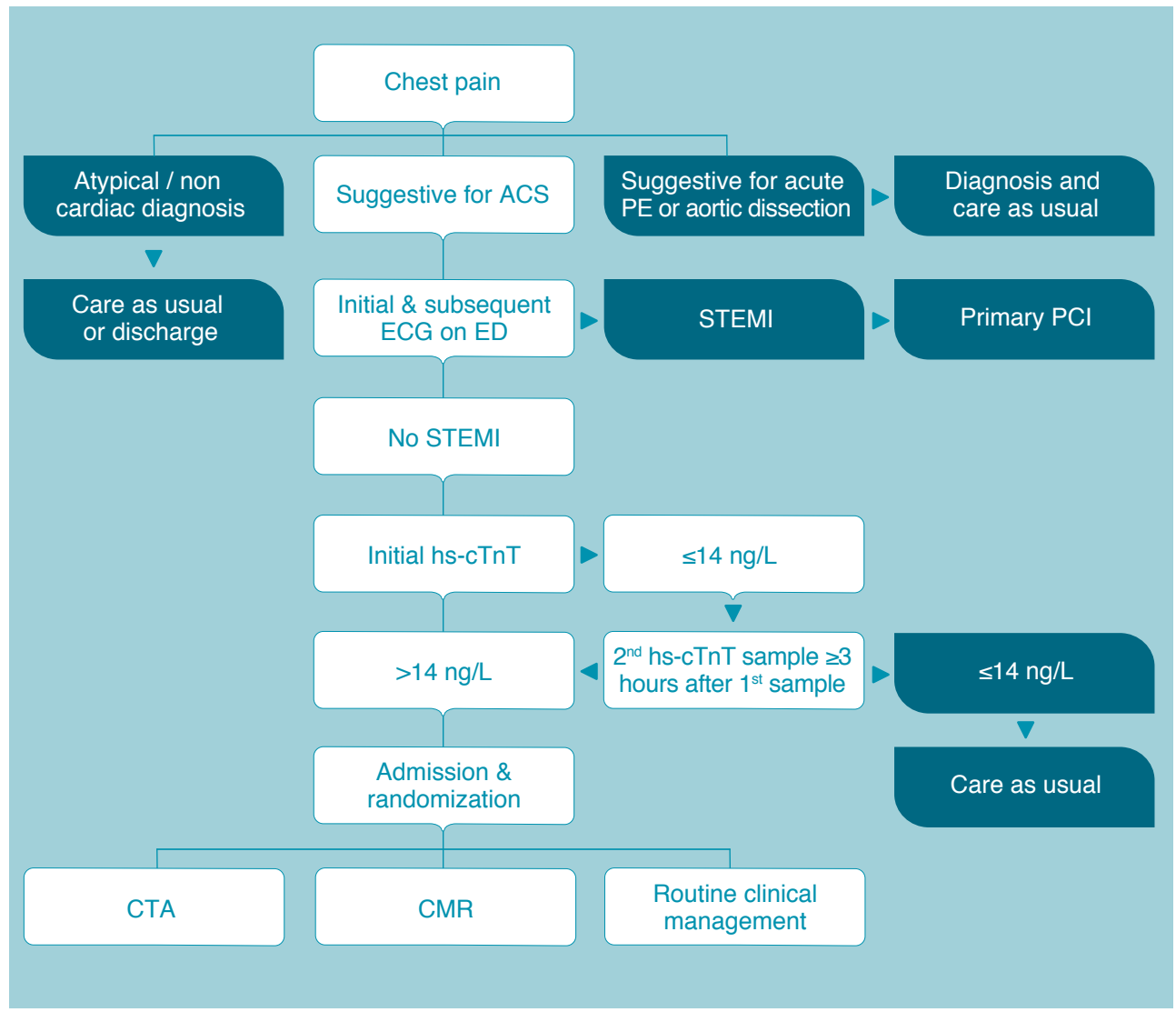

ACS = acute coronary syndrome, ECG = electrocardiography, $\mathrm{CMR}=$ cardiovascular magnetic resonance imaging, CTA = computed tomography angiography, ED = emergency department, hs-cTnT = high sensitive cardiac troponin $\mathrm{T}, \mathrm{PCl}=$ percutaneous coronary intervention, $\mathrm{PE}=$ pulmonary embolism, $\mathrm{STEMI}=$ ST-elevation myocardial infarction.

by a neurologist (preferably supported by imaging techniques). MACE and major procedurerelated complications are scored during admission, and 1-month and 1-year follow up. The definitions of recurrent $\mathrm{Ml}$ and/or reinfarction are adapted from the universal definition of Ml. ${ }^{1}$

Costs will be assessed from a health care perspective. Implementing CMR or CTA early in the diagnostic process is expected to prevent unnecessary ICA and reduce the length of hospitalization in patients with noncoronary myocardial disease. Health care costs will be retrieved for all patients using hospital databases and patient records. Unit costs will be based on standard prices using the Dutch manual for cost research. ${ }^{20}$

The economic evaluation will be a cost-effectiveness analysis, with quality-adjusted life years as an effectiveness measure. For this purpose, health state utilities will be derived using the EuroQol (baseline on admission and 1, 6, and 12 months after admission). ${ }^{21}$ To investigate 
the cost-effectiveness of the 3 strategies, incremental cost-effectiveness ratios will be calculated. Uncertainty surrounding the costs and effects will be examined using nonparametric bootstrap analyses with 1,000 replications. Cost-effectiveness acceptability curves will be derived to show the probability of each strategy being cost-effective, for a range of possible maximum values a decision maker is willing to pay for a quality-adjusted life year. ${ }^{22}$

\section{Eligibility criteria}

The detailed inclusion and exclusion criteria are shown in Table 1. All consecutive patients are screened for eligibility on the ED by cardiologists in training and their supervisors, 24 hours a day, 7 days per week, whole year-round. Inclusion and randomization of eligible patients are performed on week days from 8:00 AM until 6:00 PM (office hours). Patients presenting on the ED with suspected NSTEMI (ie, prolonged angina pectoris or symptoms equivalent to angina, normal or nondiagnostic ECG, and increased levels of hs-cTnT [ $>14 \mathrm{ng} / \mathrm{L}$ on admission or 3 hours later]) are eligible. Patients with shock, ongoing severe ischemia requiring immediate ICA, or chest pain highly suggestive of noncardiac origin (eg, musculoskeletal and gastrointestinal) are excluded. In addition, patients with previously known CAD or cardiomyopathy and patients experiencing angina pectoris secondary to anemia, severe aortic valve stenosis, severe hypertension, or tachycardia (type II MI) are excluded. ${ }^{1} \mathrm{~A}$ log of all patients screened for eligibility is kept, including all ineligible and eligible patients but who declined participation or dropped out.

The Netherlands Heart Foundation sponsors the CARMENTA trial. The authors are solely responsible for the design and conduct of this study, all study analyses, and drafting and editing of the manuscript, and its final contents.

Table 1.

Eligibility criteria.

\section{Inclusion criteria}

- $\quad$ Prolonged symptoms suspected of cardiac origin (angina pectoris or angina equivalent), and presentation on the cardiac ED $<24$ hours after symptom onset

- Increased levels of hs-cTnT (>14 ng/L) (initial blood sample at presentation or a second sample $\geq 3$ hours after presentation)

- $\quad$ Age 18 years - 85 years

- Willing and capable to give written informed consent

- Written informed consent

\section{Exclusion criteria}

- Ongoing severe ischemia requiring immediate ICA (at discretion of cardiac ED physician/ cardiologist)

- Shock (mean arterial pressure $<60 \mathrm{mmHg}$ ) or severe heart failure (Killip Class $\geq$ III)

- STEMI (ST-elevation in 2 contiguous leads: $\geq 0.2 \mathrm{mV}$ in men or $\geq 0.15 \mathrm{mV}$ in women in leads $\mathrm{V}_{2}-\mathrm{V}_{3}$ and/or $\geq 0.1 \mathrm{mV}$ in other leads or new left bundle branch block)

- Chest pain highly suggestive of non-cardiac origin (as judged by the cardiac ED physician/ cardiologist):

- Acute aortic dissection

- $\quad$ Acute PE (high risk patient defined as Wells score $>6$ )

- Musculoskeletal or gastro-intestinal pain

- $\quad$ Other (pneumothorax, pneumonia, rib fracture, etc.) 
Table 1. (continued)

- Previously known CAD, defined as:

- Any non-invasive diagnostic imaging test positive for CAD (perfusion defects, and/or stress induced wall motion abnormalities)

- Coronary stenosis $>50 \%$ on any previous ICA or CTA

- Documented previous myocardial infarction

- Documented previous coronary artery revascularization (PCI and/or CABG)

Known cardiomyopathy (dilated, hypertrophic, infiltrative, etc.)

Pregnancy

- Life threatening arrhythmia on the cardiac ED or prior to presentation (sustained ventricular tachycardia, repetitive non-sustained ventricular tachycardia, ventricular fibrillation, sino-artial or atrio-ventricular block)

- Atrial fibrillation

- $\quad$ Tachycardia ( $\geq 100 / \mathrm{bpm})$

- Angina pectoris secondary to anemia ( $<5.6 \mathrm{mmol} / \mathrm{L})$, untreated hyperthyroidism, aortic valve stenosis (AVA $\left.\leq 1.5 \mathrm{~cm}^{2}\right)$, or severe hypertension $(>200 / 110 \mathrm{mmHg})$

- Life expectancy $<1$ year (malignancy, etc.)

- $\quad$ Contraindications to CMR:

- Metallic implant (vascular clip, neuro-stimulator, cochlear implant)

- Pacemaker or implantable cardiac defibrillator (ICD)

- Claustrophobia

- $\quad$ Body weight $>130 \mathrm{~kg}$

- $\quad$ Contraindication to CMR or CTA contrast agent (Gadolinium or lodine):

- Renal failure (estimated GFR $\leq 30 \mathrm{~mL} / \mathrm{min} / 1.73 \mathrm{~m}^{2}$ ) / chronic renal failure stage 4-5

- Known severe contrast allergy (patient with mild allergy is eligible for inclusion when pre-medication according to hospital guidelines can be administered)

- Contraindication to adenosine:

- High degree atrio-ventricular block (2nd or 3rd degree)

- Severe bronchial asthma

- Chronic obstructive pulmonary disease Gold $\geq$ III

- Concomitant use of dipyridamole (Persantin)

- $\quad$ Long QT syndrome (congenital)

$\mathrm{AVA}=$ aortic valve area; $\mathrm{bpm}=$ beats per minute; $\mathrm{CABG}=$ coronary artery bypass grafting; $\mathrm{CAD}=$ coronary artery disease; $\mathrm{CMR}=$ cardiovascular magnetic resonance; $\mathrm{CTA}=$ computed tomography angiography; $\mathrm{ED}=$ emergency department; GFR = glomerular filtration rate; hs-cTnT = high sensitivity cardiac troponin T; ICA = invasive coronary angiography; ICD = implantable cardiac defibrillator; $\mathrm{PCI}=$ percutaneous coronary intervention; STEMI = ST-elevation myocardial infarction.

\section{Randomization}

Patients are randomized immediately after initial ED evaluation and after obtaining informed consent. Patients are randomized in a 1:1:1 fashion to one of the following strategies: (1) CMR, or (2) CTA early in the diagnostic process, or (3) routine clinical management without early noninvasive imaging. A stratified randomization method is used to equally distribute patients with an hs-cTnT concentration of 15 to $50 \mathrm{ng} / \mathrm{L}$ and patients with an hs-cTnT concentration of $>50 \mathrm{ng} / \mathrm{L}$ (based on the highest hs-cTnT value of the first 2 blood samples) among 1 of the 3 strategies. Variable block randomization $(3,6$, or 9 patients per block) is assembled to safeguard equal distribution of patients equally over time and to prevent prediction of allocation of patients.

Randomization is performed with TENALEA randomization software (FormsVision BV, Abcoude, The Netherlands) provided by the Clinical Trial Center Maastricht. The software is an 
Internet-based service supporting online patient registration and randomization. The online randomization module includes comprehensive reporting tools, audit tools, and tools for monitoring operational system components.

\section{Patient care (treatment) in randomization arms Randomization arm 1: Routine clinical care}

In the routine clinical management arm, patients are not intended to undergo early CMR or CTA. Patients are admitted and treated according to current guidelines and clinical judgment. The decision to proceed to ICA, and additional downstream testing is made on clinical grounds and left at the discretion of the clinical cardiologist taking care of the patient. Recommendations are provided to prevent heterogeneity between attending cardiologists (Figure 2).

Figure 2.

Recommendations to guide clinical management in clinical routine arm.

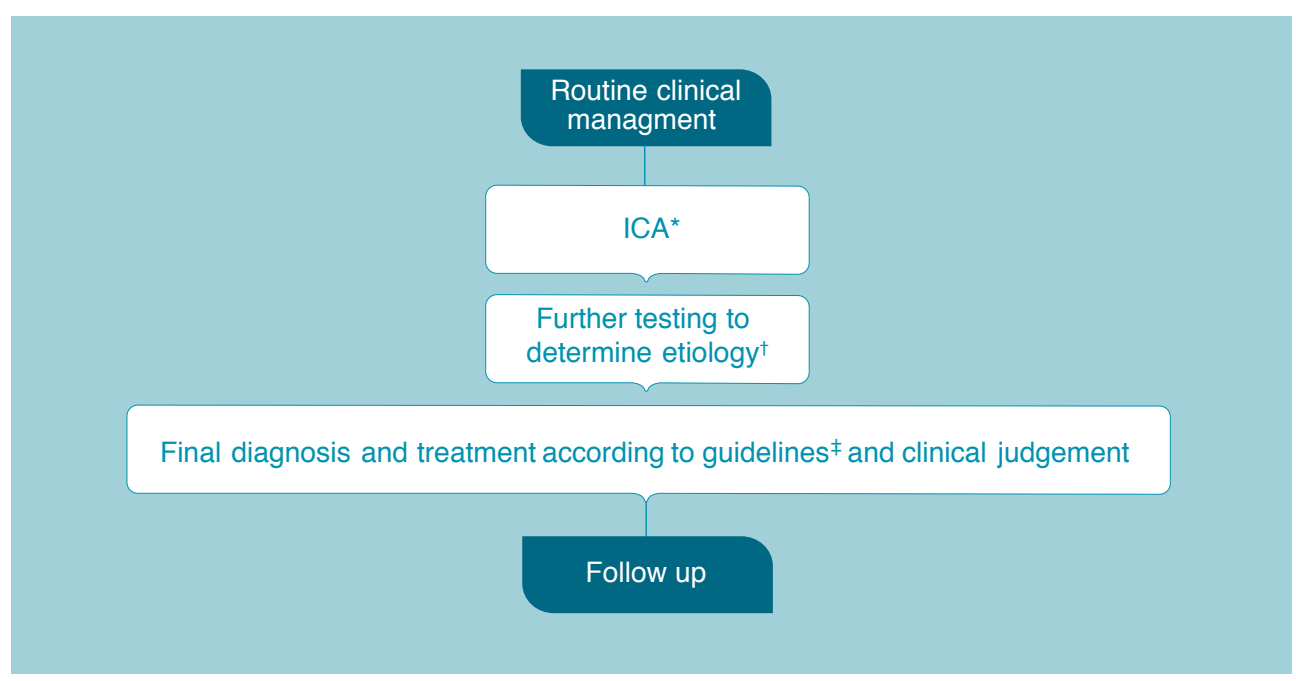

* If appropriate according to clinical judgment and in absence of regular contra-indications.

$\dagger$ If coronary angiography results are ambiguous.

$\ddagger$ Current guidelines: European Society of Cardiology, American College of Cardiology, Netherlands Society of Cardiology and local hospital protocols

\section{Randomization arm 2: Cardiovascular magnetic resonance imaging (CMR)}

A comprehensive CMR study is performed on a clinical whole-body 3.0-T multitransmit magnetic resonance imaging scanner (Achieva; Philips Medical Systems, Best, The Netherlands) as soon as possible after admission ( $<72$ hours). A bright blood sequence in the transversal plane covering the whole heart and large vessels is used to determine anatomy and extracardiac pathology. Cine-CMR in the short axis (multislice, covering the whole heart), left ventricular outflow tract, and horizontal and vertical long-axis view (single slice) is used to evaluate ventricular volumes, regional wall motion abnormalities, and overall function. T2-weighted CMR in short-axis view (multislice, 
covering the whole heart), horizontal and vertical long- axis view (single slice), and adenosinestress-rest perfusion CMR (basal, mid, and apical slice) and DE-CMR in short axis (multislice, covering the whole heart) and horizontal and vertical long axis (single slice) are used to detect edema, ischemia, and/or scar, respectively. All images are reviewed step by step during scanning. Additional nonstandardized images are obtained when observations during standardized views remain ambiguous. Gadolinium contrast infusion (Gadovist $0.2 \mathrm{mmol} / \mathrm{kg}$ body weight; Bayer Pharma AG, Berlin, Germany) is used for perfusion and DE-CMR imaging. A coronary etiology of chest pain is assumed in case of the following: subendocardial or transmural late enhancement on DE-CMR in the territory of a coronary artery with/without regional wall motion abnormalities on cine, with/without obvious increased signal intensity on T2-weighted-CMR, and/or a subendocardial or transmural perfusion defect corresponding to the distribution territory of a coronary artery during rest and/or stress perfusion.

\section{Randomization arm 3: Computed tomography angiography (CTA)}

A comprehensive CT scanning investigation is performed using a second-generation dual-source CT scanner (Somatom Definition Flash; Siemens Medical Solutions, Forchheim, Germany) as soon as possible after admission ( $<72$ hours). To achieve a stable heart rate of $<65$ beats/min, patients will be premedicated with beta blocking agents (if no contraindications, $50 \mathrm{mg}$ metoprolol oral and up to $20 \mathrm{mg}$ metoprolol intravenously before the scan). Sublingual nitrates (if no contraindications) will ensure maximal vasodilatation to enhance coronary lumen visualization prior to scanning.

A nonenhanced scan is performed to determine the coronary calcium score, using the method of Agatston et al. ${ }^{23} \mathrm{~A}$ testbolus is used to ensure optimal timing for CTA. Computed tomography angiography is performed using a dual-head injector contrast protocol (Ultravist 300; Bayer Pharma AG, Berlin, Germany) with a total amount of $120 \mathrm{~mL}$ to facilitate sufficient late-enhancement imaging. Every patient in the CTA arm will undergo a non-contrast baseline CT scan, coronary CTA, and, for experimental reasons, DE imaging.

In patients with a stable heart rate $<65$ beats/min, a prospectively triggered high-pitch spiral protocol is used. In patients with a heart rate $\geq 65$ beats/min or in case of an irregular heart rhythm, a retrospectively gated helical protocol with dose modulation is used. Dual-energy (DE) images are acquired 6 minutes after contrast injection using a prospectively gated dual-energy scanning protocol. Images are reconstructed with thin slices, and field of view and reconstruction kernel are adapted to evaluate the coronary arteries, to assess the whole lung, pulmonary arteries, and the aorta. Images are directly viewed and evaluated on a dedicated postprocessing workstation (MultiModality Workplace; Siemens Medical Solutions).

A coronary etiology of the chest pain syndrome is considered highly likely in case of the following: a significant stenosis ( $\geq 70 \%$ luminal narrowing) or total occlusion in a coronary artery. Also, an Agatston score of more than 1,000 will be considered as evidence of a coronary etiology, in the absence of AAS, PE, or alternative causes.

\section{CMR and CTA analysis and recommendations}

For both CMR and CTA, the following noncoronary myocardial disease diagnoses are made: (peri)myocarditis, stress cardiomyopathy, other cardiomyopathies (eg, amyloidosis and sarcoidosis), AAS, PE, and other (non-) cardiac (incidental) findings. A CMR of CTA investigation is "equivocal" when the images are nondiagnostic, owing to insufficient image quality (artifacts) or incomplete image acquisition, and when a final diagnosis cannot be made. A CMR or CTA study is interpreted as "normal" if the images are diagnostic and no (extra-)cardiac pathology is seen. 
All CMR and CTA images are interpreted simultaneously and routinely by 2 experienced readers, a cardiologist and a radiologist, to come to a diagnosis including extracardiac diagnosis. During scanning, a step-by-step algorithm is followed, such that at each point, the scan can be interrupted after a diagnosis is made to minimize study scan duration and minimize hazard for the patient.

Immediately after the investigation, diagnostic information from CMR or CTA will be reported in the electronic hospital records (time stamped) and the responsible clinician notified. The final decision to perform additional diagnostic testing or intervention is left at the discretion of the attending cardiologist. Recommendations are provided to prevent heterogeneity between supervising cardiologists (Figure 3).

\section{Figure 3.}

Recommendations to guide clinical management in CMR or CTA arm.

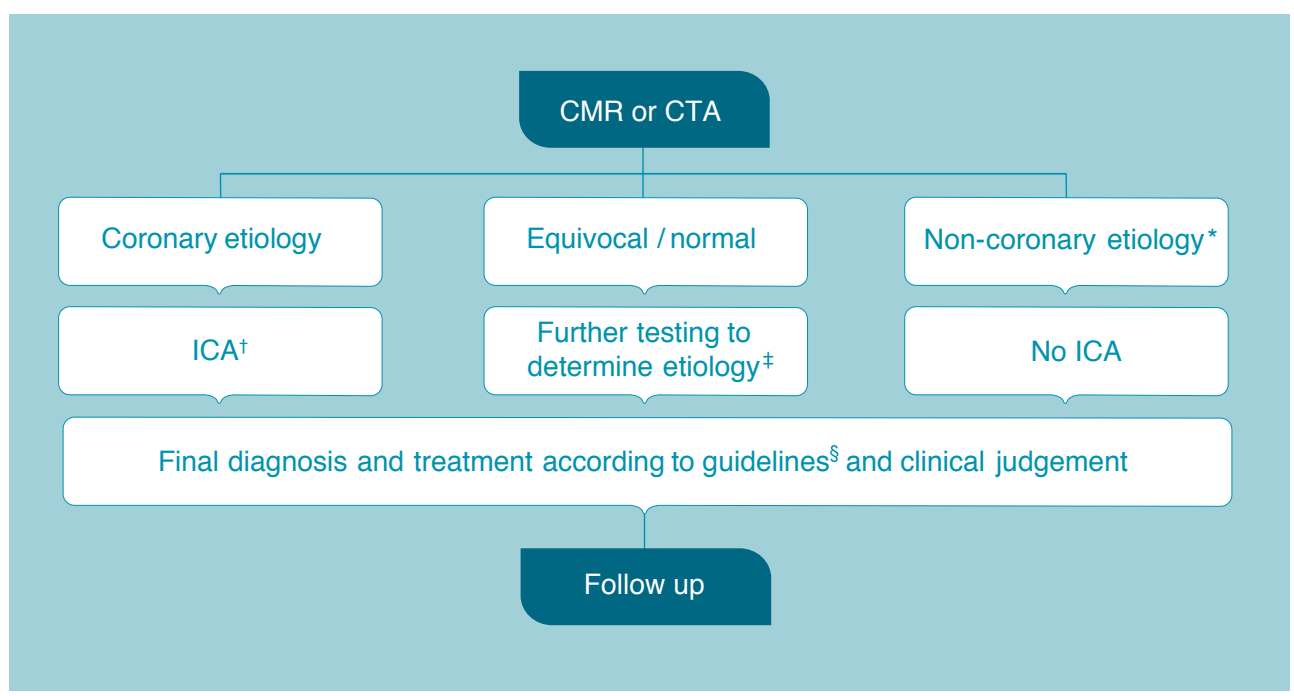

* Cardiomyopathy (Takotsubo, hypertrophic, dilated, infiltrative), myocarditis, pericarditis, aortic dissection, acute pulmonary embolism

$\dagger$ If appropriate according to clinical judgment and in absence of contra-indications.

$\ddagger$ Left at the discretion of caring cardiologist

$\S$ Current guidelines: European Society of Cardiology, American College of Cardiology, Netherlands Society of Cardiology and local hospital protocols

\section{Patient safety}

An independent statistician will perform an interim analysis after 50, 100, and 200 included patients, to reduce the risk of exposure of study participants to a possibly inferior strategy. The results of this interim analysis will be reported to the medical ethical committee. For patient safety, MACE rate (all-cause death, revascularization not planned during the initial admission, re-admission for heart failure, and recurrent MI) between groups will be compared. The CMR or CTA arm will be discontinued in case the interim analysis shows a significant $(P<0.05)$ increase in MACE in patients in either arm. No additional patients will be randomized to the inferior 
strategy, but the other 2 strategies (CMR or CTA vs routine clinical care) will be continued. The follow-up of included patients will continue even if the inclusion of new patients is stopped. After randomization, the cardiologist taking care of the patient can deviate from the study protocol at all times. If other urgent diagnostics or therapeutics than prescribed by the study protocol are necessary, this will receive priority. Protocol violations will be reported.

\section{Sample size calculation}

The primary end point of the present study is a reduction in total number of patients with at least 1 ICA during initial admission by the application of noninvasive diagnostic imaging techniques CMR or CTA early in the diagnostic process as compared with routine clinical management. The primary comparison groups in this randomized controlled trial are, therefore, CMR vs standard care and CTA vs standard care.

Based on clinical experience, approximately $75 \%$ of admitted patients with NSTEMI undergo ICA during initial hospitalization. This is supported by data from the CRUSADE and ACTION registry, reporting an overall rate of in-hospital ICA of $73 \%$ and $80 \%$, respectively. ${ }^{24,25}$ Trials such as the ICTUS, CRUSADE, FRISC II, PURSUIT, TIMI IIIB, GRACE, and MATE report that up to $7 \%$ to $25 \%$ of patients with clinically suspected $\mathrm{MI}$ have normal coronary arteries or insignificant disease at ICA and may ultimately be diagnosed as having noncoronary myocardial disease. ${ }^{26} \mathrm{It}$ is expected that these numbers will increase when using the new hs-cTn assays to detect myocardial injury. Early noninvasive imaging (either CMR or CTA) may filter out noncoronary myocardial disease, reducing the need for ICA to approximately $60 \%$ of patients. Ninety-six patients per treatment arm with completed study protocols will be sufficient to detect this difference in proportions with a power of $80 \%$ and a value of 0.05 . Accounting for a dropout rate of $10 \%$, it is assumed that in total, 321 patients have to be enrolled.

\section{Data analysis}

For all 3 groups, the relative risk of ICA will be calculated. To evaluate the primary objective, the total number of patients with at least one ICA during the initial admission will be compared between groups by $\chi^{2}$ analysis. Comparison will be done between a CMR-guided approach vs standard care, a CTA-guided approach vs standard care, and a CMR vs a CTA-guided approach. Multivariable logistic regression models will be used to adjust for potential confounders.

To assess clinical outcome (a composite of MACEs and major procedure-related complications) over time, Kaplan-Meier plots will be constructed and groups will be compared by using a log-rank test. To assess clinical outcome, Cox regression models will be fitted to adjust for confounders. A prespecified secondary analysis will be performed on the effect of hs-cTnT level and patient age on the primary and secondary end points. Prespecified subgroups are the following: hs-cTnT (15-50 and $>50 \mathrm{ng} / \mathrm{L}$ ) and age ( $<60$ and $\geq 60$ years).

Differences between the 3 groups in quality of life will be reported descriptively. In addition, differences between the randomization groups in both generic and disease-specific quality of life will be tested using analysis of variance.

\section{SUMMARY}

The CARMENTA trial investigates whether the implementation of CMR or CTA early in the diagnostic process in patients presenting with acute chest pain, nondiagnostic or normal ECG, and elevated hs-cTnT levels (ie, suspected NSTEMI) leads to an early alternative diagnosis than $\mathrm{MI}$ (eg, myocarditis, PE, etc) as compared with routine clinical management. Consequently, this could prevent unnecessary ICA and associated complications and reduce length of hospitalization and costs, without having a detrimental effect on clinical outcome. Especially in the current era 
of hs-cTn assays that have very high sensitivity but lower specificity for acute MI than conventional (fourth generation) troponin assay, this trial may have important implications for the future diagnostic workup of patients with suspected but not yet proven NSTEMI. 


\section{REFERENCES}

1. Thygesen K, Alpert JS, Jaffe AS, Simoons ML, Chaitman BR, White HD. Third Universal Definition of Myocardial Infarction. Circulation 2012; 126:2020-35.

2. Wang K, Asinger RW, Marriott HJ. ST-segment elevation in conditions other than acute myocardial infarction. N Engl J Med 2003;349:2128-35.

3. Agewall S, Giannitsis E, Jernberg T, Katus $H$. Troponin elevation in coronary vs. non-coronary disease. Eur Heart J 2011;32:404-11.

4. Haaf $\mathrm{P}$, Drexler B, Reichlin T, et al. High-sensitivity cardiac troponin in the distinction of acute myocardial infarction from acute cardiac noncoronary artery disease. Circulation 2012;126:31-40.

5. Reichlin T, Hochholzer W, Bassetti S, et al. Early diagnosis of myocardial infarction with sensitive cardiac troponin assays. $\mathrm{N}$ Engl $\mathrm{J}$ Med 2009;361:858-67.

6. Keller T, Zeller T, Peetz D, et al. Sensitive troponin I assay in early diagnosis of acute myocardial infarction. N Engl J Med 2009;361:868-77.

7. Assomull RG, Lyne JC, Keenan N, et al. The role of cardiovascular magnetic resonance in patients presenting with chest pain, raised troponin, and unobstructed coronary arteries. Eur Heart $J$ 2007;28:1242-9.

8. Morrow DA. Clinical application of sensitive troponin assays. N Engl J Med 2009;361:913-5.

9. Kim RJ, Fieno DS, Parrish TB, et al. Relationship of MRI delayed contrast enhancement to irreversible injury, infarct age, and contractile function. Circulation 1999;100:1992-2002.

10. Mahrholdt H, Wagner A, Judd RM, Sechtem U, Kim RJ. Delayed enhancement cardiovascular magnetic resonance assessment of non-ischaemic cardiomyopathies. Eur Heart J 2005;26:1461-74.

11. Kwong RY, Schussheim AE, Rekhraj S, et al. Detecting acute coronary syndrome in the emergency department with cardiac magnetic resonance imaging. Circulation 2003;107:531-7.

12. Plein S, Greenwood JP, Ridgway JP, Cranny G, Ball SG, Sivananthan MU. Assessment of non-STsegment elevation acute coronary syndromes with cardiac magnetic resonance imaging. J Am Coll Cardiol 2004;44:2173-81.

13. Laraudogoitia Zaldumbide E, Perez-David E, Larena JA, et al. The value of cardiac magnetic resonance in patients with acute coronary syndrome and normal coronary arteries. Rev Esp Cardiol 2009;62:976-83.

14. Leurent G, Langella B, Fougerou C, et al. Diagnostic contributions of cardiac magnetic resonance imaging in patients presenting with elevated troponin, acute chest pain syndrome and unobstructed coronary arteries. Arch Cardiovasc Dis 2011;104:161-70.

15. Meijboom WB, Mollet NR, Van Mieghem CA, et al. 64-Slice CT coronary angiography in patients with non-ST elevation acute coronary syndrome. Heart 2007;93:1386-92.

16. Vanhoenacker PK, Heijenbrok-Kal MH, Van Heste $\mathrm{R}$, et al. Diagnostic performance of multidetector CT angiography for assessment of coronary artery disease: meta-analysis. Radiology 2007;244:419-28.

17. Takakuwa KM, Halpern EJ. Evaluation of a "triple rule-out" coronary CT angiography protocol: use of
64-Section CT in low-to-moderate risk emergency department patients suspected of having acute coronary syndrome. Radiology 2008;248:438-46.

18. Hlatky MA, Douglas PS, Cook NL, et al. Future directions for cardiovascular disease comparative effectiveness research: report of a workshop sponsored by the national heart, lung, and blood institute. J Am Coll Cardiol 2012;60:569-80.

19. Mehran R, Rao SV, Bhatt DL, et al. Standardized bleeding definitions for cardiovascular clinical trials: a consensus report from the Bleeding Academic Research Consortium. Circulation 2011;123:2736-47.

20. Hakkaart-van Roijen L, Tan S.S., Bouwmans C.A.M. Handleiding voor kostenonderzoek. Methoden en standaard kostprijzen voor economische evaluaties in de gezondheidszorg. 2010.

21. EuroQol--a new facility for the measurement of health-related quality of life. The EuroQol Group. Health Policy 1990;16:199-208.

22. van Hout BA, Al MJ, Gordon GS, Rutten FF. Costs, effects and C/E-ratios alongside a clinical trial. Health economics 1994;3:309-19.

23. Agatston AS, Janowitz WR, Hildner FJ, Zusmer NR, Viamonte M, Jr., Detrano R. Quantification of coronary artery calcium using ultrafast computed tomography. J Am Coll Cardiol 1990;15:827-32.

24. Ryan JW, Peterson ED, Chen AY, et al. Optimal timing of intervention in non-ST-segment elevation acute coronary syndromes: insights from the CRUSADE (Can Rapid risk stratification of Unstable angina patients Suppress ADverse outcomes with Early implementation of the ACC/AHA guidelines) Registry. Circulation 2005;112:3049-57.

25. Leonardi S, Chen AY, Gharacholou SM, et al. Limitations of using cardiac catheterization rates to assess the quality of care for patients with non-STsegment elevation myocardial infarction. Am Heart J 2012;164:502-8.

26. Kim HW, Farzaneh-Far A, Kim RJ. Cardiovascular magnetic resonance in patients with myocardial infarction: current and emerging applications. J Am Coll Cardiol 2009;55:1-16. 


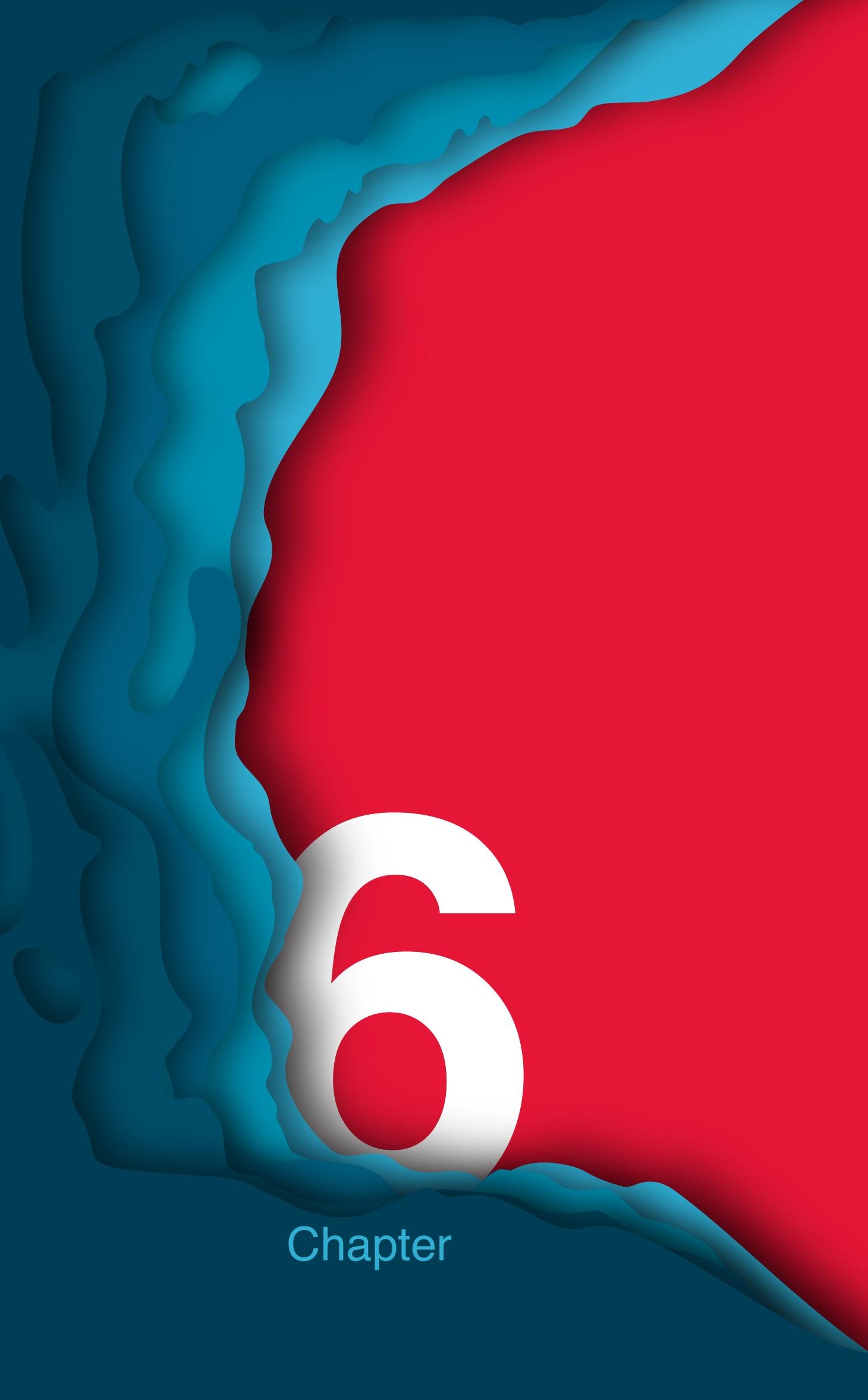




\section{Initial imaging-guided strategy versus routine care in patients with non-ST-segment elevation myocardial infarction}

Martijn W. Smulders, MD, ${ }^{1,2}$ Bas L.J.H. Kietselaer, MD, PhD, ${ }^{1,2,3}$ Joachim E. Wildberger, MD, PhD, ${ }^{2,3}$ Pieter C. Dagnelie, PhD, ${ }^{2,4}$ Hans-Peter Brunner-La Rocca, MD,, ${ }^{1,2}$ Alma M.A. Mingels, PhD, ${ }^{5}$ Yvonne J.M. van Cauteren, MD, ${ }^{1,2,3}$ Ralph A.L.J. Theunissen, MD, ${ }^{1}$ Mark J. Post, MD, PhD, ${ }^{2,6}$ Simon Schalla, MD, PhD, ${ }^{1,2,3}$ Sander M.J. van Kuijk, PhD, ${ }^{7}$ Marco Das, MD, PhD, ${ }^{2,3,8}$ Raymond J. Kim, MD, ${ }^{9}$ Harry J.G.M. Crijns, MD, PhD, ${ }^{1,2}$ Sebastiaan C.A.M. Bekkers, MD, PhD'1,2,3

Department of ${ }^{1}$ Cardiology, ${ }^{2}$ Cardiovascular Research Institute Maastricht (CARIM), ${ }^{3}$ Radiology and Nuclear Medicine, ${ }^{4}$ Internal Medicine, ${ }^{5}$ Clinical Chemistry, ${ }^{6}$ Physiology, ${ }^{7}$ Clinical Epidemiology \& Medical Technology Assessment, Maastricht University Medical Center, Maasticht, The Netherlands, and department of ${ }^{8}$ Diagnostic and Interventional Radiology, Helios Klinikum, Duisburg, Germany, and department of ${ }^{9}$ Cardiology and Radiology, Duke Cardiovascular Magnetic Resonance Center, Durham, North Carolina, USA 


\section{ABSTRACT}

\section{Background}

Patients with non-ST-elevation-myocardial-infarction (MI) and elevated high-sensitivity cardiactroponins (hs-cTn) often routinely undergo invasive coronary angiography (ICA) but many do not have obstructive coronary artery disease (CAD).

\section{Objectives}

This study investigated whether cardiovascular magnetic resonance imaging (CMR) or computed tomographic angiography (CTA) may serve as a safe gatekeeper for ICA.

\section{Methods}

This randomized controlled trial (NCT01559467) in 207 patients (64 years, 62\% male) with acute chest pain, elevated hs-cTnT levels (>14ng/L) and inconclusive electrocardiogram, compared a CMR- or CTA-first strategy with a control strategy of routine clinical care. Follow-up ICA was recommended when initial CMR or CTA suggested myocardial ischemia, infarction or obstructive CAD ( $\geq 70 \%$ stenosis). Primary efficacy and secondary safety endpoints were referral to ICA during hospitalization and one-year outcomes (major adverse cardiac events and complications), respectively.

\section{Results}

The CMR and CTA first strategies reduced ICA compared to routine clinical care $(87 \%[p=0.001]$, $66 \%$ [ $p<0.001$ ], and $100 \%$, respectively) with similar outcome (hazard ratios CMR vs. routine 0.78 [95\% Cl 0.37-1.61], CTA vs. routine 0.66 [0.31-1.42] and CMR vs. CTA 1.19 [0.53-2.66]). Obstructive CAD after ICA was found in $61 \%$ of patients in the routine clinical care, in $69 \%$ in the CMR ( $p=0.308$ vs. routine) and in $85 \%$ in the CTA-first ( $p=0.006$ vs. routine) strategy. In the non-CMR and non-CTA arms, follow-up CMR and CTA were performed in $67 \%$ and $13 \%$ of patients and led to a new diagnosis in $33 \%$ and $3 \%$, respectively, $p<0.001$.

\section{Conclusions}

A novel strategy of implementing CMR or CTA first in the diagnostic process in non-ST-elevation$\mathrm{MI}$ is a safe gatekeeper for ICA. 


\section{INTRODUCTION}

Patients with acute chest pain and inconclusive electrocardiogram (ECG) are a daily diagnostic challenge in the emergency department. Current high-sensitivity cardiac troponin (hs-cTn) assays allow ruling out acute myocardial infarction (MI) early and with high confidence. ${ }^{1,2}$ However, elevated troponin levels simply indicate myocardial injury that is typically secondary to epicardial coronary arteriosclerotic plaque rupture and thrombosis, but can also be due to microvascular, non-coronary myocardial, or extra-cardiac diseases. ${ }^{3}$

Patients with acute chest pain, inconclusive ECG, and elevated troponin levels are initially regarded and treated as $\mathrm{MI}$ and referred to invasive coronary angiography (ICA), ${ }^{4,5}$ but up to one third does not have obstructive coronary artery disease (CAD). ${ }^{6,7}$ Although ICA in these circumstances is generally regarded useful, its diagnostic yield may be improved by a more sophisticated approach to minimize procedural risks and health care costs. ${ }^{8,9}$

Cardiovascular magnetic resonance (CMR) and computed tomography angiography (CTA) are uniquely suitable to either rule out obstructive CAD or differentiate between coronary, non-coronary cardiac, and extra-cardiac diseases. ${ }^{10-13}$ While CMR and CTA improve the selection of patients benefitting from ICA in stable angina pectoris and troponin-negative acute coronary syndrome, this is unclear in hs-cTn-positive non-ST elevation MI (NSTEMI). ${ }^{14,15}$

This randomized clinical trial investigates whether a novel strategy incorporating either CMR or CTA first in the diagnostic pathway of patients with hs-cTn-positive acute chest pain can reduce the number of patients referred to ICA without detrimental effect on clinical outcome compared to routine clinical care.

\section{METHODS}

\section{Study design and population}

The CARMENTA (The role of initial CARdiovascular Magnetic rEso-Nance imaging and computed Tomography Angiography in non-ST-elevation myocardial infarction patients) trial was a three arm, prospective, open label, single center, randomized controlled, comparative effectiveness trial comparing a diagnostic strategy incorporating CMR or CTA first as a gatekeeper for ICA to a control strategy (i.e. routine clinical care) in patients with NSTEMI.

Consecutive patients presenting between April 11, 2012, and May 26, 2016, to the emergency department of the Maastricht University Medical Center with acute chest pain, normal or inconclusive ECG (absence of ST-T elevation and/or dynamic ST-T wave changes suggesting myocardial ischemia), and elevated hs-cTnT levels ( $>14 \mathrm{ng} / \mathrm{l}$ at baseline or $3 \mathrm{~h}$ after presentation) were evaluated by a study-independent cardiologist. Because NSTEMI was the initial working diagnosis, hospital admission was considered vital for further diagnostic evaluation and management. All patients were deemed potentially suitable for ICA before inclusion, enrollment, and randomization. Thereafter, further patient management, including decision on ICA, was left to the discretion of study-independent cardiologists and not dictated by the study protocol.

Exclusion criteria included ongoing severe ischemia requiring immediate ICA (e.g. ongoing chest pain, dynamic ST-T wave changes), chest pain suggestive of non-MI origin (e.g. myocarditis, pulmonary embolism), previously known CAD (e.g. prior MI, revascularization, $>50 \%$ stenosis, non-invasive imaging positive for myocardial ischemia), a type II MI (e.g. tachycardia, atrial fibrillation, severe hypertension, aortic valve stenosis, hypotension, anemia), patient age $>85$ years, and regular contraindications for CMR and CTA (see Supplemental Table 1 for the eligibility criteria).

Serum hs-cTnT levels were assessed using the $5^{\text {th }}$ generation cardiac troponin-T immunoassay (Cobas $6000 / 8000$ instrument, Roche Diagnostics, Mannheim, Germany) with a detection limit of $5 \mathrm{ng} / \mathrm{L}, 10 \% \mathrm{CV}$ cut-off at $13 \mathrm{ng} / \mathrm{L}$, and $99^{\text {th }}$ percentile upper reference limit of $14 \mathrm{ng} / \mathrm{L}$ according to the package insert. 
Prior to patient recruitment, the trial was registered at ClinicalTrials.gov (identifier NCT01559467). The study design has been described previously. ${ }^{16}$ The study was approved by the institutional ethics committee of the Maastricht University Medical Center, conducted according to the principles of the Declaration of Helsinki and is reported according to the CONSORT guidelines. All participants gave oral and written informed consent before randomization.

\section{Randomization and study protocol}

Patients were randomly assigned to one of three diagnostic strategies in a 1:1:1 ratio using Web-based software (TENALEA, FormsVision BV, Abcoude, The Netherlands) with random permuted block sizes.

Patients randomized to the control arm (routine clinical care) received care as usual in accordance with current guidelines and without initial CMR or CTA.,5 Although left at the discretion of the treating cardiologist, routine clinical care usually involves ICA. For ICA, a coronary etiology (myocardial infarction or ischemia) was diagnosed when obstructive CAD was found ( $\geq 70 \%$ luminal narrowing in any epicardial coronary artery).

Patients randomized to CMR were scanned on a 3-Tesla magnetic resonance imaging scanner (Achieva; Philips, Best, The Netherlands). The CMR protocol included: transversal multiplane bright blood imaging (to assess anatomy and extra-cardiac pathology), cine-CMR (regional and global function), T2-weighted CMR (edema), rest and stress perfusion imaging to evaluate myocardial ischemia after infusing adenosine, and delayed-enhancement CMR (presence and pattern of focal scar). For safety reasons, adenosine stress perfusion was planned at the end and when a CMR diagnosis was still unknown. A coronary etiology (myocardial infarction or ischemia) was suggested in case of the following abnormalities in a coronary artery distribution territory: 1) subendocardial or transmural hyperenhancement on delayed-enhancement-CMR, with/without regional wall motion abnormalities on cine-CMR or obvious increased signal intensity on T2-weighted-CMR and/or 2) stress-induced subendocardial or transmural first-pass perfusion defect. Non-coronary diagnoses such as (peri-) myocarditis, Takotsubo cardiomyopathy, pulmonary embolism, and incidental findings were also scored. ${ }^{17}$

Patients randomized to CTA were scanned on a second-generation dual-source computedtomography scanner (Somatom Definition Flash; Siemens, Forchheim, Germany) using a non-enhanced scan to determine coronary calcium score and an enhanced triple rule-out angiography protocol to visualize the aorta, pulmonary arteries, and coronary arteries in a single scan. A coronary etiology (myocardial infarction or ischemia) was suggested in case of: 1) obstructive $C A D$, defined as $\geq 70 \%$ luminal narrowing in any epicardial coronary artery, or 2 ) Agatston score $\geq 1,000$ in the absence of extra-cardiac findings such as acute aortic dissection or pulmonary embolism. ${ }^{18}$

CMR and CTA images were interpreted immediately after scanning by 2 experienced readers. Follow-up ICA was recommended when initial CMR or CTA suggested a coronary etiology and discouraged in case of a non-coronary etiology (e.g. myocarditis or pulmonary embolism). If the scan was normal, equivocal or of non-diagnostic quality, the scan results were provided but without a formal recommendation to perform or avoid ICA. Follow-up diagnostic testing (including ICA), medical therapy, and discharge was considered as part of clinical decision making (i.e. not driven by the study protocol) and left at the discretion of the treating cardiologist. See Supplemental Figure 1 for a visual overview of the recommendations provided following CMR or CTA. 


\section{End points}

The primary efficacy endpoint was the proportion of patients referred to ICA during initial hospitalization. The secondary endpoints of safety were the occurrence of major adverse cardiac events (MACE), and procedure-related complications within one month and one year. MACE was a composite of all-cause mortality, recurrent MI, unplanned coronary revascularization after the index event or congestive heart failure requiring hospitalization. Additionally, a composite of MACE and procedure-related complications, (i.e. adverse events including significant bleeding, contrast-induced nephropathy, renal failure, nephrogenic systemic fibrosis, allergic reaction requiring urgent therapy, dissection or perforation of a vessel, stroke, or transient ischemic attack), during one-month and one-year follow-up were scored. Clinical and contrast-induced nephropathy-related events were adjudicated by two independent committees using all available clinical data but masked to the allocated strategy.

During 1-year follow-up, cumulative radiation exposure from diagnostic testing was recorded in the picture archiving and communication system (Agfa HealthCare version 6.6.1.5003, Mortsel, Belgium; and IBC pro version 2.00.003, Comecer S.p.A., Bologna, Italy). Cumulative effective radiation exposure (in $\mathrm{mSv}$ ) was calculated with standardized conversion factors for ICA (dose-area product), CTA (dose-length product), and scintigraphy (MBq) from admission to 1-year follow-up..$^{19,20}$

\section{Statistical analysis}

All analyses were conducted on an intention-to-treat basis. To evaluate the primary efficacy endpoint, the proportion of patients with at least one ICA during initial admission was compared between groups using Chi-squared or Fisher's Exact tests as appropriate. Differences were also expressed as relative risks of both early non-invasive imaging techniques compared to routine clinical care and to each other.

Continuous outcome variables with normally distributed data were expressed as mean \pm standard deviation and differences between groups were compared using one-way ANOVA with Bonferroni correction for post-hoc comparisons. Continuous data with non-normal distribution were presented as a median with interquartile range (IQR) and differences between groups were tested with the independent samples Kruskal-Wallis test. Kaplan Meier plots were computed to evaluate the cumulative incidence of clinical outcome over time. Differences in the cumulative incidence between groups were compared using the log-rank test and the Cox proportional hazards regression model. The proportional hazards assumption was assessed by computing the scaled Schoenfeld residuals and testing their correlation with time. A significant correlation with time would imply deviation from proportionality and violation of the assumption. A two-tailed $p$-value $<0.05$ was considered statistically significant. Statistical analyses were performed with SPSS statistics v. 24.0.0.1 (IBM corporation, Armonk, New York).

Sample size calculation determined that including 288 patients (96 patients per arm) would yield a power of $80 \%$, at a significance level of 0.05 , to detect an absolute reduction of $15 \%$ in ICA rate in the non-invasive imaging strategy arms compared to routine clinical care, assuming an ICA rate in the routine clinical care group of $75 \%$. The expected $75 \%$ ICA rate in the routine clinical care group was based on clinical experience and supported by registries. ${ }^{21,22}$ To ensure patient safety, three pre-specified interim analyses of the safety endpoint (MACE rate) were performed after inclusion of 50,100 , and 200 patients by an independent committee. The protocol was amended to allow evaluation of the primary efficacy and secondary safety interim endpoints after inclusion of 200 participants by a separate independent interim analysis committee. This committee concluded that continuation of the study would unlikely alter both endpoint results and recommended discontinuation of patient inclusion. This recommendation was followed by the trial steering committee. 


\section{RESULTS}

\section{Study population and randomization}

During the recruitment period, 771 patients with acute chest pain, an inconclusive ECG, abnormal hs-cTnT levels and without previously known CAD were screened for eligibility. In total, 564 patients met the exclusion criteria and 207 patients were randomized, of whom 69 patients were assigned to routine clinical care, 68 patients to the CMR-first, and 70 patients to the CTA-first diagnostic strategy. Follow-up was complete in 204 patients (Figure 1). Mean age was $64 \pm 12$ years and $62 \%$ was male. Baseline characteristics are presented in Table 1 . The majority of baseline characteristics were equally distributed between groups, except for gender, cardiovascular risk factors, and ECG findings. All patients were hospitalized with a median time to discharge of 5 days (IQR 3-7) for routine clinical care, 5 days (IQR 4-8) for the CMR-first ( $p=0.345$ vs. routine), and 4 days (IQR $3-7)$ for the CTA-first strategy ( $p=0.480$ vs. routine). Out of the 69 patients assigned to routine clinical care, 1 patient did not have ICA as a first test but CTA was performed first instead. Follow-up ICA in this patient excluded obstructive CAD that was initially suggested by CTA. In total, ICA showed obstructive CAD in 42 out of 69 patients (61\%).

Out of 68 patients assigned to the CMR-first strategy, 8 had ICA instead of CMR first (obstructive CAD was found in 7), because of technical problems $(n=3)$, claustrophobia $(n=3)$, unforeseen urgent ICA $(n=1)$, and not fitting into the bore of the scanner $(n=1)$. The single patient who required unforeseen urgent ICA for nontechnical reasons experienced ongoing symptoms accompanied by widening of the QRS complex and dynamic ST-T changes. CMR suggested a coronary etiology in 46 out of 60 patients that underwent CMR first (77\%) and myocarditis in 1 patient. Follow-up ICA was performed in 45 out of 46 patients with a coronary etiology suggested by initial CMR. The remaining patient did not undergo follow-up ICA because of end-stage malignancy. Adenosine stress-perfusion CMR suggested a coronary etiology in 22 patients of whom $16(73 \%)$ had obstructive CAD on follow-up ICA. CMR was normal in $8(13 \%)$, equivocal in $4(7 \%)$, and of non-diagnostic quality in 1 patient. In these latter 13 patients, follow-up angiography was performed in 10 (6 ICA and 4 CTA), revealing borderline obstructive CAD in 1 patient (10\%) who had a single $70 \%$ stenosis (fractional flow reserve was not performed). Of all patients randomized to the CMR-first strategy and who underwent ICA during initial admission, obstructive CAD was found in 41 out of 59 patients (69\%, $p=0.308$ vs. routine clinical care [61\%]).

Of the 70 patients assigned to the CTA-first strategy, 2 did not have CTA as a first test because of technical problems. One patient underwent ICA first, showing obstructive CAD, and the other patient was discharged after a normal exercise test and echocardiogram. CTA suggested obstructive CAD in $44(65 \%)$ and acute pulmonary embolism in 2 out of the remaining 68 patients (3\%). Follow-up ICA was performed in 43 out of 44 patients with obstructive CAD suggested on initial CTA. The remaining patient did not undergo follow-up ICA because of significant intestinal bleeding after initiating dual antiplatelet therapy. An Agatston score $\geq 1,000$ without relevant extra-cardiac findings was observed in 7 patients, all of them having a $\geq 70 \%$ coronary artery stenosis by CTA and follow-up ICA. CTA was normal in 10 (15\%), suggested non-obstructive CAD (<70\% luminal narrowing in any epicardial coronary artery) in $10(15 \%)$, or was of non-diagnostic quality in 2 patients $(3 \%)$. In these latter 22 patients, follow-up ICA was only performed in the 2 patients with a non-diagnostic scan showing obstructive CAD in 1 patient. Of all patients randomized to the CTA-first strategy and who underwent ICA during initial admission, obstructive CAD was found in 39 out of 46 patients $(85 \%, p=0.006$ vs. routine clinical care $[61 \%])$. Patient flow based on imaging results and corresponding ICA findings are shown in Supplemental Figure 1. 


\section{Figure 1.}

Patient screening, enrolment, randomization and follow-up.

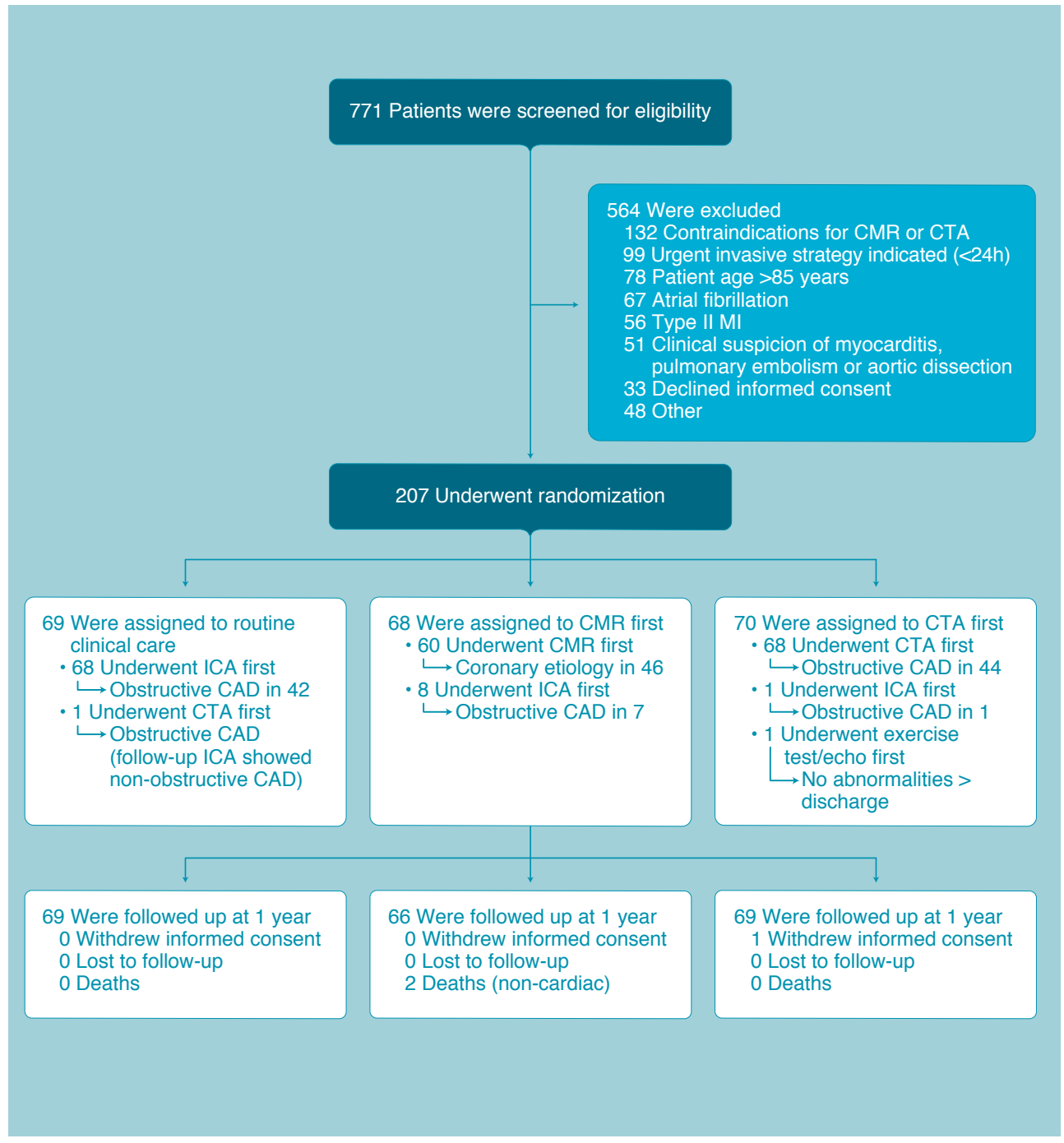

Patients randomized to routine clinical care received care as usual. In the CMR- or CTA-first strategy, patients underwent CMR or CTA as a first diagnostic test. Based on the results of CMR or CTA, referral to follow-up ICA was either advised or discouraged. Patient follow-up was 1 year.

$\mathrm{CMR}=$ cardiovascular magnetic resonance; $\mathrm{CAD}=$ coronary artery disease; $\mathrm{CTA}=$ cardiac computed tomography angiography; ICA=invasive coronary angiography; $\mathrm{Ml}=$ myocardial infarction. 
Table 1.

Baseline demographic and clinical characteristics.

\begin{tabular}{|c|c|c|c|c|c|c|c|}
\hline \multirow{2}{*}{ Variable } & \multirow{2}{*}{$\begin{array}{l}\text { Patients } \\
\text { (N=207) }\end{array}$} & \multicolumn{2}{|l|}{ Strategy } & \multirow[b]{2}{*}{$\begin{array}{l}\text { CTA first } \\
(\mathrm{N}=70)\end{array}$} & \multirow[b]{2}{*}{$\begin{array}{l}\text { p-value } \\
\text { routine } \\
\text { vs CMR }\end{array}$} & \multirow[b]{2}{*}{$\begin{array}{l}\text { p-value } \\
\text { routine } \\
\text { vs CTA }\end{array}$} & \multirow[b]{2}{*}{$\begin{array}{l}\text { p-value } \\
\text { CMR vs } \\
\text { CTA }\end{array}$} \\
\hline & & $\begin{array}{l}\text { Routine } \\
\text { clinical care } \\
(\mathrm{N}=69)\end{array}$ & $\begin{array}{l}\text { CMR first } \\
(\mathrm{N}=68)\end{array}$ & & & & \\
\hline Age - year & $63.8 \pm 11.5$ & $63.5 \pm 11.5$ & $64.0 \pm 9.4$ & $63.9 \pm 13.3$ & 0.797 & 0.869 & 0.954 \\
\hline $\begin{array}{l}\text { Male gender - } \\
\text { No. (\%) }\end{array}$ & 129 (62) & $41(59)$ & $37(54)$ & $51(73)$ & 0.554 & 0.094 & 0.024 \\
\hline $\mathrm{BMI}-\mathrm{kg} / \mathrm{m}^{2}$ & $27.2 \pm 4.4$ & $27.2 \pm 4.4$ & $27.6 \pm 4.4$ & $26.9 \pm 4.6$ & 0.564 & 0.717 & 0.355 \\
\hline \multicolumn{8}{|l|}{$\begin{array}{l}\text { Clinical history - } \\
\text { No. (\%) }\end{array}$} \\
\hline \multicolumn{8}{|l|}{ Vascular disease } \\
\hline Stroke & $8(4)$ & $2(3)$ & $3(4)$ & $3(4)$ & 0.681 & 1.000 & 1.000 \\
\hline TIA & $12(6)$ & $4(6)$ & $4(6)$ & $4(6)$ & 1.000 & 1.000 & 1.000 \\
\hline PVD & $15(7)$ & $6(9)$ & $5(7)$ & $4(6)$ & 1.000 & 0.532 & 0.743 \\
\hline \multicolumn{8}{|l|}{$\begin{array}{l}\text { Cardiovascular risk } \\
\text { factors }\end{array}$} \\
\hline Hypertension & $98(47)$ & $36(52)$ & $29(43)$ & 33 (47) & 0.264 & 0.553 & 0.596 \\
\hline Diabetes & $23(11)$ & $8(12)$ & $11(16)$ & $4(6)$ & 0.438 & 0.217 & 0.048 \\
\hline $\begin{array}{l}\text { Hypercholeste- } \\
\text { rolemia }\end{array}$ & 70 (34) & $30(44)$ & $21(31)$ & $19(27)$ & 0.127 & 0.044 & 0.628 \\
\hline $\begin{array}{l}\text { Positive family } \\
\text { history }\end{array}$ & $95(46)$ & $29(42)$ & $37(54)$ & $29(41)$ & 0.147 & 0.609 & 0.214 \\
\hline Smoking & 79 (38) & $31(45)$ & $23(34)$ & $25(36)$ & 0.184 & 0.268 & 0.816 \\
\hline $\begin{array}{l}\text { No. of } \\
\text { cardiovascular risk } \\
\text { factors }\end{array}$ & $1.8 \pm 1.2$ & $1.9 \pm 1.2$ & $1.8 \pm 1.1$ & $1.6 \pm 1.2$ & 0.411 & 0.065 & 0.252 \\
\hline \multicolumn{8}{|l|}{$\begin{array}{l}\text { Prior medication - } \\
\text { No. }(\%)\end{array}$} \\
\hline Aspirin & $40(19)$ & $12(17)$ & $14(21)$ & $14(20)$ & 0.633 & 0.693 & 0.932 \\
\hline Beta-blocker & 36 (17) & $11(16)$ & $9(13)$ & $16(23)$ & 0.654 & 0.303 & 0.142 \\
\hline ACE-inhibitor & $21(10)$ & $8(12)$ & $7(10)$ & $6(9)$ & 0.807 & 0.554 & 0.729 \\
\hline Statin & $54(26)$ & $23(33)$ & $13(19)$ & $18(26)$ & 0.059 & 0.325 & 0.353 \\
\hline \multicolumn{8}{|l|}{ Loading dose at ED } \\
\hline Aspirin & $159(77)$ & $52(75)$ & $53(78)$ & $54(77)$ & 0.721 & 0.805 & 0.911 \\
\hline Thienopyridine & $192(93)$ & $65(94)$ & $63(93)$ & $64(91)$ & 0.745 & 0.745 & 0.792 \\
\hline \multicolumn{8}{|l|}{ Electrocardiogram } \\
\hline Heart rate $-\mathrm{bpm}$ & $72.6 \pm 15.1$ & $73.1 \pm 14.0$ & $71.9 \pm 16.8$ & $72.8 \pm 14.5$ & 0.658 & 0.882 & 0.760 \\
\hline $\begin{array}{l}\text { LBBB/RBBB - } \\
\text { No. (\%) }\end{array}$ & $12(6)$ & $3(4)$ & $3(4)$ & $6(9)$ & 1.000 & 0.493 & 0.493 \\
\hline $\begin{array}{l}\text { Isolated T-wave } \\
\text { inversion - No. (\%) }\end{array}$ & $23(11)$ & $5(7)$ & $11(16)$ & $7(10)$ & 0.104 & 0.563 & 0.281 \\
\hline
\end{tabular}


Table 1. (continued)

\begin{tabular}{|c|c|c|c|c|c|c|c|}
\hline \multirow[b]{2}{*}{ Variable } & \multirow{2}{*}{$\begin{array}{l}\text { Patients } \\
(\mathrm{N}=\mathbf{2 0 7})\end{array}$} & \multicolumn{6}{|l|}{ Strategy } \\
\hline & & \begin{tabular}{|l|} 
Routine \\
clinical care \\
(N=69)
\end{tabular} & $\begin{array}{l}\text { CMR first } \\
(\mathrm{N}=68)\end{array}$ & $\begin{array}{l}\text { CTA first } \\
(\mathrm{N}=70)\end{array}$ & $\begin{array}{l}\text { p-value } \\
\text { routine } \\
\text { vs CMR }\end{array}$ & $\begin{array}{l}\text { p-value } \\
\text { routine } \\
\text { vs CTA }\end{array}$ & $\begin{array}{l}\text { p-value } \\
\text { CMR vs } \\
\text { CTA }\end{array}$ \\
\hline $\begin{array}{l}\text { ST-segment } \\
\text { changes - No. (\%) }\end{array}$ & $42(20)$ & $18(26)$ & $8(12)$ & $16(23)$ & 0.033 & 0.658 & 0.086 \\
\hline \multicolumn{8}{|l|}{$\begin{array}{l}\text { Laboratory } \\
\text { assessment }\end{array}$} \\
\hline $\begin{array}{l}\text { Baseline troponin } \\
<50 \mathrm{ng} / \mathrm{L}-\mathrm{No} .(\%)\end{array}$ & $92(44)$ & $31(45)$ & $30(44)$ & $31(44)$ & 0.924 & 0.939 & 0.984 \\
\hline $\begin{array}{l}\text { Peak troponin - } \\
\text { ng/L }\end{array}$ & $78(37-285)$ & $78(44-310)$ & $87(38-278)$ & $78(35-278)$ & 0.708 & 0.529 & 0.821 \\
\hline \multicolumn{8}{|l|}{ Risk score } \\
\hline GRACE-score & $115.4 \pm 23.8$ & $116.0 \pm 25.0$ & $115.7 \pm 22.3$ & $114.4 \pm 24.2$ & 0.948 & 0.710 & 0.745 \\
\hline GRACE-score $>140$ & $29(14)$ & $11(16)$ & $8(12)$ & $10(14)$ & 0.479 & 0.785 & 0.660 \\
\hline
\end{tabular}

Continuous data are expressed as mean \pm standard deviation or median (interquartile range), categorical data as number (percentage). Risk factor family history was unknown in 1 patient. Abbreviations: ACE = angiotensin converting enzyme; $\mathrm{BMI}=$ body-mass index; $\mathrm{CMR}=$ cardiovascular magnetic resonance; $\mathrm{CTA}=$ computed tomography angiography; ED = emergency department; GRACE = Global Registry of Acute Coronary Events; LBBB = left bundle branch block; PVD = peripheral vessel disease; RBBB = right bundle branch block; TIA = transient ischemic attack.

\section{Primary efficacy endpoint}

Implementing CMR or CTA as a first test reduced the proportion of patients referred to ICA during initial hospitalization ( $87 \%$ [ $p=0.001$ vs. routine] and $66 \%$ [p $<0.001$ vs. routine] compared to routine clinical care (100\%), respectively, Central Illustration). Significantly fewer ICA were performed in the CTA-first than CMR-first strategy $(p=0.004)$. The reduction in ICA in the CMR or CTA-first strategy compared to routine clinical care was persistent after one year, $88 \%$ ( $p=0.003$ vs. routine), $70 \%$ ( $p<0.001$ vs. routine), and $100 \%$, respectively. The $100 \%$ referral rate to ICA in the routine clinical care arm was significantly larger than the $75 \%$ predicted ICA referral rate $(p<0.001)$. However, an additional analysis showed that the upper limits of the confidence intervals of ICA rates in the CMR or CTA first strategies were substantially below one and therefore still support the main conclusions (see Supplemental Table 2).

\section{Secondary safety endpoints}

One-year follow-up was complete for 204 patients (99\%), with an average follow up of $1.3 \pm 0.5$ years. One patient in the CTA-first strategy withdrew informed consent after 25 days. Two patients randomized to CMR died from non-cardiac causes (lung and gastric cancer). In both cases, the malignancy was unknown prior to randomization, first suggested by CMR and confirmed by additional testing. In total, the composite endpoint MACE was observed in 16 patients $(8 \%$; all-cause mortality $(n=2)$, recurrent $M I(n=7)$, unplanned coronary revascularization after the index event $(n=6)$ or congestive heart failure requiring hospitalization $(n=1))$. One-month and one-year MACE were similar between groups (Figure 2A and Supplemental Figure 2A). In 28 patients (14\%), procedure related events or adverse events (no MACE) 
occurred (local vascular or coronary vessel injury $(n=10)$, cerebrovascular complications $(n=5)$, nephropathy $(n=4)$, significant bleeding $(n=3)$, serious allergic reaction $(n=3)$, peri-procedural MI $(n=2)$, life-threatening arrhythmia $(n=1))$. A composite of MACE and procedure-related complications occurred in $23 \%$ of patients in the routine clinical arm, $19 \%$ of patients in the CMR-first ( $p=0.560$ vs. routine), and $16 \%$ of patients in the CTA-first strategy ( $p=0.265$ vs. routine, Figure 2B and Supplemental Figure 2B). No adenosine-related complications were observed. No evidence of violation of the proportional hazards assumption was found ( $p$ values for the correlation of the Schoenfeld residuals with time between 0.124 and 0.721 ).

\section{Central Illustration}

Early CMR or CTA in NSTEMI: a safe gatekeeper for invasive coronary angiography.

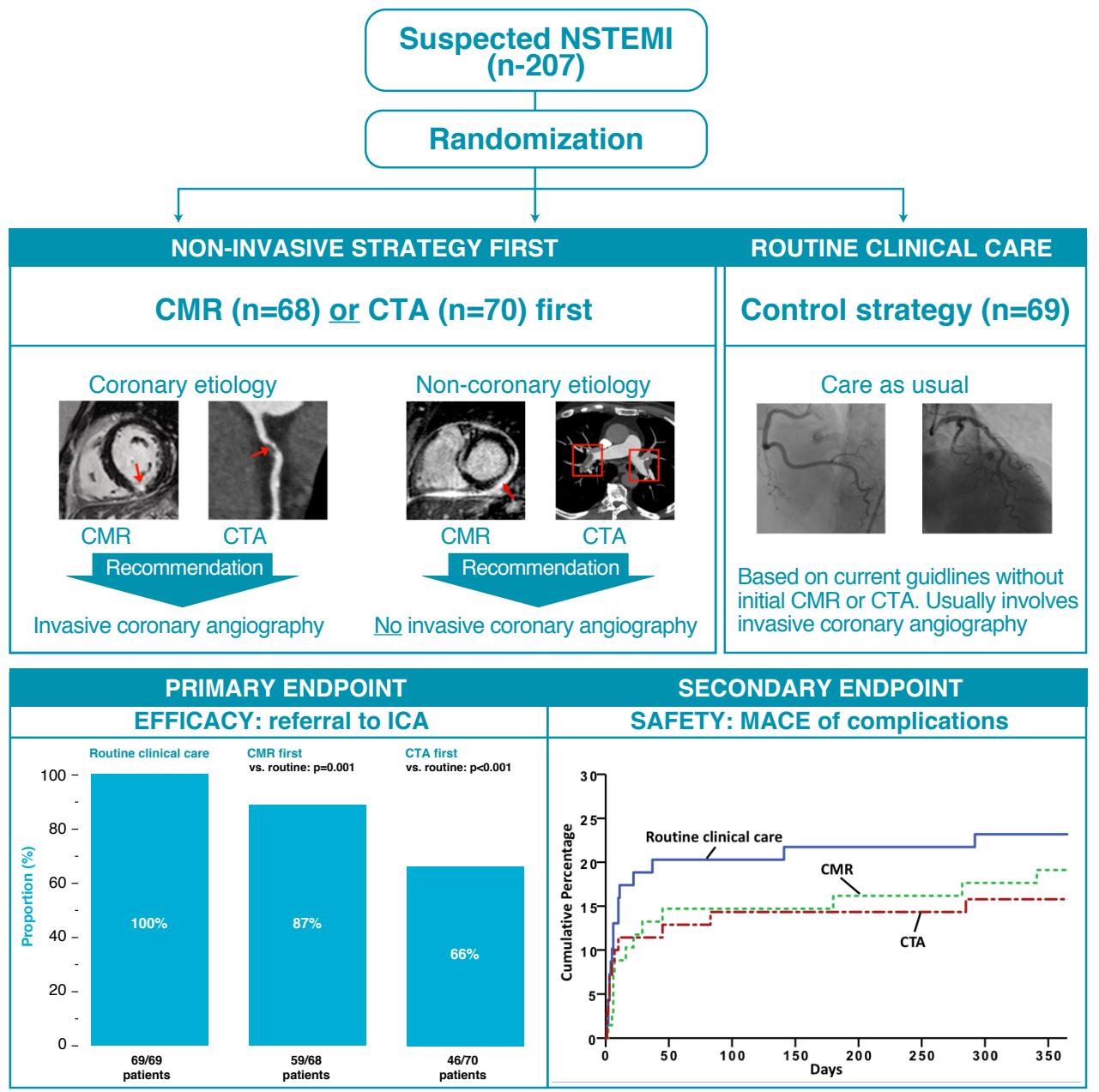




\section{Legend Central Illustration}

This is a randomized controlled clinical trial investigating a CMR- or CTA-first versus routine clinical care in NSTEMI patients. Follow-up ICA was recommended when initial CMR or CTA suggested myocardial ischemia, infarction or obstructive coronary artery disease. ICA was discouraged in case of a clear alternative diagnosis such as a myocarditis or pulmonary embolism. No formal recommendation was provided in case of a normal, inconclusive or non-diagnostic CMR or CTA result. This novel diagnostic strategy in NSTEMI of incorporating CMR- or CTA-first, as compared to routine clinical care, reduces referral to invasive coronary angiography (primary endpoint), with no detrimental effect on clinical outcome (secondary endpoint). CMR=cardiovascular magnetic resonance; $C T A=$ cardiac computed tomography angiography; ICA=invasive coronary angiography; NSTEMI=non-ST-elevation myocardial infarction.

\section{Additional observations}

Follow-up CMR was performed in 16 out of 27 patients (59\%) who had non-obstructive CAD or normal coronary arteries on ICA in the routine clinical care strategy and in 17 out of 22 patients (77\%) who had either non-obstructive CAD, a normal, or non-diagnostic scan in the CTA-first strategy. In total, 33 out of 49 patients $(67 \%)$ in whom the diagnosis remained unknown in the two non-CMR arms had a follow-up CMR scan. This revealed a new and clinically relevant diagnosis in 16 patients (33\%), including myocarditis $(n=7)$, MI $(n=7)$, hypertrophic $(n=1)$, and dilated cardiomyopathy $(n=1)$. Similarly, follow-up CTA was performed in 1 out of 27 patients (4\%) who had non-obstructive CAD on ICA in the routine clinical care strategy and in 4 out of 13 patients $(31 \%)$ who had a normal, equivocal, or non-diagnostic CMR scan in the CMR-first strategy. In total, 5 out of 40 patients (13\%) in whom the diagnosis remained unknown in the two non-CTA arms had a follow-up CTA scan. This revealed a new and clinically relevant diagnosis in 1 patient (3\%) who had a pulmonary embolism. Hence, follow-up CMR was more commonly ordered than follow-up CTA ( $67 \%$ vs. $13 \%, p<0.001)$ and more often led to new clinical diagnosis (33\% vs. $3 \%, p<0.001)$.

Median time to revascularization during the initial admission was similar in all groups: in the CMR-first strategy, 76 hours (IQR: 46 to 141 hours [ $p=0.946$ vs. routine]); in the CTA-first strategy, $72 \mathrm{~h}$ (IQR: 28 to 141 hours [p = 0.977 vs. routine]); and in the routine clinical care arm, 52 hours (IQR: 40 to 145 hours ).

Median one-year cumulative ionizing radiation exposure was 7.0 (IQR 3.2-14.3) millisieverts. The effective radiation dose was significantly higher in the CTA-first group (13.0 [IQR 7.7-20.7] millisieverts, $\mathrm{p}<0.001$ for both) than in routine clinical care (4.1 [IQR 2.5-8.9]), or CMR-first strategies (4.9 [IQR 1.9-9.6] millisieverts). Radiation dose was similar in a routine clinical care and CMR first strategy $(\mathrm{p}=0.945)$.

\section{DISCUSSION}

This trial shows that a diagnostic strategy incorporating CMR or CTA first in patients with acute chest pain or its equivalent, an inconclusive ECG, and elevated hs-cTnT levels (i.e. non-ST elevation $\mathrm{MI}$ ), safely reduces the number of ICA compared to routine clinical care (Central illustration). This new approach also led to a more appropriate selection of patients sent for ICA in comparison to routine clinical care, in which greater than one-third of patients did not have obstructive CAD.

Evaluating patients with non-ST-elevation MI is challenging. A central component of the diagnostic strategy includes assessment of coronary anatomy using ICA, despite a non-trivial proportion of patients having non-obstructive CAD. ${ }^{4,5}$ In the conventional cardiac troponin assay 


\section{Figure 2.}

Kaplan-Meier estimates of the secondary safety endpoints for 1-year follow-up.
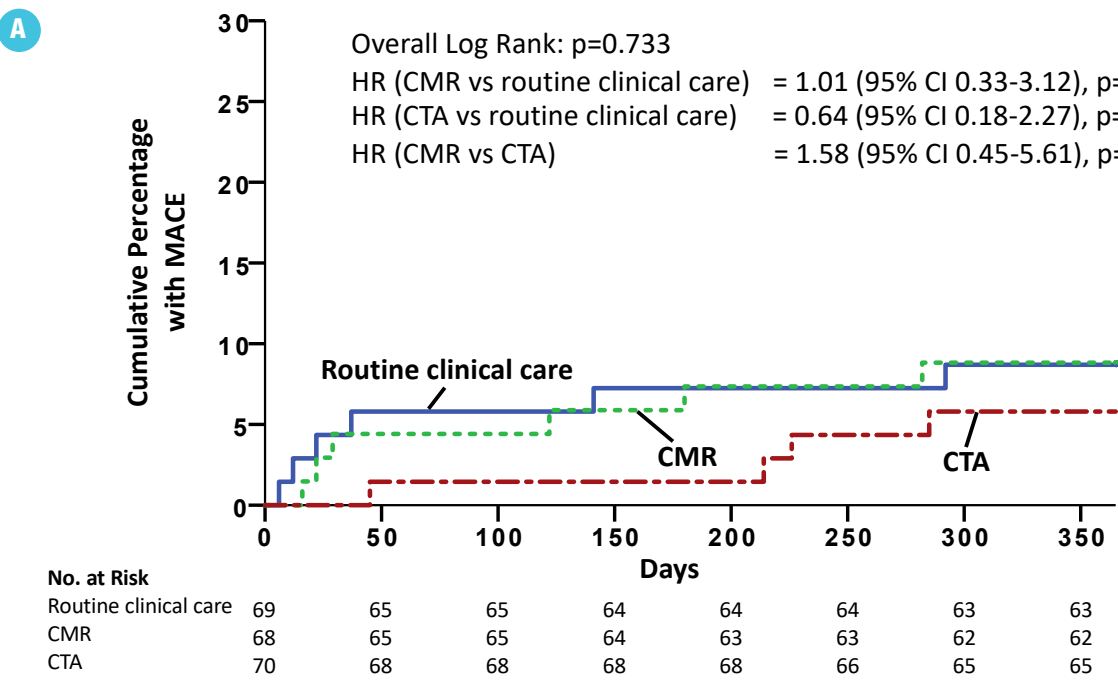

No. at Risk

$\begin{array}{lllllllll}\text { Routine clinical care } & 69 & 65 & 65 & 64 & 64 & 64 & 63 & 63 \\ \text { CMR } & 68 & 65 & 65 & 64 & 63 & 63 & 62 & 62 \\ \text { CTA } & 70 & 68 & 68 & 68 & 68 & 66 & 65 & 65\end{array}$

B

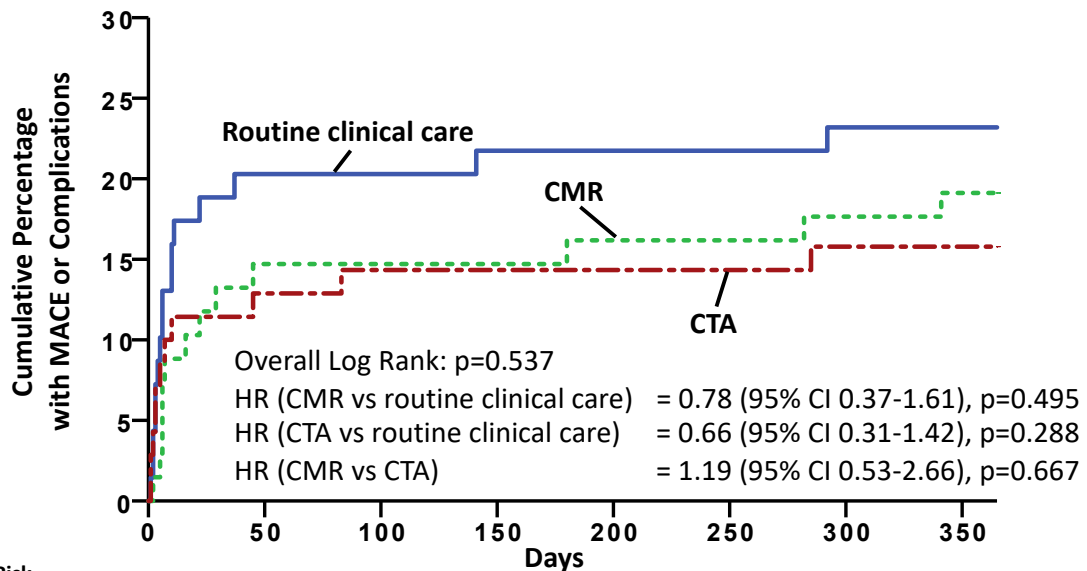

No. at Risk

Routine clinical care 69

CMR 68

CTA 70

55
58
60

$\begin{array}{ll}55 & 54 \\ 58 & 58 \\ 59 & 59\end{array}$

54
57
59

$\begin{array}{lll}54 & 53 & 53 \\ 57 & 56 & 55 \\ 59 & 58 & 58\end{array}$

The secondary safety endpoint (Panel A) was MACE (a composite of all-cause mortality, recurrent myocardial infarction, revascularization not planned during the index event or congestive heart failure requiring hospitalization). Panel B shows a composite of MACE and other adverse events (i.e. significant bleeding, contrast induced nephropathy, renal failure, nephrogenic systemic fibrosis, allergic reaction requiring urgent therapy, dissection or perforation of a vessel, stroke or transient ischemic attack).

$\mathrm{CMR}=$ cardiovascular magnetic resonance; $\mathrm{CTA}=$ cardiac computed tomography angiography; HR=hazard ratio; $\mathrm{MACE}=$ major adverse cardiac events. 
era, the prevalence of non-obstructive CAD ranged between $9-25 \%^{23-26}$ and may reach up to $29 \%$ with the current hs-cTn assay. ${ }^{7}$ Non-invasive imaging as a gatekeeper for ICA has already been demonstrated in patients with chest pain and normal troponin levels. ${ }^{14,15}$ To our knowledge, our trial is the first to show this gatekeeping potential of a CMR or CTA-first strategy in troponinpositive patients with type-I non-ST elevation MI (patients with type II MI were excluded). Of interest, all patients in the routine clinical care arm underwent ICA, illustrating that an early invasive approach has become an automatic and possibly, a dogmatic decision. By showing the increased diagnostic efficiency of a CMR or CTA-first strategy, our results create a different viewpoint and open up new avenues in the evaluation of patients with acute chest pain and elevated hs-cTn levels.

The composite rate of death and $\mathrm{MI}$ in our trial was low compared to previous studies with non ST-elevation MI (4\% vs. $8-14 \%) .{ }^{24,25}$ However, it is important to note that we used a hs-cTn assay whereas previous studies used conventional troponin assays. To date, there is no evidence for a prognostic benefit of a routine invasive versus a conservative management strategy in patients with unstable angina pectoris or non-ST elevation MI who have elevated conventional troponins. ${ }^{27} \mathrm{~A}$ routine invasive strategy may only be beneficial for those at the highest risk for recurrent events but harmful for those at low risk. Although point-to-point conversion of high-sensitivity troponin values to comparable conventional troponin values is not recommended, the median hs-cTn values in our study (78 [IQR 37-285] ng/l) match with low-range conventional troponin values. This designates our patients as low-to-intermediate risk, consistent with the observed low event rate, and justifies a primary non-invasive strategy. Moreover, a trend of decreased MACE and complications was observed in the CMR and CTA-first strategies compared to routine clinical care.

CMR-first strategy did not reduce the number of ICA as much as the CTA-first strategy for which there may be a potential explanation. By design, we only provided a formal recommendation in favor or against a follow-up ICA in a subset of patients. Specifically, we did not provide a formal recommendation when the scans were normal. Follow-up testing was left at the clinician's discretion when a scan was normal. It appears that clinicians trusted CTA more than CMR. When we would have also discouraged ICA when the scan was normal, the rates of ICA would have been further reduced in the CMR first arm. Apparently, anatomical exclusion of obstructive CAD in non-ST elevation $\mathrm{MI}$ is regarded a necessary and reassuring first step and many clinicians still have to become accustomed to the potential of CMR in this respect. Of interest, 10 out of 13 patients with a normal, equivocal, or non-diagnostic quality CMR scan underwent angiography of whom only one had a single, borderline-obstructive lesion of which the real significance remains unknown because fractional flow reserve was not performed.

CMR was favored when the diagnosis remained unclear after ICA or CTA first. Significantly more patients were referred to follow-up CMR than follow-up CTA and CMR significantly more often led to a new and clinically relevant diagnosis. More than half of these patients had a non-ischemic etiology, among them myocarditis or cardiomyopathy. Moreover, follow-up CMR scans revealed that a substantial number of patients had myocardial necrosis in the distribution territory of a coronary artery, suggesting MI in the absence of obstructive CAD, which is consistent with previous studies. ${ }^{28}$ Potential mechanisms of these $\mathrm{MI}$ with non-obstructive coronary arteries (MINOCA) include coronary artery spasm, transitory thrombotic occlusion with self-lysis, plaque shift with distal embolization, or microvascular disease. ${ }^{29}$ Without CMR, the diagnosis of $\mathrm{MI}$ and corresponding medical therapy may have falsely been missed. 


\section{Limitations}

The results of this trial may not yet be widely applicable because patients with a previous history of myocardial disease and/or other severe (non)cardiac comorbidities were excluded. Referral to ICA was not obligatory nor protocol driven but left at the discretion of the study independent cardiologist. The observation that all patients (100\%) in the routine clinical care arm eventually underwent ICA was not intended nor foreseen but was an interesting observation by itself. Apparently, patients are still considered at sufficiently high risk even in the current hs-cTn era to justify early referral to ICA. Because ICA referral was not dictated by the study protocol, this allowed us to evaluate current practice in the hs-cTn era and at the same time assess the potency of implementing an early non-invasive imaging strategy. Previous registries showed lower rates of ICA, because older patients and those with severe (non)cardiac comorbidities are generally refrained from ICA. ${ }^{21}$ In hindsight and based on more recent data, the estimated $75 \%$ ICA referral rate on which the sample size calculation was based can be considered an underestimate. ${ }^{30}$ However, this could have only minimally affected our main results. Based on the equivalence of groups due to randomization, similarly high intentional referral rates to ICA can be assumed in both non-invasive imaging strategies as compared to the routine clinical care arm if it weren't for the imaging related results. There was no blinding for treatment allocation and referral to ICA was not strictly protocol driven. We cannot exclude that awareness of the randomization influenced behavior of the study-independent cardiologist and contributed to an increased ICA rate in the control arm. However, additional analyses without the routine clinical care arm (Supplemental Table 2) indicated that the CMR- and CTA-first strategies significantly reduced the rate of ICA compared with a situation in which ICA was the default option. Moreover, our comparative effectiveness randomized controlled trial design allows evaluating the overall clinical effects of implementing early CMR and CTA in the diagnostic process. A CTA-first strategy was associated with a substantial increase in cumulative ionizing radiation dose. Although the CMR-first strategy only reduced ICA in one out of eight patients, far less than the CTA-first strategy, both strategies showed a similar trend towards fewer complications compared to routine clinical care. A final conclusion on the most effective strategy is therefore premature and additional cost-effectiveness analysis is needed. This was a single-center study and requires validation in a multicenter setup.

\section{CONCLUSIONS}

In patients with non-ST elevation MI, a novel diagnostic strategy incorporating CMR or CTA first, reduces the number of ICA compared to routine clinical care, while improving appropriate referral to ICA, with no detrimental effect on clinical outcome. 


\section{REFERENCES}

1. Reichlin T, Hochholzer W, Bassetti $S$ et al. Early diagnosis of myocardial infarction with sensitive cardiac troponin assays. N Engl J Med 2009;361:858-67.

2. Shah ASV, Anand A, Sandoval Y et al. High-sensitivity cardiac troponin I at presentation in patients with suspected acute coronary syndrome: a cohort study. Lancet 2015;386:2481-2488.

3. Newby LK, Jesse RL, Babb JD et al. ACCF 2012 expert consensus document on practical clinical considerations in the interpretation of troponin elevations: a report of the American College of Cardiology Foundation task force on Clinical Expert Consensus Documents. J Am Coll Cardiol 2012;60:2427-63.

4. Amsterdam EA, Wenger NK, Brindis RG et al. 2014 AHA/ACC Guideline for the Management of Patients With Non-ST-Elevation Acute Coronary Syndromes: A Report of the American College of Cardiology/ American Heart Association Task Force on Practice Guidelines. J Am Coll Cardiol 2014;24:e139-e228.

5. Roffi M, Patrono C, Collet JP et al. ESC Guidelines for the management of acute coronary syndromes in patients presenting without persistent ST-segment elevation: Task Force for the Management of Acute Coronary Syndromes in Patients Presenting without Persistent ST-Segment Elevation of the European Society of Cardiology (ESC). Eur Heart $J$ 2015;37:267-315.

6. Kim HW, Farzaneh-Far A, Kim RJ. Cardiovascular magnetic resonance in patients with myocardial infarction: current and emerging applications. J Am Coll Cardiol 2009;55:1-16.

7. Melki D, Lugnegård $\mathrm{J}$, Alfredsson $\mathrm{J}$ et al. Implications of Introducing High-Sensitivity Cardiac Troponin T Into Clinical Practice. J Am Coll Cardiol 2015;65:1655-1664

8. Jolly SS, Yusuf $S$, Cairns $J$ et al. Radial versus femoral access for coronary angiography and intervention in patients with acute coronary syndromes (RIVAL): a randomised, parallel group, multicentre trial. Lancet 2011;377:1409-20.

9. Patel MR, Peterson ED, Dai D et al. Low diagnostic yield of elective coronary angiography. $N$ Engl J Med 2010;362:886-95.

10. Mahrholdt H, Wagner A, Judd RM, Sechtem U, Kim RJ. Delayed enhancement cardiovascular magnetic resonance assessment of non-ischaemic cardiomyopathies. Eur Heart J 2005;26:1461-74.

11. Takakuwa KM, Halpern EJ. Evaluation of a "triple rule-out" coronary CT angiography protocol: use of 64-Section CT in low-to-moderate risk emergency department patients suspected of having acute coronary syndrome. Radiology 2008;248:438-46.

12. Cury RC, Shash K, Nagurney JT et al. Cardiac magnetic resonance with T2-weighted imaging improves detection of patients with acute coronary syndrome in the emergency department. Circulation 2008;118:837-44.

13. Hoffmann U, Bamberg F, Chae CU et al. Coronary computed tomography angiography for early triage of patients with acute chest pain: the ROMICAT (Rule Out Myocardial Infarction using Computer Assisted Tomography) trial. J Am Coll Cardiol 2009;53:1642-50.
14. Greenwood JP, Ripley DP, Berry C et al. Effect of Care Guided by Cardiovascular Magnetic Resonance, Myocardial Perfusion Scintigraphy, or NICE Guidelines on Subsequent Unnecessary Angiography Rates: The CE-MARC 2 Randomized Clinical Trial. JAMA 2016;316:1051-1060.

15. Litt HI, Gatsonis C, Snyder B et al. CT angiography for safe discharge of patients with possible acute coronary syndromes. N Engl J Med 2012;366:1393403.

16. Smulders MW, Kietselaer BL, Das M et al. The role of cardiovascular magnetic resonance imaging and computed tomography angiography in suspected non-ST-elevation myocardial infarction patients: Design and rationale of the CARdiovascular Magnetic rEsoNance imaging and computed Tomography Angiography (CARMENTA) trial. Am Heart $\mathrm{J}$ 2013;166:968-75.

17. American College of Cardiology Foundation Task Force on Expert Consensus D, Hundley WG, Bluemke DA et al. ACCF/ACR/AHA/NASCI/SCMR 2010 expert consensus document on cardiovascular magnetic resonance: a report of the American College of Cardiology Foundation Task Force on Expert Consensus Documents. J Am Coll Cardiol 2010;55:2614-62.

18. Raff GL, Chinnaiyan KM, Cury RC et al. SCCT guidelines on the use of coronary computed tomographic angiography for patients presenting with acute chest pain to the emergency department: a report of the Society of Cardiovascular Computed Tomography Guidelines Committee. J Cardiovasc Comput Tomogr 2014;8:254-71.

19. Mettler FA, Jr., Huda W, Yoshizumi TT, Mahesh M. Effective doses in radiology and diagnostic nuclear medicine: a catalog. Radiology 2008;248:254-63.

20. Einstein AJ, Moser KW, Thompson RC, Cerqueira MD, Henzlova MJ. Radiation dose to patients from cardiac diagnostic imaging. Circulation 2007;116:1290-305.

21. Puymirat E, Taldir G, Aissaoui $\mathrm{N}$ et al. Use of invasive strategy in non-ST-segment elevation myocardial infarction is a major determinant of improved long-term survival: FAST-MI (French Registry of Acute Coronary Syndrome). JACC Cardiovasc Interv 2012;5:893-902.

22. Ryan JW, Peterson ED, Chen AY et al. Optimal timing of intervention in non-ST-segment elevation acute coronary syndromes: insights from the CRUSADE (Can Rapid risk stratification of Unstable angina patients Suppress ADverse outcomes with Early implementation of the ACC/AHA guidelines) Registry. Circulation 2005;112:3049-57.

23. Invasive compared with non-invasive treatment in unstable coronary-artery disease: FRISC II prospective randomised multicentre study. FRagmin and Fast Revascularisation during InStability in Coronary artery disease Investigators. Lancet 1999;354:708-15.

24. Fox KA, Poole-Wilson PA, Henderson RA et al. Interventional versus conservative treatment for patients with unstable angina or non-ST-elevation myocardial infarction: the British Heart Foundation RITA 3 randomised trial. Randomized Intervention Trial of unstable Angina. Lancet 2002;360:743-51. 
25. Swahn E, Alfredsson J, Afzal R et al. Early invasive compared with a selective invasive strategy in women with non-ST-elevation acute coronary syndromes: a substudy of the OASIS 5 trial and a meta-analysis of previous randomized trials. Eur Heart J2012;33:51-60.

26. Hirsch A, Windhausen F, Tijssen JG et al. Diverging associations of an intended early invasive strategy compared with actual revascularization, and outcome in patients with non-ST-segment elevation acute coronary syndrome: the problem of treatment selection bias. Eur Heart J 2009;30:645-54.

27. Fanning JP, Nyong J, Scott IA, Aroney CN, Walters $\mathrm{DL}$. Routine invasive strategies versus selective invasive strategies for unstable angina and non-ST elevation myocardial infarction in the stent era. Cochrane Database Syst Rev 2016:CD004815.

28. Tornvall P, Gerbaud E, Behaghel A et al. Myocarditis or "true" infarction by cardiac magnetic resonance in patients with a clinical diagnosis of myocardial infarction without obstructive coronary disease: A meta-analysis of individual patient data. Atherosclerosis 2015;241:87-91.

29. Agewall S, Beltrame JF, Reynolds HR et al. ESC working group position paper on myocardial infarction with non-obstructive coronary arteries. Eur Heart $J$ 2017;38:143-153.

30. Badings EA, Hermanides RS, Van Der Sluis A et al. Use, timing and outcome of coronary angiography in patients with high-risk non-ST-segment elevation acute coronary syndrome in daily clinical practice: insights from a 'real world' prospective registry. Neth Heart J 2019;27:73-80. 


\section{Supplemental Table 1.}

Eligibility criteria.

\section{Inclusion criteria}

- Prolonged symptoms suspected of cardiac origin (angina pectoris or angina

equivalent), and presentation on the cardiac $E D<24$ hours after symptom onset

- Increased levels of high-sensitive cardiac troponin T ( $>14 \mathrm{ng} / \mathrm{L}$ ) (initial blood sample at presentation or a second sample $\geq 3$ hours after presentation)

- $\quad$ Age 18 years -85 years

- Willing and capable to give written informed consent

- Written informed consent

\section{Exclusion criteria}

- Ongoing severe ischemia requiring immediate ICA (at discretion of cardiac ED physician/ cardiologist)

- STEMI (ST-elevation in 2 contiguous leads: $\geq 0.2 \mathrm{mV}$ in men or $\geq 0.15 \mathrm{mV}$ in women in leads $\mathrm{V} 2-\mathrm{V} 3$ and/or $\geq 0.1 \mathrm{mV}$ in other leads or new left bundle branch block)

- Chest pain highly suggestive of non-cardiac origin (as judged by the cardiac ED physician/ cardiologist):

- Acute aortic dissection

- Acute pulmonary embolism (high risk patient defined as Wells score $>6$ )

- Musculoskeletal or gastro-intestinal pain

- Other (pneumothorax, pneumonia, rib fracture, etc.)

- Type II myocardial infarction

- Atrial fibrillation

- Tachycardia ( $\geq 100 / \mathrm{bpm})$

- Severe hypertension $(>200 / 110 \mathrm{mmHg})$

- Aortic valve stenosis (AVA $\leq 1.5 \mathrm{~cm} 2$ )

- Shock (mean arterial pressure $<60 \mathrm{mmHg}$ )

- Severe heart failure (Killip Class $\geq$ III)

- Anemia $(<5.6 \mathrm{mmol} / \mathrm{L})$

- Untreated hyperthyroidism

- Life threatening arrhythmia on or prior to presentation (sustained ventricular tachycardia, repetitive non-sustained ventricular tachycardia, ventricular fibrillation, sino-artial or atrio-ventricular block)

- Previously known CAD, defined as:

- Any non-invasive diagnostic imaging test positive for CAD (stress induced wall motion abnormalities or perfusion defects)

- Coronary stenosis $>50 \%$ on any previous ICA or CTA

- Previous myocardial infarction

- Previous coronary artery revascularization (PCI and/or $\mathrm{CABG})$

- Known cardiomyopathy (dilated, hypertrophic, infiltrative, etc.)

- Pregnancy

- $\quad$ Life expectancy $<1$ year (malignancy, etc.)

- $\quad$ Contraindications to CMR

- Metallic implant (ferromagnetic implants e.g. vascular clip, neuro-stimulator, cochlear implant)

- Pacemaker or implantable cardiac defibrillator

- Claustrophobia

- Body weight $>130 \mathrm{~kg}$

- Contraindication to CMR or CTA contrast agent (Gadolinium or lodine):

- Renal failure (estimated GFR $\leq 30 \mathrm{~mL} / \mathrm{min} / 1,73 \mathrm{~m} 2$ ) / chronic renal failure stage 4-5

- Known severe contrast allergy (patient with mild allergy is eligible for inclusion when pre-medication according to hospital guidelines can be administered) 
- Contraindication to adenosine

- High degree atrio-ventricular block (2nd or 3rd degree)

- Severe asthma bronchiale

- Chronic obstructive pulmonary disease GOLD $\geq$ III

- Concomitant use of dipyridamole (Persantin)

- Long QT syndrome (congenital)

Abbreviations: $A V A=$ aortic valve area; $C A B G=$ coronary artery bypass grafting; $C A D=$ coronary artery disease; $\mathrm{CMR}=$ cardiovascular magnetic resonance; $\mathrm{CTA}=$ computed tomography angiography; $\mathrm{ED}=$ emergency department; GFR = glomerular filtration rate; ICA = invasive coronary angiography; $\mathrm{PCI}=$ percutaneous coronary intervention; STEMI = ST-elevation myocardial infarction.

\section{Supplemental Table 2.}

Proportion of patients in whom invasive coronary angiography was performed during initial admission for CMR or CTA first without the control group.

\begin{tabular}{l|l|l} 
& Non-invasive imaging strategy & \\
\hline ICA referral rate & CMR first & CTA first \\
\hline $\mathbf{( 9 5 \% ~ C l ) ~}$ & $87 \%$ & $66 \%$ \\
\hline
\end{tabular}

Abbreviations: $\mathrm{Cl}=$ confidence interval; $\mathrm{CMR}=$ cardiovascular magnetic resonance; $\mathrm{CTA}=$ computed tomography angiography ; ICA = invasive coronary angiography. 


\section{Supplemental Figure 1.}

Patient flow based on imaging results and corresponding ICA findings.

A Cardiovascular magnetic resonance arm

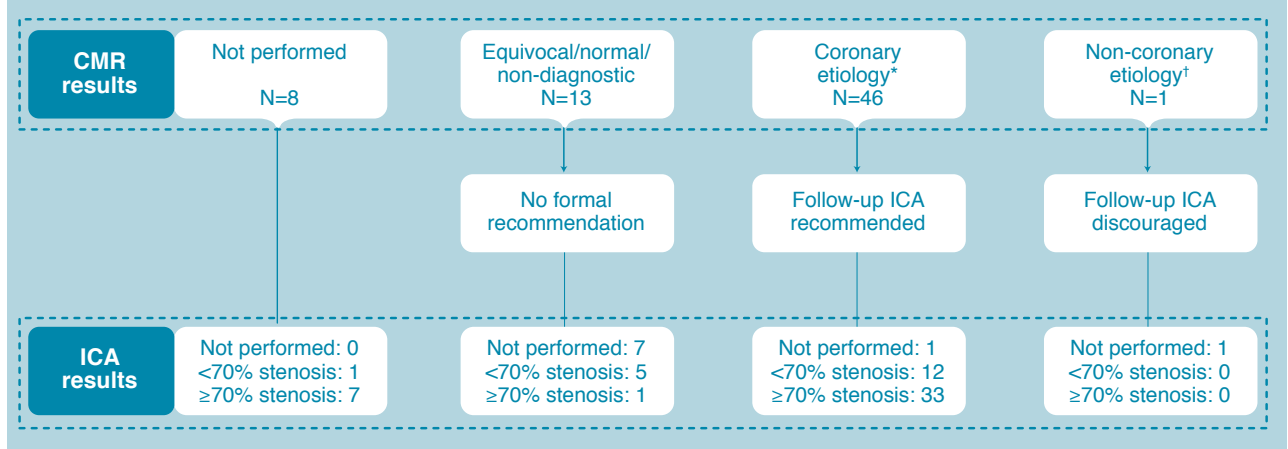

* Coronary etiology was defined as: subendocardial or transmural hyperenhancement on delayed enhancement CMR in the territory of a coronary artery with/without regional wall motion abnormalities on cine-CMR, with/ without obvious increased signal intensity on T2-weighted-CMR, and/or a subendocardial or transmural perfusion defect corresponding to the distribution territory of a coronary artery during rest and/or stress perfusion

${ }^{\dagger}$ Non-coronary etiology included: (peri-) myocarditis, Takotsubo cardiomyopathy, pulmonary embolism, dilated cardiomyopathy, hypertrophic cardiomyopathy

CMR = cardiovascular magnetic resonance; ICA = invasive coronary angiography.

\section{B Computed tomography angiography arm}

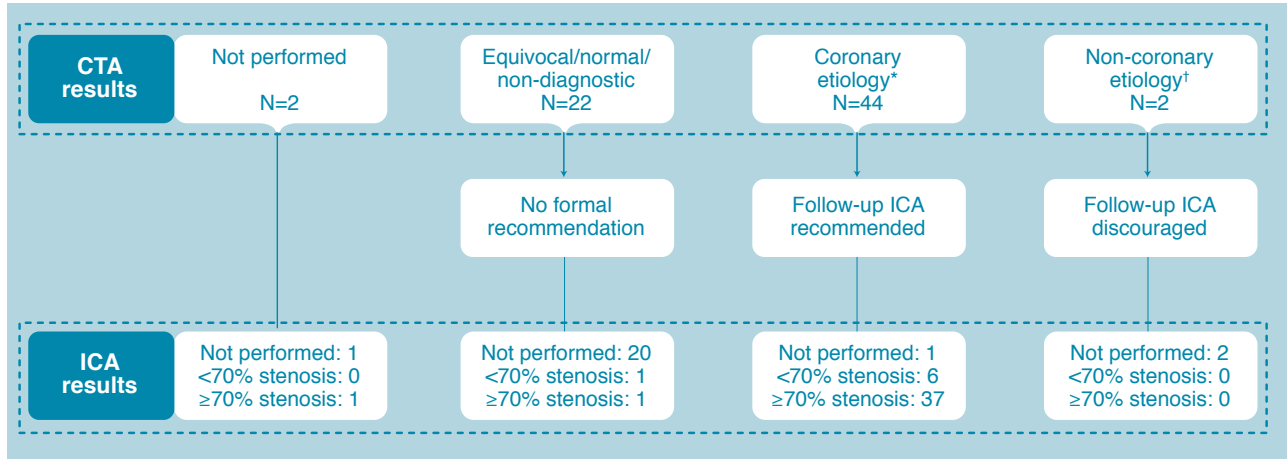

*Coronary etiology was defined as: obstructive coronary artery disease, defined as $\geq 70 \%$ luminal narrowing in any epicardial coronary artery, or Agatston score $\geq 1,000$ in the absence of extra-cardiac findings such as acute aortic dissection or pulmonary embolism ${ }^{\dagger}$ Non-coronary etiology included: pulmonary embolism, aortic dissection CTA = computed tomography angiography; ICA = invasive coronary angiography. 
Supplemental Figure 2.

Kaplan-Meier estimates of the secondary safety endpoints for 1-month follow-up.

A

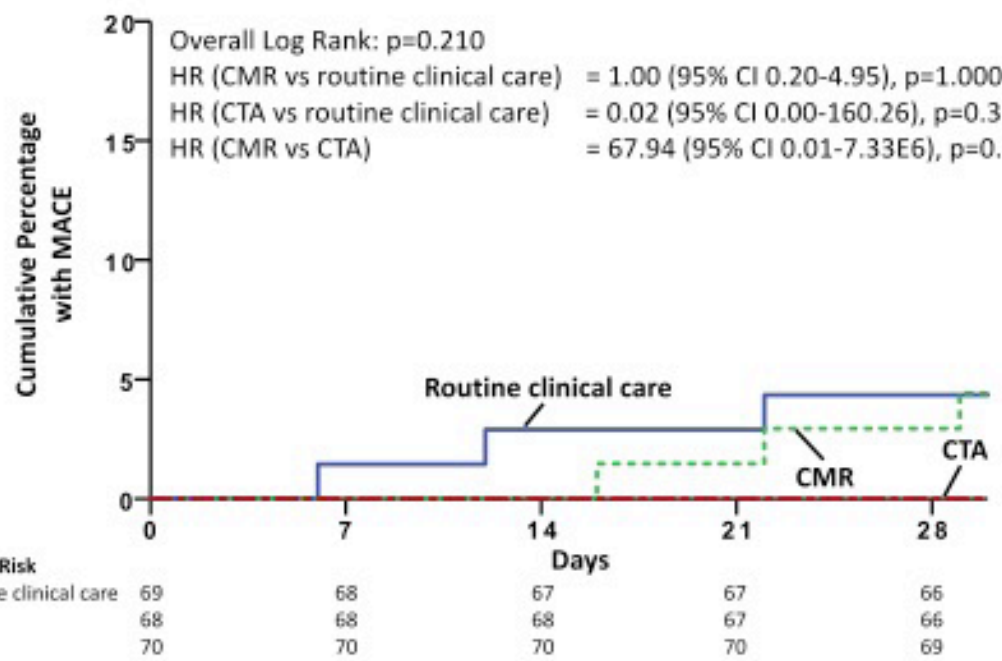

B

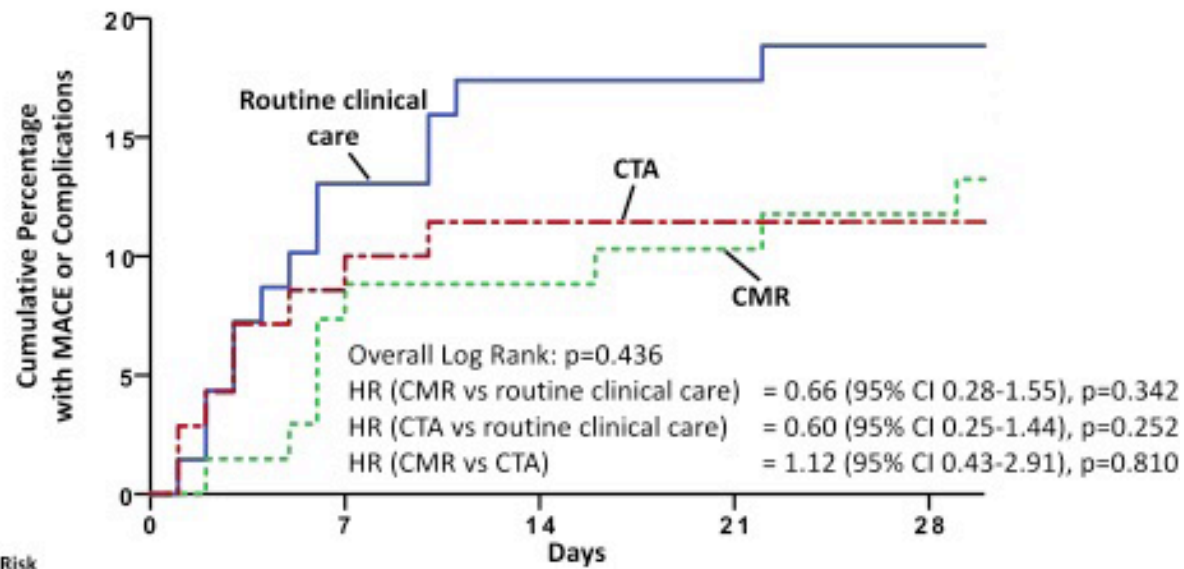

No, at Risk

Routine clinical care 69

CMR 68

CTA

68
70

60

57

$62-62$

$63 \quad 62$

$\begin{array}{ll}57 & 56 \\ 61 & 60 \\ 62 & 61\end{array}$

The secondary safety endpoint (Panel A) was MACE, ie. a composite of all-cause mortality, recurrent myocardial infarction, revascularization not planned during the index event (percutaneous coronary intervention and/or coronary artery bypass grafting) or congestive heart failure requiring hospitalization. Panel $B$ shows a composite of MACE and other adverse events. Abbreviations: $\mathrm{CMR}=$ cardiovascular magnetic resonance; CTA = cardiac computed tomography angiography; HR = hazard ratio; ICA = invasive coronary angiography; MACE = major adverse cardiac events. 


\section{Editorial Comment}




\section{Up-front noninvasive imaging in low-risk NSTEMI An old keeper at a new gate}

Admir Dedic, MD, PhD, ${ }^{1,2}$ Murat Arslan, MD, ${ }^{1,2}$ Joseph S. Alpert, MD ${ }^{3}$

Department of ${ }^{1}$ Cardiology, ${ }^{2}$ Radiology and Nuclear Medicine, Erasmus Medical Center, Rotterdam, the Netherlands, and department of ${ }^{3}$ Medicine, University of Arizona College of Medicine, Tucson, Arizona, USA 
The introduction of high-sensitivity troponin (hs-cTn) assays has changed our perspective on myocardial infarction (MI) and the way we practice medicine. These new assays detect smaller amounts of myocardial injury in a shorter time. Their role is essential in patients with acute chest pain and a normal or inconclusive electrocardiogram (ECG). ${ }^{1}$ In the case of serial low hs-cTn levels, one can assume that there is no myocardial injury and the chances of finding $\mathrm{Ml}$ are therefore very low. Patients with serial low hs-cTn values and no other alarming findings can be sent home safely after exclusion of other life-threatening conditions, and generally they have a good prognosis. ${ }^{2,3}$

However, the improved sensitivity in detecting myocardial injury has come with a reduced specificity for the diagnosis of MI. Elevated hs-cTn levels indicate myocardial injury but not the underlying pathologic mechanism. Ml, itself further divided in 5 subtypes, is part of the spectrum of myocardial injury. ${ }^{4}$ Boundaries between infarction and injury have become more vague, and in patients with acute chest pain, slightly elevated troponin levels, and no other clinical clues, it can be challenging to determine the underlying etiology. In these cases, it is important to differentiate between MI type 1 (caused by atherosclerotic plaque disruption), MI type 2 (oxygen supply and demand imbalance), and nonischemic myocardial injury (structural myocardial disease not caused by ischemia) because each of these entities requires a different approach.

It is estimated that up to one-third of patients with acute chest pain and a normal or inconclusive ECG will still have an unclear diagnosis after hs-cTn sampling. ${ }^{5}$ Performing invasive coronary angiography (ICA) routinely to test for the presence of significant coronary artery disease is not without risk and is costly. Most important, it is probably unnecessary because almost one-half of patients will have a diagnosis of type $2 \mathrm{Ml}$ or a nonischemic myocardial injury. ${ }^{6}$ Because the number of hs-cTn positive patients is increasing and our medical resources have limits, we are compelled to seek a more efficient yet safe diagnostic approach.

An attractive strategy is to use noninvasive imaging up front as a gatekeeper for ICA. In this issue of the Journal, Smulders et al. ${ }^{7}$ investigated whether a first-step diagnostic strategy with cardiac magnetic resonance (CMR) imaging or coronary computed tomography angiography (CTA) would improve diagnostic efficiency in patients with acute chest pain and elevated hs-cTn levels, but no indication for urgent ICA. The authors randomized 207 patients to either routine care or 1 of the 2 noninvasive imaging arms. The results of CMR and coronary CTA were then sent to the respective patient's attending physician with the expectation that patients with minimal or no obstructive coronary artery disease could avoid ICA. Implementing CMR or CTA as a first step reduced the rate of ICA to $87 \%$ and $66 \%$, respectively, without compromising safety (defined as all-cause mortality, recurrent $\mathrm{MI}$, unplanned coronary revascularization after the index event, or heart failure requiring hospitalization within 1 year). Additionally, 33 of 49 patients $(67 \%)$ in whom the diagnosis remained unknown in the 2 non-CMR arms eventually also underwent CMR. A new and clinically relevant diagnosis was found in 16 patients. In the same way, 5 of 40 patients with no clear diagnosis in the non-CTA arms underwent CTA at a later stage, revealing 1 new and clinically relevant diagnosis. A first-step strategy with coronary CTA was associated with a higher radiation dose (13.0 mSv vs. 4.1 and $4.9 \mathrm{mSv}$ for the CMR and ICA groups, respectively).

It is of interest that a negative coronary CTA report was more effective than a similar CMR message at convincing attending physicians to forgo ICA, which in part might be explained by the fact that coronary CTA and ICA are both anatomic modalities. In patients with an unclear diagnosis after initial testing, CMR proved to be more useful because this functional modality also visualizes structural abnormalities resulting in myocardial injury. 
The authors are to be congratulated on their work because they address an important clinical dilemma and open the floor for a discussion on this topic. Their study has a number of strengths such as the randomized assignment of patients to an initial noninvasive gatekeeping strategy while allowing a real-world process of clinical decision making to determine the diagnostic and treatment protocol for each patient. Potential weaknesses might be that the treatment strategy was not determined before randomization and the surprisingly high referral rate to ICA of $100 \%$ in the routine care arm. Also, individuals with known pre-existing coronary artery disease were excluded from the trial. These individuals should be the subject for a follow-up investigation in our opinion. Finally, a cost-benefit analysis would be of interest in determining how much economic benefit might accrue from similar "noninvasive study first" protocols.

Previous experiences with up-front noninvasive imaging largely date from the conventional troponin era, in which they were used to rule out $\mathrm{Ml}$ in patients with acute chest pain and normal troponin levels. ${ }^{8,9}$ In the era of hs-cTn, ruling out of MI with noninvasive imaging has become redundant as the negative predictive value of serial low hs-cTn levels approaches $100 \%{ }^{2,10}$ Noninvasive imaging is now gradually being used in low-risk, hs-cTn-positive patients with a normal or inconclusive ECG to try to avoid unnecessary referral to ICA. Future studies will determine whether this is safe and efficient. In this regard, it may be more sensible to combine the strengths of different noninvasive imaging modalities, rather than trying to appoint 1 gatekeeper. As an anatomic modality, coronary CTA is an attractive noninvasive alternative for ICA. At the same time, CMR, with its tissue-characterization abilities, can assess for etiologies that are not detected by coronary CTA or echocardiography. A stepwise noninvasive strategy consisting of echocardiography, coronary CTA, and CMR might well be the answer we are looking for. 


\section{REFERENCES}

1. Roffi M, Patrono C, Collet JP, et al. 2015 ESC guidelines for the management of acute coronary syndromes in patients presenting without persistent ST-segment elevation: Task Force for the Management of Acute Coronary Syndromes in Patients Presenting without Persistent ST-Segment Elevation of the European Society of Cardiology (ESC). Eur Heart J 2016;37:267-315.

2. Twerenbold R, Neumann JT, Sorensen NA, et al. Prospective validation of the $0 / 1-\mathrm{h}$ algorithm for early diagnosis of myocardial infarction. J Am Coll Cardiol 2018;72:620-32.

3. Chapman AR, Lee KK, McAllister DA, et al. Association of high-sensitivity cardiac troponin I concentration with cardiac outcomes in patients with suspected acute coronary syndrome. JAMA 2017;318:1913-24.

4. Thygesen K, Alpert JS, Jaffe AS, et al. Fourth universal definition of myocardial infarction (2018). J Am Coll Cardiol 2018;72:2231-64.

5. Twerenbold R, Boeddinghaus J, Nestelberger T, et al. Clinical use of high-sensitivity cardiac troponin in patients with suspected myocardial infarction. J Am Coll Cardiol 2017;70:996-1012.

6. Shah ASV, Sandoval Y, Noaman A, et al. Patient selection for high sensitivity cardiac troponin testing and diagnosis of myocardial infarction: prospective cohort study. BMJ 2017;359:j4788.

7. Smulders MW, Kietselaer BLJH, Wildberger JE, et al. Initial imaging-guided strategy versus routine care in patients with non-ST-segment elevation myocardial infarction. J Am Coll Cardiol 2019;74:2466-77.

8. Ingkanisorn WP, Kwong RY, Bohme NS, et al. Prognosis of negative adenosine stress magnetic resonance in patients presenting to an emergency department with chest pain. J Am Coll Cardiol 2006;47:1427-32.

9. Hoffmann U, Truong QA, Schoenfeld DA, et al. Coronary CT angiography versus standard evaluation in acute chest pain. N Engl J Med 2012;367: 299-308.

10. Dedic A, Lubbers MM, Schaap J, et al. Coronary CT angiography for suspected ACS in the era of highsensitivity troponins: randomized multicenter study. J Am Coll Cardiol 2016;67:16-26. 


\section{Performance of CMR methods for differentiating acute from chronic myocardial infarction}

Martijn W. Smulders, MD, ${ }^{1}$ Sebastiaan C.A.M. Bekkers, MD, PhD, ${ }^{1}$ Han W. Kim, MD, ${ }^{2,3}$ Lowie M.R. Van Assche, MD, ${ }^{2}$ Michele A. Parker, MS, ${ }^{2}$ Raymond J. Kim, MD ${ }^{2,3,4}$

Department of ${ }^{1}$ Cardiology, Maastricht University Medical Center, Maasticht, The Netherlands, and ${ }^{2}$ Duke Cardiovascular Magnetic Resonance Center, department of ${ }^{3}$ Cardiology and ${ }^{4}$ Radiology, Duke Cardiovascular Magnetic Resonance Center, Durham, North Carolina, USA 


\section{ABSTRACT}

\section{Objectives}

The purpose of this study was to assess the performance of cardiac magnetic resonance (CMR) methods for discriminating acute from chronic myocardial infarction (MI).

\section{Background}

Although T2-weighted CMR is thought to be accurate in differentiating acute from chronic MI, few studies have reported on diagnostic accuracy, and these generally compared extremes in infarct age (e.g., $<1$ week old vs. more than 6 months old) and did not evaluate other CMR methods that could be informative.

\section{Methods}

A total of 221 CMR studies were performed at various time points after ST-segment elevation myocardial infarction in 117 consecutive patients without a history of $\mathrm{MI}$ or revascularization enrolled prospectively at 2 centers. Imaging markers of acute $\mathrm{MI}(<1$ month) were T2 hyperintensity on double inversion recovery turbo spin echo (DIR-TSE) images, microvascular obstruction (MO) on delayed-enhancement CMR, and focally increased end-diastolic wall thickness (EDWT) on cine-CMR.

\section{Results}

The prevalence of T2-DIR-TSE hyperintensity decreased with infarct age but remained substantial up to 6 months post-MI. In contrast, the prevalence of both MO and increased EDWT dropped sharply after 1 month. T2-DIR-TSE sensitivity, specificity, and accuracy for identifying acute $\mathrm{MI}$ were $88 \%, 66 \%$, and $77 \%$ compared with $73 \%, 97 \%$, and $85 \%$, respectively, for the combination of MO or increased EDWT. On multivariable analysis, persistence of T2-hyperintensity in intermediate-age infarcts ( 1 to 6 months old) was predicted by larger infarct size, diabetes, and better T2-DIR-TSE image quality score. For infarct size $\geq 10 \%$ of the left ventricle, a simple algorithm incorporating all CMR components allowed classification of infarct age into 3 categories ( $<1$ month old, 1 to 6 months old, and $\geq 6$ months old) with $80 \%$ ( $95 \%$ confidence interval: $73 \%$ to $87 \%$ ) accuracy.

\section{Conclusions}

T2-DIR-TSE hyperintensity is specific for infarcts $<6$ months old, whereas $\mathrm{MO}$ and increased EDWT are specific for infarcts $<1$ month old. Incorporating multiple CMR markers of acute MI and their varied longevity leads to a more precise assessment of infarct age. 


\section{INTRODUCTION}

It is vital to determine whether a myocardial infarction (MI) is recent or chronic because there are implications for patient management and prognosis. The determination, however, can be challenging because acute $\mathrm{MI}$ is often clinically unrecognized, and if testing is delayed 1 to 2 weeks, diagnostic electrocardiographic changes and elevated biomarkers have usually resolved. ${ }^{1}$

T2-weighted cardiac magnetic resonance (CMR) can detect necrosis-associated myocardial edema, and recent expert reviews and consensus guidelines have touted this technique as an excellent method to distinguish acute from chronic Ml. ${ }^{2-4}$ However, the time frame for detecting "acute" T2-weighted CMR changes is unclear, and, to date, only 3 studies have reported on diagnostic performance in 54,50 , and 46 patients, respectively. ${ }^{5-7}$ Moreover, these studies have the potential limitation of spectrum bias in that enrolled patients generally had extremes in infarct age (e.g., $<1$ week vs. more than 6 months). Hence, the diagnostic utility of T2-weighted CMR requires additional validation, especially in patients with intermediate-age infarcts.

Additionally, other CMR markers may be useful in discriminating acute from chronic MI, including the presence of microvascular obstruction (MO) on delayed-enhancement (DE)-CMR and focally increased end-diastolic wall thickness (EDWT) on cine CMR. The utility of these methods in comparison with T2-weighted techniques has not been previously reported.

The purpose of the present 2-center study was to examine the diagnostic performance of CMR methods in differentiating acute from chronic MI. Unlike previous reports, we: 1) included patients with intermediate-age infarcts ( 1 to 6 months old); 2) compared multiple CMR methods that could be informative; and 3 ) incorporated an assessment of image quality to help distinguish potentially artifactual from true findings.

\section{METHODS}

\section{Population}

We prospectively recruited 122 patients with a first-time ST-segment elevation myocardial infarction (STEMI) at 2 centers (Maastricht University Medical Center, Maastricht, the Netherlands; Duke Cardiovascular Magnetic Resonance Center, Durham, North Carolina). The diagnosis of STEMI required appropriate cardiac biomarkers with 12-lead electrocardiography showing ST-segment elevation ( $\geq 0.2 \mathrm{mV}$ in 2 or more contiguous precordial leads or $\geq 0.1 \mathrm{mV}$ in $\geq 2$ contiguous limb leads). ${ }^{1}$ Consecutive patients admitted for primary $\mathrm{PCl}$ who agreed to undergo CMR were enrolled. Patients with previous MI, revascularization, or CMR contraindications were excluded. CMR was performed for research, and results were not used for clinical decision making. Four patients did not complete CMR (hemodynamic instability or claustrophobia); 1 had recurrent MI before CMR and was excluded. No patient was excluded because of image quality. The final population consisted of 117 patients. Because of scheduling, 5 did not undergo scanning for 1 month. Hence, 112 underwent $\mathrm{CMR}<1$ month after acute MI. Eighty-six and 23 patients underwent scans 1 to 6 months and $\geq 6$ months post-AMI, respectively (total of 221 scans). In patients with multiple scans, there were no cardiac events between scans. The ethics board at both sites approved the study; all patients gave written informed consent.

Admission data including medications were recorded. Coronary angiograms were reviewed to assess infarct-related-artery (IRA) reperfusion. Thrombolysis In Myocardial Infarction (TIMI) flow grade was scored as follows: $0=$ absence of flow; 1 = faint flow with incomplete filling; $2=$ delayed flow with complete filling; 3 = normal flow. ${ }^{8}$ 


\section{Cardiovascular magnetic resonance}

Scanners (1.5-T, Philips Intera, Best, the Netherlands or Siemens Avanto, Erlangen, Germany) with standard protocols were used. Cine images were acquired in multiple short-axis and 3 long-axis views using steady-state free precession (slice thickness, $6 \mathrm{~mm}$; gap, $4 \mathrm{~mm}$; in-plane resolution, $\approx 1.7 \times 1.4 \mathrm{~mm}$ ). A short-axis stack of T2-weighted images encompassing the left ventricle and matched in location with cine images was obtained using a double inversion recovery turbo spin echo (DIR-TSE) sequence (repetition time, 2 R-R intervals; echo time, 100 $\mathrm{ms}$ [Philips], $80 \mathrm{~ms}$ [Siemens]; slice thickness, $8 \mathrm{~mm}$; gap, $2 \mathrm{~mm}$; in-plane resolution, $\approx 1.9 \times 1.4$ ) with spectrally selective fat suppression and vendor-supplied coil-intensity correction. A conventional black-blood sequence was used so that findings could be placed in context with previous studies reporting diagnostic performance. ${ }^{5-7}$ Additionally, black-blood sequences are the most commonly used in clinical practice because they are commercially available from all magnetic resonance imaging scanner vendors. Delayed enhancement imaging was performed using a segmented inversion recovery sequence, 10 to 20 min after 0.15 to $0.20 \mathrm{mmol} / \mathrm{kg}$ gadolinium contrast (gadolinium-diethylenetriaminepentaacetic acid or gadoversetamide).

\section{Image Analysis}

Scans were interpreted in random order by consensus of 3 observers blinded to patient identity, clinical data, and CMR date. Three separate interpretations were performed, weeks apart: first, with only T2-DIR-TSE images available; second, with only cine-CMR and DE-CMR images available; and third, with all components available. Standard quantitative assessments were performed to measure infarct size and left ventricular (LV) ejection fraction based on manual planimetry of DE-CMR and cine-CMR images, respectively.

Prespecified imaging markers. The presence and location of CMR abnormalities were determined visually using the 17-segment model. Window and level were preset according to society guidelines so that noise was still detectable and infarcted regions were not overly saturated. ${ }^{9}$ The following were used as markers of acute $\mathrm{Ml}: 1$ ) hyperintense myocardium on T2-DIR-TSE; 2) the presence of MO on DE-CMR (central hypoenhancement within hyperenhancement); and 3) increased EDWT on cine-CMR ( $>150 \%$ of remote, measured in the segment with most severe dysfunction). Regional wall thinning (EDWT $<50 \%$ of remote) was also noted. ${ }^{10}$ In patients with T2-DIR-TSE hyperintensity both $<1$ month and 1 to 6 months post-AMI, quantitative analysis of signal intensity ratio and contrast-to-noise ratio (CNR) were performed: signal intensity $(\mathrm{SI})$ ratio $=\left(\right.$ mean $\mathrm{SI}_{\text {hyperintense area }} /$ mean $\left.\mathrm{SI}_{\text {remote area }}\right)$ and CNR $=\left(\right.$ mean $\mathrm{SI}_{\text {hyperintense area }}$ - mean $\left.\mathrm{SI}_{\text {remote area }}\right) /\left(1.5 \times \mathrm{SD}\right.$ of background signal outside body). ${ }^{11}$

Match with IRA. Angiograms were analyzed blinded to the identity and CMR to localize the IRA perfusion territory on the 17-segment model. ${ }^{12}$ The location of the CMR abnormality was considered correct if the number of segments with CMR abnormality within the IRA was greater than that outside the IRA.

Image quality was graded as follows: 0 = equivocal: major artifacts, diagnosis uncertain; 1 = satisfactory: minor artifacts, images interpretable; 2 = excellent: high diagnostic confidence. The presence and location of slow-flow (nonsuppressed blood signal adjacent to endocardium) and signal dropout (myocardial signal similar to noise) artifacts were scored using the 17-segment model.

\section{Statistical Analysis}

Continuous data are reported as mean $\pm \mathrm{SD}$. Comparisons of continuous data were made using 2-sample or paired Student t-tests. Comparisons of discrete data were made using chi-square tests. The prevalence of CMR abnormalities according to infarct age was assessed using the 
chi-square test for trend. McNemar's test was used to compare diagnostic performance. To identify characteristics associated with T2-DIR-TSE hyperintensity, univariable logistic regression analysis was performed. Characteristics with a $p$-value $<0.1$ were considered candidates for subsequent multivariable analysis. Final model variables were determined by stepwise selection. Statistical tests were 2 tailed; $p<0.05$ was considered significant (SAS version 9.3, SAS Institute, Cary, North Carolina).

\section{RESULTS}

\section{Population}

The baseline clinical characteristics are shown in Table 1 (60\% and 40\% enrolled at Maastricht University and Duke University, respectively). Overall, patients had moderate infarct size $(15.7 \pm 10.8 \%)$ and preserved LV ejection fraction (48.6 $\pm 10.3 \%)$.

\section{Prevalence of CMR Abnormalities}

T2-DIR-TSE. The prevalence of T2-hyperintensity was high (88\%) during the first month post-MI (Figure 1A). Of the $13(12 \%)$ that did not have T2- hyperintensity during the first month, 12 had small infarcts $(<10 \% \mathrm{LV})$ or poor image quality. The prevalence of T2-hyperintensity then steadily decreased with infarct age, but was still $33 \%$ for Mls 3 to 6 months old and $17 \%$ for Mls $\geq 6$ months old. After discounting hyperintense regions that were remote from the IRA territory and thus likely artifactual, the prevalence decreased to $4 \%$ for Mls $\geq 6$ months old, but remained relatively high at $32 \%$ for Mls 3 to 6 months old (Figure 1B). Patient examples with persistent T2-hyperintensity in intermediate-age infarcts are shown in Figure 2.

Figure 1.

Prevalence of T2-DIR-TSE hyperintensity at different time-points post-myocardial infarction.

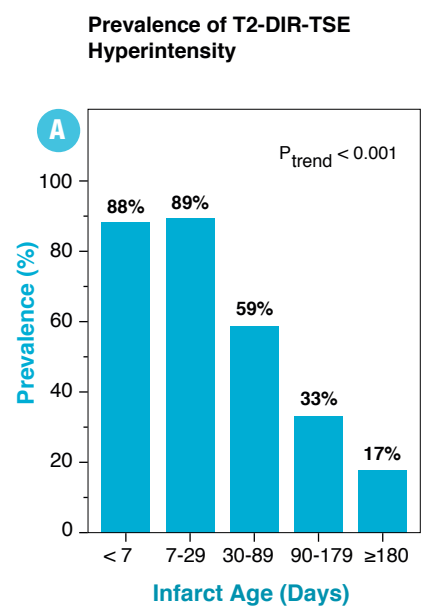

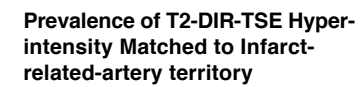

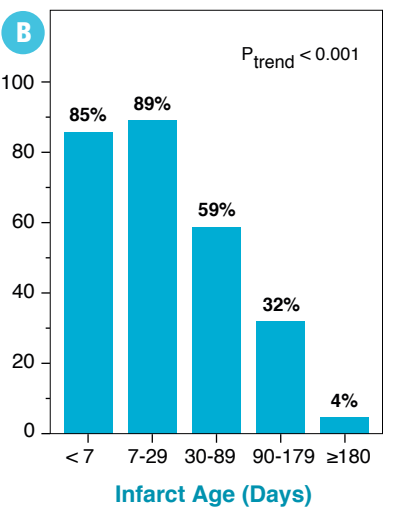

Prevalence of T2-DIR-TSE Hyperintensity in Scans with Satisfactory/ Excellent Image Quality

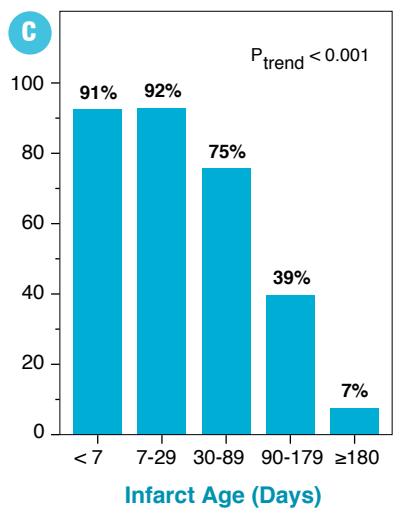

(A) All scans. (B) Only scans with T2-hyperintense regions that match the infarct-related artery determined by angiography included. (C) Only scans with satisfactory or excellent image quality included. T2-DIR-TSE = T2-weighted double inversion recovery turbo spin echo. 
Table 1.

Baseline Patient Characteristics.

\begin{tabular}{|c|c|}
\hline Age (Years) & $57.8 \pm 11.1$ \\
\hline Male Gender & $98(83.8 \%)$ \\
\hline \multicolumn{2}{|l|}{ Clinical History } \\
\hline \multicolumn{2}{|c|}{ Coronary Artery Disease Risk Factors } \\
\hline Hypertension & $49(41.9 \%)$ \\
\hline Diabetes & $12(10.3 \%)$ \\
\hline Hypercholesterolemia & $47(40.2 \%)$ \\
\hline Positive Family History & $55(47.0 \%)$ \\
\hline Smoking & $91(77.8 \%)$ \\
\hline Number of Risk Factors & $2.2 \pm 1.0$ \\
\hline \multicolumn{2}{|c|}{ Medications During AMI Hospitalization } \\
\hline Aspirin & $115(98.3 \%)$ \\
\hline Beta-Blocker & $114(97.4 \%)$ \\
\hline ACE-Inhibitor & $99(84.6 \%)$ \\
\hline Statin & $116(99.1 \%)$ \\
\hline Thienopyridine & $108(92.3 \%)$ \\
\hline Glycoprotein IlbIlla Inhibitor & $27(23.1 \%)$ \\
\hline \multicolumn{2}{|l|}{ Cardiac Enzymes* } \\
\hline Peak Troponin T $(\mu \mathrm{g} / \mathrm{L})$ & $5.3 \pm 4.4$ \\
\hline Peak CK-MB (U/L) & $177.3 \pm 129.5$ \\
\hline \multicolumn{2}{|l|}{ Cardiac Catheterization } \\
\hline \multicolumn{2}{|l|}{ Number of Diseased Vessels $†$} \\
\hline One & $61(52.1 \%)$ \\
\hline Two & $29(24.8 \%)$ \\
\hline Three & $27(23.1 \%)$ \\
\hline \multicolumn{2}{|l|}{ Infarct Related Artery } \\
\hline RCA & $55(47.0 \%)$ \\
\hline LAD & 42 (35.9\%) \\
\hline LCx & $20(17.1 \%)$ \\
\hline \multicolumn{2}{|l|}{ TIMI-3 Flow } \\
\hline Pre-procedure & $21(17.9 \%)$ \\
\hline Final & $104(88.9 \%)$ \\
\hline
\end{tabular}

Values are mean \pm SD or $\mathrm{n}(\%)$. *Five patients had troponin I measurements. †Significant coronary artery disease defined as $>70 \%$ stenosis. ACE = angiotensin-converting-enzyme; $\mathrm{AMI}=$ acute myocardial infarction; CK-MB =creatine kinase-myocardial band; LAD = left anterior descending artery; $L C x=$ left circumflex artery; RCA = right coronary artery; TIMI = Thrombolysis In Myocardial Infarction. 
Figure 2.

Patient Examples.

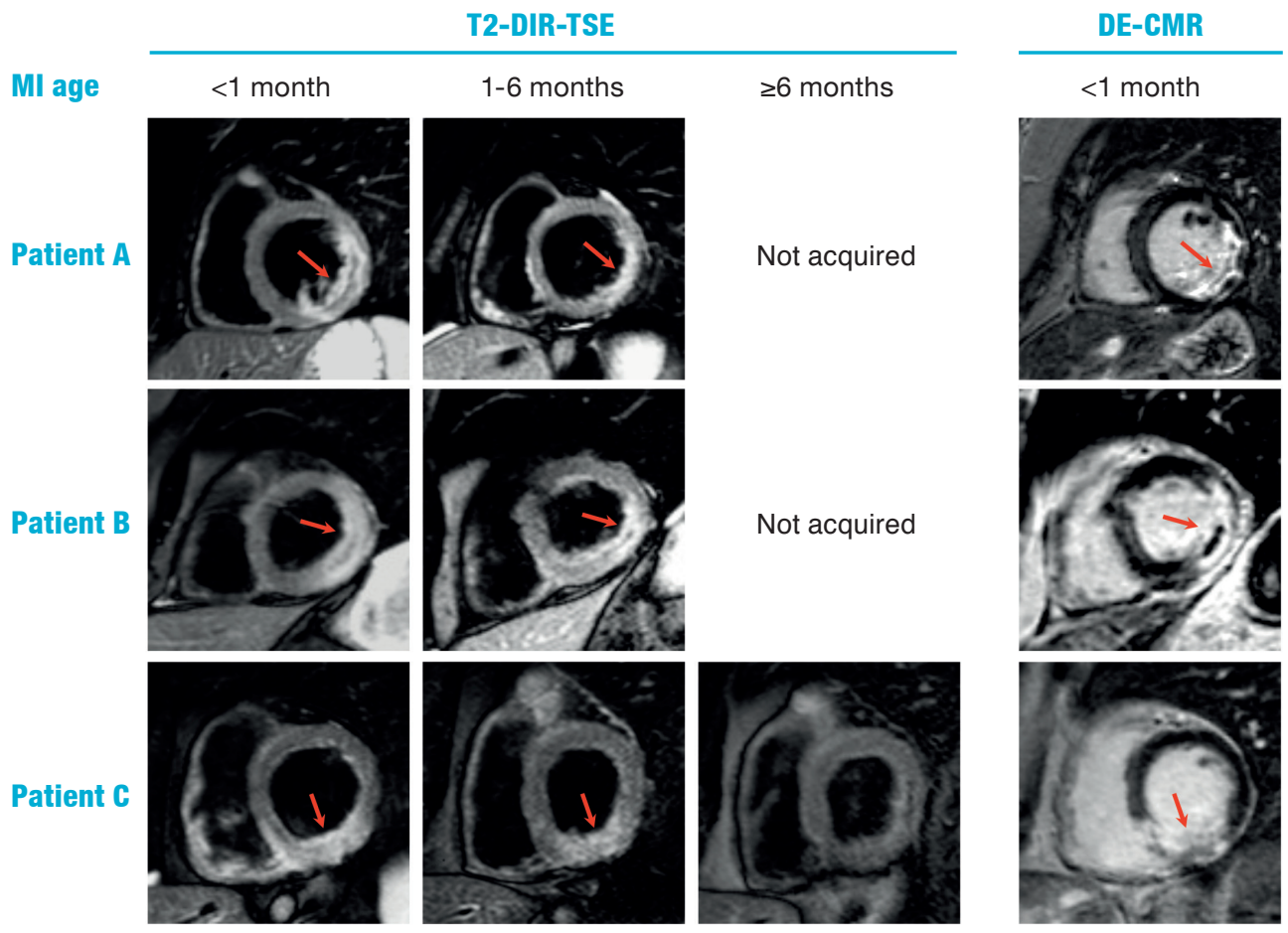

Examples demonstrating that T2-DIR-TSE hyperintensity (arrows) seen acutely ( $<1$ month) can persist when reimaged 1 to 6 months post-MI. In all 3, T2-hyperintense regions match the location of DE-CMR hyperenhancement (arrows).

$\mathrm{DE}-\mathrm{CMR}=$ delayed-enhancement cardiac magnetic resonance; $\mathrm{MI}=$ myocardial infarction; T2-DIR-TSE =T2-weighted double inversion recovery turbo spin echo.

DE-CMR and Cine-CMR. Examples of MO and regionally increased EDWT are shown in Figure 3A. Even early post-MI, the prevalence of $\mathrm{MO}$ and increased EDWT were moderate, and both decreased sharply with infarct age (Figure 3B). In all cases, MO and increased EDWT were located in the correct IRA territory. The combination of MO or increased EDWT allowed a higher detection rate of Mls $<1$ month old $(73 \%$ vs. $55 \%$ for $\mathrm{MO}$ alone and $42 \%$ for increased EDWT alone) without significantly increasing the detection rate of Mls $\geq 1$ month old. The prevalence of regional wall thinning steadily increased with infarct age; however, given that $6 \%$ of infarcts $<1$ week old had wall thinning, it was not an absolute marker of chronic MI, nor was it sensitive for chronic MI in that only $35 \%$ of infarcts $\geq 6$ months old had thinning.

Effect of Image Quality. Of T2-DIR-TSE images, 66\% were graded satisfactory or excellent compared with $92 \%$ and $93 \%$ for DE-CMR and cine-CMR, respectively (Figure 4A). T2-DIR-TSE slow-flow artifact was usually apical, whereas signal dropout was often inferolateral; however, any location could be affected (Figure 4B). When only scans with 
Figure 3.

Prevalence of microvascular obstruction and increased end-diastolic wall-thickness.

(A)

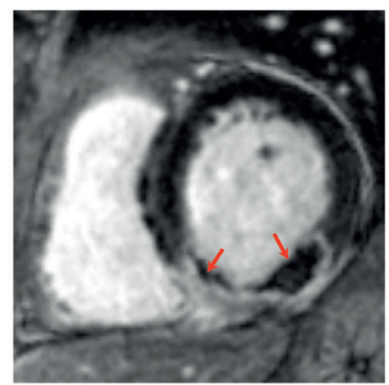

DE-CMR

Microvascular

Obstruction (MO)
Cine-CMR

Increased End-Diastolic Wall Thickness (EDWT)

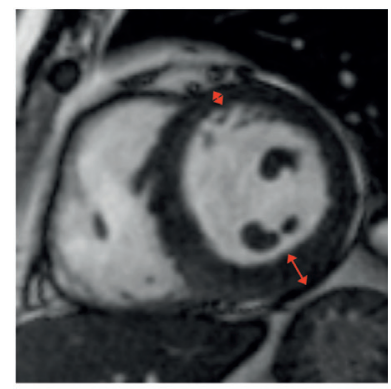

MO or Increased EDWT

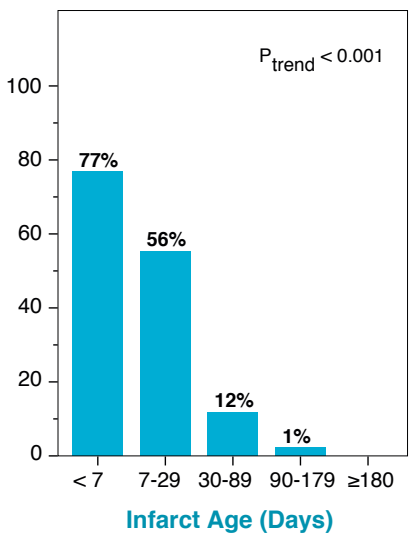

(A) Example of MO and increased EDWT in patients with 3-day-old inferior myocardial infarction.

(B) Prevalence of MO, increased EDWT, and the combined marker MO or increased EDWT over time.

$\mathrm{DE}-\mathrm{CMR}=$ delayed-enhancement cardiac magnetic resonance; EDWT = end-diastolic wall thickness; $\mathrm{MO}=$ microvascular obstruction .

satisfactory or excellent image quality were included, the prevalence of T2 hyperintensity increased for intermediate-age MI (Figure 1C), whereas it remained low (7\%) for Mls $\geq 6$ months old. There was no effect of DE-CMR and cine-CMR image quality score on the prevalence of $\mathrm{MO}$ and increased EDWT, respectively.

\section{Diagnostic Performance}

Table 2 shows the diagnostic performance of CMR for individual components and combinations. When T2-DIR-TSE was interpreted alone, there was relatively high sensitivity $(88 \%$; $95 \%$ confidence interval [CI]: $81 \%$ to $94 \%$ ) but moderate specificity ( $66 \%$; $95 \% \mathrm{Cl}$ : $56 \%$ to $75 \%$ ) for the diagnosis of acute $\mathrm{MI}(<1$ month old). In contrast, when only delayed-enhancement and cine-CMR images were available, the finding of MO and increased EDWT, individually, had poor sensitivity ( $55 \%$ and $42 \%$, respectively) but both were very specific ( $98 \%$ and $99 \%$, respectively). The combination of $\mathrm{MO}$ or increased EDWT provided a substantial increase in sensitivity $(73 \%$; 
Figure 4.

Image quality.

(A)
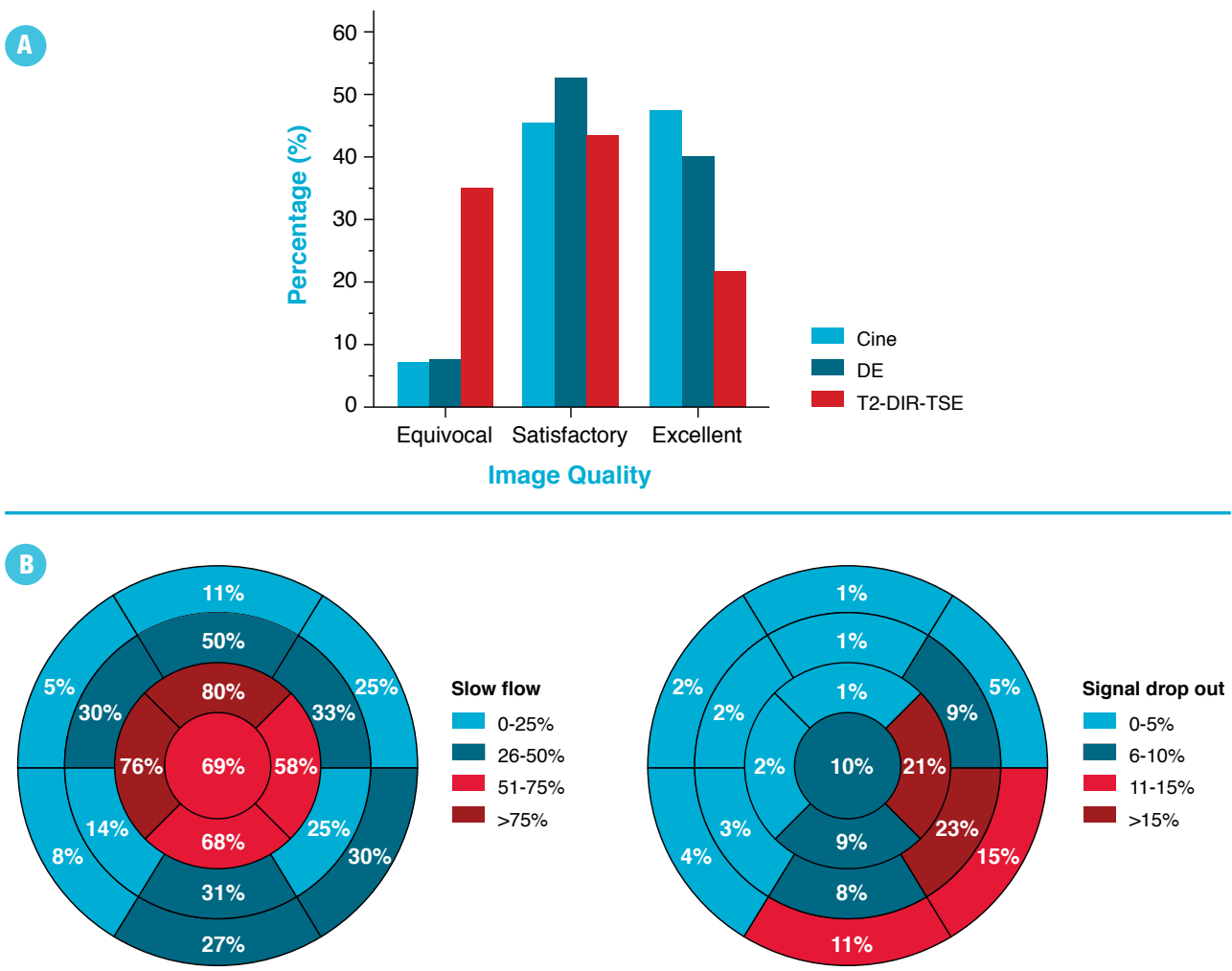

(A) Frequency of image quality scores. (B) Frequency of T2-DIR-TSE artifacts according to location. $\mathrm{DE}=$ delayed enhancement; T2-DIR-TSE = T2-weighted double inversion recovery turbo spin echo.

$95 \% \mathrm{Cl}: 64 \%$ to $81 \%$ ), while maintaining a high specificity (97\%; $95 \% \mathrm{Cl}$ : $92 \%$ to $99 \%$ ), which was greater than the specificity seen for T2-DIR-TSE $(p<0.001)$. When all CMR components were made available during the interpretation, sensitivity, specificity, and accuracy were slightly higher than for T2-DIR-TSE alone ( $p=0.16, p=0.05, p=0.02$, respectively).

For Mls <6 months old, the specificity of T2-DIR-TSE alone was $83 \%$ (95\% Cl: $66 \%$ to $99 \%)$. The specificity rose to $93 \%(95 \% \mathrm{Cl}: 79 \%$ to $100 \%)$ when considering only those scans with satisfactory or excellent image quality. Likewise, the specificity of T2-DIR-TSE increased to $96 \%$ (95\% Cl: $87 \%$ to $100 \%)$ when the complete examination was made available because T2-hyperintense regions remote from the infarcted territory (by DE-CMR) were considered artifactual.

\section{Presence of T2-DIR-TSE hyperintensity in Acute MI}

Of 112 scans performed $<1$ month post-MI, 96 had T2-hyperintensity identified in the correct IRA territory. Multivariable logistic regression analysis demonstrated that the presence of increased EDWT and higher T2-DIR-TSE image quality score were associated with successful 
Table 2.

Diagnostic Performance of CMR for Detecting Acute ( $<1$ Month old) Myocardial Infarction.

\begin{tabular}{|c|l|l|l}
\hline $\begin{array}{l}\text { CMR Abnormality } \\
\text { Individual components }\end{array}$ & Sensitivity & Specificity & Accuracy \\
\hline T2-DIR-TSE hyperintensity & $88 \%(81-94)$ & $66 \%(56-75)$ & $77 \%(71-83)$ \\
\hline MO & $55 \%(46-65)$ & $98 \%(94-100)$ & $76 \%(70-82)$ \\
\hline $\begin{array}{c}\text { Increased EDWT } \\
\text { Combinations }\end{array}$ & $42 \%(33-52)$ & $99 \%(95-100)$ & $70 \%(64-76)$ \\
\hline MO or Increased EDWT & $73 \%(64-81)$ & $97 \%(92-99)$ & $85 \%(80-89)$ \\
\hline T2 or Increased EDWT & $87 \%(79-92)$ & $70 \%(60-78)$ & $78 \%(72-83)$ \\
\hline T2 or MO & $92 \%(85-96)$ & $70 \%(60-78)$ & $81 \%(75-86)$ \\
\hline All CMR Components Available & & & \\
\hline MO or Increased EDWT or T2 & $92 \%(85-96)$ & $70 \%(60-78)$ & $81 \%(75-86)$ \\
\hline
\end{tabular}

Values are \% (95\% confidence interval).

$\mathrm{CMR}=$ cardiac magnetic resonance; EDWT = end-diastolic wall thickness; $\mathrm{M0}=$ microvascular obstruction; T2-DIR-TSE = T2-weighted double inversion recovery turbo spin echo.

identification of T2-hyperintensity (Table 3). The presence of $\mathrm{MO}$ was not associated with the identification of T2-hyperintensity in acute MI.

\section{Persistence of T2-DIR-TSE hyperintensity in Intermediate-Aged MI}

Eighty-three patients had scans performed both $<1$ month and 1 to 6 months post-MI. The mean extent of T2-hyperintensity was less on the later scan (4.5 \pm 2.7 vs. $1.1 \pm 1.8$ segments, $p<0.001)$. The degree of hyperintensity as measured by SIR $(1.77 \pm 0.51$ vs. $1.35 \pm 0.18, p<0.001)$ and CNR $(35.8 \pm 23.4$ vs. $17.4 \pm 11.2, p<0.001)$ was also lower. Multivariable analysis demonstrated that the presence of diabetes, larger infarct size, and better T2-DIR-TSE image quality on the 1- to 6-month scans were independently associated with persistence of T2-hyperintensity in intermediate-age infarcts (Table 4).

\section{Classification Into Infarct Age Categories}

Because T2-DIR-TSE hyperintensity appeared to be specific for infarcts $<6$ months old and MO and increased EDWT were specific for infarcts $<1$ month old, a simple algorithm incorporating all components was devised. The presence of MO or increased EDWT was used to signify MIs $<1$ month old; the presence of T2-hyperintensity in the absence of MO or increased EDWT to indicate MIs 1 to 6 months old; and the absence of MO or increased EDWT and T2-hyperintensity to indicate Mls more than 6 months old. Infarct sizes $\geq 5 \%$ or $\geq 10 \%$ of LV mass occurred in $84 \%$ or $62 \%$ of the population, respectively, and the algorithm was $70 \%$ (95\% Cl: $63 \%$ to $77 \%$ ) or $80 \%(95 \% \mathrm{Cl}: 73 \%$ to $87 \%)$ accurate in categorizing infarct age, respectively.

\section{DISCUSSION}

Differentiating an $\mathrm{Ml}$ that is 1 to 2 weeks old from an $\mathrm{Ml}$ that is months old is crucial for patient management and risk stratification. For example, the risk of sudden death is highest within 30 
Table 3.

Characteristics Associated With Presence of T2-DIR-TSE hyperintensity in Mls $<1$ Month old.

\begin{tabular}{|c|c|c|c|c|}
\hline \multirow[t]{2}{*}{ Variables } & \multicolumn{2}{|l|}{ Univariable } & \multicolumn{2}{|l|}{ Multivariable } \\
\hline & OR (95\% CI) & p Value & OR $(95 \%$ CI) & p Value \\
\hline \multicolumn{5}{|l|}{ General } \\
\hline Age & $1.01(0.96,1.06)$ & 0.78 & & \\
\hline Male Gender & $0.72(0.15,3.45)$ & 0.68 & & \\
\hline \multicolumn{5}{|l|}{ Clinical History } \\
\hline Hypertension & $0.92(0.32,2.67)$ & 0.88 & & \\
\hline Diabetes & * & & & \\
\hline Hypercholesterolemia & $1.38(0.44,4.29)$ & 0.58 & & \\
\hline Positive Family History & $0.85(0.29,2.44)$ & 0.76 & & \\
\hline Smoking & $1.84(0.57,5.94)$ & 0.31 & & \\
\hline Number of Risk Factors & $1.28(0.75,2.19)$ & 0.37 & & \\
\hline \multicolumn{5}{|l|}{ Cardiac Enzymes } \\
\hline Peak Troponin T & $1.09(0.94,1.26)$ & 0.25 & & \\
\hline Peak CK-MB & $1.002(0.998,1.007)$ & 0.33 & & \\
\hline \multicolumn{5}{|l|}{ Cardiac Catheterization } \\
\hline Infarct Related Artery - RCA & $0.37(0.12,1.14)$ & 0.08 & & \\
\hline Pre-Procedure TIMI-3 Flow & $0.94(0.60,1.47)$ & 0.78 & & \\
\hline Final TIMI-3 Flow & $\dagger$ & & & \\
\hline Number of Diseased Vessels & $0.62(0.33,1.16)$ & 0.14 & & \\
\hline \multicolumn{5}{|l|}{ CMR } \\
\hline LVEF & $1.000(0.948,1.054)$ & 1.00 & & \\
\hline Infarct Size & $1.02(0.97,1.08)$ & 0.40 & & \\
\hline MO & $1.73(0.59,5.02)$ & 0.32 & & \\
\hline Increased EDWT & $13.80(1.75,108.7)$ & 0.013 & $12.81(1.57,104.76)$ & 0.017 \\
\hline MO or Increased EDWT & $4.60(1.53,13.8)$ & 0.007 & & \\
\hline T2-DIR-TSE Image Quality Score & $4.01(1.62,9.88)$ & 0.003 & $4.09(1.52,11.02)$ & 0.005 \\
\hline
\end{tabular}

${ }^{*}$ Cannot be calculated because in the patient group without T2-hyperintensity, none had diabetes.

†Cannot be calculated because in the patient group without T2-hyperintensity, all had TIMI flow grade 3.

$\mathrm{Cl}=$ confidence interval; $\mathrm{CMR}=$ cardiac magnetic resonance; $\mathrm{EDWT}=$ end-diastolic wall thickness;

$\mathrm{LVEF}$ = left ventricular ejection fraction; $\mathrm{MO}=$ microvascular obstruction; $\mathrm{OR}=$ odds ratio;

$\mathrm{RCA}=$ right coronary artery; T2-DIR-TSE = T2-weighted double inversion recovery turbo spin echo;

$\mathrm{TIMI}=$ Thrombolysis In Myocardial Infarction.

days after MI among patients with LV dysfunction; thus, early implementation of strategies to reduce the risk of sudden death may be warranted in selected patients. ${ }^{13}$ However, primary prevention implantable cardioverter-defibrillator implantation should not be performed for at least 40 days post-MI, even in those with the requisite level of LV dysfunction, in part because 
of the dynamic nature of LV functional improvement in the first several weeks after $\mathrm{MI} .{ }^{14}$ Hence, knowledge of infarct age is essential to follow contemporary practice guidelines, yet the majority of acute $\mathrm{Ml}$ events are clinically unrecognized, precluding this determination. ${ }^{15}$

In this 2-center study of patients with STEMI who underwent CMR at known time points after a documented MI, we found that T2-DIR-TSE hyperintensity in infarcted regions was specific for infarcts $<6$ months old, whereas microvascular obstruction and increased EDWT was specific for infarcts $<1$ month old. Multivariable analysis demonstrated that persistence of T2-hyperintensity in intermediate-age infarcts (1 to 6 months old) was predicted by larger infarct size, the presence of diabetes, and better T2-DIR-TSE image quality. A simple algorithm was developed incorporating multiple CMR markers of acute $\mathrm{MI}$ and accounting for their different longevity. This allowed classification of infarct age into 3 specific categories ( $<1$ month old, 1 to 6 months old, and more than 6 months old) rather than just "acute" or "chronic" categories, and for infarct size $\geq 10 \%$ of the left ventricle, the algorithm was found to be accurate in $80 \%$ of cases.

Our finding that T2-DIR-TSE is $66 \%$ specific for differentiating Mls $<1$ month old appears to be at odds with previous studies. For instance, Abdel-Aty et al. ${ }^{5}$ reported $96 \%$ specificity for discriminating acute from chronic MI (chronic defined as more than 4 weeks old). Likewise, Stork et al. ${ }^{6}$ and $\mathrm{O}$ h-lci et al. ${ }^{7}$ reported $98 \%$ and $99 \%$ specificity, respectively. However, it is important to note that these earlier studies were not designed to evaluate a broad spectrum of infarct age. Instead, the focus was on extremes, comparing MI within days of admission with infarcts sometimes years older. Specifically, Abdel-Aty et al. ${ }^{5}$ compared patients with infarcts $4 \pm 3$ days versus $17 \pm 19$ months-old, Stork et al. ${ }^{6}$ compared Mls $5 \pm 3$ days versus $8 \pm 3$ months old, and $\mathrm{O}$ h-Ici et al. ${ }^{7}$ compared Mls $4 \pm 1$ days old versus $196 \pm 39$ days old. Hence, given the potential for selection bias, it is possible the reported specificity values are overly optimistic.

The primary basis for the low specificity that we report using the threshold of $<1$ month for acute $\mathrm{MI}$ is the observation that T2-DIR-TSE hyperintensity often persists for several months post-MI (Figures 1 and 2). From the literature, the duration of T2-hyperintensity after acute MI is unclear. The few published studies are inconsistent. In 8 canines, Aletras et al. ${ }^{16}$ reported that none of the T2-hyperintense regions seen at 2 days post-MI were observed at 2 months. However, Ghugre et al. ${ }^{17}$ in a porcine model, demonstrated persistent T2 elevation in the infarcted region at 6 weeks post-MI, albeit only 4 animals were studied at this time-point. Schulz-Menger et al..$^{18}$ showed in 8 patients with hypertrophic cardiomyopathy and iatrogenic MI from septal artery embolization that infarct-related T2-hyperintensity visible at 28 days had entirely resolved by 90 days in all 8 patients. In contrast, Mather et al. ${ }^{19}$ reported that $73 \%$ of patients with a first STEMI who underwent primary percutaneous coronary intervention had visible T2-hyperintensity at 90 days; Nilsson et al. ${ }^{20}$ suggested that T2-hyperintensity was detectable even at 1 year, although this occurred only in 3 patients. Thus, there is discordance in the literature, and a complicating factor is that the studies are unclear as to whether T2-DIR-TSE images were interpreted separately or in conjunction with the rest of the CMR data, nor is it clear whether interpretations were performed blinded to the CMR study date. In the present study, the sample size was larger, T2-DIR-TSE images were interpreted separately from other CMR data blinded to the study date, image quality was assessed, and the IRA territory was determined by coronary angiography to help distinguish true from artifactual findings.

We used a conventional black-blood sequence to obtain T2-weighted images because it is the most commonly used in clinical practice and has the most extensive literature. ${ }^{2}$ Although image quality occasionally can be suboptimal with this sequence, we believe that T2-hyperintensity by other sequences may also be specific for Mls $<6$ months old for the following reasons. First, when only scans with better image quality were considered, the specificity of T2-DIR-TSE 
Table 4.

Characteristics Associated With Persistence of T2-DIR-TSE hyperintensity in Intermediate-Aged MI.

\begin{tabular}{|c|c|c|c|c|}
\hline \multirow[t]{2}{*}{ Variables } & \multicolumn{2}{|l|}{ Univariable } & \multicolumn{2}{|l|}{ Multivariable } \\
\hline & OR (95\% CI) & p Value & OR $(95 \%$ CI) & p Value \\
\hline \multicolumn{5}{|l|}{ General } \\
\hline Age & $1.02(0.98,1.06)$ & 0.45 & & \\
\hline Male Gender & $0.50(0.16,1.60)$ & 0.24 & & \\
\hline \multicolumn{5}{|l|}{ Clinical History } \\
\hline Hypertension & $1.19(0.48,3.00)$ & 0.71 & & \\
\hline Diabetes & $4.17(0.96,18.10)$ & 0.06 & $5.53(1.13,27.10)$ & 0.035 \\
\hline Hypercholesterolemia & $0.91(0.34,2.40)$ & 0.84 & & \\
\hline Positive Family History & $0.69(0.28,1.72)$ & 0.43 & & \\
\hline Smoking & $1.16(0.36,3.79)$ & 0.80 & & \\
\hline Number of Risk Factors & $1.12(0.69,1.81)$ & 0.65 & & \\
\hline \multicolumn{5}{|l|}{ Cardiac Enzymes } \\
\hline Peak Troponin T & $1.09(0.98,1.21)$ & 0.13 & & \\
\hline Peak CK-MB & $1.003(1.000,1.007)$ & 0.048 & & \\
\hline \multicolumn{5}{|l|}{ Cardiac Catheterization } \\
\hline Infarct Related Artery - RCA & $0.32(0.12,0.80)$ & 0.015 & & \\
\hline Pre-Procedure TIMI-3 Flow & $0.59(0.32,1.09)$ & 0.09 & & \\
\hline Final TIMI-3 Flow & * & & & \\
\hline Number of Diseased Vessels & $0.62(0.33,1.16)$ & 0.14 & & \\
\hline \multicolumn{5}{|l|}{ CMR (on baseline scan) } \\
\hline LVEF & $0.94(0.89,0.99)$ & 0.031 & & \\
\hline Infarct Size & $1.08(1.03,1.13)$ & 0.003 & $1.08(1.03,1.14)$ & 0.002 \\
\hline MO & $3.56(1.37,9.24)$ & 0.009 & & \\
\hline Increased EDWT & $0.84(0.34,2.07)$ & 0.71 & & \\
\hline MO or Increased EDWT & $2.57(0.84,7.85)$ & 0.10 & & \\
\hline \multicolumn{5}{|l|}{ CMR (1-6 months scan) } \\
\hline T2-DIR-TSE Image Quality Score & $2.02(1.08,3.79)$ & 0.029 & $2.18(1.10,4.33)$ & 0.026 \\
\hline
\end{tabular}

* Cannot be calculated because in the patient group without T2-hyperintensity, all had TIMI flow grade $\mathrm{Cl}=$ confidence interval; $\mathrm{CK}=$ creatine kinase; EDWT = end-diastolic wall thickness; LVEF = left ventricular ejection fraction; $\mathrm{MO}=$ microvascular obstruction; $\mathrm{OR}=$ odds ratio; $\mathrm{RCA}=$ right coronary artery; $\mathrm{TIMI}=$ thrombolysis in myocardial infarction .

hyperintensity for Mls $<6$ months old increased to $93 \%$ (from $83 \%$ ). Second, for scans with better image quality, T2-DIR-TSE hyperintense regions were invariably within the correct IRA perfusion territory by coronary angiography and matched the infarct location determined by DE-CMR. Third, when T2-DIR-TSE images were read in conjunction with cine and delayed-enhancement 
images (complete examination available), so that apparent T2-hyperintense regions remote from the infarcted territory could be considered artifactual, the specificity of T2-hyperintensity for Mls $<6$ months old increased to $96 \%$. These findings suggest that any technical limitations with the T2-DIR-TSE sequence should not affect the general interpretation that T2-hyperintensity is specific for Mls $<6$ months old because a different sequence with better image quality would likely result in an even higher specificity of T2-hyperintensity for Mls $<6$ months old.

The underlying cause of T2-DIR-TSE hyperintensity after MI is thought to be edema. ${ }^{2,5}$ However, the data in the present study are perhaps not entirely consistent with this conjecture. In animal models, myocardial tissue water content increases markedly within minutes to hours after acute reperfused $\mathrm{MI} .{ }^{21}$ In patients, the rapid, near-doubling in LV EDWT in the setting of acute $\mathrm{MI}$ is assuredly the consequence of increased tissue water. ${ }^{22,23}$ Hence, an acute increase in EDWT should provide a quantitative measure of edema. With this in mind, it is interesting that the time course of increased EDWT was clearly different from that of T2-DIR-TSE hyperintensity in the present study because it was exceedingly rare for increased EDWT to be present in infarcts more than 1 month old. This finding is consistent with that reported by Ghugre et al. who demonstrated complete resolution of acutely thickened myocardium by 4 weeks and, moreover, found this was matched in time with the resolution of edema, as verified by histopathology. ${ }^{17}$ Similarly, in a human postmortem study, Fishbein et al. reported that infarction-related edema and inflammation, which was ubiquitous in the early days after acute $\mathrm{MI}$, had entirely resolved by 35 days. ${ }^{24}$ These findings strongly suggest that infarction-related edema should resolve by 1 month, and T2-DIR-TSE hyperintensity that persists far beyond this time is due to a different mechanism. We propose that T2-DIR-TSE hyperintensity seen 1 to 6 months post-MI, long after resolution of increased EDWT, reflects a fundamental alteration in underlying tissue, involving vascular, fibroblastic, and collagenous proliferation in replacement of necrotic myocytes rather than simply excess water content. ${ }^{24}$

Although the sensitivity of T2-DIR-TSE for acute MI ( $<1$ month old) was relatively high at $88 \%$, this is lower than that reported by the initial studies. More recently, Viallon et al. compared a variety of black-blood and bright-blood T2-weighted sequences in the setting of a first STEMI and also reported a lower sensitivity in detecting acute $\mathrm{MI}$, with a high of $80 \%$ among all sequences. ${ }^{25}$ The authors attributed the lower sensitivity (and the apparent discrepancy with older reports) to the fact that T2 images were read in isolation, blinded to all other CMR data, which was not the case in previous investigations.

It is well established that $\mathrm{MO}$ can complicate acute $\mathrm{MI}$, and this signals a poor prognosis. ${ }^{10}$ However, because many acute infarcts do not have $\mathrm{MO}$, it has not been thought to be particularly useful for differentiating acute from chronic MI. The results of the present study corroborate those of earlier reports regarding the prevalence and time course of $\mathrm{MO}$. These studies consistently report a prevalence of approximately $50 \%$ in the first week after $\mathrm{MI},{ }^{6,26}$ with a rapid decrease to near zero within 1-month. 17,19 The present study, however, is the first to suggest that $\mathrm{MO}$ and increased EDWT may be synergistic for the detection of acute MI. The combination provided higher test sensitivity without reducing specificity for the identification of Mls $<1$ month old (Table 2). From a pathophysiological viewpoint, this suggests that although both phenomena are associated with larger infarct sizes, the 2 may represent different pathways of post-infarction injury. Indeed, MO, by virtue of restricting myocardial tissue level reperfusion, may limit acute edema (and therefore limit increased EDWT), albeit with the consequence of reducing cellular infiltration that could speed infarct healing. 
By leveraging the multiple CMR markers of acute $\mathrm{MI}$ and their different longevity, we developed a simple algorithm to classify infarct age as $<1$ month old, 1 to 6 months old, and more than 6 months old. We emphasize that this algorithm should be considered only a guide. In patients with acute $\mathrm{MI}$ but small infarct size (e.g., $<10 \%$ of the left ventricle), MO and increased EDWT are frequently absent. Thus, the presence of T2-DIR-TSE hyperintensity may reflect MIs either $<1$ month old or 1 to 6 months old, and, accordingly in this situation, infarct age should be interpreted simply as $<6$ months old. An additional limitation is that many infarcts 1 to 6 months old did not have T2-DIR-TSE hyperintense regions. This was associated with infarct size; therefore, at present, it appears prudent to consider small infarcts without T2-DIR-TSE hyperintense regions (and without MO and increased EDWT) simply as more than 1 month old. Despite this limitation, the lack of persistent T2-DIR-TSE hyperintensity was also associated with suboptimal image quality, and it is likely the significance of this limitation will decrease with technical advances in CMR.

\section{CONCLUSIONS}

In this prospective 2-center study, we found that T2-DIR-TSE is sensitive but not specific for detecting Mls $<1$ month old because T2-hyperintensity often persists for months. In contrast, the presence of MO or focally increased EDWT was observed to be specific for Mls $<1$ month old, and, when used in conjunction with T2-hyperintensity, the combination frequently provided a more precise assessment of infarct age. 


\section{REFERENCES}

1. Alpert JS, Thygesen K, Antman E, Bassand JP. Myocardial infarction redefined-a consensus document of The European Society of Cardiology/ American College of Cardiology. J Am Coll Cardiol 2000;36:959-69.

2. Eitel I, Friedrich MG. T2-weighted cardiovascular magnetic resonance in acute cardiac disease. $J$ Cardiovasc Magn Reson 2011;13:13.

3. Perazzolo Marra M, Lima JA, lliceto S. MRI in acute myocardial infarction. Eur Heart J 2011;32:284-93.

4. Stillman AE, Oudkerk M, Bluemke D, et al. Assessment of acute myocardial infarction: current status and recommendations from $\mathrm{NASCl}$ and the ESCR. Int J Cardiovasc Imaging 2011;27:7-24.

5. Abdel-Aty $\mathrm{H}$, Zagrosek A, Schulz-Menger J, et al. Delayed enhancement and T2-weighted cardiovascular magnetic resonance imaging differentiate acute from chronic myocardial infarction. Circulation 2004;109:2411-6.

6. Stork A, Muellerleile K, Bansmann PM, et al. Value of T2-weighted, first-pass and delayed enhancement, and cine CMR to differentiate between acute and chronic myocardial infarction. Eur Radiol 2007;17:610-7.

7. h-Ici DO, Ridgway JP, Kuehne T, et al. Cardiovascular magnetic resonance of myocardial edema using a short inversion time inversion recovery (STIR) black-blood technique: diagnostic accuracy of visual and semi-quantitative assessment. J Cardiovasc Magn Reson 2012;14:22.

8. Chesebro JH, Knatterud G, Roberts R, et al. Thrombolysis in Myocardial Infarction (TIMI) Trial, Phase I: A comparison between intravenous tissue plasminogen activator and intravenous streptokinase. Circulation 1987;76:142-54.

9. Schulz-Menger J, Bluemke DA, Bremerich J, et al. Standardized image interpretation and post processing in cardiovascular magnetic resonance: Society for Cardiovascular Magnetic Resonance (SCMR) board of trustees task force on standardized post processing. J Cardiovasc Magn Reson 2013;15:35.

10. Albert TS, Kim RJ, Judd RM. Assessment of no-reflow regions using cardiac MRI. Basic Res Cardiol 2006;101:383-90.

11. Simonetti OP, Kim RJ, Fieno DS, et al. An improved MR imaging technique for the visualization of myocardial infarction. Radiology 2001;218:215-23.

12. Kim RJ, Albert TS, Wible JH, et al. Performance of delayed-enhancement magnetic resonance imaging with gadoversetamide contrast for the detection and assessment of myocardial infarction: an international, multicenter, double-blinded, randomized trial. Circulation 2008;117:629-37.

13. Solomon SD, Zelenkofske S, McMurray JJ, et al. Sudden death in patients with myocardial infarction and left ventricular dysfunction, heart failure, or both. N Engl J Med 2005;352:2581-8.

14. Yancy CW, Jessup M, Bozkurt B, et al. 2013 ACCF/ AHA guideline for the management of heart failure: a report of the American College of Cardiology Foundation/American Heart Association Task Force on practice guidelines. Circulation 2013;128:e240-327.
15. Kim HW, Klem I, Shah DJ, et al. Unrecognized non-Q-wave myocardial infarction: prevalence and prognostic significance in patients with suspected coronary disease. PLoS Med 2009;6:e1000057.

16. Aletras AH, Tilak GS, Natanzon A, et al. Retrospective determination of the area at risk for reperfused acute myocardial infarction with T2-weighted cardiac magnetic resonance imaging: histopathological and displacement encoding with stimulated echoes (DENSE) functional validations. Circulation 2006;113:1865-70.

17. Ghugre NR, Ramanan V, Pop M, et al. Quantitative tracking of edema, hemorrhage, and microvascular obstruction in subacute myocardial infarction in a porcine model by MRI. Magn Reson Med 2011;66:1129-41.

18. Schulz-Menger J, Gross M, Messroghli D, Uhlich F, Dietz R, Friedrich MG. Cardiovascular magnetic resonance of acute myocardial infarction at a very early stage. J Am Coll Cardiol 2003;42:513-8.

19. Mather AN, Fairbairn TA, Artis NJ, Greenwood JP, Plein S. Timing of cardiovascular MR imaging after acute myocardial infarction: effect on estimates of infarct characteristics and prediction of late ventricular remodeling. Radiology 2011;261:116-26.

20. Nilsson JC, Nielsen G, Groenning BA, et al. Sustained postinfarction myocardial oedema in humans visualised by magnetic resonance imaging. Heart 2001;85:639-42.

21. Whalen DA, Jr., Hamilton DG, Ganote CE, Jennings RB. Effect of a transient period of ischemia on myocardial cells. I. Effects on cell volume regulation. Am J Pathol 1974;74:381-97.

22. Croisille P, Kim HW, Kim RJ. Controversies in cardiovascular MR imaging: T2-weighted imaging should not be used to delineate the area at risk in ischemic myocardial injury. Radiology 2012;265:12-22.

23. Haendchen RV, Corday E, Torres M, Maurer G, Fishbein MC, Meerbaum S. Increased regional end-diastolic wall thickness early after reperfusion: a sign of irreversibly damaged myocardium. JACC 1984;3:1444-53.

24. Fishbein MC, Maclean D, Maroko PR. The histopathologic evolution of myocardial infarction. Chest 1978;73:843-9.

25. Viallon M, Mewton N, Thuny F, et al. T2-weighted cardiac MR assessment of the myocardial area-atrisk and salvage area in acute reperfused myocardial infarction: comparison of state-of-the-art dark blood and bright blood T2-weighted sequences. J Magn Reson Imaging 2012;35:328-39.

26. Bekkers SC, Smulders MW, Passos VL, et al. Clinical implications of microvascular obstruction and intramyocardial haemorrhage in acute myocardial infarction using cardiovascular magnetic resonance imaging. Eur Radiol 2010;20:2572-8. 


\section{Editorial Comment}




\section{Healing after myocardial infarction A loosely defined process}

Andrew E. Arai, MD

Advanced Cardiovascular Imaging, National Heart, Lung, and Blood Institute, National Institutes of Health, Bethesda, Maryland, USA

Journal of the American College of Cardiology: Cardiovascular Imaging. 2015;8:680-683 
Although all physicians probably have a good intuitive sense of the clinical presentation of acute myocardial infarction (MI), the clinical definitions of acute $\mathrm{MI}$ and healing $\mathrm{MI}$ are surprisingly imprecise. The redefinition of acute myocardial infarction in 2000 centered squarely on clinical presentation and a typical rise and fall in troponin as a new and better definition of Ml. ${ }^{1}$ Those guidelines advised that the term Ml should be preceded by "acute, healing, or healed" as modifiers that relate to the pathological processes underlying each of these phases.

"An acute or evolving infarction is characterized by the presence of polymorphonuclear leukocytes. If the interval between the onset of infarction and death is brief (e.g., $6 \mathrm{~h}$ ), minimal or no polymorphonuclear leukocytes may be seen. The presence of mononuclear cells and fibroblasts and the absence of polymorphonuclear leukocytes characterize a healing infarction. A healed infarction is manifested as scar tissue without cellular infiltration. The entire process leading to a healed infarction usually requires five to six weeks or more. Furthermore, reperfusion alters the gross and microscopic appearance of the necrotic zone by producing myocytes with contraction bands and large quantities of extravasated erythrocytes."

Since clinicians cannot see such pathological features except in fatal cases with an autopsy, a less precise definition was introduced using the following time scale as an approximation of the pathological phases: acute ( $6 \mathrm{~h}$ to 7 days); healing ( 7 to 28 days), healed ( 29 days or more). ${ }^{1}$ The Third Universal Definition of Myocardial Infarction, focused less on the healing phases after MI, simply stated that it takes at least 5 to 6 weeks for an MI to heal. ${ }^{2}$

With the exception of not including the first $6 \mathrm{~h}$ as part of the definition of an acute MI, I find the 2000 Guidelines definitions of acute and healing phases of $\mathrm{Ml}$ a useful construct. At the same time, cardiac magnetic resonance (CMR) findings at various times after acute MI have made me reconsider the rather loose definitions of the healing and healed phases.

Along that line, Smulders et al. ${ }^{3}$ from Maastricht University Medical Center and from Duke University studied how well various CMR methods can distinguish acute from chronic MI. In brief, a combination of T2-weighted magnetic resonance imaging (MRI), end-diastolic wall thickness, and the presence or absence of microvascular obstruction (MO) accurately categorized the age of the infarct as $<1$ month, 1 to 6 months, and more than 6 months old. These data are valuable as they help refine our understanding of parameters that are useful for differentiating acute from chronic MI. This work also raises important questions about why T2 abnormalities persist for $>1$ month after acute $\mathrm{MI}$ in so many patients. The implications are broader; the healing process after acute MI takes longer than most clinicians think.

We first became interested in imaging myocardial edema associated with acute $\mathrm{Ml}$ as a potential method for differentiating acute from chronic MI. We pursued this line of research after we found that a rest CMR scan in the emergency department was quite sensitive to detecting acute coronary syndrome but limited by difficulty differentiating acute from chronic wall motion abnormalities. ${ }^{4}$ Friedrich et al. ${ }^{5}$ had been studying T2 as a method to detect myocardial edema in myocarditis and acute MI. ${ }^{6}$ The concept that tissue characterization with MRI could distinguish acute from chronic MI was exciting and diagnostically relevant. We followed a different tract of trying to understand why the post-MI T2 abnormalities were more extensive than the infarcted myocardium. This led to the realization that T2 in the first $48 \mathrm{~h}$ after MI was detecting edema in the ischemic zone or area at risk. However, as the story develops, it is clear that there are important differences between the T2 abnormalities associated with early post-ischemic edema, 1 week post-infarct inflammation, and longer term healing after MI.

Recent work by Fernández-Jiménez et al. ${ }^{7}$ brilliantly demonstrates in a swine infarct model that there is a period of $\sim 24 \mathrm{~h}$ in which post- ischemic T2 abnormalities are detectable, but this fades faster than in canine models. ${ }^{8}$ In canine models, the initial post-ischemic T2 abnormalities 
are still present for at least $48 \mathrm{~h}$. Most interestingly in the swine model, a second phase of T2 abnormality develops to show a T2 abnormality that is as strong as the early abnormalities and likely explained by an inflammatory response. Because inflammatory responses to acute injury do not typically last 6 months, one might reasonably wonder what could explain the abnormal T2 over such a long period of time.

Because there is limited pre-clinical CMR data in the 1- to 6-month time period post-MI, human autopsy data may provide insights into the healing process that parallel what has been observed by imaging. Mallory et al. ${ }^{9}$ reported one of the first large pathological series of human autopsies after acute MI $(n=72)$ in 1939. Several aspects of this classic study caught my attention.

- First, small infarcts healed faster than more extensive infarcts.

- Second, the rate of healing was faster when the remaining circulation was better.

- Third, the majority of human pathological features of healing MI were comparable to the observations in canine experimental MI with a few exceptions (most of which they considered minor).

- The chief difference was that canine infarcts healed more quickly than human infarcts.

Table 1.

Time course of pathologic findings after human acute myocardial infarction

\begin{tabular}{l|l|l|l|l|l|l|l|}
\hline Days & n & Necrosis & $\begin{array}{l}\text { Waviness } \\
\text { and Thinning }\end{array}$ & Myocytolysis & $\begin{array}{l}\text { Intercellular } \\
\text { Edema }\end{array}$ & Hemorrhage & $\begin{array}{l}\text { Vascular } \\
\text { Proliferation }\end{array}$ \\
\hline $1-7$ & 121 & 96 & 94 & 16 & 96 & 77 & 17 \\
\hline $8-14$ & 30 & 97 & 73 & 33 & 70 & 90 & 100 \\
\hline $15-21$ & 14 & 71 & 57 & 21 & 50 & 64 & 100 \\
\hline $22-28$ & 10 & 50 & 30 & 30 & 20 & 50 & 100 \\
\hline $29-35$ & 10 & 20 & 0 & 10 & 10 & 20 & 100 \\
\hline $36-90$ & 7 & 0 & 0 & 0 & 0 & 14 & 100 \\
\hline Combining days 1-28 for correlation with Smulders et al. ${ }^{3}$ & & & \\
\hline $1-28$ & 175 & 160 (91) & 147 (84) $35(20)$ & $146(83)$ & $134(77)$ & $74(42)$ \\
\hline
\end{tabular}

Values are $\%$ or $n(\%)$. The top of the table summarizes the human pathological findings throughout the first 90 days after acute myocardial infarction, equivalent to the way the data were first presented in 1978 by Fishbein et al. ${ }^{10}$ The additional analysis condensed the "acute" phase as a combination of the first 28 days after the infarct was added to represent the data as closely to those of Smulders et al., ${ }^{3}$ who defined acute $\mathrm{Ml}$ as the first 30 days after MI.

In humans, necrosis and polymorphonuclear leukocyte infiltration were common features in the first 7 days. Removal of necrotic cells and replacement by connective tissue dominated the next 5 weeks. The collagen deposition started in the second week and was completed by \% months after the acute MI.

In 1978, Fishbein et al. ${ }^{10}$ studied the histopathological features seen during the first 90 days after human acute $\mathrm{Ml}$ in an autopsy series of 192 patients. They confirmed most of the observations 
Figure 1.

Time Course of Components of the Healing Process After Acute MI

\section{Histopathological Findings After Human Acute MI}

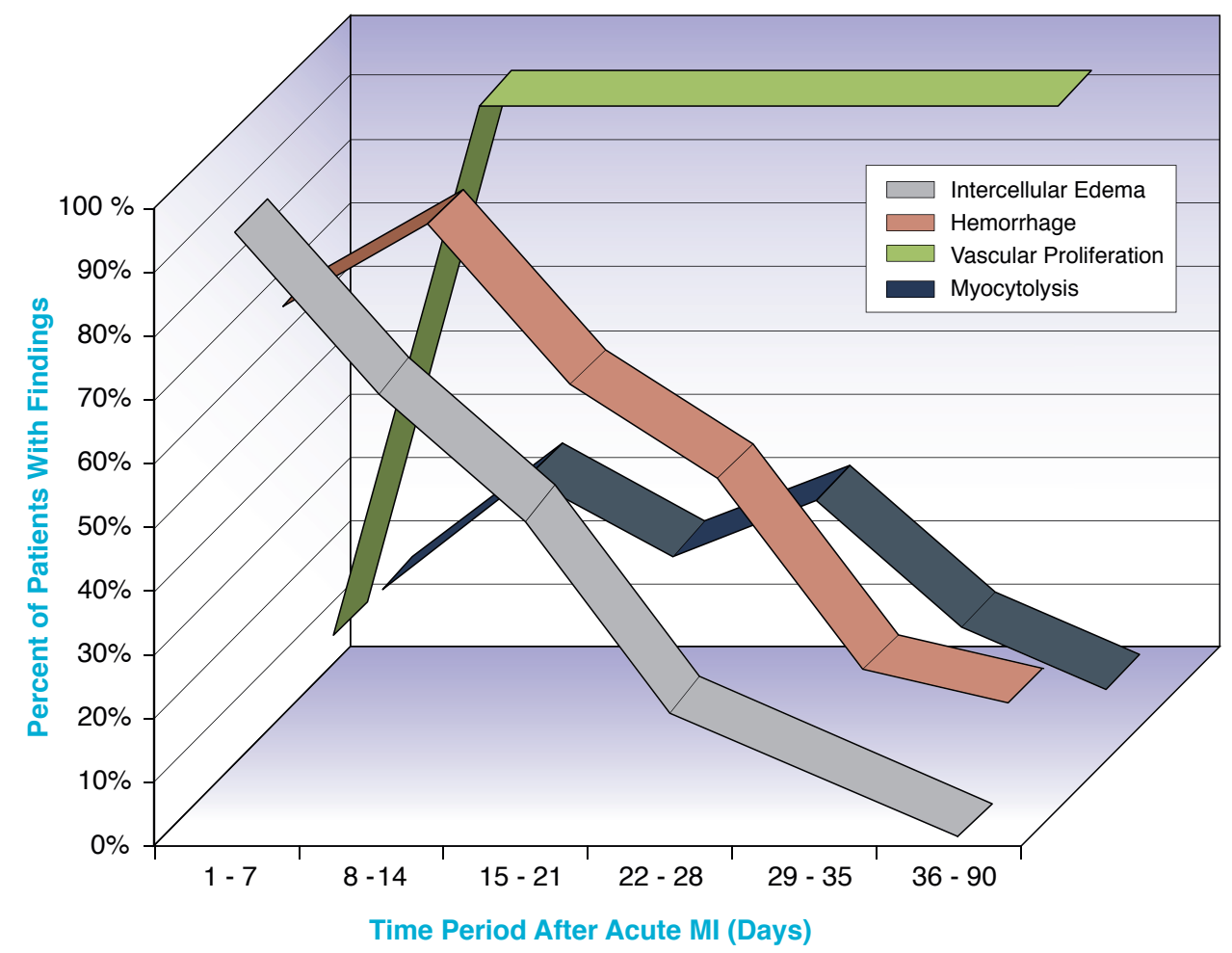

Intercellular edema resolves by $\sim 35$ days post-MI. Vascular proliferation and continued remodeling of the collagen scar in the time period 36 to 90 days post-MI likely play a role in the more prolonged abnormalities seen in myocardial T2. Adapted with permission from Fishbein et al. ${ }^{10}$ $\mathrm{MI}=$ myocardial infarction .

of Mallory et al. ${ }^{9}$ They specifically described features of edema and the inflammatory response that are relevant to recent imaging studies of acute MI. In particular, they found that intercellular edema was present during the first 1 to 7 days in $96 \%$ of human acute MIs (Table 1, Figure 1). The severity of intercellular edema was most severe on day 1 , moderate through most of the rest of the first week post-MI, and generally mild thereafter. Between 36 and 90 days post-MI, edema was not seen in human Mls.

Thus, myocardial edema cannot explain the more prolonged increases in myocardial T2, as observed by Smulders et al. ${ }^{3}$ in this issue of iJACC, as the authors correctly discuss. The time course is more complicated and more prolonged than many imagers have assumed with back of the hand arguments. Edema is a prominent factor in the first 24 to $48 \mathrm{~h}$ after acute MI. 
Myocardial T2 in the healing phases after acute $\mathrm{Ml}$ is more than simply edema (Table 1). However, T2-weighted imaging after acute MI is intriguingly sensitive to at least 3 of the known pathological processes that take place in the first 7 days (edema, hemorrhage, and the inflammatory response). T2 is also sensitive to post-MI healing processes observed during the next 7 to 90 days (resolving edema, hemorrhage, inflammation, and prolonged hypervascularity). Edema, inflammation, and increased vascularity all affect $\mathrm{T} 2$ by increases in water content. Hemorrhage and the transition to a dense collagen scar can decrease T2. Thus, there is likely a combination of competing factors in the later time period that affect the T2 properties of the healing acute MI.

Smulders et al. ${ }^{3}$ suggest that lack of blinding or selection of patients at extremes of time post-infarct in previous studies may have explained why the sensitivity of T2-weighted imaging was higher in those papers than in the current study. An equally plausible explanation relates to the present study- specific definition of "acute MI" as $<30$ days post-infarct. As described in the human autopsy studies, there are many processes changing over the first 30 days. The Fishbein et al. ${ }^{10}$ study indicates that edema should be present in $~ 83 \%$ of subjects at 30 days if one combines all of their data between day 0 and day 28 . Thus, the sensitivity of T2 in the present study $(88 \%)$ is about what one might expect for the 0 to 30 -day time frame post-MI. The larger issue with $\mathrm{T} 2$ seems to be specificity (66\% in the current study), a problem that might be helped by quantitative methods (either T2 maps or T1 maps). ${ }^{11}$ Combinations of microvascular obstruction, increased wall thickness, or T2 seem to perform better than any single characteristic.

Ultimately, one can learn from pathological imaging correlations. We can improve our understanding of both the diagnostic features seen on imaging as well as the underlying pathophysiology if we keep an open mind. Although the ability to intervene in acute MI has focused so much attention on the first few hours of presentation and treatment, the healing process is more complicated and more prolonged than many physicians might guess. 


\section{REFERENCES}

1. Alpert JS, Thygesen K, Antman E, Bassand JP. Myocardial infarction redefined--a consensus document of The Joint European Society of Cardiology/American College of Cardiology Committee for the redefinition of myocardial infarction. J Am Coll Cardiol 2000;36:959-69.

2. Thygesen K, Alpert JS, Jaffe AS, et al. Third universal definition of myocardial infarction. Eur Heart J 2012;33:2551-67.

3. Smulders MW, Bekkers SC, Kim HW, Van Assche LM, Parker MA, Kim RJ. Performance of CMR Methods for Differentiating Acute From Chronic MI. JACC Cardiovasc Imaging 2015;8:669-79.

4. Kwong RY. Detecting Acute Coronary Syndrome in the Emergency Department With Cardiac Magnetic Resonance Imaging. Circulation 2003;107:531-7.

5. Friedrich MG, Sechtem U, Schulz-Menger J, et al. Cardiovascular magnetic resonance in myocarditis: A JACC White Paper. J Am Coll Cardiol 2009;53:1475-87.

6. Abdel-Aty $\mathrm{H}$, Zagrosek A, Schulz-Menger J, et al. Delayed enhancement and T2-weighted cardiovascular magnetic resonance imaging differentiate acute from chronic myocardial infarction. Circulation 2004;109:2411-6.

7. Fernandez-Jimenez R, Sanchez-Gonzalez J, Aguero J, et al. Myocardial edema after ischemia/ reperfusion is not stable and follows a bimodal pattern: imaging and histological tissue characterization. J Am Coll Cardiol 2015;65:315-23.

8. Hammer-Hansen S, Ugander M, Hsu LY, et al. Distinction of salvaged and infarcted myocardium within the ischaemic area-at-risk with T2 mapping. European heart journal cardiovascular Imaging 2014;15:1048-53.

9. Mallory GK, White PD, Salcedo-Salgar J. The speed of healing of myocardial infarction. Am Heart $J$ 1939;18:647-71.

10. Fishbein MC, Maclean D, Maroko PR. The histopathologic evolution of myocardial infarction. Chest 1978;73:843-9.

11. Ugander M, Bagi PS, Oki AJ, et al. Myocardial edema as detected by pre-contrast T1 and T2 CMR delineates area at risk associated with acute myocardial infarction. JACC Cardiovasc Imaging 2012;5:596-603. 
PART

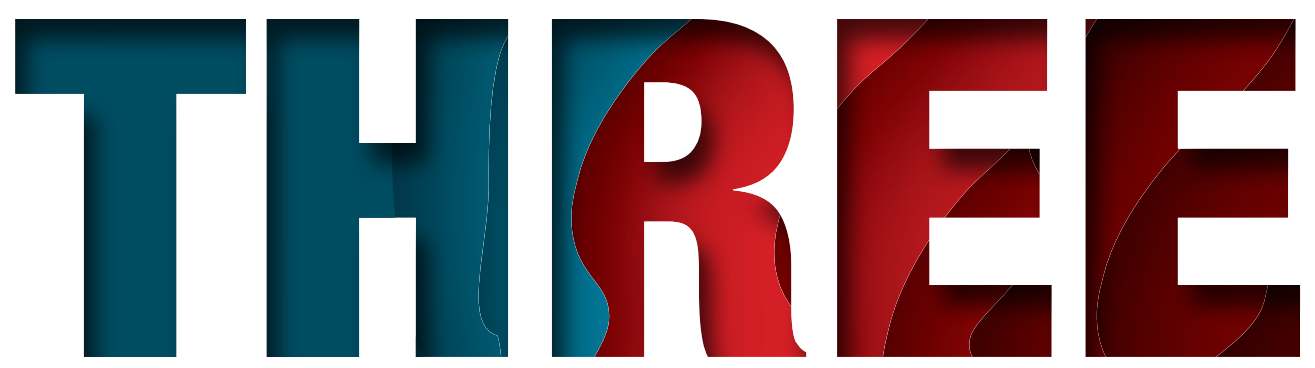


Chronic chest pain 


\section{An uncommon cause of typical cardiac chest pain}

Martijn W. Smulders, MD, ${ }^{1}$ Arthur W.F. du Mee, MD, ${ }^{2}$ Bart de Vries, MD, PhD, ${ }^{3}$ Peyman Sardari Nia, MD, $\mathrm{PhD}^{4}$

Department of ${ }^{1}$ Cardiology, ${ }^{2}$ Radiology, ${ }^{3}$ Pathology, ${ }^{4}$ Cardiothoracic Surgery, Maastricht University Medical Center, Maasticht, The Netherlands 


\section{CASE REPORT}

A 64-year-old woman presented with typical angina during exercise for 2 weeks. An exercise treadmill test provoked similar chest pain and showed abnormal ST segments suggestive of myocardial ischemia during peak exercise. A prospectively ECG-triggered adaptive dual-source coronary computed tomography angiography ruled out coronary artery disease. Instead it demonstrated a nonenhanced clover-like structure attached to the left coronary cusp of the aortic valve with a close relation to the left coronary sinus (Figure 1A). Subsequent transthoracic and transesophageal echocardiography confirmed a very mobile mass with a stalk-like attachment to the cusp (Figure 1B and Movie 1). A papillary fibroelastoma was considered highly likely, and urgent minimal invasive surgical removal of the tumor was performed to prevent thrombi-embolic complications and direct mechanical obstruction (Figure 1C). Histopathologic examination proved the diagnosis of papillary fibroelastoma (Figure 1D). After surgery, the patient was free of symptoms and remains so to date. This case illustrates that chest pain has a broad differential diagnosis including nonatherosclerotic coronary myocardial disease. Noninvasive imaging might clarify the underlying etiology in patients with chest pain.

\section{Figure 1.}

A papillary fibroelastoma as a cause for chest pain.

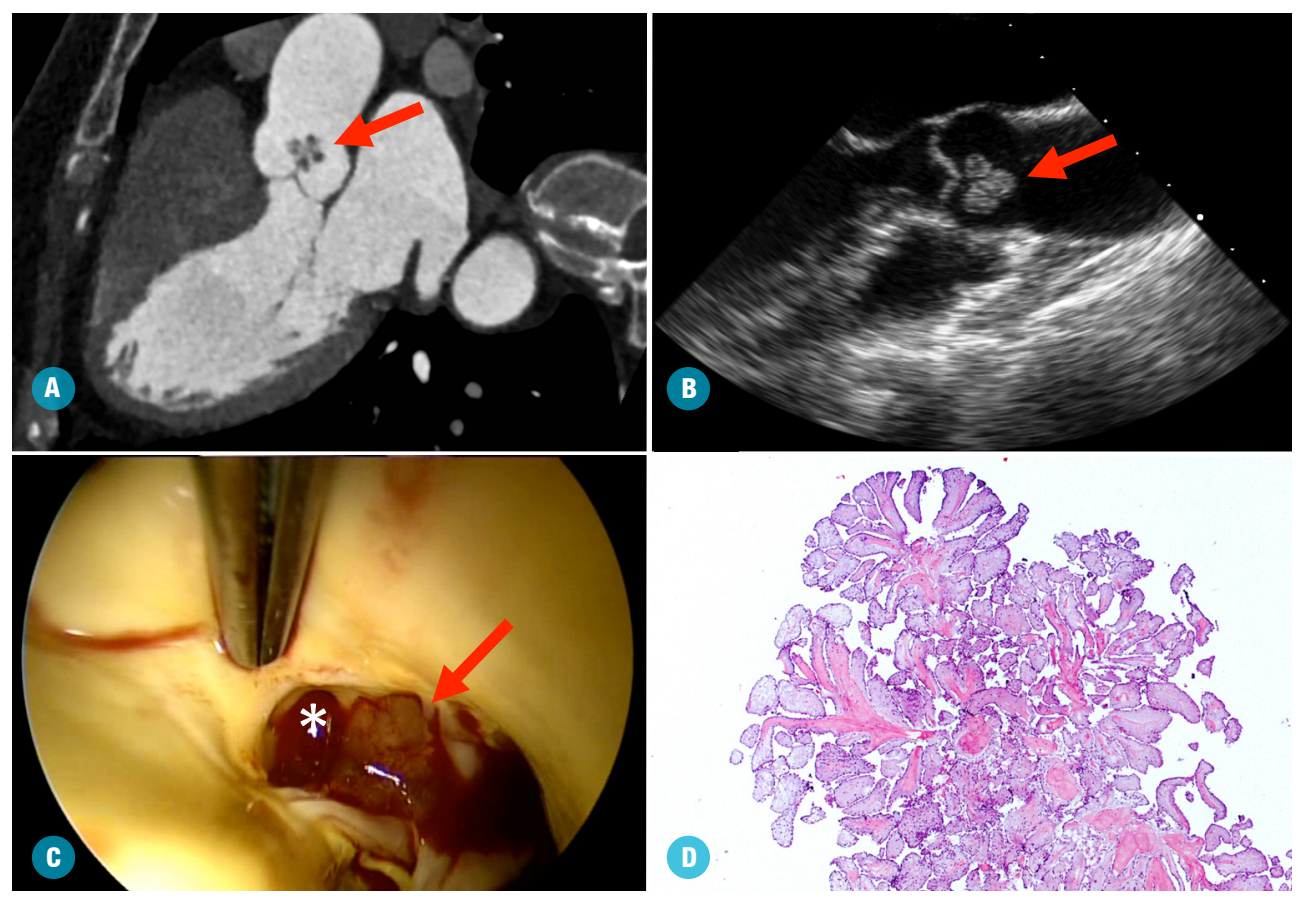

A, Computed tomography angiography image reconstructed in the left ventricular outflow tract plane shows a nonenhanced tumor (arrow) attached to the aortic valve. B, A heavily mobile mass (arrow) was found on a transesophageal echocardiogram. C, Photograph taken periprocedurally just before removal of the tumor. It demonstrates the close relation of the tumor (arrow) with the coronary ostium (asterisk). D, Microscopy imaging confirming the diagnosis papillary fibroelastoma. 
Movie 1.

3D Transesophageal Echocardiography real-time image and multiplanar reconstructions of the aortic valve in a patient with a papillary fibroelastoma.
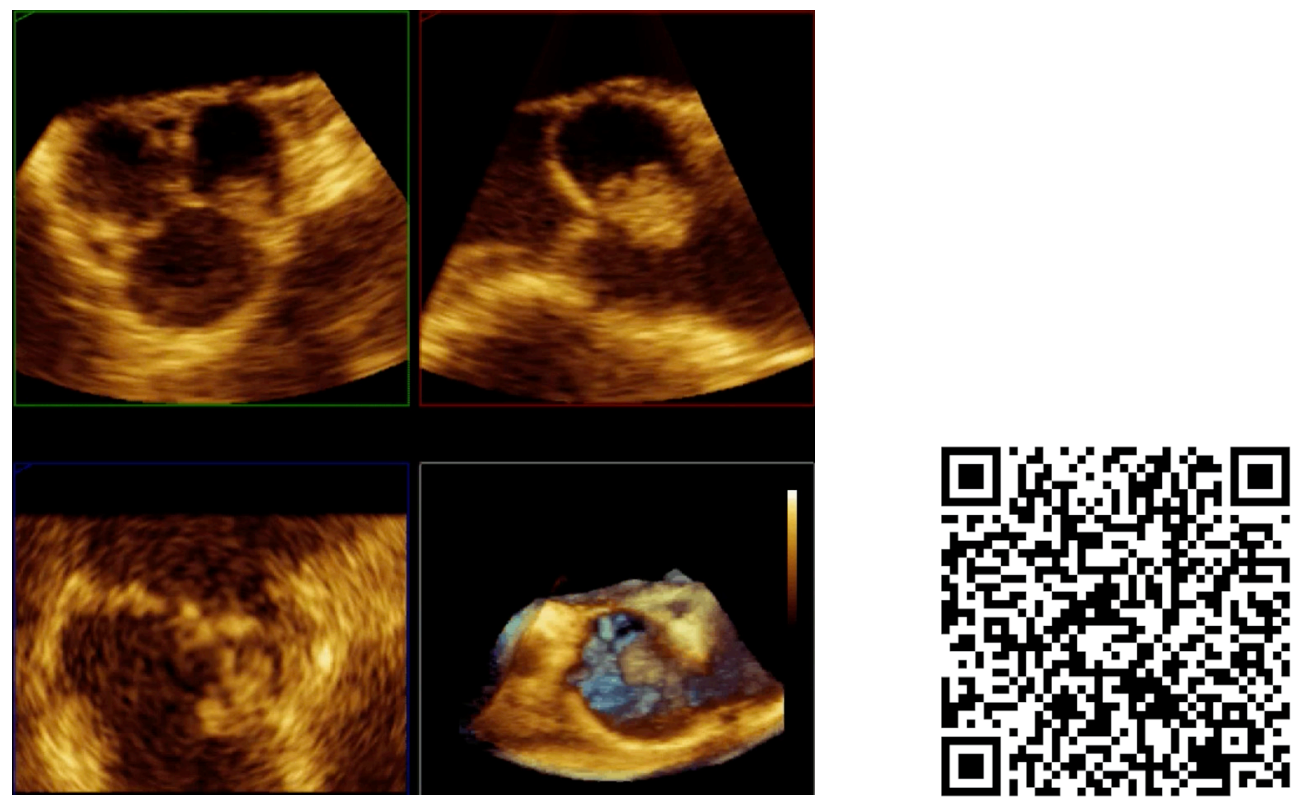

Note the heavily mobile mass attached to the valve near the origin of the left coronary artery. 


\section{Comparison of the prognostic value of negative non-invasive cardiac investigations in patients with suspected or known coronary artery disease - a meta-analysis}

Martijn W. Smulders, MD, ${ }^{1,2^{*}}$ Caroline Jaarsma, MD, PhD, ${ }^{1 *}$ Patricia J. Nelemans, MD, PhD, ${ }^{3}$ Sebastiaan C.A.M. Bekkers, MD, PhD, ${ }^{1,2,4}$ Jan Bucerius, MD, ${ }^{2,5,6}$ Tim Leiner, MD, PhD, ${ }^{7}$ Harry J.G.M. Crijns, MD, PhD, ${ }^{1,2}$ Joachim E. Wildberger, MD, PhD, ${ }^{2,4}$ Simon Schalla, $\mathrm{MD}, \mathrm{PhD}^{1,2,4}$

* Authors contributed equally to this work.

Department of ${ }^{1}$ Cardiology, ${ }^{2}$ Cardiovascular Research Institute Maastricht (CARIM), ${ }^{3}$ Epidemiology, ${ }^{4}$ Radiology, ${ }^{5}$ Nuclear Medicine, Maastricht University Medical Center, Maasticht, The Netherlands, and department of ${ }^{6}$ Nuclear Medicine, University Hospital Aachen, Aachen, Germany, and department of ${ }^{7}$ Radiology, Utrecht University Medical Center, Utrecht, The Netherlands 


\title{
ABSTRACT
}

\begin{abstract}
Aims
To compare the prognostic value of negative non-invasive cardiac investigations (coronary computed tomographic angiography [CCTA], cardiovascular magnetic resonance [CMR], exercise electrocardiographic testing [EET], positron emission tomography [PET], stressechocardiography [SE], and single-photon emission tomography [SPECT]) in patients with suspected or known coronary artery disease (CAD) and to explore the effect of adjustment for population event risk and presence of CAD.
\end{abstract}

\section{Methods and results}

MEDLINE/PubMed database, EMBASE and Cochrane Library were searched from January-1990 to April-2015 for studies reporting annual event rates (AER) of myocardial infarction (MI) and cardiac death. Pooled estimates of AERs were calculated using a DerSimonian and Laird random-effects model. Multivariable linear meta-regression analysis was performed to compare the AER after a negative test result between modalities and to adjust for population event risk and proportion of patients with CAD. In 165 studies (122,721 patients), pooled AERs after negative test results differed significantly between modalities ranging from $0.32 \%$ for CCTA to $1.66 \%$ for $\mathrm{SE}, \mathrm{P}<0.001$. However, the AER after a negative test result was positively correlated $(r=0.726, P<0.001)$ with population event risk. Adjusting for population event risk and proportion of patients with CAD resulted in more similar event rates after a negative test result.

\section{Conclusion}

This meta-analysis is the first study comparing the prognostic value of all available non-invasive cardiac investigations. Outcome differences between modalities after a negative test result are profoundly influenced by large variations in population event risk and a negative test result for all modalities conveys an excellent prognosis for patients with suspected or known CAD. 


\section{INTRODUCTION}

Non-invasive cardiac investigations such as coronary computed tomographic angiography (CCTA), cardiovascular magnetic resonance imaging (CMR), exercise electrocardiographic testing (EET), positron emission tomography (PET), stress echocardiography (SE), and single-photon emission tomography (SPECT) are increasingly being applied for risk stratification of patients with suspected or known coronary artery disease (CAD). The prognostic value is one of the most clinically relevant features of cardiovascular investigations. ${ }^{1-9}$ Risk stratification is important to identify patients at low risk for future cardiovascular events as opposed to patients that may benefit from medical therapy or coronary revascularization. ${ }^{2,9}$ Therefore, a negative test result should reassure both patient and physician that further downstream testing can be safely withheld. Previous systematic reviews were mostly limited to 1 or 2 modalities, studied a highly selected population or compared dedicated study protocols (e.g. exercise SPECT and $\mathrm{SE}) .3,4,6,8$ To the best of our knowledge, a comprehensive analysis and comparison of all different non-invasive cardiac investigations based on the published data has not been performed in one study before. Additionally, the influence of the pre-test probability on differences of the prognostic value of a negative cardiac investigation test result between all non-invasive modalities has not been explored in a single study.

This meta-analysis was conducted to provide a higher level of evidence on the prognostic value of a negative non-invasive cardiac investigation test result for all commonly used modalities in patients with suspected or known CAD. The primary purpose of this study was to compare the prognostic value of negative non-invasive cardiac investigation test results while accounting for differences in population event risk and the proportion of patients with known CAD.

\section{METHODS}

\section{Data sources and searches}

We searched the MEDLINE/PubMed, EMBASE, and Cochrane Library databases for English literature from January 1990 to April 2015 on the prognostic value of different non-invasive cardiac investigations in patients with suspected or known CAD. We used the following Medical Subject Headings (MESH) and search terms: 'exercise test', 'bicycle ergometry test', 'electrocardiography', 'imaging, magnetic resonance', 'single photon emission computed tomography', 'positron emission tomography', 'stress echocardiography', 'computed tomography', ' $x$ ray', 'prognosis', and 'coronary artery disease'. The exact search terms used for MEDLINE are available in Supplementary data online, Appendix A.

Additionally, we screened the bibliographies of all selected articles, relevant reviews, and meta-analyses for potential suitable references. Only peer reviewed and published studies were included (e.g. no abstracts). Authors were not contacted for additional information not given in the main manuscript, tables or appendices. The final study selection was undertaken in consensus by two reviewers.

\section{Study selection}

Studies assessing the prognostic value of CCTA, CMR perfusion (CMR-perf), CMR wall motion (CMR-wm), EET, PET, SE, or SPECT in patients with suspected or known CAD with a follow-up of at least 3 months were eligible for inclusion. We included studies reporting absolute numbers or an annual event rate (AER) of cardiac death and non-fatal myocardial infarction (MI) for patients with a negative test. The primary aim of this study was to compare the prognostic value after a negative test between all non-invasive cardiac investigations in patients with suspected 
or known CAD. Therefore, we excluded studies that only screened asymptomatic subjects or highly specific populations such as patients with a (non-)ST elevation MI, severe left ventricular dysfunction or immediately after revascularization.

Care was taken to identify and exclude duplicate patient populations. Articles published by the same research group were included only if it was unambiguous that different patient populations had been included, otherwise the study with the largest sample size was selected. If more than one diagnostic test had been evaluated within a single publication (e.g. EET and SPECT), each modality was considered separately when possible. Studies reporting multiparametric imaging protocols were included only if data on the individual imaging parameter or technique was derivable. The current meta-analysis was performed according to the MOOSE and PRISMA guidelines (checklists available see Supplementary data online, Appendixes B and C)..$^{10}$

\section{Definitions and data extraction}

The definition of a negative test result differed for each modality. For the purpose of the current study, we defined a negative test result as 1) $<50 \%$ luminal narrowing on CCTA, 2) absence of reversible wall motion abnormalities on CMR-wm or SE, 3) absence of reversible perfusion defects on CMR-perf, PET, or SPECT, or 4) absence of ST-segment depression on EET. It was considered sufficient if a perfusion or wall motion study only presented data for patients without any abnormalities (i.e. 'neither fixed nor reversible' wall motion abnormalities or perfusion defects).

We extracted general information about the study such as first author, journal, and year of publication. Other variables of interest consisted of design (i.e. retrospective or prospective), patient and study characteristics (e.g. mean age, proportion of patients with CAD at baseline, and sample size), technical information on the specific non-invasive cardiac investigation (e.g. tracer, stressor), and follow-up duration. Subsequently, we extracted all derivable absolute numbers and AERs (with 95\% confidence intervals [CI]) for cardiac death and $\mathrm{MI}$ after a negative test result. If available, total event rates of cardiac death and MI during follow-up, i.e. population event risk, were also recorded as indicators of baseline event risk in the entire study population regardless of the test result. Total event rates were derived only from studies reporting event rates for the total population and regardless of the test result. Two investigators derived the data and discrepancies were resolved in consensus by a third investigator.

\section{Quality assessment}

Study quality assessment was performed for each study using a 6-point scoring system adapted from the Newcastle-Ottawa Scale for the assessment of quality of observational studies. ${ }^{11}$ The following parameters were scored: (1) representative study population (i.e. no selection bias), (2) adequate description of patient characteristics (i.e. age, sex, and history of CAD, MI, or revascularization [1 point was added if all characteristics were appropriately described]) (3) outcome of interest not present at start of the study, (4) confirmation of outcome by corroboration by e.g. medical records, (5) follow-up duration of $\geq 1$ year, (6) complete follow-up of $\geq 90 \%$ of the study population. Studies scoring 6 points on this adapted Newcastle-Ottawa Scale were considered as studies with high quality.

\section{Data synthesis and analysis}

A pooled estimate of the annual probability of future cardiac death or $\mathrm{MI}$ in patients with negative test results was calculated for each non-invasive modality. AERs were derived from individual 
Figure 1.

Flow chart of literature search and study selection.

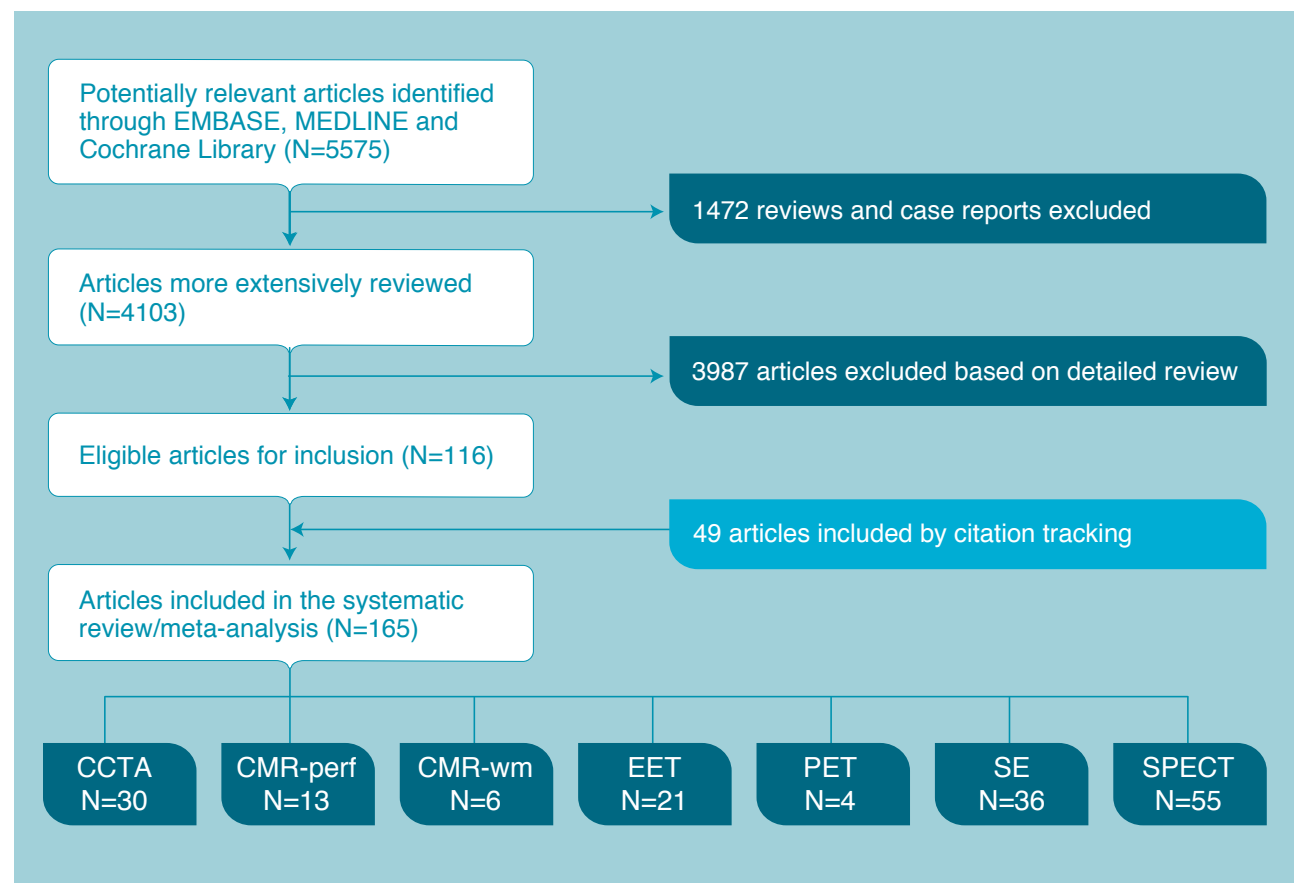

studies or were calculated by dividing the total number of recorded events (cardiac death or MI) by the mean or median follow-up period, assuming a constant event rate during follow-up..$^{12}$ In concordance with current guidelines, the number of cardiac deaths or MI was considered the most appropriate endpoint for prognostic risk assessment. ${ }^{9}$ To stabilize variance of the proportions from individual studies, Freeman-Tukey arcsine square root transformed proportions were pooled using a DerSimonian and Laird random-effects model. ${ }^{13}$ The weighted mean of the transformed proportions was back transformed for calculation of pooled AERs after negative test results. Additional subgroup analyses were performed to investigate the influence of study design (i.e. prospective and retrospective), stressor (i.e. pharmacological and exercise testing), and follow-up duration (stratified by the median follow-up) on the differences of the prognostic value after a negative test result between all non-invasive cardiac investigations.

Multivariable linear meta regression analysis was used for comparing modalities with respect to AER after a negative test result. Modalities were coded by dummy variables and the modality associated with the lowest unadjusted AER after a negative test result was nominated as the reference category. The regression coefficient with $95 \%$ confidence interval corresponding with a specific modality indicates the difference in pooled proportions compared to the reference category. To adjust for potential confounding by population event risk and proportion of patients with CAD at baseline, these variables were entered as covariates in the meta-regression model. Adjusted regression coefficients were used to estimate the annual risk of events after a negative test result for each modality at a constant population event risk and proportion of patients with 
pre-existing CAD. For this purpose, we estimated pooled AER for each modality using the pooled estimate of population event risk and/or proportion of patients with pre-existing CAD.

Heterogeneity of the study results was examined using tau squared statistics and the $I^{2}$ index. The $\mathrm{I}^{2}$ estimates the percentage of total variation across studies and modalities that can be attributed to differences between studies rather than chance, an $\mathrm{I}^{2}$ of $0 \%$ indicates no heterogeneity. ${ }^{14}$ Differences in results between studies with small vs. large sample size were evaluated by the Egger test for funnel plot asymmetry. The intercept of the regression line provides a measure for asymmetry. Values $<0.1$ were considered as indicative of funnel plot asymmetry because of limited power of the test.

In all other analyses, P-values $<0.05$ were considered to indicate statistical significance. All analyses were performed using Statsdirect (v. 2.8.0, Cheshire, UK) and Stata (v. 11, College Station, Texas, USA).

\section{RESULTS}

\section{Literature search}

The initial literature search yielded 5575 potentially relevant references, of which 1472 reviews and case reports were excluded. A more detailed review of the 4103 remaining articles led to the exclusion of another 3987 articles, resulting in 116 articles eligible for inclusion. Citation tracking identified an additional 49 articles. Ultimately, 165 studies met our inclusion criteria: 30 CCTA, 13 CMR-perf, 6 CMR-wm, 21 EET, 4 PET, 36 SE, and 55 SPECT studies (Figure 1).

\section{Characteristics of included studies}

A total of 122,721 patients were included in this meta-analysis. The mean follow-up time was 2.7 \pm 1.7 years and the median follow-up 2.3 years with an interquartile range of 1.5-3.4. Seventy-four percent of studies had a mean follow-up time of $<3$ years. The mean age was $60 \pm 5$ years and $55 \%$ of the population was male. Overall, $19 \%$ of patients had known CAD at baseline and $15 \%$ had a history of MI. The prevalence of CAD at baseline differed considerably between modalities from $3 \%$ for CCTA to $51 \%$ for CMR-wm (Table 1). The overall study quality score was 5 (SD 1) points and $16 \%$ of the studies were scored as having a high quality (i.e. 6 points, see Supplementary data online, Appendix D). The characteristics, outcome data and references of all studies included are presented in the appendix (see Supplementary data online, Appendix E Tables A1a-A7a and references).

\section{Comparison of annualized event rates after a negative test result between modalities}

For all 7 modalities, a negative test result was associated with a low AER for future cardiac death and MI. A first comparison without adjustment for baseline risk and based on all 165 studies indicated that a negative CCTA test result was associated with the lowest pooled AER (i.e. $0.32 \%$ [95\% $\mathrm{Cl} 0.22-0.43]$ ) and differed significantly from CMR-wm, EET, SE, and SPECT (Figure 2A). The prognostic value of CMR-perf and PET did not significantly differ from CCTA. The AERs after a negative test result for each individual study are presented in Forest plots (see Supplementary data online, Appendix F). Subgroup analyses showed that differences in the prognostic value after a negative test result between the non-invasive cardiac investigations were not influenced by the study design or follow-up duration (see Supplementary data online, Appendix G). For SE and SPECT studies, the pooled AERs after a negative test were lower for studies using exercise stress $(1.23 \%$ [95\% Cl 0.68-1.94] and $1.04 \%$ [95\% $\mathrm{Cl} 0.67-1.49])$ than 
for studies using pharmacological stress $(1.94 \%$ [95\% Cl 1.22-2.82] and $1.88 \%[95 \% \mathrm{Cl}$ 1.01-3.01]), although this difference was not statistically significant $(P=0.387$ and $P=0.132$, respectively). Restriction of the analysis to 45 studies which included only patients with suspected CAD (thus without known CAD), resulted in lower AERs after a negative test and a substantial reduction of differences between modalities (Figure 2B).

Table 1.

Characteristics of all included studies $(n=165)$.

\begin{tabular}{|l|l|l|l|l|l|l|l} 
& $\begin{array}{l}\text { Median } \\
\text { follow-up } \\
\text { in years (IQR) }\end{array}$ & $\begin{array}{l}\text { Male } \\
\text { gender }\end{array}$ & $\begin{array}{l}\text { Age in years } \\
\text { (SD) }\end{array}$ & $\begin{array}{l}\text { Known } \\
\text { CAD / MI }\end{array}$ & $\begin{array}{l}\text { Patients with } \\
\text { a negative } \\
\text { test (n) }\end{array}$ & $\begin{array}{l}\text { Patients with } \\
\text { a negative } \\
\text { test (\%) }\end{array}$ & $\begin{array}{l}\text { Total } \\
\text { patients } \\
\text { (n) }\end{array}$ \\
\hline CCTA & $1.9(1.2-3.3)$ & $57 \%$ & $51(4)$ & $3 \% / 1 \%$ & 13,888 & $77 \%$ & 18,020 \\
\hline CMR-perf & $1.8(1.2-2.5)$ & $59 \%$ & $60(4)$ & $38 \% / 22 \%$ & 3,394 & $66 \%$ & 5,112 \\
\hline CMR-wm & $2.1(2.0-3.3)$ & $66 \%$ & $63(1)$ & $51 \% / 27 \%$ & 4,736 & $76 \%$ & 6,199 \\
\hline EET & $3.1(1.8-4.1)$ & $64 \%$ & $56(4)$ & $23 \% / 17 \%$ & 12,021 & $75 \%$ & 16,040 \\
\hline PET & $2.3(2.2-2.6)$ & $36 \%$ & $62(2)$ & $24 \% / 9 \%$ & 1,796 & $68 \%$ & 2,627 \\
\hline SE & $2.4(1.2-3.7)$ & $54 \%$ & $61(6)$ & $28 \% / 23 \%$ & 14,506 & $72 \%$ & 20,086 \\
\hline SPECT & $2.3(1.9-3.6)$ & $51 \%$ & $62(6)$ & $15 \% / 14 \%$ & 42,521 & $78 \%$ & 54,637 \\
\hline
\end{tabular}

$\mathrm{CAD}=$ coronary artery disease. $\mathrm{CCTA}=$ coronary computed tomographic angiography. $\mathrm{Cl}=$ confidence interval. CMR-perf $=$ cardiovascular magnetic resonance perfusion. CMR-wm $=$ cardiovascular magnetic resonance wall motion. EET $=$ exercise electrocardiographic testing. $\mathrm{IQR}=$ interquartile range. $\mathrm{MI}=$ myocardial infarction. PET=positron emission tomography. SD = standard deviation. SE = stress echocardiography. SPECT = single-photon emission tomography.

\section{Influence of the population event risk on the prognosis after a negative test result}

Data on the population event risk (as indicator of baseline risk in the entire study population regardless of the test result) could be derived from 119 studies, including 53,454 patients with a negative test result. This subset of 119 studies was representative for all 165 studies included as similar event rates after a negative test result were observed for all modalities (see Supplementary data online, Appendix H). In these 119 studies, the AER after a negative test result was positively correlated with the population event risk, with an overall $r=0.726$ and $P$ $<0.001$ (Figure 3). Furthermore, this figure illustrates that certain modalities were generally evaluated in study populations at higher event risk (e.g. for SE total AER $3.82 \%[95 \% \mathrm{Cl}$ 2.76-5.03]) than other modalities (e.g. for CCTA total AER $0.74 \%$ [95\% $\mathrm{Cl} 0.46-1.09]$, which is five times lower than for SE). Multivariable linear meta regression analysis with adjustment for annualized population event risk was performed. The results were used to estimate the annual risk of events after a negative test result for each modality at a population event risk of $2.06 \%$, in the 119 studies. Differences between modalities in AER after a negative test result (Figure 2C) became substantially smaller when adjusting for the between modality differences in population event risk. The $\mathrm{I}^{2}$ index decreased from $64.7 \%$ to $32.0 \%$. However, AER after negative EET, SE, and SPECT remained higher than the risk of adverse events after a normal CCTA. An analysis with adjustment for both population event risk (i.e. 2.06\%) and proportion of patients with known CAD at baseline (i.e. $25 \%$ ) could be performed in a subset of 71 studies that provided information 
Figure 2.

Pooled annualized event rates (AER) for cardiac death and myocardial infarction after a negative test result for all commonly used non-invasive cardiac investigations.
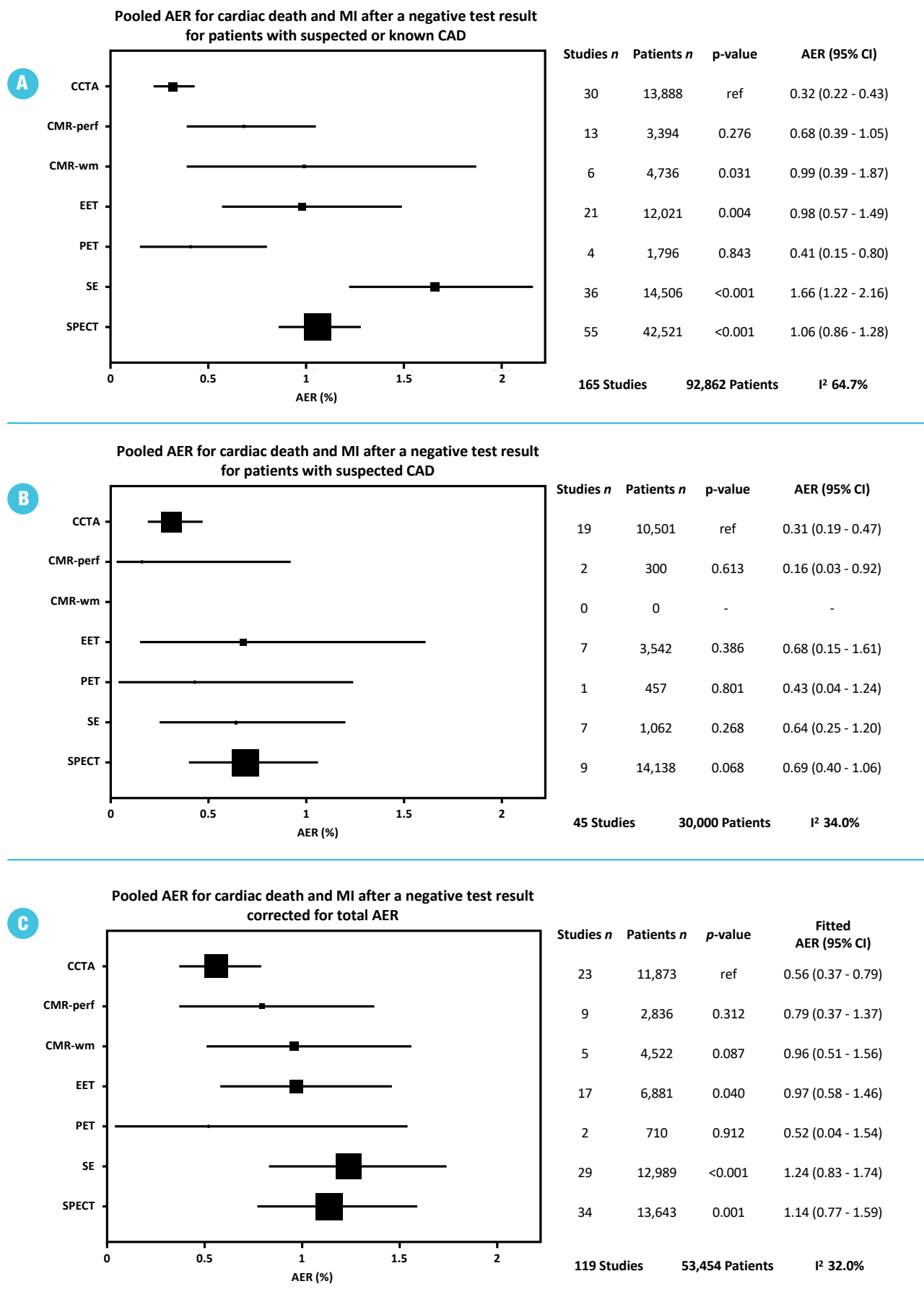

\begin{tabular}{|c|c|c|c|}
\hline Studies $n$ & Patients $n$ & $p$-value & $\begin{array}{c}\text { Fitted } \\
\text { AER }(95 \% \mathrm{Cl})\end{array}$ \\
\hline 23 & 11,873 & ref & $0.56(0.37-0.79)$ \\
\hline 9 & 2,836 & 0.312 & $0.79(0.37-1.37)$ \\
\hline 5 & 4,522 & 0.087 & $0.96(0.51-1.56)$ \\
\hline 17 & 6,881 & 0.040 & $0.97(0.58-1.46)$ \\
\hline 2 & 710 & 0.912 & $0.52(0.04-1.54)$ \\
\hline 29 & 12,989 & $<0.001$ & $1.24(0.83-1.74)$ \\
\hline 34 & 13,643 & 0.001 & $1.14(0.77-1.59)$ \\
\hline $119 \mathrm{St}$ & & 154 Patients & $I^{2} 32.0 \%$ \\
\hline
\end{tabular}




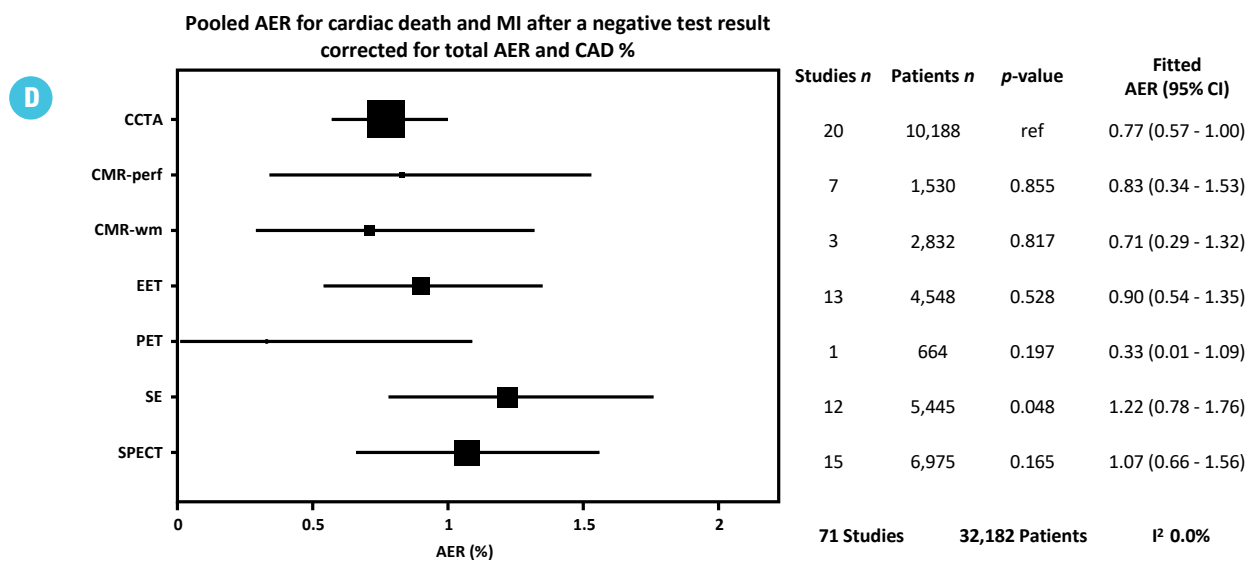

Panel A presents the pooled AER for all studies in patients with suspected or known CAD and panel B shows the results for studies including patients suspected for CAD only. Panel $C$ and panel $D$ represent the fitted AERs per modality after a negative test result adjusted for 'population event risk' and 'population event risk and prevalence of CAD', respectively. The weighted mean of the transformed proportions was back transformed for calculation of the adjusted (fitted) AER after a negative test result. The adjusted AER after a negative test result was fitted for the annualized population event risk (i.e. $2.06 \%$ [95\% $\mathrm{Cl} 1.72-2.43]$, panel $\mathrm{C}$ and $\mathrm{D}$ ) and proportion of patients with $\mathrm{CAD}$ (i.e. $25 \%$, panel D) in this subset of 119 and 71 studies. For clarification and interpretation of panel $D$, the characteristics of the included SPECT studies were relatively close to the mean population event risk and proportion of patients with baseline presence of CAD, while CCTA studies differed substantially with a lower population event risk and near absence of CAD at baseline. Therefore, adjustment to the overall mean did not substantial shift the results for SPECT (panel A vs. panel D), but fitting the AER of the CCTA studies to the mean population even risk and baseline presence of CAD (thus towards a higher risk for CCTA) resulted in a much higher adjusted AER.

on these two potential confounders. Heterogeneity between study results decreased further to an $1^{2}$ of $0 \%$. The discrepancies in pooled AERs at a population event risk of $2.06 \%$ and proportion with pre-existing $\mathrm{CAD}$ of $25 \%$ became even smaller resulting in a rather similar prognosis after a negative test result, although AER after a negative SE test was still slightly higher in comparison with a normal CCTA test result $(P=0.048$, Figure 2D and see Supplementary data online, Appendix H).

\section{DISCUSSION}

The current study is, to the best of our knowledge, the first meta-analysis comparing the prognostic value of a negative test result between all commonly used non-invasive cardiac investigations in patients with suspected or known CAD. Our results strengthen the general concept that a negative test result yields an excellent prognosis for all modalities. However, we also demonstrate that significant differences exist between modalities, with pooled AERs for cardiac death and $\mathrm{MI}$ ranging from $0.32 \%$ for CCTA to $1.66 \%$ for SE after a negative test result and that this variation was highly associated with the population event risk, which differed up to five-fold across modalities. Adjusting for the population event risk and the proportion of patients with pre-existing CAD resulted in absence of heterogeneity between study results and a more similar prognosis after a negative test result. 


\section{Figure 3.}

The annualized event rates (AER) for cardiac death and myocardial infarction after a negative test result in relation to population event risk.

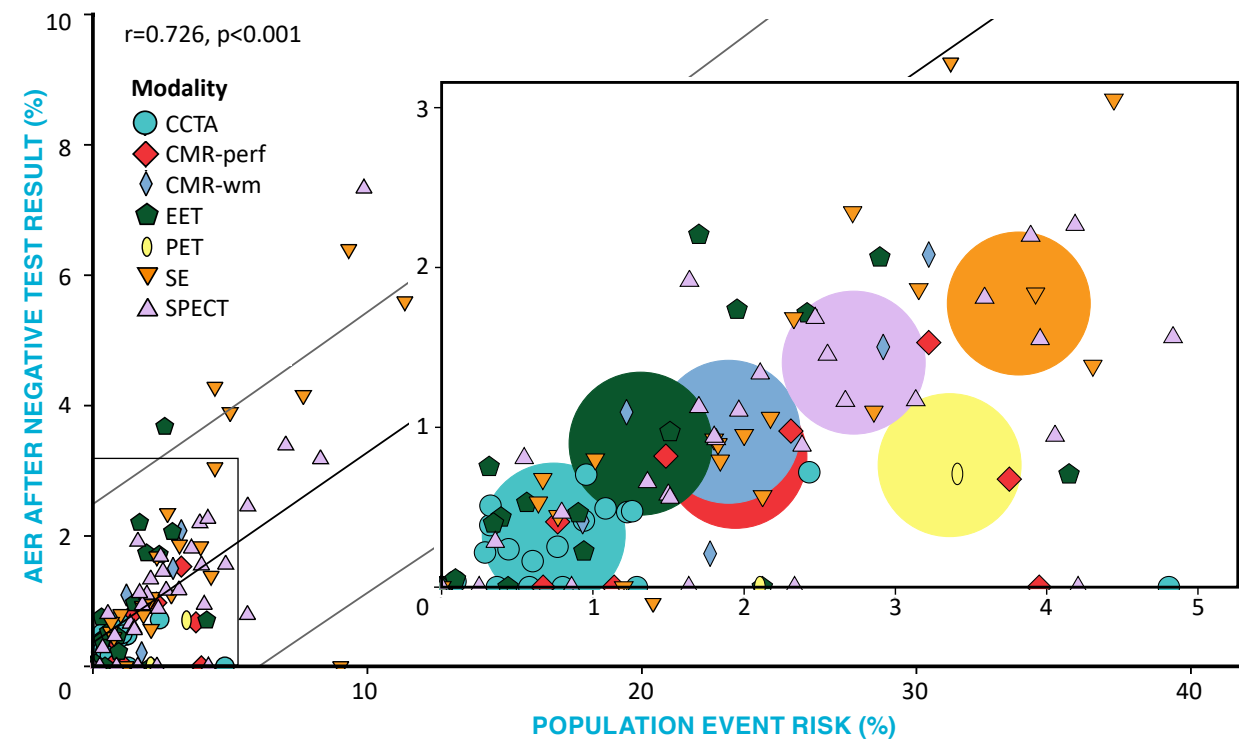

\begin{tabular}{l|l|l|l|l|l|l|l|}
\hline CGCTA & CMR-perf & CMR-wm & EET & PET & SE & SPECT \\
\hline Studies $n$ & 23 & 9 & 5 & 17 & 2 & 29 & 34 \\
\hline Patients $n$ & 15,937 & 4,423 & 5,985 & 10,579 & 1,556 & 18,569 & 25,574 \\
\hline $\begin{array}{l}\text { Negative } \\
\text { test \% }\end{array}$ & 74 & 64 & 76 & 65 & 46 & 70 & 53 \\
\hline $\begin{array}{l}\text { Follow up } \\
\text { median in } \\
\text { years (IQR) }\end{array}$ & $\begin{array}{l}2.00 \\
(1.30-3.30)\end{array}$ & $\begin{array}{l}2.50 \\
(1.45-2.90)\end{array}$ & $\begin{array}{l}2.10 \\
(1.55-4.95)\end{array}$ & $\begin{array}{l}2.60 \\
(1.65-3.90)\end{array}$ & $\begin{array}{l}2.00 \\
(1.70-2.30)\end{array}$ & $\begin{array}{l}2.30 \\
(1.05-4.15)\end{array}$ & $\begin{array}{l}2.30 \\
(1.60-3.60)\end{array}$ \\
\hline $\begin{array}{l}\text { Weighted } \\
\text { AER neg test }\end{array}$ & $\begin{array}{l}0.33 \\
(0.22-0.46)\end{array}$ & $\begin{array}{l}0.82 \\
(0.46-1.27)\end{array}$ & $\begin{array}{l}0.97 \\
(0.32-1.97)\end{array}$ & $\begin{array}{l}0.90 \\
(0.44-1.52)\end{array}$ & $\begin{array}{l}0.76 \\
(0.26-1.53)\end{array}$ & $\begin{array}{l}1.77 \\
(1.26-2.37)\end{array}$ & $\begin{array}{l}1.40 \\
(1.05-1.81)\end{array}$ \\
\hline $\begin{array}{l}\text { Population } \\
\text { event risk }\end{array}$ & $\begin{array}{l}0.74 \\
(0.46-1.09)\end{array}$ & $\begin{array}{l}1.94 \\
(1.18-2.89)\end{array}$ & $\begin{array}{l}1.90 \\
(1.07-2.95)\end{array}$ & $\begin{array}{l}1.32 \\
(0.71-2.10)\end{array}$ & $\begin{array}{l}3.36 \\
(2.52-4.31)\end{array}$ & $\begin{array}{l}3.82 \\
(2.76-5.03)\end{array}$ & $\begin{array}{l}2.72 \\
(2.11-3.42)\end{array}$ \\
\hline
\end{tabular}

For each study $(n=119)$, the AER after a negative test result is presented in relation to the population event risk regardless of the test. The AER after a negative test result was positively correlated with the population event risk, with an overall $r=0.726$ and $P<0.001$. The box in the centre is a magnification of the smaller box in the lower left corner of the main figure (no data points exist behind the magnification). The larger circles in the magnified diagram represent the weighted $A E R$ for each modality.

$\mathrm{AER}=$ annualized event rate, $\mathrm{CAD}=$ coronary artery disease, $C C T A=$ cardiac computed tomography angiography, CMR-perf = cardiovascular magnetic resonance perfusion imaging, CMR-wm = cardiovascular magnetic resonance wall motion imaging, EET = exercise electrocardiography, IQR $=$ interquartile range, $\mathrm{PET}=$ positron emission tomography, ref = reference, $\mathrm{SE}=$ stress echocardiography, $\mathrm{SPECT}$ = single-photon emission computed tomography. 
Over the last decades, non-invasive cardiac investigations have emerged as a robust element in the work-up of patients with suspected or known CAD..$^{1-9}$ Although non-invasive investigations are initially used as a diagnostic tool, its prognostic value after a negative test result is important. A negative test result should reassure both patient and physician, obviating the need for further downstream testing or therapy. Referral of patients to the appropriate modality should be based on the pre-test probability. 2,9 In addition, according to Bayes' theorem, the pre-test probability should also be considered when evaluating the prognostic value of a negative test result between modalities. ${ }^{15}$ In the current study, we calculated the actual pre-test probability (population event risk) by pooling the number of events in the entire population (i.e. regardless of the test result) for each modality. This provided insight into the differences in baseline risk of populations referred to the studied modalities. Considerable variations in the pooled estimates of population event risk (ranging from $0.74 \%$ in CCTA studies to $3.82 \%$ in SE studies) and baseline prevalence of known CAD (ranging from $3 \%$ for CCTA to 51\% for CMR-wm) were observed between modalities, indicating that some tests are applied in patients at lower risk and others in patients at higher risk. Furthermore, differences in population event risk substantially affected the comparison of the prognostic value of a negative test result. Thus, the general belief that CCTA has a superior negative predictive value is not supported by the results from our meta-analysis, since we uniquely show that the apparently superior negative predictive value of CCTA is merely a result of studies including low risk populations and disappears with adjustment.

Of the seven non-invasive cardiac investigations included in this study, the majority was based on the detection of myocardial ischaemia (i.e. perfusion defects, wall motion abnormalities, or electrocardiographic changes) while CCTA evaluated the coronary anatomy and severity of stenosis. CCTA is currently able to gauge the haemodynamic significance of CAD by using non-invasive fractional flow reserve or CT perfusion, but data on their prognostic value is still limited. ${ }^{16-19}$ According to the definition of the studies included in the current meta-analysis, a negative test result was defined as either $<50 \%$ luminal narrowing on CCTA or the absence of ischaemia for all other cardiac investigations. Notably, a negative test result does not rule out the presence of other prognostic indicators such as non-obstructive CAD, coronary calcifications, myocardial fibrosis or wall motion abnormalities at rest. ${ }^{3,20,21}$ Although CCTA is able to evaluate the presence of non-obstructive CAD, the appropriate treatment and associated prognostic implications of these findings are presently still unclear. ${ }^{3}$ The recent PROMISE trial showed that a strategy using anatomical testing (i.e. CCTA) or functional testing (i.e. EET, SPECT, or SE) in patients suspected for CAD resulted in similar outcomes. ${ }^{22}$ Although the outcome data per test result are still awaited, the primary findings of the PROMISE trial are corroborated by the results of our meta-analysis, as we demonstrated similar event rates between modalities for studies investigating patients suspected for CAD only.

In addition to the pre-test probability, the clinical question (e.g. detection of a significant stenosis or myocardial ischaemia) and the prognostic value, other test-specific advantages and disadvantages should also be weighted before ordering a diagnostic test. For instance, EET or SE may be valuable choices since they offer important prognostic information and have many benefits such as widespread availability, low costs, and easy applicability. However, the EET studies often report non-diagnostic tests due to a limited exercise capacity or baseline ECG changes, and SE is known to be highly dependent on operator skills and the constitution of a patient. Exposure to ionizing radiation should always be taken into account when choosing a modality such as CCTA, PET, or SPECT, although substantial advances have been made to reduce the amount of radiation by technical and protocol adjustments. ${ }^{23-25} \mathrm{CMR}$ is a comprehensive imaging modality that offers 
diagnostic versatility, but drawbacks include the confined space within the bore of the magnet and the restricted applicability in patients with ferromagnetic implants. Selecting the appropriate cardiac investigation therefore depends greatly on the clinical setting, the patient's ability to exercise, as well as local availability and expertise.

As with any meta-analysis, our results are subject to heterogeneity between study results and the presence of publication bias. In the current meta-analysis, the results of patients with suspected or known CAD were pooled. Presenting the data for all patients reflects the body of literature most accurately on this topic as the majority of studies investigating non-invasive cardiac investigations consists of a mixed study population and it also represents a typical outpatient clinic population. Possible heterogeneity in patient management during follow-up cannot be excluded, since information regarding possible differences in (medical) therapy was not available on a per-patient basis. A direct comparison between different modalities within the same study population could overcome some of these drawbacks. However, data on the comparison between modalities was sparse and included only 12 studies selected for the current meta-analysis. Furthermore, these 12 studies showed much variation with respect to patient outcome and therefore did not allow a reliable analysis. Another limitation of this meta-analysis is its relatively short follow-up period (with a median follow-up of 2.3 [1.5-3.4] years).

\section{CONCLUSIONS}

Over the last decades, non-invasive cardiac investigations have expanded rapidly and play an important role in the daily management of patients with suspected or known CAD. This meta-analysis gives an overview of the literature on the prognostic value of all non-invasive cardiac investigations. The current study provides a strong level of evidence that a negative non-invasive cardiac investigation test result conveys an excellent prognosis. Differences in outcome after a negative test result between modalities can mainly be explained by significant variations in pre-test probability and proportion of pre-existing CAD. Adjustment for population event risk and proportion of patients with pre-existing CAD resulted in absence of the heterogeneity between study results and an excellent prognosis after a negative test result for all modalities. Even though referral of patients to a specific modality depends on the pre-test probability and clinical scenario, a negative test result should provide reassurance and arguably challenges the need for further downstream testing.

Online supplemental material (e.g. search criteria, check lists, study characteristics and outcome, and references) is available via:

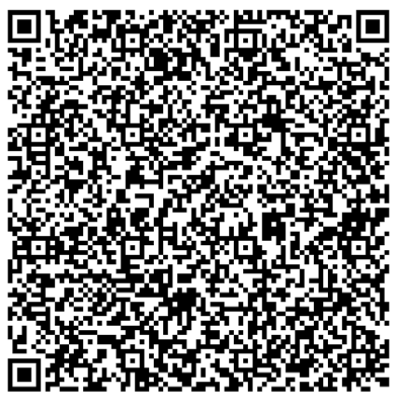




\section{REFERENCES}

1. Dorbala S, Hachamovitch R, Curillova Z, et al. Incremental prognostic value of gated $\mathrm{Rb}-82$ positron emission tomography myocardial perfusion imaging over clinical variables and rest LVEF. JACC Cardiovasc Imaging 2009;2:846-54.

2. Finn SD, Gardin JM, Abrams J, et al. 2012 ACCF/ AHA/ACP/AATS/PCNA/SCAI/STS Guideline for the diagnosis and management of patients with stable ischemic heart disease: a report of the American College of Cardiology Foundation/American Heart Association Task Force on Practice Guidelines, and the American College of Physicians, American Association for Thoracic Surgery, Preventive Cardiovascular Nurses Association, Society for Cardiovascular Angiography and Interventions, and Society of Thoracic Surgeons. J Am Coll Cardiol 2012;60:e44-e164.

3. Hulten EA, Carbonaro S, Petrillo SP, Mitchell JD, Villines TC. Prognostic value of cardiac computed tomography angiography: a systematic review and meta-analysis. J Am Coll Cardiol 2011;57:1237-47.

4. Lipinski MJ, McVey CM, Berger JS, Kramer CM, Salerno M. Prognostic value of stress cardiac magnetic resonance imaging in patients with known or suspected coronary artery disease: a systematic review and meta-analysis. J Am Coll Cardiol 2013;62:826-38.

5. Mark DB, Shaw L, Harrell FE, Jr., et al. Prognostic value of a treadmill exercise score in outpatients with suspected coronary artery disease. N Engl J Med 1991;325:849-53.

6. Metz LD, Beattie M, Hom R, Redberg RF, Grady D, Fleischmann KE. The prognostic value of normal exercise myocardial perfusion imaging and exercise echocardiography: a meta-analysis. J Am Coll Cardiol 2007;49:227-37.

7. Olmos LI, Dakik H, Gordon R, et al. Long-term prognostic value of exercise echocardiography compared with exercise 201TI, ECG, and clinical variables in patients evaluated for coronary artery disease. Circulation 1998;98:2679-86.

8. Rafique AM, Biner S, Ray I, Forrester JS, Tolstrup K, Siegel RJ. Meta-analysis of prognostic value of stress testing in patients with asymptomatic severe aortic stenosis. Am J Cardiol 2009;104:972-7.

9. Task Force M, Montalescot G, Sechtem U, et al. 2013 ESC guidelines on the management of stable coronary artery disease: the Task Force on the management of stable coronary artery disease of the European Society of Cardiology. Eur Heart $\mathrm{J}$ 2013;34:2949-3003.

10. Stroup DF, Berlin JA, Morton SC, et al. Metaanalysis of observational studies in epidemiology: a proposal for reporting. Meta-analysis Of Observational Studies in Epidemiology (MOOSE) group. JAMA : the journal of the American Medical Association 2000;283:2008-12.

11. Wells G, Shea B, O'Connel D. The NewcastleOttawa Scale (NOS) for assessing the quality of nonrandomised studies in meta-analyses. Available at: http://www.ohri.ca/programs/clinical_epidemiology/oxford.asp. 2013.

12. Bamberg F, Sommer WH, Hoffmann V, et al. Metaanalysis and systematic review of the long-term predictive value of assessment of coronary atherosclerosis by contrast-enhanced coronary computed tomography angiography. J Am Coll Cardiol 2011;57:2426-36.

13. DerSimonian R, Laird N. Meta-analysis in clinical trials. Controlled clinical trials 1986;7:177-88.

14. Higgins JP, Thompson SG, Deeks JJ, Altman DG. Measuring inconsistency in meta-analyses. BMJ 2003;327:557-60.

15. Fletcher R, Fletcher SW. Clinical Epidemiology: The Essentials. Lippincott Williams And Wilkins Philadelphia, Pennsylvania, United States of America 2013.

16. Min JK, Leipsic J, Pencina MJ, et al. Diagnostic accuracy of fractional flow reserve from anatomic CT angiography. JAMA 2012;308:1237-45.

17. Rochitte CE, George RT, Chen MY, et al. Computed tomography angiography and perfusion to assess coronary artery stenosis causing perfusion defects by single photon emission computed tomography: the CORE320 study. Eur Heart J 2014;35:1120-30.

18. Douglas PS, Pontone G, Hlatky MA, et al. Clinical outcomes of fractional flow reserve by computed tomographic angiography-guided diagnostic strategies vs. usual care in patients with suspected coronary artery disease: the prospective longitudinal trial of $\mathrm{FFR}(\mathrm{CT})$ : outcome and resource impacts study. Eur Heart J 2015;36:3359-67.

19. Norgaard BL, Leipsic J, Gaur S, et al. Diagnostic performance of noninvasive fractional flow reserve derived from coronary computed tomography angiography in suspected coronary artery disease: the NXT trial (Analysis of Coronary Blood Flow Using CT Angiography: Next Steps). J Am Coll Cardiol 2014;63:1145-55.

20. Kim HW, Klem I, Shah DJ, et al. Unrecognized non-Q-wave myocardial infarction: prevalence and prognostic significance in patients with suspected coronary disease. PLoS Med 2009;6:e1000057.

21. Polonsky TS, McClelland RL, Jorgensen NW, et al. Coronary artery calcium score and risk classification for coronary heart disease prediction. JAMA : the journal of the American Medical Association 2010;303:1610-6.

22. Douglas PS, Hoffmann U, Patel MR, et al. Outcomes of anatomical versus functional testing for coronary artery disease. The New England journal of medicine 2015;372:1291-300.

23. Chang SM, Nabi F, Xu J, Raza U, Mahmarian JJ. Normal stress-only versus standard stress/rest myocardial perfusion imaging: similar patient mortality with reduced radiation exposure. J Am Coll Cardiol 2010;55:221-30.

24. Fazel R, Krumholz HM, Wang Y, et al. Exposure to low-dose ionizing radiation from medical imaging procedures. The New England journal of medicine 2009;361:849-57.

25. Lell MM, Wildberger JE, Alkadhi H, Damilakis J, Kachelriess M. Evolution in Computed Tomography: The Battle for Speed and Dose. Invest Radiol 2015;50:629-44. 


\section{Editorial Comment}




\section{Cardiac investigation for prognosis in coronary artery disease: where negative is positive}

Roxy Senior, MD, and Rajdeep S. Khattar, MD

Department of Cardiology, Royal Brompton Hospital, Biomedical Research Unit, National Heart and Lung Institute, Imperial College, London, United Kingdom 
Despite improvements in health care, cardiovascular disease remains the leading cause of morbidity and mortality worldwide. ${ }^{1} \mathrm{New}$-onset suspected stable angina is a widespread clinical problem. Following Bayesian analysis, if a patient has a very low-pretest probability of coronary artery disease (CAD), the risk of a hard cardiac event (cardiac death or acute myocardial infarction) is very low and therefore no further test is required for prognosis. Conversely, patients with suspected stable angina and an intermediate to high-pretest probability of CAD should benefit from risk stratification by a non-invasive test that has the ability to predict a good outcome if the test is normal. ${ }^{2}$ This provides a sort of 'warranty' period for at least the medium term and helps to reassure both the patient and physician. An unequivocally normal result also precludes the need for further cardiac investigations and this can be both comforting and convenient for the patient. Furthermore, in an era of increasing cardiac investigation and spiralling health care costs, a reliably normal/negative initial test which can avoid further testing should benefit health care systems by delivering both efficient, high-quality care and at the same time limit costs.

Presently, a plethora of non-invasive cardiac investigations are available to investigate stable chest pain for suspected or known coronary artery disease. These investigations may be divided into functional tests that detect reversible myocardial ischaemia or anatomical tests which delineate the coronary artery arteries. Functional tests involve stress testing with physiological exercise or pharmacological agents for the detection of myocardial ischaemia. The most widely used test continues to be the exercise electrocardiography (ExECG) which has a Class $1 \mathrm{~A}$ indication for patients who can exercise and have no resting ECG abnormalities. ${ }^{2,3}$ However, imaging techniques which are widely available and commonly used are single-photonemission tomography (SPECT) and stress echocardiography (SE). Newer techniques include cardiac magnetic resonance (CMR) imaging and positron-emission tomography (PET). Coronary computerized tomographic angiography (CCTA) is a non-invasive technique that assesses the coronary artery anatomy. All of these techniques are advocated for the assessment of suspected angina both by the European and the American guidelines. ${ }^{2,3}$

The meta-analysis conducted by Smulders et al. ${ }^{4}$ is timely, addressing the relative prognostic value of a negative test of the above contemporary cardiac imaging techniques, in symptomatic patients with stable chest pain. The analysis was well conducted and took into account the history of known CAD, prevalence of CAD and actual hard cardiac event rate in each of the studies selected for the analysis. True to the present clinical scenario, SPECT followed by SE formed the bulk of the study population, closely followed by CCTA. The number of CMR trials for the assessment of CAD either by wall motion or perfusion was relatively small comprising $25 \%$ and $10 \%$ of the SE and SPECT population, respectively; the PET population was considerably smaller. Unlike real-world circumstances, the number of patients who underwent ExECG was lower than that evaluated by SPECT, SE, or CCTA and this can be accounted for by publication bias. To the best of our knowledge, this was the largest and most robust meta-analysis on this subject and the conclusions were clear. If by functional testing there was no evidence of myocardial ischaemia or by non-invasive anatomic testing there was no obstructive coronary artery disease, then the event rates were comparable and very low. An initial apparent lower event rate of a normal CCTA over a normal SPECT/SE was accounted for after adjustment for the population event rate and prevalence of known CAD. This was also true when patients without known CAD and suspected angina were evaluated. Thus, according to the meta-analysis, a normal CCTA which excludes significant obstructive CAD directly does not confer any lower risk compared to a normal functional test which excludes reversible ischaemia. This was clearly highlighted by two large prospective randomized studies comparing CCTA with functional testing, PROMISE and SCOT-HEART. Both trials showed that strategies based on anatomic vs. functional testing have similar outcomes. ${ }^{5,6}$ However, it must 
be pointed out that the mean duration of follow-up of the population in the meta-analysis was intermediate at around 2 years, similar to the population in PROMISE and SCOT-HEART trials.

It was also very interesting to note that CCTA was predominantly performed in a very low-risk group in whom the prevalent hard event rate was only $0.72 \% / y e a r$. A negative scan reduced it by $50 \%$. In contrast, the prevalent event rate of the population evaluated by SPECT / SE was 4-5 times higher with reduction in event rate by $50 \%$ which is similar to CCTA when the functional test was negative for ischaemia. It is similarly interesting to note that ExEcg was performed in those with a $20 \%$ prevalence of previous AMI and possibly resting ECG changes. While good exercise tolerance predicts good outcomes, ECG changes may lead to unnecessary downstream tests. Another aspect to ponder on, though not shown in this study, is that the negative predictive value for cardiac events did not change significantly in those with an intermediate pretest probability of CAD, demonstrated in a meta-analysis comparing SE and SPECT.7 In a meta-analysis, it needs to be highlighted that when comparing two different studies, even if most confounding factors are adjusted for, there is always a possibility that certain peculiarities specific to a given population studied may not have been captured. Ideally, when two techniques are compared, it should be in the same patient population. The authors acknowledged the intrinsic limitation of this type of research methodology and analysis. Another caveat to consider in this meta-analysis is the definition of normality. For functional testing, the absence of reversible abnormalities was considered normal. It is known that fixed WMA/perfusion defect carries risk. This factor was not adjusted for in the analysis which may account for borderline statistical significance between CCTA and SE after other potential confounding factors were adjusted for. However, when patients with suspected CAD only are considered the difference between CCTA and SE were abolished probably because of low likelihood of prevalence of fixed abnormalities in this population.

So, given that the outcome of a negative test is similar across all contemporary technologies what factors should determine the best initial test for the investigation of patients with suspected stable angina? Let us consider the largest group of patients investigated for CAD i.e. those with new-onset suspected stable angina and no previous history of CAD. Both PROMISE and SCOT-HEART demonstrated that event rates in such a population are low, approximating to $1.5 \% / y e a r$. This is likely because of healthier lifestyles, better control of modifiable cardiovascular risk factors, and earlier institution of preventative measures. Thus, to investigate such patients one needs a relatively safe test (ALARA principle, as low as reasonably achievable), one which is widely available, highly feasible, provides high-diagnostic tests (low-inconclusive tests) and has a low-initial cost. Both CCTA and nuclear scans are techniques that involve ionizing radiation; the latter is also relatively costly. CMR is not readily available and is costly. SE and Ex ECG are widely available, do not involve ionizing radiation and are relatively inexpensive. However, ExECG can only be performed in those able to exercise and is indeterminate in approximately $20 \%$ of patients giving rise to further down-stream testing. ${ }^{6}$ On the contrary, SE with the advent of transpulmonary contrast agents is diagnostic in almost $99 \%$ of patients. ${ }^{8}$ In a recent randomized study, cost to diagnosis of CAD was cheaper with SE than ExECG in patients presenting with suspected stable angina. ${ }^{8}$ There is now evidence to suggest that SE with transpulmonary contrast agents could be the initial test of choice in such a population. ${ }^{9} \mathrm{~A}$ further advancement is the ability of ultrasound to assess atherosclerosis and myocardial ischaemia simultaneously using carotid ultrasound (CU) and SE, respectively. This combination provided incremental prognostic information in patients with suspected CAD. ${ }^{10}$ Reassuringly, this information by SE-CU is very similar to that provided by SPECT-CT. ${ }^{11}$ In the high-risk population, similar considerations should be applied to determine the most cost-effective and safe approach for diagnostic testing. 


\section{REFERENCES}

1 British Heart Foundation. https://www.bhf.org.uk/ research/heart-statistics (18 February 2017, date last accessed).

2. Montalescot G, Sechtem U, Achenbach S, et al. 2013 ESC guidelines on the management of stable coronary artery disease: the Task Force on the management of stable coronary artery disease of the European Society of Cardiology. Eur Heart $\mathrm{J}$ 2013;34:2949-3003.

3. Finn SD, Gardin JM, Abrams J, et al. 2012 ACCF/ AHA/ACP/AATS/PCNA/SCAI/STS Guideline for the diagnosis and management of patients with stable ischemic heart disease: a report of the American College of Cardiology Foundation/American Heart Association Task Force on Practice Guidelines, and the American College of Physicians, American Association for Thoracic Surgery, Preventive Cardiovascular Nurses Association, Society for Cardiovascular Angiography and Interventions, and Society of Thoracic Surgeons. J Am Coll Cardiol 2012;60:e44-e164.

4. Smulders MW, Jaarsma C, Nelemans PJ, et al. Comparison of the prognostic value of negative non-invasive cardiac investigations in patients with suspected or known coronary artery disease-a meta-analysis. Eur Heart $\mathrm{J}$ Cardiovasc Imaging 2017; 18:980-7.

5. Douglas PS, Hoffmann U, Patel MR, et al. Outcomes of anatomical versus functional testing for coronary artery disease. The New England journal of medicine 2015;372:1291-300.

6. The SCOT-HEART investigators. CT coronary angiography in patients with suspected angina due to coronary heart disease (SCOT-HEART): an openlabel, parallel-group, multicentre trial. Lancet 2015;385:2383-91.

7. Metz LD, Beattie M, Hom R, Redberg RF, Grady D, Fleischmann KE. The prognostic value of normal exercise myocardial perfusion imaging and exercise echocardiography: a meta-analysis. J Am Coll Cardiol 2007;49:227-37.

8. Zacharias K, Ahmed A, Shah BN, et al. Relative clinical and economic impact of exercise echocardiography vs. exercise electrocardiography, as first line investigation in patients without known coronary artery disease and new stable angina: a randomized prospective study. Eur Heart J Cardiovasc Imaging 2017; 18:195-202.

9. Vrints CJM, Senior R, Crea F, Sechtem U. Assessing suspected angina: requiem for coronary computed tomography angiography or exercise electrocardiogram? Eur Heart J 2017;38:1792-800.

10. Ahmadvazir S, Shah BN, Zacharias K, Senior R. Incremental Prognostic Value of Stress Echocardiography With Carotid Ultrasound for Suspected CAD. JACC Cardiovasc Imaging 2018;11:173-80.

11. Van Werkhoven JM, Schuijf JD, Gaemperli O, et al. Prognostic value of multislice computed tomography and gated single-photon emission computed tomography in patients with suspected coronary artery disease. J Am Coll Cardiol 2009;53:623-32. 
PART
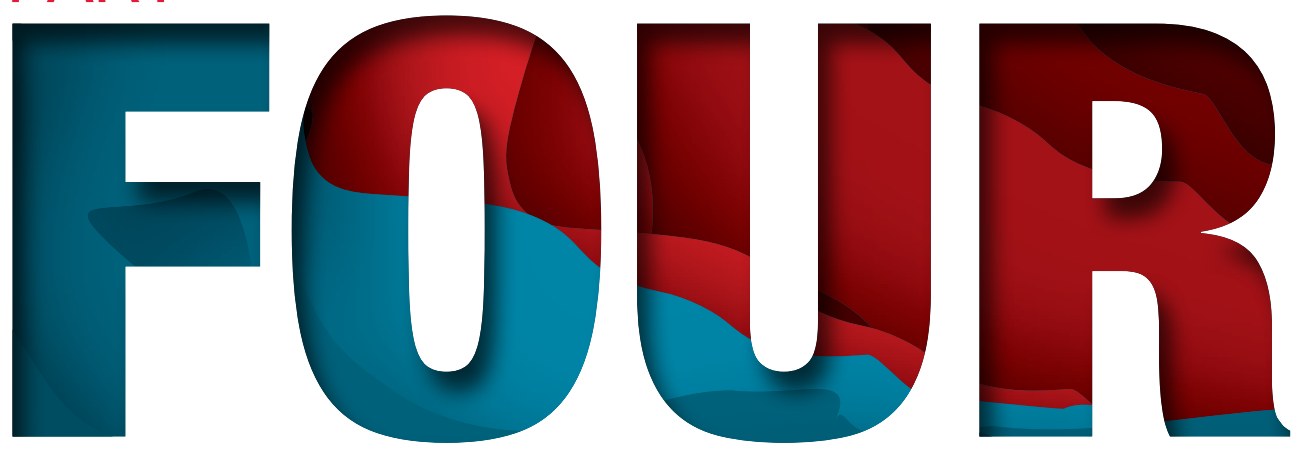


\section{Discussion and summary}


General discussion and summary 
This thesis describes the role of non-invasive diagnostic testing in patients with acute and chronic chest pain. Chest pain is a common presenting symptom and can be the result of cardiac as well as non-cardiac etiologies. Currently, diagnostic testing is mainly focused on ruling out obstructive coronary artery disease or other life-threatening diseases. While considered crucial in patients with chest pain,1,2 ineffective use and overspending of cardiovascular testing must be avoided as much as possible. ${ }^{3,4}$ Here, an overview of the current as well as anticipated and suggested changing role of non-invasive testing in patients with chest pain is provided. This chapter summarizes the main results of this thesis and discusses its findings in the light of the current literature.

\section{ACUTE CHEST PAIN}

\section{Ruling out acute myocardial infarction}

Acute chest pain is the most common symptom in the (cardiac) emergency department. ${ }^{5}$ Accurate diagnosis can be a challenge, because symptom presentation can be vague and the differential diagnosis broad. The initial diagnostic workup is mainly focused on ruling out life-threatening diseases such as acute myocardial infarction (Chapter 1), pulmonary embolism or acute aortic dissection. For this purpose, history taking, physical examination, electrocardiography and even risk scores or clinical prediction tools lack sufficient accuracy. ${ }^{6}$ Because of its high-sensitivity, measuring cardiac troponin levels is crucial in patients with acute chest pain to rule out acute myocardial infarction. ${ }^{1,7}$

\section{Figure 1.}

Likelihood of acute myocardial infarction: contemporary versus high-sensitivity cardiac troponin T levels at presentation in acute chest pain.

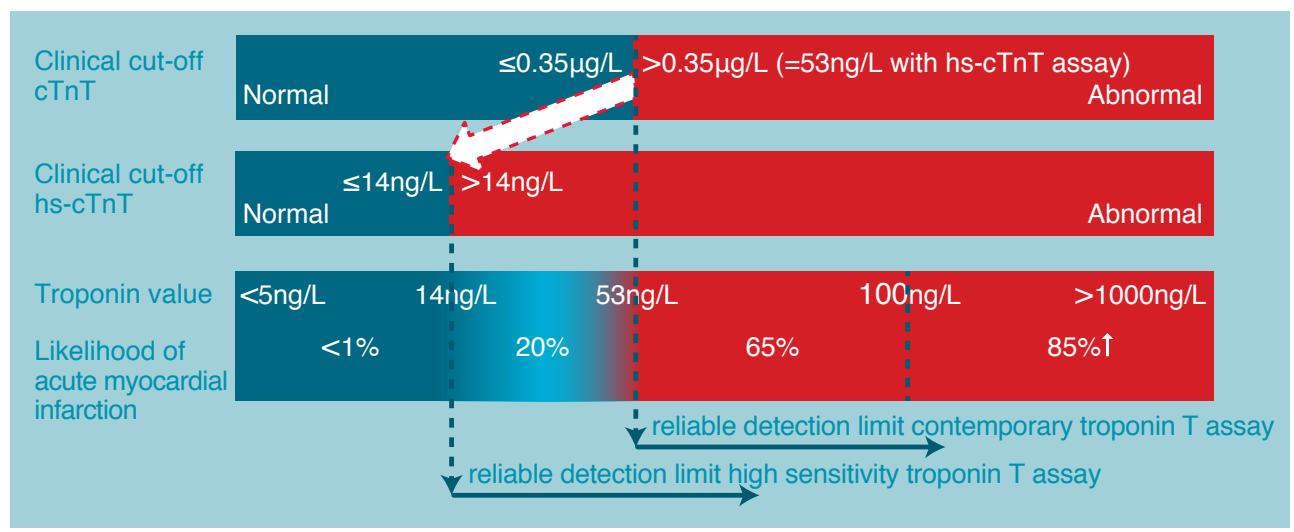

Figure showing the decreased likelihood of acute myocardial infarction when using a high-sensitivity cardiac troponin $\mathrm{T}$ assay as compared to a contemporary troponin $\mathrm{T}$ assay when a normal troponin value is measured. A cut-off value of $0.035 \mathrm{mg} / \mathrm{L}$ using the contemporary troponin $\mathrm{T}$ (cTnT) assay corresponds with a value of 53ng/L using the high-sensitivity cardiac troponin T (hs-cTnT) assay. The clinical interpretation "normal vs. abnormal" is based on a value exceeding the 99th percentile upper reference limit measured with an analytical imprecision of $\leq 10 \%$. 
Advances in biomarker assay technology have led to the development of high-sensitivity cardiac troponin assays (Chapter 2). These assays have substantially contributed to a faster and more reliable rule out of acute myocardial infarction. ${ }^{8-10}$ Compared to the contemporary troponin assays, their improved analytical performance enables accurate detection of much lower troponin concentrations. This has resulted in a lower diagnostic cut-off threshold to reliably rule out acute myocardial infarction as compared to contemporary assays (Figure 1). Based on a single high-sensitivity cardiac troponin level, acute myocardial infarction can be ruled out with $99 \%$ confidence. Moreover, undetectable troponin levels at presentation have a negative predictive value of $99.6 \%-99.8 \%$ in ruling out acute myocardial infarction. ${ }^{8,10}$

Even when risk scores are low and contemporary troponin levels are normal, physicians often still seek reassurance and order additional non-invasive cardiac tests. As shown in the appendix of table 1 in chapter $\mathbf{2}$, a negative test for myocardial ischemia or coronary artery disease predicts an excellent prognosis. Previous reports already raised concerns whether routine additional (outpatient) diagnostic testing in patients with normal contemporary troponin levels is useful. ${ }^{11,12}$ Specifically, they failed to show an improvement in patient outcome, resulted in more false positive downstream testing that themselves resulted in an increased use of potential harmful invasive procedures, increased ionizing radiation exposure and health care costs. The improved ability of the high-sensitivity cardiac troponin assays to rule out acute myocardial infarction have aggravated these concerns, but real-world data supporting this were lacking.

In chapter 3, we describe an observational study in 918 patients that consecutively presented with acute chest pain and who had normal high-sensitivity cardiac troponin $\mathrm{T}$ levels after extensive emergency department evaluation. The study was undertaken to identify clinical characteristics of adverse outcome (cardiac death, myocardial infarction, revascularization and admission for heart failure) and to evaluate the role of additional diagnostic testing. This study shows that one-year cardiac death or myocardial infarction event rate is extremely low, below $1 \%$. Baseline patient characteristics identified 786 patients $(86 \%)$ at low risk for adverse outcome. Nevertheless, (non-)invasive cardiac testing to rule out myocardial ischemia or coronary artery disease, was ordered for in a substantial number of patients (326 out $786(41 \%)$ ). Abnormal test results were observed in only 27 patients (8\%), in whom in only 11 management was changed (revascularization [n=5], medication $[n=6]$ ). Of the five patients undergoing revascularization, one patient had a ST-elevation myocardial infarction 13 days after intervention because of in-stent thrombosis. To stress, the diagnostic yield of additional testing and change in management are low in troponin negative acute chest pain patients. These results suggest that the use of additional testing should be restricted in these very low risk patients. Larger multi-center trials, preferably with a randomized controlled trial design or propensity matched cohorts with an adequate sample size to assess long term clinical outcome and cost-effectiveness, are required to confirm this. A recent study showed that a diagnostic approach based on clinical parameters, safely reduces inpatient hospital care and additional diagnostic testing..$^{13}$

By definition, unstable angina pectoris is not ruled out when troponin values are normal. ${ }^{1}$ Its clinical relevance however, is debatable. First, unstable angina pectoris is poorly defined and often diagnosed without objective evidence. Second, a high-sensitivity cardiac troponin assay often reclassifies patients diagnosed with unstable angina pectoris and normal contemporary troponin assay values to acute myocardial infarction, resulting in a substantial decline in the prevalence of unstable angina..$^{14-16}$ Despite this rationale, we observed that patients with a highly suspicious clinical history consistent with typical angina pectoris have a worse outcome and more often have abnormal test results (chapter 3 ). Whether these patients really have unstable angina pectoris or represent part of the spectrum of stable coronary artery disease is currently unknown. 
Many patients with acute chest pain in whom acute myocardial infarction has been ruled out will be discharged without a formal diagnosis ( $88 \%$ in chapter 3 ). In the accompanying editorial to chapter 3 authors argue that finding a diagnosis is important for patients. Obviously, other potentially life-threatening diseases such as a pulmonary embolism, aortic dissection, pneumothorax or acute abdominal pathology should be ruled out, if suspected. However, the differential diagnosis is broad and chest pain can be of musculoskeletal, gastrointestinal, or respiratory origin (Chapter $\mathbf{1}$ table 1). The yield of additional (non-)cardiac investigations to find the underlying cause of chest pain is generally low and costly. ${ }^{17,18}$ Furthermore, additional testing to rule out diseases with low risk does not reassure patients or reduce concern. ${ }^{19}$ The best alternative for patient and physician reassurance, when a diagnosis remains unknown, is by showing that prognosis is excellent. Prognostication should ideally already commence outside the hospital and the development of pre-hospital risk scores including (point-of-care) troponin testing seem very promising. ${ }^{20,21}$ First responders (i.e. general physician or ambulance paramedics) can calculate a score that includes clinical variables, electrocardiography and a troponin test. Prospective studies are underway to investigate whether patients identified at low risk can be managed outside the hospital and by a general practitioner. However, triage of patients presenting very shortly after symptom onset remains challenging. A negative troponin test result is less reliable if symptom onset was $<3$ hours when measuring troponins. ${ }^{22}$

\section{Acute myocardial infarction in the era of high-sensitivity cardiac troponin assays}

Diagnosing acute myocardial infarction requires clinical evidence consistent with acute myocardial ischemia (e.g. symptoms, new ischemic electrocardiographic changes, imaging evidence of new loss of myocardium or wall motion abnormalities) and a rise and/or fall of cardiac troponin values, with at least one value above the $99^{\text {th }}$ percentile upper reference limit. ${ }^{23}$ A new concept in the recently updated universal definition of myocardial infarction guidelines is the differentiation of myocardial infarction from myocardial injury. Myocardial infarction is a clinical diagnosis based on evidence of myocardial ischemia, while myocardial injury is solely based on elevated troponin values irrespective of the underlying pathophysiological mechanism. ${ }^{23}$ Table 1 in chapter 4 describes different causes of myocardial injury, and include injury related to myocardial ischemia, non-coronary myocardial and primary extra-cardiac disease. Myocardial ischemia may occur as a result of plaque rupture or erosion with superimposing thrombus formation obstructing coronary flow (type I myocardial infarction) or a mismatch in oxygen supply and demand (type II myocardial infarction). Importantly, type II myocardial infarction occurs more frequently in patients with underlying stable coronary artery disease and is by definition not caused by plaque disruption. ${ }^{23}$ Clinical distinction between type I, type II myocardial infarction, other non-coronary myocardial injuries or even chronic pathology is often difficult clinically, especially during the initial evaluation on the emergency department.

High-sensitivity cardiac troponin assays are more sensitive and detect smaller amounts of myocardial damage compared to the contemporary assay. The downside of this improved sensitivity is a lower specificity for acute myocardial infarction, as measurable troponin levels can be detected in other conditions. In particular mildly elevated troponin levels have a low positive predictive value for acute myocardial infarction (Figure 1). A more quantitative assessment of troponin levels may overcome some of these issues compared to a binary approach to diagnose infarction (i.e. normal versus elevated troponin levels). ${ }^{24,25}$ The current 2015 ESC guideline categorizes patients into three different risk groups based on the troponin level at presentation and change over time (1 hour). ${ }^{1}$ Low and stable troponin levels effectively 
rule out an acute myocardial infarction. A diagnosis of acute myocardial infarction can be established with reasonably high confidence when troponin levels are high or markedly changing over time (of note, $16 \%$ still does not have an acute myocardial infarction in this group) ${ }^{26}$ The remaining patients (25\%) are categorized as 'observe category' and often require additional testing. The differential diagnosis is broad, and include non-cardiac diseases (38\%), acute coronary syndrome (36\%), type II myocardial infarction and non-coronary cardiac disease $(24 \%) .{ }^{27}$ Characterizing these patients by using non-invasive imaging is often useful to initiate appropriate therapy.

In clinical practice, high-sensitivity cardiac troponin values are generally still being labeled as either positive (i.e. $>99^{\text {th }}$ percentile) or negative for acute myocardial infarction (Figure 1). The rationale for this may be based on: 1) extrapolation of clinical interpretation of the former contemporary troponin assay, 2) absence of uniform change criteria (variation in time and amount of change required for diagnosis), 3) normal versus abnormal is simple and more straightforward compared to interpreting a continuous troponin value and assessing a change over time. However, using this dichotomous interpretation of troponin levels, results in a low specificity (82\%) and low positive predictive value (56\%) for acute myocardial infarction. ${ }^{28}$

\section{Myocardial infarction with non-obstructive coronary arteries}

Patients with acute chest pain and elevated troponin levels are routinely managed as having myocardial infarction until proven otherwise. Consequently, current practice is predominantly concentrated on establishing or ruling out obstructive coronary artery disease and patients are often routinely sent to invasive coronary angiography. Nevertheless, non-obstructive coronary artery disease is frequently observed at invasive coronary angiography resulting in a diagnosis of myocardial infarction with non-obstructive coronary arteries (MINOCA). The prevalence of MINOCA varies across studies based on the definition of non-obstructive coronary arteries, patient selection and patient characteristics, but can be observed in up to one third of patients with suspected acute myocardial infarction (Table 1). The underlying causes of MINOCA are heterogeneous and include plaque rupture with spontaneous coronary recanalization and/or distal embolization of plaque debris, coronary spasm, myocarditis, stress cardiomyopathy, microvascular dysfunction, and others (Chapter 4). Importantly, MINOCA has a comparable or even worse long-term prognosis compared to patients with myocardial infarction and obstructive coronary artery disease. ${ }^{29,30}$ Patients diagnosed with MINOCA therefore deserve special attention and a comprehensive diagnostic evaluation. Because clinical characteristics cannot be relied on for making the correct final diagnosis, additional diagnostic testing is necessary. Importantly, current guidelines do not yet provide a diagnostic pathway how to deal with these patients.,23,31

In chapter 4 (published in 2015), a diagnostic algorithm is proposed that starts in the catheterization laboratory and incorporates invasive as well as non-invasive diagnostic testing with a central role for CMR to narrow down the differential diagnosis. In 2017, an ESC working group position paper on MINOCA reported a relatively similar diagnostic approach. ${ }^{32}$ MINOCA is first detected in the catheterization laboratory, when obstructive coronary artery disease or a spontaneous coronary dissection is ruled out. Routine invasive coronary angiography only visualizes the coronary lumen and cannot definitely rule out the presence of a vulnerable plaque, spasm or non-coronary myocardial disease. Although CMR is a key tool to characterize the type of myocardial injury, it seems reasonable to first perform intracoronary imaging and provocative testing during the initial cardiac catheterization. Intracoronary imaging (i.e. intravascular ultrasound [IVUS] and optical coherence tomography [OCT]) can reveal plaque disruption or thrombus in approximately one third of patients, already clarifying the cause of MINOCA in the cathlab..$^{33,34}$ 
Table 1.

Prevalence of non-obstructive coronary artery disease in suspected acute coronary syndrome.

\begin{tabular}{|c|c|c|c|c|}
\hline Study & Suspected ACS & $\begin{array}{l}<70 \% \\
\text { stenosis* }\end{array}$ & $\begin{array}{l}<50 \% \\
\text { stenosis* }\end{array}$ & No stenosis \\
\hline \multicolumn{5}{|l|}{ Trial } \\
\hline FRISC II & $\mathrm{ECG} \downarrow / \mathrm{CK}-\mathrm{MB}+/ \mathrm{CTnT}+$ & - & $14 \%$ & - \\
\hline TACTICS-TIMI $18^{2}$ & ECG $\downarrow /$ cTnT + / CAD history & - & - & $13 \%$ \\
\hline RITA $3^{3}$ & ECG $\downarrow / C A D$ history ${ }^{\wedge}$ & - & - & $22 \%$ \\
\hline ICTUS $^{4}$ & cTnT +, ECG $\downarrow /$ CAD history & $9 \%$ & - & - \\
\hline LIPSIA-NSTEMI ${ }^{5}$ & cTnT + & - & - & $12 \%$ \\
\hline OASIS $5^{6}$ & $>60 y$, ECG $\downarrow$, CK-MB + & - & - & $25 \%$ \\
\hline CARMENTA $^{7}$ & Hs-cTnT + & $39 \%$ & $32 \%$ & - \\
\hline \multicolumn{5}{|l|}{ Registry/review } \\
\hline Pasupathy et al. ${ }^{8}$ & Systematic review MINOCA & - & $6 \%$ & - \\
\hline Melki et al. ${ }^{9}$ & Registry STEMI / NSTEMI & - & - & $12-29 \%$ \\
\hline SWEDEHEART ${ }^{10}$ & Registry STEMI / NSTEMI & - & $8 \%$ & - \\
\hline Jobs et al. ${ }^{11}$ & Meta-analysis NSTEMI & - & - & $20 \%$ \\
\hline
\end{tabular}

* Prevalence of non-obstructive coronary artery disease is given for patients with a routine (invasive) strategy using invasive coronary angiography.

" Definition of "no stenosis", "no significant coronary artery disease", or "normal vessels" was not provided in manuscript.

- Data not presented in manuscript

$\wedge$ Patients with new pathological $Q$ waves or CK-(MB) twice the upper limit of normal were excluded $\mathrm{ACS}=$ acute coronary syndrome; $\mathrm{CAD}=$ coronary artery disease; $\mathrm{CK}-\mathrm{MB}=$ creatine kinase-MB; $\mathrm{CTn}=$ contemporary troponin assay; ECG $\downarrow=$ electrocardiogram showing ST depression; hs-cTn = high-sensitivity cardiac troponin assay; NSTEMI = non-ST elevation myocardial infarction; STEMI = ST elevation myocardial infarction.

1) Lancet 1999; 354: 708-15; ${ }^{2)} \mathrm{N}$ Engl J Med 2001; 344: 1879-87; ${ }^{3)}$ Lancet 2002; 360: 743-51 ; ${ }^{4} \mathrm{~N}$ Engl J Med 2005; 353:1095-104 and Eur Heart J 2009; 30: 45-654; ${ }^{5}$ Eur Heart J 2012; 33:2035-43; 6) Eur Heart J 2012; 33:51-60; " ${ }^{7)}$ Chapter 6, J Am Coll Cardiol 2019; 74: 2466-2477; ${ }^{8)}$ Circulation 2015;131:861-70; 9) J Am Coll Cardiol 2015;65:1655-64; ${ }^{10)}$ Circulation 2017;135:1481-89; ${ }^{11)}$ Lancet 2017; 390: 737-46.

Another study in patients with MINOCA, showed that provocative testing induced coronary spasm in almost half of patients. ${ }^{35}$ However, whether routine performance of intracoronary imaging and provocative testing is cost-effective, tailors therapy and ultimately improves patient outcome, needs to be awaited. Left ventriculography is commonly performed to assess wall motion abnormalities in the acute setting. However, its clinical use is controversial as it requires a substantial amount of contrast material and radiation, while it can be replaced easily by echocardiography or CMR. Additionally, wall motion abnormalities are unspecific and require confirmation by CMR to differentiate between infarction, myocarditis or stress cardiomyopathy. ${ }^{32}$

The non-invasive approach is primarily based on CMR. The role of CTA is limited, as coronary imaging is already available through invasive angiography or intracoronary imaging. Nevertheless, two clinical scenarios may trigger referral for CTA. Although the prevalence of pulmonary embolism in patients with MINOCA is extremely low, CTA should be considered in 
the appropriate clinical setting. ${ }^{36} \mathrm{CTA}$ may also be indicated to assess the presence of extraluminal atherosclerosis or high risk plaque characteristics (e.g. napkin ring sign) when intracoronary imaging is not available. Whether newer techniques such as quantitative vulnerable plaque imaging, non-invasive fractional flow reserve, perfusion or delayed enhancement CT will find its way into the diagnostic approach in MINOCA patients, remains to be seen. ${ }^{37}$

CMR provides a comprehensive assessment of the heart in a single non-invasive investigation (e.g. anatomy, function, edema, ischemia and fibrosis). It is a well-validated technique to identify and differentiate between common coronary and non-coronary myocardial diseases. ${ }^{38,39}$ Several observational studies have assessed the diagnostic value of CMR in MINOCA (Table 2). A pooled analysis of the current literature in almost 2000 patients shows that CMR can provide a diagnosis in $71 \%$ of MINOCA patients (i.e. 19\% myocardial infarction, $32 \%$ myocarditis, $16 \%$ cardiomyopathy, $4 \%$ others). Although in a substantial number of patients (29\%) CMR does not provide a diagnosis, their prognosis is excellent. ${ }^{40,41} \mathrm{~A}$ normal CMR study in MINOCA has been associated with: 1) Attenuated/small troponin release. ${ }^{40}$ 2) Diffuse injury rather than focal myocardial injury, which is more difficult to detect with conventional CMR sequences. Other sequences such as T1/T2 mapping may increase the diagnostic performance, but are not routinely applied in patients with MINOCA. ${ }^{42-44} 3$ ) Microvascular disease. Whether adenosine stress and rest first pass perfusion CMR can detect microvascular dysfunction is unknown. 4) Too much delayed CMR acquisition (i.e. stress cardiomyopathy may have already been recovered at the time of $\mathrm{CMR}$ ). 5) False positive troponin test results in absence of myocardial injury caused by an analytical error/interpretation in the laboratory.

Many gaps in the current knowledge of MINOCA remain. Although CMR plays a key role (Chapter 4), studies on the most optimal diagnostic strategy in MINOCA are scarce. Furthermore, appropriate management is currently based on expert opinion rather than on clinical or patient outcome trials. While dual antiplatelet therapy in MINOCA with presence of plaque rupture seems appropriate, routine prescription of antiplatelets in MINOCA does not improve outcome. ${ }^{45}$ MINOCA should be considered as a working diagnosis with multiple potential etiologies, requiring individually tailored therapy. Maastricht UMC+ and Zuyderland $\mathrm{MC}$ have now initiated a prospective registry of all patients admitted with MINOCA, in whom a comprehensive diagnostic strategy is recommended. This allows comparison between different (non-)invasive tests in relation to outcome and final diagnosis, and it is anticipated that at least some remaining issues will be unraveled.

\section{Early non-invasive approach in troponin positive acute chest pain}

Patients with acute chest pain, an inconclusive electrocardiogram and elevated cardiac troponin levels are generally initially suspected of having acute non-ST elevation myocardial infarction and referred for invasive coronary angiography. ${ }^{1}$ It is questionable whether a routine invasive approach is still the way to go as many patients do not have obstructive coronary artery disease. A meta-analysis of studies including patients with suspected myocardial infarction based on a contemporary troponin assay, could not show a benefit in patient outcome for a routine invasive approach. ${ }^{46} \mathrm{~A}$ routine invasive strategy may only be beneficial for those at the highest risk for recurrent events (e.g. ischemic ECG changes and/or high troponin levels), but potentially harmful for those at low(er) risk. The implementation of high-sensitivity cardiac troponin assays has led to the identification of patients with mildly elevated troponin levels. Arguably, these low risk patients will not benefit from a routine invasive approach. Furthermore, a twofold higher incidence of patients with abnormal troponin levels is observed when using these high-sensitivity assay. ${ }^{47}$ This is paralleled by a significant increase in referral to invasive coronary angiograms and an increase in non-diagnostic studies. ${ }^{47}$ 


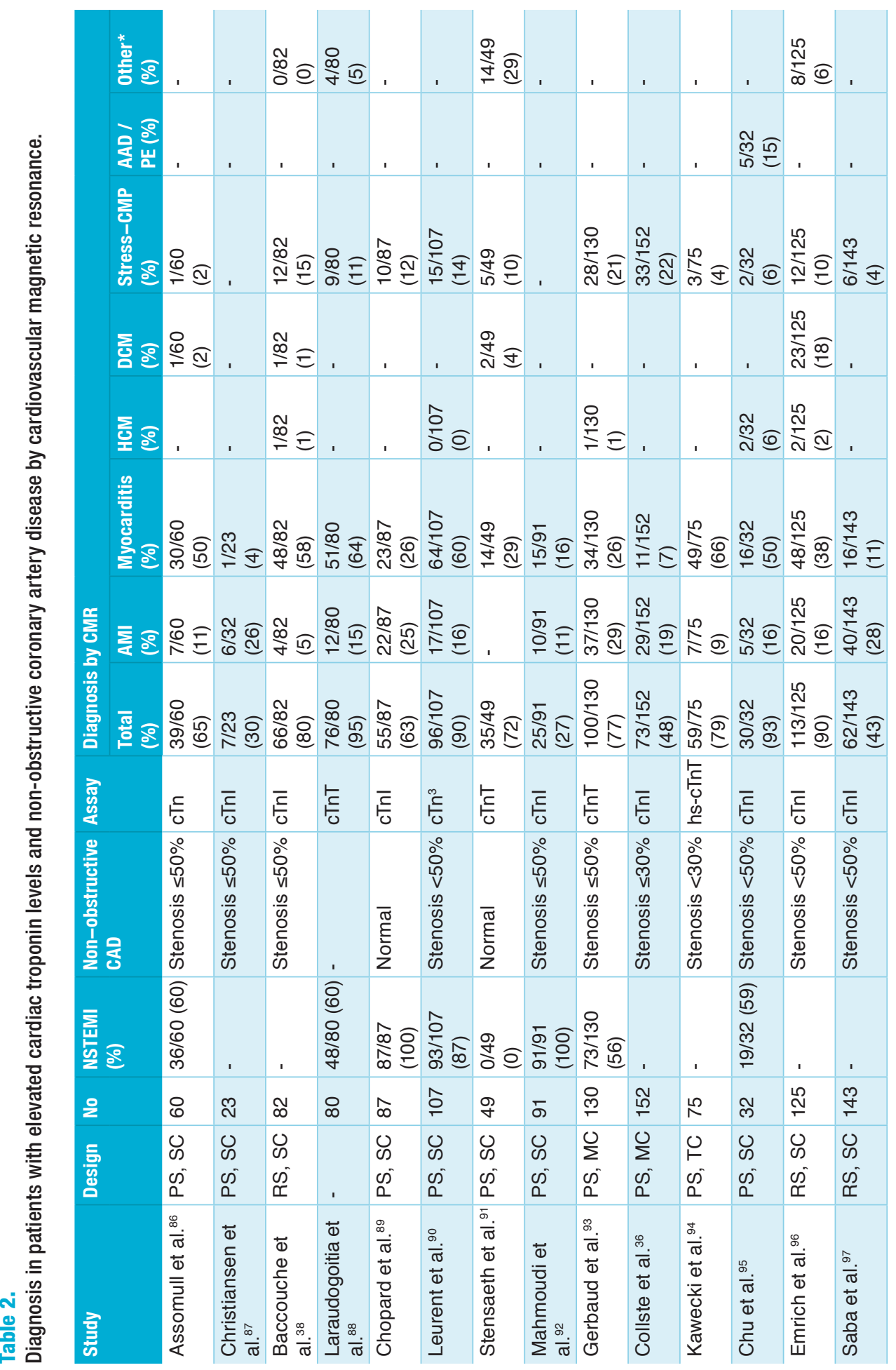




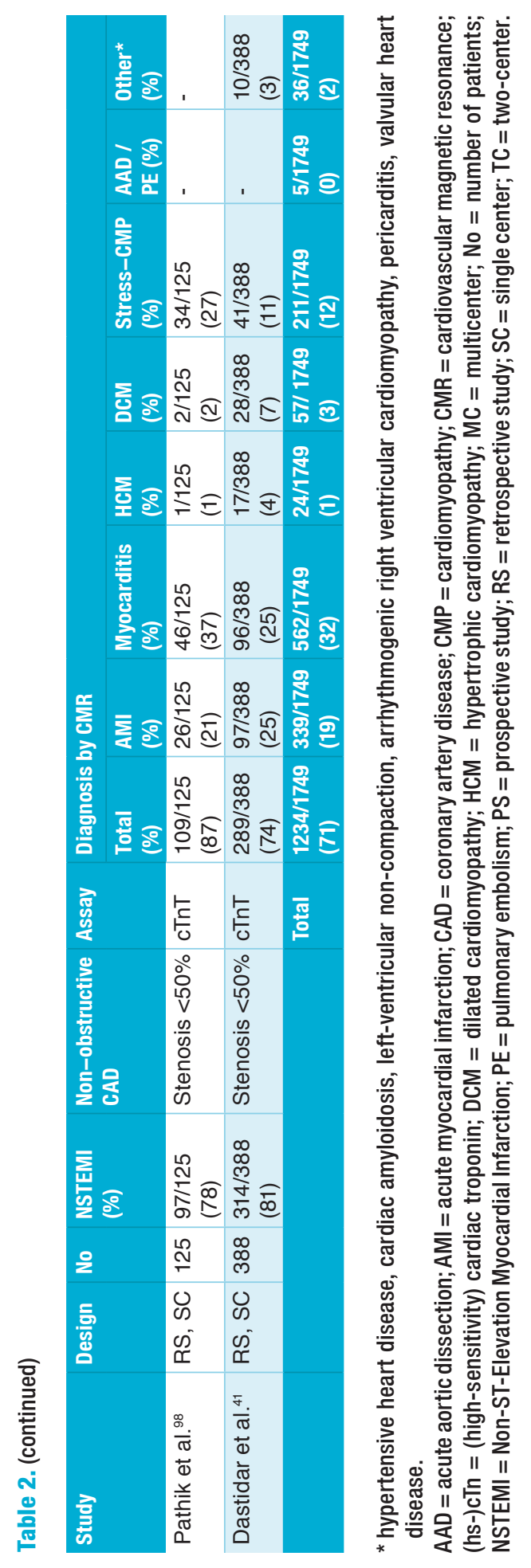


Non-diagnostic invasive procedures should be avoided to prevent potential procedure-related complications, prolonged hospitalization and increased health care costs. Improved patient selection for invasive coronary angiography is needed in the current era of high-sensitivity cardiac troponin assays.

Chapter 5 and 6 describe the design and main study results of the CARMENTA trial. This trial was undertaken to investigate whether a non-invasive imaging strategy first and prior to anticipated invasive coronary angiography could safely reduce the number of invasive coronary angiographies in patients with non-ST elevation myocardial infarction and elevated high-sensitivity cardiac troponin T levels. Routine clinical care usually involves invasive coronary angiography without early non-invasive imaging. The CARMENTA trial is a randomized controlled, single center clinical trial and for the first time investigates the clinical effectiveness and safety of implementing CMR or CTA imaging first in patients with suspected non-ST elevation myocardial infarction. We found, in 207 patients, that the CMR and CTA first strategies effectively reduced the proportion of patients referred to invasive coronary angiography during initial hospitalization $(87 \%$ [ $p=0.001$ vs. routine] and $66 \%[p<0.001$ vs. routine] as compared to routine clinical care [100\%], respectively). This reduction in invasive coronary angiography led to a more appropriate referral for invasive coronary angiography. Obstructive coronary artery disease seen during invasive coronary angiography is present in $61 \%$ in the routine clinical care, in $69 \%$ in the CMR ( $p=0.308$ vs. routine) and in $85 \%$ in the CTA first ( $p=0.006$ vs. routine) strategy, respectively. Moreover, the non-invasive imaging strategy first was safe and a trend towards a lower composite endpoint of major adverse cardiac events and complications was observed as compared to routine clinical care. This implies that a non-invasive imaging strategy first in suspected non-ST elevation myocardial infarction can be considered a safe gatekeeper for invasive coronary angiography.

Patients included in the CARMENTA trial were generally at low-intermediate risk, reflected by a relatively low rate of one-year mortality and recurrent myocardial infarction (4\%), a low to intermediate GRACE score (mean 115), low prevalence of ST-deviation on the electrocardiogram (20\%) and low range of peak high-sensitivity cardiac troponin T levels (median $78 \mathrm{ng} / \mathrm{L}$ ). This low-intermediate risk population was a result of excluding patients with signs of ongoing myocardial ischemia, persistent ST-deviation and a known history of coronary artery disease. A pre-specified subgroup analysis in patients at even lower risk with baseline troponin $T$ values between 15-50ng/L (low range), showed an even higher effectiveness for a non-invasive imaging strategy first. A CMR or CTA first approach reduced the proportion of invasive coronary angiography to $80 \%$ for CMR and $52 \%$ for CTA. ${ }^{48}$ Both non-invasive imaging arms did not delay the time to revascularization. Performing CMR or CTA within 72 hours of admission was logistically achievable. That this 'delayed' invasive strategy is safe is supported by a recent meta-analysis and the VERDICT trial showing that an early invasive strategy does not reduce long-term mortality as compared to a delayed invasive strategy (72 hours). ${ }^{49,50}$

It is noteworthy that our results suggest that clinicians trusted a "normal" CTA more than a "normal" CMR result. Apparently, anatomical exclusion of obstructive coronary artery stenosis is still regarded a necessary and reassuring first step. This is also reflected by the per protocol analysis, showing that follow-up coronary angiography was ordered for in only 2 out of 22 patients $(9 \%)$ with a (nearly) normal CTA, while this was in 10 out of 13 patients $(77 \%)$ with a normal or non-conclusive CMR. However, obstructive coronary artery disease was found in only 1 patient with a normal CMR, but fractional flow reserve was not performed. Likely, study results for CMR could have been improved if clinicians would have trusted a normal CMR result.

Another important and not anticipated observation is related to the $100 \%$ referral rate to 
invasive coronary angiography in the routine clinical care strategy. Before the start of the study, we estimated that approximately $75 \%$ of patients would be referred for invasive coronary angiography during initial hospitalization based on our own clinical experience at that time and other studies, such as the CRUSADE $(n=56.352) .{ }^{51}$ Apparently, cardiologists considered the included patients at sufficiently high risk to justify early referral for invasive coronary angiography, although this regimen was not obligatory or protocol driven. From the FAST-MI registry, we know that patients who did not undergo invasive coronary angiography were generally older $(>75$ years), had a history of previous myocardial infarction, congestive heart failure, and/or chronic renal failure, as compared to those who underwent invasive coronary angiography. ${ }^{52}$ We believe that excluding these patients in the CARMENTA trial has led to the difference between the expected and observed referral rate. Similar to our observation, more recent real-world registries in the last decade confirm higher referral rates to invasive coronary angiography (90-95\%) in non-ST elevation myocardial infarction. ${ }^{53,54}$

The diagnosis remained unknown after the initial test in all three arms in a substantial number of patients. In the routine clinical care, the CTA first and CMR first arm this was the case in $27(39 \%), 22(32 \%)$ and 13 patients (22\%), respectively. Follow-up CMR was more commonly performed than follow-up CTA in patients in whom the diagnosis remained unknown after the initial test, revealing a new diagnosis in one third of patients (myocarditis, myocardial infarction, and cardiomyopathy). Establishing these diagnoses is clinically very relevant because they modify management. The proportion of new diagnoses by CMR in suspected MINOCA patients is lower in our trial than reported previously (Table 2). First this may be related to lower troponin levels observed in the CARMENTA trial, which is known to be associated with a normal/ non-diagnostic CMR study. ${ }^{40}$ Second, it could be related to timing of follow-up CMR study as some patients were scanned relatively late after the event.

What are the clinical implications and future perspectives of the trial described in chapter 6 ? The gatekeeping potential of CMR and CTA confirms prior research in other circumstances. ${ }^{55-57}$ In particular, the reduction of invasive coronary angiography was most pronounced in patients with mildly elevated troponin levels, suggesting that a non-invasive imaging first approach could be considered in this group instead of a routine invasive strategy. A large-scale and multicenter setup with long term follow-up focused on patient outcome and cost-effectiveness is necessary to support this novel strategy. Furthermore, more advanced imaging techniques including quantitative plaque characterization, fractional flow reserve and delayed enhancement $\mathrm{CT}$, and quantitative perfusion and T1/T2 mapping using CMR may have additional clinical value. A study identifying specific patient groups that will benefit most from a certain strategy, either invasive or non-invasive is currently ongoing and initiated at Maastricht UMC+.

\section{Characterizing myocardial infarction with cardiovascular magnetic resonance}

In the absence of collateral flow, prolonged acute coronary artery occlusion triggers many pathophysiological events that ultimately result in acute myocardial infarction (i.e. myocardial cell death due to prolonged ischemia). ${ }^{23}$ Persistent ischemia results in irreversible myocardial injury after 40 minutes that starts at the endocardium and slowly progresses towards the epicardium as a wave front leading to a transmural myocardial infarction without timely reperfusion. ${ }^{58}$ Due to persistent ischemia and inflammatory processes, increases in tissue water content and end-diastolic wall thickness can be observed..$^{59}$ Furthermore, ischemia impairs contractile function and results in regional wall motion abnormalities. Timely restoration of blood flow may salvage any residual viable myocardium within the area at risk (i.e. amount of jeopardized myocardium). Still, epicardial revascularization does not guarantee reperfusion of the microvascular circulation. 
Figure 2.

Suggested diagnostic algorithm in a patient presenting with acute chest pain.

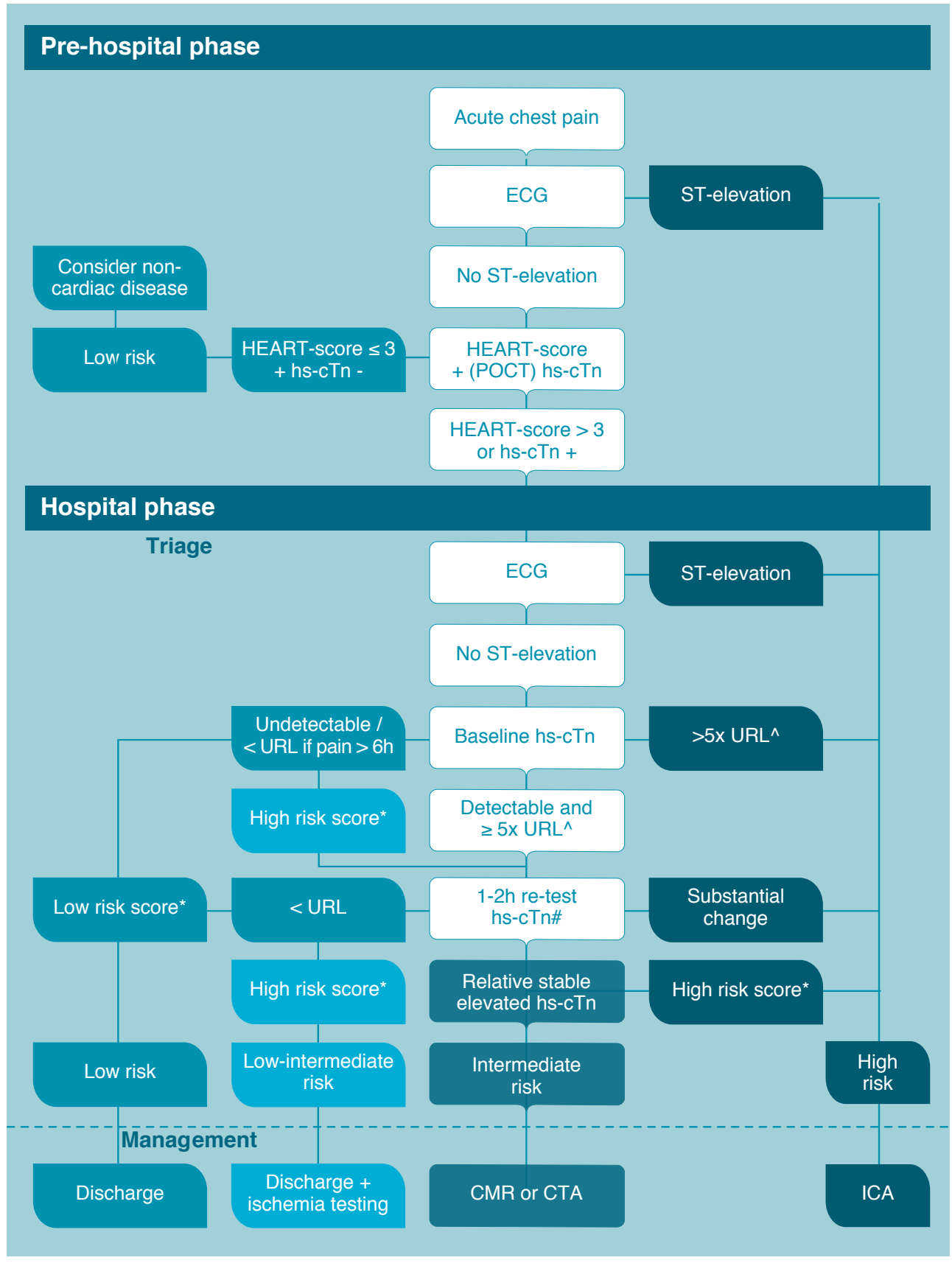




\section{Legend Figure 2.}

Pre-hospital assessment (by a general practitioner or ambulance paramedics) of patients with acute chest pain may prevent overcrowding of the emergency department with patients at low risk for acute cardiac disease and may initiate appropriate treatment in patients considered at high risk for acute myocardial infarction (e.g. ST-elevation). Risk stratification in the emergency department based on clinical risk scores, ECG, baseline and changing troponin level may categorize patients into low, low-intermediate, intermediate and high risk, in whom discharge, discharge and (outpatient) ischemia testing, CMR or CTA, or ICA should be considered, respectively. Follow-up CMR should be considered in patients with non-obstructive coronary arteries on ICA.

${ }^{*}$ Risk scores incorporating clinical scenario and elaborated testing.

\# Small changes in troponin level in the lower range of troponin levels may remain undetected due to assay precision issues. A 2-3 hour protocol may be preferred when baseline troponin levels are low to allow detection of a larger delta with higher analytical precision. ${ }^{70}$

$\wedge$ Currently, the URL is based on the $99^{\text {th }}$ percentile of a healthy reference population and the analytical precision of the troponin assay. It is expected that specific URL's for different populations will be developed based on age, gender, renal function, presence of stable structural heart disease and other co-morbidities.

$\mathrm{CMR}$ = cardiovascular magnetic resonance; $\mathrm{CTA}=$ computed tomography angiography; ECG = electrocardiogram; hs-cTn = high-sensitivity cardiac troponin; ICA = invasive coronary angiography; POCT = point of care testing; $\mathrm{UA}=$ unstable angina pectoris; $\mathrm{URL}=$ upper reference limit.

Absence of microvascular reperfusion is described as microvascular obstruction (or the 'no-reflow' phenomenon) and heavily injured microvasculature may result in intramyocardial hemorrhage when the microvasculature disrupts..$^{60,61}$ All of these processes require a specific time to heal. Infarct healing is a complex process which includes an inflammatory cascade with influx of inflammatory cells and formation of granulation tissue. Ultimately, collagen synthesis is activated resulting in chronic scar tissue without active inflammation. Intriguingly, most infarct characteristics can be directly or indirectly visualized using CMR (editorial chapter 7).

It is important to realize that the study described in chapter 7 was published in 2015 . At this time it was generally accepted that T2-weighted CMR allowed differentiating between acute and chronic myocardial infarction. ${ }^{62-64}$ This theory was based on 3 small studies that investigated the role of T2-weighted CMR in patients with $<1$ week and $>6$ months old myocardial infarctions. It was concluded that the hyperintense signal on T2-weighted imaging was only present in the acute phase ( $<1$ week after the acute event). ${ }^{65-67}$ In contrast to these earlier studies, we systematically evaluated the role of CMR in a range of patients with different infarct ages (221 CMR scans from two centers). In addition to T2-weighted CMR to evaluate the presence of edema, we incorporated other CMR infarct phenotypes such as increased end-diastolic wall thickness and microvascular obstruction to determine infarct age. We found that T2-weighted hyperintensity gradually resolved over time but may persist up to 6 months after acute myocardial infarction and that this was associated with larger infarct size, presence of diabetes and better T2-weighted CMR image quality.

Intriguingly, this study may provide some insight into the underlying mechanism of T2-weighted hyperintensity after acute myocardial infarction. Increased T2-weighted signal is considered to represent edema. However, increased end-diastolic wall thickness, a marker of myocardial edema, was only present in <1-month-old myocardial infarction, which is consistent with an earlier human postmortem study. ${ }^{68}$ The time course of T2-weighted hyperintensity (present up to 6 months after infarction) is different compared to increased end-diastolic wall thickness (up to 1 month after infarction), which arguably implies a different underlying pathophysiological mechanism. We hypothesized that persistent T2-weighted hyperintensity reflects a prolonged infarct healing process, which includes modifications in tissue and vascular characteristics and 
not only increases in water content. In the current study, larger infarct size and the presence of diabetes, predict persistence of T2-weighted hyperintensity. These findings support our hypothesis, as healing processes are impaired and take longer in patients with diabetes and it is reasonable to expect prolonged healing processes in larger myocardial infarction.

Furthermore, it is unlikely that persistence of T2-weighted hyperintensity is a result of imaging artifacts (e.g. slow flow or signal dropout). In the current study, we used a conventional triple inversion black-blood spin echo sequence and observed that better image quality independently predicts the presence of T2-hyperintensity during follow-up. Newer T2-weighted bright blood and T2-mapping sequences are less prone to imaging artifacts and have improved image quality. We hypothesized that newer sequences with less artifacts may even increase the number of patients with persistent hyperintense signal. Our hypothesis was recently confirmed in a study showing persistent T2-hyperintensity in up to two thirds of patients 6 months after infarction when using T2-mapping ${ }^{69}$ This latter study also showed that persistent T2-weighted hyperintensity as a possible reflection of ongoing inflammation, is an independent predictor of adverse remodeling and is associated with the occurrence of all-cause death and heart failure. ${ }^{69}$

\section{Suggested future diagnostic approach in patients with acute chest pain}

Based on the results of the studies presented in this thesis and review of the relevant literature, a diagnostic algorithm for patients presenting with acute chest pain is proposed (Figure 2).

\section{CHRONIC CHEST PAIN}

Additional diagnostic testing in patients with suspected coronary artery disease is dependent on the pre-test probability of having obstructive coronary artery disease. This pre-test probability is based on clinical characteristics including age, gender, risk factors and symptom characteristics. Current guidelines generally recommend abstinence of further non-invasive testing in patients with a low pre-test probability $(<15 \%)$ and high pre-test probability $(>85 \%)$ of having obstructive coronary artery disease. ${ }^{2}$ Hence, a large proportion of patients (nearly $70 \%$ ) are classified as having an intermediate pre-test probability and would require additional non-invasive diagnostic testing.$^{71}$ Clinicians have a large arsenal of non-invasive diagnostic tests at their disposal for the detection of coronary artery disease (chapter 1 ), which are both functional (i.e. exercise electrocardiography, echocardiography, CMR, SPECT) or anatomical tests (CTA). Although patient characteristics often guide the choice for a specific test, physician preference and local availability play a role. Because stress imaging tests provide additional information (e.g. cardiac, valvular function, extent of ischemia and/or irreversible injury), they are generally preferred over exercise testing. Furthermore, imaging tests may even reveal unexpected (extra-cardiac) causes or chest pain (chapter 8).

\section{Prognosis of a negative test result}

A negative test result essentially rules out (obstructive) coronary artery disease. The prognostic value of a negative test result is important. The best alternative for patient and physician reassurance, when a diagnosis remains unknown, is by showing that prognosis is excellent. In chapter 9 , we describe a meta-analysis of 165 studies including 122.721 patients that compares the prognostic value of a negative test result between all commonly used non-invasive cardiac tests in patients with suspected or known coronary artery disease. Several important novel concepts can be derived from this study. 1) The majority of tests performed are negative, supporting the concept that chest pain is frequently of non-cardiac origin. 2) A negative test result for all modalities yields an excellent prognosis. However, the annualized event rate for 
cardiac death and non-fatal myocardial infarction after a negative test result ranges from $0.32 \%$ for CTA to $1.66 \%$ for stress echocardiography. 3) The observed variation in prognosis between tests was highly associated with the overall population event risk $(r=0.726)$. Adjusting for this pre-test risk resulted in a rather comparable prognosis after a negative test result between modalities. Furthermore, restricting the analysis to studies only including patients with suspected coronary artery disease (thus excluding known disease), resulted in a comparable and excellent prognosis for all modalities (annual event rate for all $<0.7 \%$ ).

This meta-analysis was the first study to investigate the most commonly applied cardiac imaging modalities and to compare the prognostic value of a negative test result after correction for population event risk. A common drawback of meta-analyses is the heterogeneity between included studies, which precludes adequate pooling or comparison of studies. For instance, the pre-test probability for coronary artery disease varies across studies and highly influences clinical outcome. In the current study, we calculated the actual pre-test probability (population event risk) by pooling the number of events in the entire population (i.e. regardless of the test result) for each modality. This provided insight into the differences in baseline risk of patients referred to the different modalities. Adequate correction for this general population event risk uniquely allowed comparison of the prognostic value of a negative test result between modalities. Interestingly, the adjusted prognosis after a negative test result seems very similar between modalities, meaning that observed differences in outcome in trials is predominantly explained by patient selection. For example, patients included in previous CTA studies have a 5-fold lower baseline risk of events compared to patients included in studies evaluating stress echocardiography.

A limitation of this meta-analysis is the definition of a normal test result that was used (editorial chapter 9). We used commonly applied cut-off values such as a $<50 \%$ stenosis on CTA and absence of ischemia for functional tests that do not rule out the presence of non-obstructive coronary atherosclerosis. Also, the hemodynamic significance of a stenosis cannot be derived from a routine CTA exam. Nevertheless, the overall low event rate after a negative test result should be reassuring enough to avoid additional (non-invasive) testing.

\section{Anatomical versus functional diagnostic testing and treatment decisions}

The most optimal diagnostic pathway (anatomical vs. functional testing) in patients with suspected coronary artery disease remains a matter of debate. Non-invasive imaging tests can only indirectly improve patient outcome when followed by appropriate management. The intervention by itself will strongly confound any imaging studies investigating clinical outcome. The PROMISE and the SCOT-HEART trials compare a CTA and an ischemia-based strategy. In the PROMISE trial, a very low event rate and no prognostic benefit for a CTA guided strategy after a median follow-up of 2 years was observed. ${ }^{72}$ The SCOT-HEART trial however, observed a lower rate of cardiac death or myocardial infarction after 5 years follow-up for a CTA guided strategy compared to standard care..$^{73}$ These positive results are likely explained by the fact that with early detection of coronary artery disease appropriate preventive therapies are initiated (e.g. statin, aspirin, lifestyle) and/or early revascularizations that leads to fewer events over a 5 year period. ${ }^{73}$ Differences in the definitions of functional testing, patient characteristics and follow-up period, may have contributed to the different study outcomes. Standard care in SCOT-HEART and PROMISE included exercise electrocardiography in $85 \%$ and $10 \%$, and SPECT/stress echocardiography in $9 \%$ and $90 \%$ of patients, respectively. CTA based care was generally without functional testing in PROMISE, while patients randomized to the CTA-guided strategy in SCOT-HEART had prior functional testing as "standard care". Furthermore, the proportion of patients with obstructive CAD was substantially higher in SCOT-HEART. 
These two trials are the first multicenter randomized trials investigating clinical outcome based on a functional or anatomical diagnostic approach in patients with suspected angina pectoris. However, CMR, the most comprehensive non-invasive imaging modality with the highest diagnostic accuracy for detecting obstructive CAD, was not included in these trials. ${ }^{74,75}$ Future clinical outcome and cost-effectiveness studies incorporating state-of-the-art CTA and CMR guided care, compared to care according to current guidelines are urgently needed. Ultimately, this should lead to "personalized imaging". In the meantime, it's up to local expertise, patient characteristics and preference of the physician whether a functional or anatomical diagnostic strategy should be pursued. Based on current available evidence, a CTA guided approach seems superior to an approach involving exercise electrocardiography first, but does not outperform functional imaging tests.

Obstructive coronary artery disease can be diagnosed or suspected by an abnormal non-invasive test result. Treatment includes lifestyle adjustment, pharmacological therapy to relief symptoms, prevent adverse events, or coronary revascularization in therapy refractory cases and/or severe forms of coronary artery disease. Current indications for revascularization rely heavily on the presence of significant ischemia, ${ }^{76}$ using SPECT,${ }^{77}$ perfusion CMR, invasive fractional flow reserve (FFR) or instantaneous wave-free ratio (IFR) ${ }^{78-80}$ It is expected that non-invasive imaging will progressively guide referral to invasive angiography and revascularization. The recent MR-INFORM trial shows that a CMR perfusion based approach in patients with suspected coronary artery disease results in less revascularizations and is equally safe compared to an FFR guided strategy. ${ }^{81}$ Likewise, novel CT-techniques (CT-FFR or CT perfusion) add functional information to an anatomical stenosis and may facilitate appropriate selection of patients for invasive coronary angiography or revascularization in the near future. CT-FFR correlates highly with invasively measured FFR, and a strategy of CT-FFR in patients with suspected coronary artery disease safely reduces referral for invasive coronary angiography. ${ }^{82,83}$

\section{What is the prognosis of estimating prognosis?}

Future non-invasive cardiac imaging tests will focus more on predicting overall prognosis. Current routine analysis of imaging tests is rather ineffective and incomplete. Novel insights from artificial intelligence combined with big data will help the clinician with automated measurements, finding the correct diagnosis and estimating future adverse events. ${ }^{84} \mathrm{~A}$ recent study showed that machine learning (combining CTA and clinical data) performs significantly better in predicting 5 year prognosis when compared to a visual CTA assessment and established clinical risk scores in patients with suspected coronary artery disease. ${ }^{85}$ It is expected, that future scanning reports will be extended with estimates of disease and risk of adverse outcome based on automated analyses and report information on pulmonary emphysema index, bone density, epicardial fat, left ventricular mass, extracellular cardiac fibrosis, vascular calcifications, aneurysms, liver fat, (cardiac) incidentalomas, etc. This information is already available in current scans, but not yet utilized. Automated CTA analyses may also help in estimating the risk of a flow limiting stenosis or risk of plaque rupture. These kinds of analyses will provide a much better estimate of overall prognosis.

\section{THESIS CONCLUSIONS}

Evaluating patients with acute and chronic (stable) chest pain remains challenging and diagnostic testing has a crucial role. However, careful selection of patients for the appropriate test is essential to prevent ineffective use and unnecessary injuries. The results in this thesis show that patients with acute chest pain, normal troponin levels and clinically considered as low risk 
do not require additional testing. When troponin levels are elevated, non-invasive imaging (CMR or CTA) can be used as a safe gatekeeper for invasive coronary angiography. In patients with myocardial infarction, CMR provides insight into the infarct healing process and thereby allows estimating infarct age. Finally, in patients with chronic chest pain (i.e. suspected or known coronary artery disease), a negative non-invasive diagnostic test result yields an excellent prognosis which is comparable between modalities. 


\section{REFERENCES}

1. Roffi M, Patrono C, Collet JP, et al. ESC Guidelines for the management of acute coronary syndromes in patients presenting without persistent ST-segment elevation: Task Force for the Management of Acute Coronary Syndromes in Patients Presenting without Persistent ST-Segment Elevation of the European Society of Cardiology (ESC). Eur Heart J 2015;37:267-315

2. Montalescot G, Sechtem U, Achenbach S, et al. 2013 ESC guidelines on the management of stable coronary artery disease: the Task Force on the management of stable coronary artery disease of the European Society of Cardiology. Eur Heart J 2013;34:2949-3003.

3. Bhuiya FA, Pitts SR, McCaig LF. Emergency department visits for chest pain and abdominal pain: United States, 1999-2008. NCHS data brief 2010:1-8.

4. Lucas FL, DeLorenzo MA, Siewers AE, Wennberg DE. Temporal trends in the utilization of diagnostic testing and treatments for cardiovascular disease in the United States, 1993-2001. Circulation 2006;113:374-9.

5. Mockel M, Searle J, Muller R, et al. Chief complaints in medical emergencies: do they relate to underlying disease and outcome? The Charite Emergency Medicine Study (CHARITEM). European journal of emergency medicine : official journal of the European Society for Emergency Medicine 2013;20:103-8.

6. Fanaroff AC, Rymer JA, Goldstein SA, Simel DL, Newby LK. Does This Patient With Chest Pain Have Acute Coronary Syndrome?: The Rational Clinical Examination Systematic Review. JAMA 2015;314:1955-65.

7. Amsterdam EA, Wenger NK, Brindis RG, et al. 2014 AHA/ACC Guideline for the Management of Patients With Non-ST-Elevation Acute Coronary Syndromes: A Report of the American College of Cardiology/ American Heart Association Task Force on Practice Guidelines. J Am Coll Cardiol 2014;24:e139-e228.

8. Bandstein N, Ljung R, Johansson M, Holzmann MJ. Undetectable high-sensitivity cardiac troponin $\mathrm{T}$ level in the emergency department and risk of myocardial infarction. J Am Coll Cardiol 2014;63:2569-78.

9. Reichlin T, Hochholzer W, Bassetti S, et al. Early diagnosis of myocardial infarction with sensitive cardiactroponin assays. NEnglJMed2009;361:858-67.

10. Shah ASV, Anand A, Sandoval Y, et al. High-sensitivity cardiac troponin I at presentation in patients with suspected acute coronary syndrome: a cohort study. Lancet 2015;386:2481-8.

11. Prasad V, Cheung M, Cifu A. Chest pain in the emergency department: the case against our current practice of routine noninvasive testing. Arch Intern Med 2012;172:1506-9.

12. Redberg RF. Coronary CT angiography for acute chest pain. N Engl J Med 2012;367:375-6.

13. Sharp AL, Baecker AS, Shen E, et al. Effect of a HEART Care Pathway on Chest Pain Management Within an Integrated Health System. Ann Emerg Med 2019.

14. Sandoval Y, Apple FS, Smith SW. High-sensitivity cardiac troponin assays and unstable angina. European heart journal Acute cardiovascular care 2018;7:120-8.
15. Braunwald E, Morrow DA. Unstable angina: is it time for a requiem? Circulation 2013;127:2452-7.

16. Reichlin T, Twerenbold R, Reiter $\mathrm{M}$, et al. Introduction of high-sensitivity troponin assays: impact on myocardial infarction incidence and prognosis. Am J Med 2012;125:1205-13 e1.

17. Fruergaard $\mathrm{P}$, Launbjerg $\mathrm{J}$, Hesse $\mathrm{B}$, et al. The diagnoses of patients admitted with acute chest pain but without myocardial infarction. Eur Heart $\mathrm{J}$ 1996;17:1028-34.

18. Spalding L, Reay E, Kelly C. Cause and outcome of atypical chest pain in patients admitted to hospital. Journal of the Royal Society of Medicine 2003;96:122-5.

19. Rolfe A, Burton C. Reassurance after diagnostic testing with a low pretest probability of serious disease: systematic review and meta-analysis. JAMA internal medicine 2013;173:407-16.

20. van Dongen DN, Fokkert MJ, Tolsma RT, et al. Value of Prehospital Troponin Assessment in Suspected Non-ST-Elevation Acute Coronary Syndrome. Am J Cardiol 2018;122:1610-6.

21. van Dongen DN, Tolsma RT, Fokkert MJ, et al. Pre-hospital risk assessment in suspected non-STelevation acute coronary syndrome: A prospective observational study. European heart journal Acute cardiovascular care 2018.

22. Crea F, Jaffe AS, Collinson PO, et al. Should the 1h algorithm for rule in and rule out of acute myocardial infarction be used universally? Eur Heart $J$ 2016;37:3316-23.

23. Thygesen K, Alpert JS, Jaffe AS, et al. Fourth universal definition of myocardial infarction (2018). Eur Heart J 2019;40:237-69.

24. Mueller M, Biener M, Vafaie M, et al. Absolute and relative kinetic changes of high-sensitivity cardiac troponin $T$ in acute coronary syndrome and in patients with increased troponin in the absence of acute coronary syndrome. Clin Chem 2012;58:209-18.

25. Twerenbold R, Jaffe A, Reichlin T, Reiter M, Mueller C. High-sensitive troponin $T$ measurements: what do we gain and what are the challenges? Eur Heart J 2012;33:579-86.

26. Reichlin T, Schindler C, Drexler B, et al. One-hour rule-out and rule-in of acute myocardial infarction using high-sensitivity cardiac troponin T. Arch Intern Med 2012;172:1211-8.

27. Nestelberger T, Wildi K, Boeddinghaus $\mathrm{J}$, et al. Characterization of the observe zone of the ESC 2015 high-sensitivity cardiac troponin $0 \mathrm{~h} / \mathrm{h}$-algorithm for the early diagnosis of acute myocardial infarction. Int J Cardiol 2016;207:238-45.

28. Lipinski MJ, Baker NC, Escarcega RO, et al. Comparison of conventional and high-sensitivity troponin in patients with chest pain: a collaborative meta-analysis. Am Heart J 2015;169:6-16 e6.

29. Andersson HB, Pedersen F, Engstrom T, et al. Long-term survival and causes of death in patients with ST-elevation acute coronary syndrome without obstructive coronary artery disease. Eur Heart $\mathrm{J}$ 2018;39:102-10.

30. Safdar B, Spatz ES, Dreyer RP, et al. Presentation, Clinical Profile, and Prognosis of Young Patients 
With Myocardial Infarction With Nonobstructive Coronary Arteries (MINOCA): Results From the VIRGO Study. J Am Heart Assoc 2018;7:1-14.

31. American College of Emergency $P$, Society for Cardiovascular A, Interventions, et al. 2013 ACCF/ AHA guideline for the management of ST-elevation myocardial infarction: a report of the American College of Cardiology Foundation/American Heart Association Task Force on Practice Guidelines. J Am Coll Cardiol 2013;61:e78-140.

32. Agewall S, Beltrame JF, Reynolds HR, et al. ESC working group position paper on myocardial infarction with non-obstructive coronary arteries. Eur Heart J 2017;38:143-53.

33. Reynolds HR, Srichai MB, Iqbal SN, et al. Mechanisms of myocardial infarction in women without angiographically obstructive coronary artery disease. Circulation 2011;124:1414-25.

34. Opolski MP, Spiewak M, Marczak M, et al. Mechanisms of Myocardial Infarction in Patients With Nonobstructive Coronary Artery Disease: Results From the Optical Coherence Tomography Study. JACC Cardiovasc Imaging 2018.

35. Montone RA, Niccoli G, Fracassi F, et al. Patients with acute myocardial infarction and non-obstructive coronary arteries: safety and prognostic relevance of invasive coronary provocative tests. Eur Heart $J$ 2018;39:91-8.

36. Collste O, Sorensson P, Frick M, et al. Myocardial infarction with normal coronary arteries is common and associated with normal findings on cardiovascular magnetic resonance imaging: results from the Stockholm Myocardial Infarction with Normal Coronaries study. Journal of internal medicine 2013;273:189-96.

37. Ozaki Y, Okumura M, Ismail TF, et al. Coronary CT angiographic characteristics of culprit lesions in acute coronary syndromes not related to plaque rupture as defined by optical coherence tomography and angioscopy. Eur Heart J 2011;32:2814-23.

38. Baccouche $H$, Mahrholdt $H$, Meinhardt $G$, et al. Diagnostic synergy of non-invasive cardiovascular magnetic resonance and invasive endomyocardial biopsy in troponin-positive patients without coronary artery disease. Eur Heart J 2009;30:2869-79.

39. Kim RJ, Fieno DS, Parrish TB, et al. Relationship of MRI delayed contrast enhancement to irreversible injury, infarct age, and contractile function. Circulation 1999;100:1992-2002.

40. Gerbaud E, Harcaut E, Coste P, et al. Cardiac magnetic resonance imaging for the diagnosis of patients presenting with chest pain, raised troponin, and unobstructed coronary arteries. Int $\mathrm{J}$ Cardiovasc Imaging 2012;28:783-94.

41. Dastidar AG, Baritussio A, De Garate E, et al. Prognostic Role of Cardiac MRI and Conventional Risk Factors in Myocardial Infarction With Nonobstructed Coronary Arteries. JACC Cardiovasc Imaging 2019.

42. Ferreira VM, Piechnik SK, Dall'Armellina E, et al. $\mathrm{T}(1)$ mapping for the diagnosis of acute myocarditis using CMR: comparison to T2-weighted and late gadolinium enhanced imaging. JACC Cardiovasc Imaging 2013;6:1048-58.
43. Friedrich MG, Sechtem U, Schulz-Menger J, et al. Cardiovascular magnetic resonance in myocarditis: A JACC White Paper. J Am Coll Cardiol 2009;53:1475-87.

44. Ferreira VM, Schulz-Menger J, Holmvang G, et al. Cardiovascular Magnetic Resonance in Nonischemic Myocardial Inflammation: Expert Recommendations. J Am Coll Cardiol 2018;72:3158-76.

45. Lindahl B, Baron T, Erlinge D, et al. Medical Therapy for Secondary Prevention and Long-Term Outcome in Patients With Myocardial Infarction With Nonobstructive Coronary Artery Disease. Circulation 2017;135:1481-9.

46. Fanning JP, Nyong J, Scott IA, Aroney CN, Walters $\mathrm{DL}$. Routine invasive strategies versus selective invasive strategies for unstable angina and non-ST elevation myocardial infarction in the stent era. Cochrane Database Syst Rev 2016:CD004815.

47. Sanchis J, Garcia-Blas S, Mainar L, et al. Highsensitivity versus conventional troponin for management and prognosis assessment of patients with acute chest pain. Heart 2014;100:1591-6.

48. Smulders MW, Kietselaer B, Wildberger JE, et al. Cardiovascular Magnetic Resonance or Computed Tomography Angiography First versus a Routine Invasive Strategy in High-sensitive Troponin-positive Suspected Non-ST-elevation Myocardial Infarction Randomized Controlled Trial. Journal of the American College of Cardiology 2018, 71 (11 Supplement) A987; DOI: 10.1016/S0735-1097(18)31528-6.

49. Jobs A, Mehta SR, Montalescot G, et al. Optimal timing of an invasive strategy in patients with non-STelevation acute coronary syndrome: a meta-analysis of randomised trials. Lancet 2017;390:737-46.

50. Kofoed KF, Kelbaek H, Hansen PR, et al. Early Versus Standard Care Invasive Examination and Treatment of Patients With Non-ST-Segment Elevation Acute Coronary Syndrome. Circulation 2018;138:2741-50.

51. Ryan JW, Peterson ED, Chen AY, et al. Optimal timing of intervention in non-ST-segment elevation acute coronary syndromes: insights from the CRUSADE (Can Rapid risk stratification of Unstable angina patients Suppress ADverse outcomes with Early implementation of the ACC/AHA guidelines) Registry. Circulation 2005;112:3049-57.

52. Puymirat E, Taldir G, Aissaoui N, et al. Use of invasive strategy in non-ST-segment elevation myocardial infarction is a major determinant of improved long-term survival: FAST-MI (French Registry of Acute Coronary Syndrome). JACC Cardiovasc Interv 2012;5:893-902.

53. Alvarez-Alvarez B, Abou Jokh Casas C, Garcia Acuna JM, et al. Temporal trends between association of evidence-based treatment and outcomes in patients with non-ST-elevation myocardial infarction. Int J Cardiol 2018;260:1-6.

54. Badings EA, Hermanides RS, Van Der Sluis A, et al. Use, timing and outcome of coronary angiography in patients with high-risk non-ST-segment elevation acute coronary syndrome in daily clinical practice: insights from a 'real world' prospective registry. Neth Heart J 2019;27:73-80.

55. Chang HJ, Lin FY, Gebow D, et al. Selective Referral Using CCTA Versus Direct Referral for Individuals Referred to Invasive Coronary Angiography for 
Suspected CAD: A Randomized, Controlled, OpenLabel Trial. JACC Cardiovasc Imaging 2018;7:1303-12.

56. Greenwood JP, Ripley DP, Berry C, et al. Effect of Care Guided by Cardiovascular Magnetic Resonance, Myocardial Perfusion Scintigraphy, or NICE Guidelines on Subsequent Unnecessary Angiography Rates: The CE-MARC 2 Randomized Clinical Trial. JAMA 2016;316:1051-60.

57. Litt HI, Gatsonis C, Snyder B, et al. CT angiography for safe discharge of patients with possible acute coronary syndromes. N Engl J Med 2012;366:1393-403.

58. Reimer KA, Jennings RB. The "wavefront phenomenon" of myocardial ischemic cell death. II. Transmural progression of necrosis within the framework of ischemic bed size (myocardium at risk) and collateral flow. Laboratory investigation; a journal of technical methods and pathology 1979;40:633-44.

59. Ghugre NR, Ramanan V, Pop M, et al. Quantitative tracking of edema, hemorrhage, and microvascular obstruction in subacute myocardial infarction in a porcine model by MRI. Magn Reson Med 2011;66:1129-41.

60. Bekkers SC, Yazdani SK, Virmani R, Waltenberger J. Microvascular obstruction: underlying pathophysiology and clinical diagnosis. J Am Coll Cardiol 2010;55:1649-60.

61. Bekkers SC, Smulders MW, Passos VL, et al. Clinical implications of microvascular obstruction and intramyocardial haemorrhage in acute myocardial infarction using cardiovascular magnetic resonance imaging. Eur Radiol 2010;20:2572-8.

62. Eitel I, Friedrich MG. T2-weighted cardiovascular magnetic resonance in acute cardiac disease. J Cardiovasc Magn Reson 2011;13:1-13.

63. Perazzolo Marra M, Lima JA, lliceto S. MRI in acute myocardial infarction. Eur Heart J 2011;32:284-93.

64. Stillman AE, Oudkerk $M$, Bluemke $D$, et al. Assessment of acute myocardial infarction: current status and recommendations from $\mathrm{NASCl}$ and the ESCR. Int J Cardiovasc Imaging 2011;27:7-24.

65. Abdel-Aty $\mathrm{H}$, Zagrosek A, Schulz-Menger J, et al. Delayed enhancement and T2-weighted cardiovascular magnetic resonance imaging differentiate acute from chronic myocardial infarction. Circulation 2004;109:2411-6.

66. Stork A, Muellerleile K, Bansmann PM, et al. Value of T2-weighted, first-pass and delayed enhancement, and cine CMR to differentiate between acute and chronic myocardial infarction. Eur Radiol 2007;17:610-7.

67. h-Ici DO, Ridgway JP, Kuehne T, et al. Cardiovascular magnetic resonance of myocardial edema using a short inversion time inversion recovery (STIR) black-blood technique: diagnostic accuracy of visual and semi-quantitative assessment. J Cardiovasc Magn Reson 2012;14:1-22.

68. Fishbein MC, Maclean D, Maroko PR. The histopathologic evolution of myocardial infarction. Chest 1978;73:843-9.

69. Carberry J, Carrick D, Haig C, et al. Persistence of Infarct Zone T2 Hyperintensity at 6 Months After Acute ST-Segment-Elevation Myocardial Infarction: Incidence, Pathophysiology, and Prognostic Implications. Circ Cardiovasc Imaging 2017;10.

70. Vasile VC, Jaffe AS. High-Sensitivity Cardiac Troponin for the Diagnosis of Patients with Acute
Coronary Syndromes. Curr Cardiol Rep 2017;19:92. 71. Bittencourt MS, Hulten E, Polonsky TS, et al. European Society of Cardiology-Recommended Coronary Artery Disease Consortium Pretest Probability Scores More Accurately Predict Obstructive Coronary Disease and Cardiovascular Events Than the Diamond and Forrester Score: The Partners Registry. Circulation 2016;134:201-11.

72. Douglas PS, Hoffmann U, Patel MR, et al. Outcomes of anatomical versus functional testing for coronary artery disease. N Engl J Med 2015;372:1291-300.

73. Newby DE, Adamson PD, Berry C, et al. Coronary CT Angiography and 5-Year Risk of Myocardial Infarction. N Engl J Med 2018;379:924-33.

74. Jaarsma C, Leiner T, Bekkers SC, et al. Diagnostic performance of noninvasive myocardial perfusion imaging using single-photon emission computed tomography, cardiac magnetic resonance, and positron emission tomography imaging for the detection of obstructive coronary artery disease: a meta-analysis. J Am Coll Cardiol 2012;59:1719-28.

75. Danad I, Szymonifka J, Twisk JWR, et al. Diagnostic performance of cardiac imaging methods to diagnose ischaemia-causing coronary artery disease when directly compared with fractional flow reserve as a reference standard: a meta-analysis. Eur Heart J 2017;38:991-8.

76. Neumann FJ, Sousa-Uva M, Ahlsson A, et al. 2018 ESC/EACTS Guidelines on myocardial revascularization. Eur Heart J 2019;40:87-165.

77. Hachamovitch R, Hayes SW, Friedman JD, Cohen I, Berman DS. Comparison of the short-term survival benefit associated with revascularization compared with medical therapy in patients with no prior coronary artery disease undergoing stress myocardial perfusion single photon emission computed tomography. Circulation 2003;107:2900-7.

78. Davies JE, Sen S, Dehbi HM, et al. Use of the Instantaneous Wave-free Ratio or Fractional Flow Reserve in PCl. N Engl J Med 2017;376:1824-34.

79. Pijls NH, van Schaardenburgh P, Manoharan G, et al. Percutaneous coronary intervention of functionally nonsignificant stenosis: 5-year follow-up of the DEFER Study. J Am Coll Cardiol 2007;49:2105-11

80. Tonino PA, De Bruyne B, Pijls NH, et al. Fractional flow reserve versus angiography for guiding percutaneous coronary intervention. $\mathrm{N}$ Engl $\mathrm{J}$ Med 2009;360:213-24

81. Nagel E, Greenwood JP, McCann GP, et al. Magnetic Resonance Perfusion or Fractional Flow Reserve in Coronary Disease. N Engl J Med 2019;380:2418-28.

82. Douglas PS, Pontone G, Hlatky MA, et al. Clinical outcomes of fractional flow reserve by computed tomographic angiography-guided diagnostic strategies vs. usual care in patients with suspected coronary artery disease: the prospective longitudinal trial of FFR(CT): outcome and resource impacts study. Eur Heart J 2015;36:3359-67.

83. Norgaard BL, Leipsic J, Gaur S, et al. Diagnostic performance of noninvasive fractional flow reserve derived from coronary computed tomography angiography in suspected coronary artery disease: the NXT trial (Analysis of Coronary Blood Flow Using CT Angiography: Next Steps). J Am Coll Cardiol 2014;63:1145-55. 
84. Dey D, Slomka P, Leeson P. Artificial intelligence in cardiovascular imaging. Journal of the American College of Cardiology 2019;73:1317-35.

85. Motwani M, Dey D, Berman DS, et al. Machine learning for prediction of all-cause mortality in patients with suspected coronary artery disease: a 5 -year multicentre prospective registry analysis. Eur Heart J 2017;38:500-7.

86. Assomull RG, Lyne JC, Keenan N, et al. The role of cardiovascular magnetic resonance in patients presenting with chest pain, raised troponin, and unobstructed coronary arteries. Eur Heart $\mathrm{J}$ 2007;28:1242-9.

87. Christiansen JP, Edwards C, Sinclair T, et al. Detection of myocardial scar by contrast-enhanced cardiac magnetic resonance imaging in patients with troponin-positive chest pain and minimal angiographic coronary artery disease. Am J Cardiol 2006;97:768-71.

88. Laraudogoitia Zaldumbide E, Perez-David E, Larena JA, et al. The value of cardiac magnetic resonance in patients with acute coronary syndrome and normal coronary arteries. Rev Esp Cardiol 2009;62:976-83.

89. Chopard R, Jehl J, Dutheil J, et al. Evolution of acute coronary syndrome with normal coronary arteries and normal cardiac magnetic resonance imaging. Arch Cardiovasc Dis 2011;104:509-17.

90. Leurent G, Langella B, Fougerou C, et al. Diagnostic contributions of cardiac magnetic resonance imaging in patients presenting with elevated troponin, acute chest pain syndrome and unobstructed coronary arteries. Arch Cardiovasc Dis 2011;104:161-70.

91. Stensaeth KH, Fossum E, Hoffmann P, Mangschau A, Klow NE. Clinical characteristics and role of early cardiac magnetic resonance imaging in patients with suspected ST-elevation myocardial infarction and normal coronary arteries. Int $\mathrm{J}$ Cardiovasc Imaging 2011;27:355-65.

92. Mahmoudi M, Harden S, Abid N, et al. Troponinpositive chest pain with unobstructed coronary arteries: definitive differential diagnosis using cardiac MRI. The British journal of radiology 2012;85:e461-6.

93. Gerbaud E, Harcaut E, Coste P, et al. Cardiac magnetic resonance imaging for the diagnosis of patients presenting with chest pain, raised troponin, and unobstructed coronary arteries. The international journal of cardiovascular imaging 2012;28:783-94.

94. Kawecki D, Morawiec B, Monney P, et al. Diagnostic contribution of cardiac magnetic resonance in patients with acute coronary syndrome and culpritfree angiograms. Medical science monitor : international medical journal of experimental and clinical research 2015;21:171-80.

95. Chu G, Zhang G, Zhu M, Zhang Z, Wu Y, Zhang H. Acute One-Stop Cardiovascular Magnetic Resonance Imaging for Differential Diagnosis in Patients with Acute Coronary Syndrome and Unobstructed Coronary Arteries. Medical principles and practice : international journal of the Kuwait University, Health Science Centre 2015;24:325-31.

96. Emrich T, Emrich K, Abegunewardene $\mathrm{N}$, et al. Cardiac MR enables diagnosis in $90 \%$ of patients with acute chest pain, elevated biomarkers and unobstructed coronary arteries. The British journal of radiology $2015 ; 88$.
97. Saba L, Fellini F, De Filippo M. Diagnostic value of contrast-enhanced cardiac magnetic resonance in patients with acute coronary syndrome with normal coronary arteries. Japanese journal of radiology 2015;33:410-7.

98. Pathik B, Raman B, Mohd Amin NH, et al. Troponinpositive chest pain with unobstructed coronary arteries: incremental diagnostic value of cardiovascular magnetic resonance imaging. European heart journal cardiovascular Imaging 2016;17:1146-52. 
PART
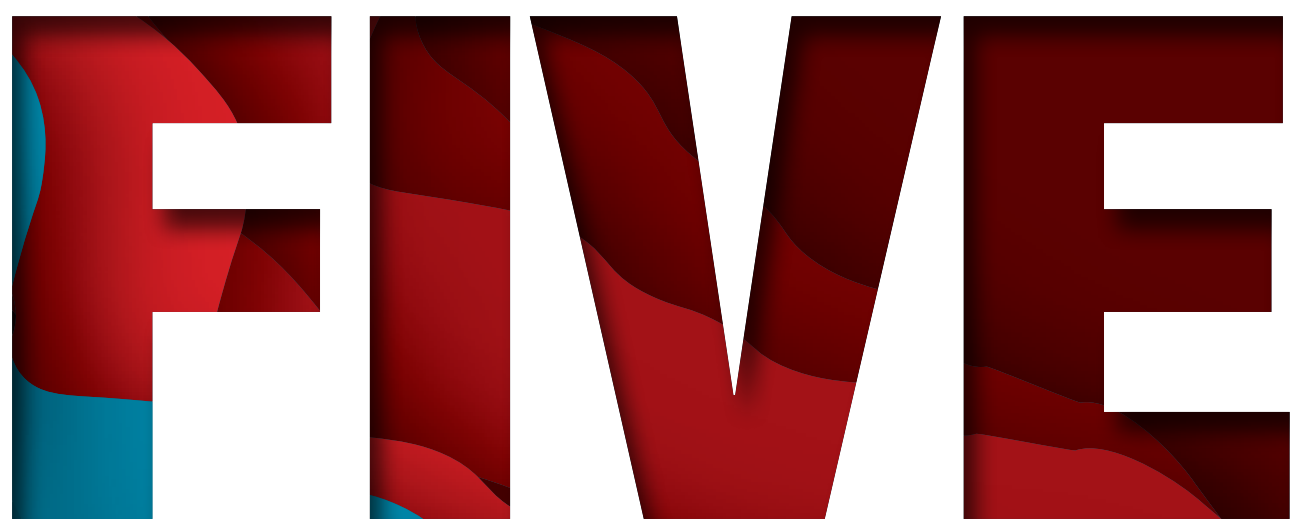
Appendices 


\section{Nederlandse samenvatting}


Pijn op de borst is een veel voorkomend symptoom en kan door zowel cardiale als niet-cardiale aandoeningen veroorzaakt worden. Non-invasieve diagnostiek wordt steeds frequenter als een essentieel onderdeel van de diagnostische evaluatie beschouwd in patiënten met pijn op de borst, maar inefficiënt en overmatig gebruik moet worden voorkomen. Dit proefschrift beschrijft de rol van non-invasieve diagnostiek in patiënten met acute en chronische pijn op de borst (Deel 1, Hoofdstuk 1).

In patiënten met acute pijn op de borst (Deel 2) is een gestructureerde diagnostische strategie noodzakelijk om een acute cardiale aandoening (bijv. myocard infarct) uit te sluiten. Hierin zijn het klinisch scenario, elektrocardiogram (ECG) en cardiale troponine testen essentieel. De invoering van hoog-sensitieve cardiale troponine testen hebben geleid tot het zeer betrouwbaar uitsluiten van een acuut myocard infarct. Deze hoge sensitiviteit gaat echter ten koste van de specificiteit om een myocard infarct aan te tonen. Hoofdstuk 2 geeft een overzicht van de klinische consequenties van invoering van deze hoog-sensitieve cardiale troponine test, gefocust op de veranderende rol van non-invasieve diagnostiek.

In hoofdstuk $\mathbf{3}$ worden de resultaten gepresenteerd van een observationele studie naar de waarde van additionele diagnostiek in patiënten met acute pijn op de borst en normale hoog-sensitieve cardiale troponine $T$ waarden. De een-jaar prognose van deze populatie is goed. Ongeveer een derde van alle patiënten ondergaat additionele diagnostiek ter uitsluiting van coronairlijden. We tonen aan dat abnormale testuitslagen in een minderheid gevonden worden en de consequenties voor therapeutisch ingrijpen nihil zijn. Dit geldt met name voor patiënten die klinisch ook als laag risico worden geïdentificeerd.

Een verhoogd troponine, met name in de lage range, is niet specifiek voor een myocard infarct. Huidige behandelstrategieën in patiënten met acute pijn op de borst en verhoogde troponine waarden zijn echter primair op coronairlijden gericht en bevatten (routinematig) een invasieve hartkatheterisatie. Sinds invoering van de hoog-sensitieve troponine testen worden er meer patiënten verwezen voor een hartkatheterisatie en wordt er steeds frequenter geen obstructief coronairlijden gezien. De differentiaal diagnose in patiënten met verdenking infarct en zonder obstructief coronairlijden (MINOCA) is breed en bevat zowel ischemische als non-ischemische (o.a. myocarditis en stress-cardiomyopathie) oorzaken. In hoofdstuk 4 stellen we een systematisch diagnostisch algoritme voor in MINOCA met een centrale rol voor cardiale MRI. Cardiale MRI leidt in $70 \%$ tot een diagnose en kan ischemische en non-ischemische oorzaken goed onderscheiden.

Idealiter zouden primair diagnostische hartkatheterisaties tot het minimum moeten worden gereduceerd. Een hartkatheterisatie kan leiden tot complicaties, hogere zorgkosten en langere opname duur. In hoofdstukken 5 \& 6 beschrijven we de CARMENTA trial, een studie in patiënten met acute pijn op de borst, een niet diagnostisch ECG en verhoogd hoog sensitief troponine $T$ (verdenking non-ST elevatie myocard infarct). Deze gerandomiseerde studie toont aan dat het aantal (diagnostische) hartkatheterisaties verminderd kan worden, als er primair een cardiale MRI of CT scan wordt verricht. Ondanks het verminderen van het aantal hartkatheterisaties, zien we dat de 1-jaars prognose tussen de groepen gelijk is en dat er een trend tot minder uitkomsten en complicaties is in de MRI en CT armen. Daarnaast toont deze studie ook aan, dat in patiënten zonder obstructief coronairlijden vaak een alternatieve diagnose zoals myocarditis wordt gevonden middels cardiale MRI.

Hoofdstuk 7 beschrijft een studie waarin de waarde van cardiale MRI wordt onderzocht in het onderscheiden van een acuut en chronisch myocard infarct. Een occlusie van een coronair arterie leidt tot het ontstaan van irreversibele schade en een cascade aan pathofysiologische processen welke de lokale weefselkarakteristieken doen veranderen door de tijd heen. 
De aan- of afwezigheid van bepaalde karakteristieken, hebben derhalve de potentie om de leeftijd van een myocard infarct in te schatten. Cardiale MRI is in staat om met gebruik van verschillende sequenties het weefsel te karakteriseren. Een nieuwe bevinding in onze studie is dat een verhoogd signaal op T2-gewogen MRI sequenties tot 6 maanden na een infarct kan blijven bestaan en daarom geen goede indicator is voor een acuut myocard infarct. Karakteristieken als microvasculaire obstructie op delayed-enhancement MRI of een verdikte wand (t.g.v. oedeem) op cine MRI werden echter alleen geobserveerd in infarcten van minder dan een maand oud.

De rol van non-invasieve diagnostiek in patiënten met chronische pijn op de borst, ook wel verdenking stabiele angina pectoris genoemd, wordt beschreven in Deel 3. Non-invasieve diagnostiek heeft een belangrijke rol in deze patiënten voor het opsporen van coronairlijden en ischemie. Abnormale test uitslagen kunnen leiden tot het initiëren van therapie of vervolg (invasieve) diagnostiek. De casus gepresenteerd in hoofdstuk 8 laat zien dat non-invasieve beeldvorming ook in staat is om alternatieve oorzaken voor pijn op de borst aan te tonen, zoals een cardiale tumor welke intermitterend myocardiale ischemie induceert door het ostiaal obstrueren van een coronair arterie.

In hoofdstuk 9 wordt een meta-analyse beschreven over de prognostische waarde van een negatieve test uitslag van de meest gebruikte non-invasieve diagnostische modaliteiten om (anatomisch of functioneel) coronairlijden aan te tonen. Deze studie heeft meerdere bevindingen: 1) een negatieve test impliceert over het algemeen een uitstekende prognose, 2) de prognose na het anatomisch uitsluiten van een stenose middels een normale cardiale CT scan is beter vergeleken met een negatieve functionele test (behoudens cardiale MRI en PET), 3) er is een sterke correlatie tussen het a-priori risico en de uiteindelijke prognose na een normale test uitslag, 4) correctie voor verschillen in populatie (a-priori risico) tussen de modaliteiten leidt tot een vergelijkbare prognose na een negatieve test uitslag voor alle modaliteiten.

In het deel 4, hoofdstuk 10, worden de conclusies van de studies in het licht van de huidige literatuur besproken. Samenvattend draagt dit proefschrift bij aan de kennis over de klinische waarde van non-invasieve diagnostiek in patiënten met zowel acute als chronische pijn op de borst. Daarnaast worden er suggesties gedaan voor het gerichter en efficiënter toepassen van non-invasieve diagnostiek. 
Appendices 207 
Valorisation 


\section{Relevance}

In Europe, 85 million inhabitants have cardiovascular disease and over 3 million Europeans experience angina pectoris (i.e. chest pain related to myocardial ischemia) or an anginal equivalent for the first time every year. ${ }^{1}$ Cardiovascular disease is the main cause of demise in developed countries., ${ }^{1,2}$ The prevalence of cardiovascular disease and its impact on morbidity and mortality is even expected to increase in the following years due to ageing.

Chest pain is the most common cause for an emergency department visit. ${ }^{3}$ The cause of chest pain ranges from a trivial ailment to more serious potentially life-threatening diseases. Non-invasive cardiovascular testing is often considered crucial in the diagnostic work-up of patients with chest pain. A substantial increase in the use of additional testing is observed over the last years. ${ }^{4,5}$ Adequate selection of patients for the appropriate test is essential to prevent ineffective use of these costly diagnostics.

The central theme of this thesis is to investigate the role of non-invasive imaging in patients with acute or chronic chest pain. Ultimately, the results of the research presented in this thesis may contribute to a more (cost-)effective use of diagnostic tests and improve patient outcome.

\section{Target groups}

Patients investigated in this thesis represent the full spectrum of chest pain. The first part of this thesis provides a general introduction to this topic. The second part of this thesis discusses the use of non-invasive diagnostic testing in patients with acute chest pain. Among patients with acute chest pain at the emergency department, the patient history, electrocardiographic and laboratory findings provide important information for risk stratification. Based on this risk assessment, patients can be categorized as: 1) low risk for acute myocardial infarction (atypical symptoms, normal electrocardiogram and low-to-normal high-sensitivity cardiac troponin levels), 2) intermediate risk for acute myocardial infarction (near)normal or inconclusive electrocardiogram and minimally elevated high-sensitivity cardiac troponin levels), and 3) high risk or definite acute myocardial infarction (significant electrocardiographic changes and/or increased troponin levels). The third part of this thesis focusses on patients with chronic chest pain. Patients with chronic chest pain can be categorized as 1) patients with suspected coronary artery disease or 2) patients with stable or new onset angina pectoris in whom coronary artery disease is already known. In this thesis, all above mentioned subgroups are investigated.

The findings of the studies presented in this thesis are relevant for cardiologists, emergency department physicians, (nuclear) radiologists, clinical chemists, general practitioners, researchers and policy makers. A diagnostic decision tree for the evaluation of patients with acute chest pain is included in chapter $\mathbf{1 0}$ of this thesis and may help physicians to decide whether additional diagnostic testing is indicated at all and to select the most appropriate modality for a specific clinical scenario.

Despite that this thesis is primarily targeted to physicians, its results could be informative for patients experiencing chest pain as well. Patients should be informed (preferably by a professional) about the diagnostic and/or prognostic value of additional cardiac testing based on their specific pre-test likelihood of having ischemic heart disease.

\section{Activities/products and innovation}

Evaluating patients with chest pain remains challenging and requires a high level of clinical experience of physicians. Categorizing patients into risk groups is a simplification of the underlying continuum in risk that ranges from $0-100 \%$ in an individual patient. It is expected that computer assisted patient care including decision support systems guided by machine learning/artificial 
intelligence may assist the treating physician by providing more specific estimates of patients' risk along a continuous scale in the (near) future. However, clinical validation studies focused on patient outcome and cost-effectiveness are needed to confirm this hypothesis.

At present, identifying subgroups of patients with different risk profiles is not only practically useful, in that it structures the diagnostic strategy, it also allows performing and comparing research.

The diagnostic tests investigated in this thesis are often routinely available in academic and non-academic hospitals. The innovation lies in the selection of patients, timing of the diagnostic test, test quality and combined interpretation of clinical data and test results.

The results in this thesis suggest the following. First, additional diagnostic testing is not useful in patients with acute chest pain at low clinical risk. Second, CMR and CTA can be used as safe gatekeepers for invasive coronary angiography in patients with acute chest pain, an inconclusive electrocardiogram and elevated high-sensitivity cardiac troponin levels (suspected non-ST elevation myocardial infarction). Third, CMR plays a crucial role in the diagnostic process of patients with suspected myocardial infarction and normal coronary arteries on coronary angiography (invasive coronary angiography or CTA). Fourth, CMR provides insight into the infarct healing process and thereby allows estimating infarct age. Fifth, a negative non-invasive imaging test result yields an excellent prognosis for patients with suspected or known stable coronary artery disease.

\section{Planning \& implementation}

We have shown that routine use of non-invasive cardiac testing in patients with acute chest pain and normal high-sensitivity cardiac troponin $\mathrm{T}$ levels has a low diagnostic yield. Restricting additional non-invasive diagnostic testing to only patients with a higher risk, was suggested in our observational study described in chapter 3 . Similar conclusions were drawn in a recent manuscript concerning a larger multicenter trial. ${ }^{6}$ Both studies suggest that standardized clinical risk stratification (including troponin measurement) for the selection of additional diagnostic testing may improve the efficacy of care while maintaining patient safety. Although promising, more robust evidence provided by randomized controlled clinical trials, large matched cohort studies preferably employing registry-based recruitment (proposed study design: no test versus test with an adequate sample size to assess patient outcome) are needed to further convince cardiologists and emergency department physicians.

Chapters 5 \& 6 describe a randomized controlled clinical trial in patients with suspected non-ST elevation myocardial infarction (i.e. acute chest pain, inconclusive electrocardiogram and elevated high-sensitivity cardiac troponin T levels). This trial shows that a CMR and CTA first strategy prevents (unnecessary) invasive coronary angiography. Despite that no difference in patient outcome was observed between groups (secondary endpoint), verification of patient safety in a larger multicenter trial is warranted. The observed trend of having less events and complications in both non-invasive imaging arms compared to a routine invasive strategy, suggests that early CMR or CTA are appropriate alternatives to a routine invasive strategy in suspected non-ST elevation myocardial infarction and should be considered in hospitals with sufficient expertise. Furthermore, it is expected that the results of the CARMENTA trial will initiate non-invasive imaging guided trials in patients with suspected non-ST elevation myocardial infarction. Likewise, a recent study showed the significance of non-invasive MR-imaging in stable coronary artery disease. ${ }^{7}$ It needs to be awaited whether our trial will already be a true game-changer in the diagnostic approach of patients with suspected non-ST elevation myocardial infarction. Given these initial results, we expect that such an "imaging-first" strategy in suspected non-ST elevation myocardial infarction patients shall provide a safe, cost effective, 
rapid and patient-friendly diagnostic and treatment approach. We anticipate this approach to fundamentally change the way the cardiovascular community will diagnose coronary artery disease and related conditions.

CMR allows us to visualize different aspects of the infarct healing process. Prior studies argued that T2-weighted CMR was able to differentiate acute and chronic myocardial infarction. We show in chapter 7, that T2-weighted hyperintensity may persist for several months after acute myocardial infarction and therefore likely does not represent myocardial edema. Moreover, we postulated a multicomponent CMR approach involving cine, T2-weighted, and delayed enhancement imaging to determine infarct age more accurately. Despite that many myocardial infarctions result in acute chest pain, triggering an emergency department visit and subsequent diagnosis of acute myocardial infarction, also silent myocardial infarction occurs frequently. In this case, the timing of the event is unknown. It is crucial for patient management to know whether a myocardial infarction is (sub)acute or chronic. For instance, dual antiplatelet therapy is only indicated in acute myocardial infarction. Another clinical implication of detecting acute myocardial infarction is related to the identification of the culprit lesion. Many patients with acute myocardial infarction have multivessel disease, in whom identification of the culprit coronary artery is often challenging. CMR may help identifying the culprit coronary artery by locating the infarcted segment and differentiate any prior injury from acute myocardial infarction. ${ }^{8}$ In our study, we used standard CMR sequences. Therefore, we believe that this approach is robust, and can directly be incorporated into clinical practice without extra costs or requirement for additional training.

The meta-analysis on patients with suspected or known coronary artery disease presented in chapter 9 concludes that prognosis is excellent when ischemia or obstructive coronary artery disease is absent, regardless of the cardiac imaging modality. Arguably, this challenges the need for additional, more advanced testing even when a more 'simple' test (for instance exercise testing) does not suggest stress-induced cardiac ischemia. However, information of patient management and any follow-up testing was not available in this study. In general, meta-analyses may only indirectly change clinical care, by informing physicians about the mean prognostic value of a modality in a specific patient population. Decision making for the individual patient, however, requires a more sophisticated approach. 


\section{REFERENCES}

1. Wilkins $E$ WL, Wickramasinghe $K$, Bhatnagar $P$, Leal J, Luengo-Fernandez R, Burns R, Rayner M, Townsend N. European Cardiovascular Disease Statistics 2017. European Heart Network, Brussels.

2. Townsend N, Wilson L, Bhatnagar P, Wickramasinghe K, Rayner M, Nichols M. Cardiovascular disease in Europe: epidemiological update 2016. Eur Heart J 2016;37:3232-45.

3. Mockel M, Searle J, Muller R, et al. Chief complaints in medical emergencies: do they relate to underlying disease and outcome? The Charite Emergency Medicine Study (CHARITEM). European journal of emergency medicine : official journal of the European Society for Emergency Medicine 2013;20:103-8.

4. Bhuiya FA, Pitts SR, McCaig LF. Emergency department visits for chest pain and abdominal pain: United States, 1999-2008. NCHS data brief 2010:1-8.

5. Lucas FL, DeLorenzo MA, Siewers AE, Wennberg $D E$. Temporal trends in the utilization of diagnostic testing and treatments for cardiovascular disease in the United States, 1993-2001. Circulation 2006;113:374-9.

6. Sharp AL, Baecker AS, Shen E, et al. Effect of a HEART Care Pathway on Chest Pain Management Within an Integrated Health System. Ann Emerg Med 2019;74:171-80.

7. Nagel E, Greenwood JP, McCann GP, et al. Magnetic Resonance Perfusion or Fractional Flow Reserve in Coronary Disease. The New England journal of medicine 2019;380:2418-28.

8. Heitner JF, Senthilkumar A, Harrison JK, et al. Identifying the Infarct-Related Artery in Patients With Non-ST-Segment-Elevation Myocardial Infarction. Circ Cardiovasc Interv 2019;12:e007305. 
Appendices 213 
Curriculum Vitae 
Martijn Willem Smulders was born on April $7^{\text {th }} 1986$ in Groningen, the Netherlands. In 2004, he graduated from pre-university school at the Onze Lieve Vrouwelyceum (Breda, the Netherlands). He started his medical training at the Faculty of Health Medicine and Life Sciences at the Maastricht University (Maastricht, the Netherlands). His interest in cardiology was triggered during a $4^{\text {th }}$ year elective clinical internship at the department of cardiology at the Maastricht University Medical Center+ (Maastricht UMC+, Maastricht, the Netherlands). He started working as a student assistant under supervision of Dr. S.C.A.M. Bekkers during the last 3 years of his medical training. This research was focused on the role of cardiovascular magnetic resonance imaging in acute myocardial infarction. After finishing his senior clinical elective in cardiology, he graduated as Medical Doctor in 2010. From July 2010 until December 2010 he worked as a research assistant at the Cardiovascular Research Institute Maastricht, followed by a 2-month residency in cardiology at the Maastricht UMC+. He started his PhD trajectory in March 2011 at the Maastricht UMC+ under supervision of Prof. dr. H.J.G.M. Crijns, Prof. dr. J.E. Wildberger, Dr. S.C.A.M. Bekkers and Dr. B.L.J.H. Kietselaer. His research was focused on the role of non-invasive cardiac imaging in patients with chest pain. During his $\mathrm{PhD}$-track he had a research collaboration with the Duke Cardiovascular Magnetic Resonance Center (Duke University, Durham, USA) under supervision of Prof. dr. R.J. Kim and visited the laboratory multiple times. Martijn received a regional scholarship travel grant from the Society for Cardiovascular Magnetic Resonance in 2013. In 2014, he was awarded with a Dr. Dekker grant of 100.000 euro by the Dutch Heart Foundation. He presented the results of his research at several international conferences and received the award for best presentation on cardiovascular imaging and coronary disease at the Netherlands Society of Cardiology in 2016 and 2019, respectively. In 2017, he won the first price of the $22^{\text {nd }}$ Pélerin symposium of the Maastricht UMC+ with his presentation on an improved diagnostic approach in patients with acute chest pain. The most important scientific results are described and discussed in this thesis. On August $1^{\text {st }}, 2016$, he started his training in cardiology at Maastricht UMC+ under supervision of Prof. dr. H.J.G.M. Crijns, Dr. E.C. Cheriex and Drs. N.H.T. Dinh. In the context of his training, he did a 2-year residency in internal medicine at the Maastricht UMC+ under supervision of Prof. dr. C.D. Stehouwer and Prof. dr. R.P. Koopmans from 2016-2018, a 1-year residency in cardiology at the Zuyderland Medical Center (Heerlen, the Netherlands) under supervision of dr. T. Lenderink, and on august $1^{\text {st }} 2019$, he continued his training in cardiology at the Maastricht UMC+. He currently lives in Maastricht, together with his wife Ellen and their son Sil and daughter Evi. 


\section{List of publications}




\section{LIST OF PUBLICATIONS}

M.W. Smulders, B.L.J.H. Kietselaer, J.E. Wildberger, P.C. Dagnelie, H.P. Brunner-La Rocca, A.M.A. Mingels, Y.J.M. van Cauteren, R.A.L.J. Theunissen, M.J. Post, S. Schalla, S.M.J. van Kuijk, M. Das, R.J. Kim, H.J.G.M. Crijns, S.C.A.M. Bekkers.

Initial Imaging-Guided Strategy Versus Routine Care in Patients With Non-ST-Segment Elevation Myocardial Infarction.

Journal of the American College of Cardiology. 2019;74:2466-77.

J.F. Heitner, A. Senthilkumar, J.K Harrison, I. Klem, M.H. Sketch, A. Ivanov, C. Hamo, L. Van Assche, J. White, J. Washam, M.R. Patel, S.C.A.M. Bekkers, M.W. Smulders, T.J. Sacchi, R.J. Kim.

Identifying the Infarct-Related Artery in Patients With Non-ST-Segment-Elevation Myocardial Infarction.

Circulation Cardiovascular Interventions. 2019; 12:e007305.

M.J.W. van Mourik MJW, D.V.J. Zaar, M.W. Smulders, J. Heijman, J. Lumens, J.E. Dokter, V. Lima Passos, S. Schalla, C. Knackstedt, G. Schummers, O. GjesdaL, T. Edvardsen, S.C.A.M. Bekkers.

Adding Speckle-Tracking Echocardiography to Visual Assessment of Systolic Wall Motion Abnormalities Improves the Detection of Myocardial Infarction.

Journal of the American Society of Echocardiography. 2019; 32:65-73.

M.W. Smulders, S.C.A.M. Bekkers, Y.J.M. van Cauteren, A. Liefhebber, J.R. Vermeer, J. Vervuurt, M.P. van Dieijen-Visser, A.M. Mingels, H.P. Brunner-La Rocca, P.C. Dagnelie, J.E. Wildberger, H.J.G.M. Crijns, B.L.J.H. Kietselaer.

Acute pijn op de borst zonder afwijkend troponine. Is aanvullende niet-invasieve diagnostiek zinvol? Nederlands tijdschrift voor geneeskunde. 2018; 162.

M.W. Smulders, S.C.A.M. Bekkers, Y.J.M. van Cauteren, A. Liefhebber, J.R. Vermeer, J. Vervuurt, M.P. van Dieijen-Visser, A.M. Mingels, H.P. Brunner-La Rocca, P.C. Dagnelie, J.E. Wildberger, H.J.G.M. Crijns, B.L.J.H. Kietselaer.

Risk stratification and role for additional diagnostic testing in patients with acute chest pain and normal high-sensitivity cardiac troponin levels.

PLoS One; 2018: e0203506

K. van der Weg, W.J. Kuijt, S.C.A.M. Bekkers, J.G.P. Tijssen, C.L. Green, M.W. Smulders, M.E. Lemmert, M.W. Krucoff, A.P.M. Gorgels.

Bursts of reperfusion arrhythmias occur independently of area at risk size and are the first marker of reperfusion injury.

International journal of cardiology. 2018; 271:240-246.

R.P. Amier, M.W. Smulders, W.M. van der Flier, S.C.A.M. Bekkers, A. Zweerink, C.P. Allaart, A. Demirkiran, S.T. Roos, P.F.A. Teunissen, Y. Appelman, N. van Royen, R.J. Kim, A.C. van Rossum, R. Nijveldt.

Long-term prognostic implications of previous silent myocardial infarction in patients presenting with acute myocardial infarction.

Journal of the American College of Cardiology: Cardiovascular Imaging. 2018; 11:1773-1781. 
R.P. Amier, R.Y.G. Tijssen, P.F.A. Teunissen, R. Fernandez-Jimenez, G. Pizarro, I. Garcia-Lunar, T. Bastante, P.M. van de Ven, A.M. Beek, M.W. Smulders, S.C.A.M. Bekkers, N. van Royen, B. Ibanez, R. Nijveldt.

Predictors of intramyocardial hemorrhage after reperfused ST-elevation myocardial infarction. Journal of the American Heart Association. 2017; 6:e005651.

M.W. Smulders, C. Jaarsma, P.J. Nelemans, S.C.A.M. Bekkers, J. Bucerius, T. Leiner, H.J.G.M. Crijns, J.E. Wildberger, S. Schalla.

Comparison of the prognostic value of negative non-invasive cardiac investigations in patients with suspected or known coronary artery disease - A meta-analysis.

European Heart Journal - Cardiovascular Imaging. 2017; 18: 980-987.

N. Hakimzadeh, J. Elias, G.W.M. Wijntjens, R. Theunissen, A. van Weert, M.W. Smulders, N. van den Akker, P.D. Moerland, H.J. Verberne, L.P. Hoebers, J.P.S. Henriques, A.M. van der Laan, M. Ilhan, M. Post, S.C.A.M. Bekkers, J.J. Piek.

Monocytic microRNA profile associated with coronary collateral artery function in chronic total occlusion patients.

Nature Scientific Reports. 2017; 7: 1532.

U.C. Nguyên, M. Mafi-Rad, J.P. Aben, M.W. Smulders, E.B. Engels, A.M. van Stipdonk, J.G. Luermans, S.C.A.M. Bekkers, F.W. Prinzen, K. Vernooy.

A novel approach for left ventricular lead placement in cardiac resynchronization therapy: Intra-procedural integration of coronary venous electro-anatomic mapping with delayed enhancement cardiac magnetic resonance imaging.

Heart Rhythm. 2017; 14:110-119.

M.W. Smulders, B.L.J.H. Kietselaer, S. Schalla, J. Bucerius, C. Jaarsma, M.P. van DieijenVisser, A.M. Mingels, H.P. Brunner-La Rocca, M.J. Post, M. Das, H.J.G.M. Crijns, J.E. Wildberger, S.C.A.M. Bekkers.

Acute Chest Pain in the High-Sensitivity Cardiac Troponin Era: A Changing Role for Non-Invasive Imaging?

American Heart Journal. 2016;177:102-111.

M.E.C.J. Hassell, R. Delewi, C.P.H. Lexis, M.W. Smulders, A. Hirsch, G. Wagner, S.C.A.M. Bekkers, I.C. van der Horst, F. Zijlstra, A.C. van Rossum, J.J. Piek, P. van der Harst, R. Nijveldt. The relationship between terminal QRS distortion on initial ECG and final infarct size at 4 months in conventional ST- segment Elevation Myocardial Infarct patients.

Journal of Electrocardiography. 2016; 49:292-299.

\section{S.C.A.M. Bekkers, M.W. Smulders.}

High biomarkers but normal angiogram. What next?

Heart Metabolism. 2015;67:15-20.

M.W. Smulders, S.C.A.M. Bekkers, H.W. Kim, L.M.R. Van Assche, M. Parker, R.J. Kim. Performance of CMR Methods for Differentiating Acute From Chronic MI.

Journal of the American College of Cardiology: Cardiovascular Imaging. 2015;8:669-79. 
M.W. Smulders, A.W.F. du Mee, B. de Vries, P. Sardari Nia.

Case report: An uncommon cause of typical cardiac chest pain.

Circulation. 2014;129:1714.

M.W. Smulders, B.L.J.H. Kietselaer, M. Das, J.E. Wildberger, H.J.G.M. Crijns, L.F. Veenstra, H.P. Brunner-La Rocca, M.P. van Dieijen-Visser, A.M.A. Mingels, P.C. Dagnelie, M.J. Post, A.P.M. Gorgels, A.D.I. van Asselt, G. Vogel, S. Schalla, R.J. Kim, S.C.A.M. Bekkers.

The role of cardiovascular magnetic resonance imaging and computed tomography angiography in suspected non-ST-elevation myocardial infarction patients: design and rationale of the CARdiovascular Magnetic rEsoNance imaging and computed Tomography Angiography (CARMENTA) trial.

American Heart Journal. 2013;166 :968-75.

C. Jaarsma, S.C.A.M. Bekkers, Z. Haidari, M.W. Smulders, P.J. Nelemans, A.P.M. Gorgels, H.J.G.M. Crijns, J.E. Wildberger, S. Schalla.

Comparison of different electrocardiographic scoring systems for detection of any previous myocardial infarction as assessed with cardiovascular magnetic resonance imaging.

American Journal of Cardiology. 2013;112:1069-74.

F.W. Körver, M. Hassell, M.W. Smulders, S.C.A.M. Bekkers, A.P.M. Gorgels.

Correlating both Aldrich and Hellemond score with cardiac magnetic resonance imaging endocardial surface area calculations in the estimation of the area at risk. Electrocardiography scores and endocardial surface area calculations: do they correlate?

Journal of Electrocardiology. 2013; 46:229-234.

C. Jaarsma, S. Schalla, E.C. Cheriex, M.W. Smulders, I.M. van Dongen, P.J. Nelemans, A.P.M. Gorgels, J.E. Wildberger, H.J.G.M. Crijns, S.C.A.M. Bekkers.

Incremental value of cardiovascular magnetic resonance over echocardiography in the detection of acute and chronic myocardial infarction.

Journal of Cardiovascular Magnetic Resonance. 2013; 16;15-5.

M.O. Versteylen, S.C.A.M. Bekkers, M.W. Smulders, B. Winkens, C. Mihl, M.H.M. Winkens, T. Leiner, MD, J.L. Waltenberger, R.J. Kim, A.P.M Gorgels.

Performance of angiographic, electrocardiographic and MRI methods to assess the area at risk in acute myocardial infarction.

Heart. 2012; 98:109-115.

M.O. Versteylen, S.C.A.M. Bekkers, M.W. Smulders, R.J. Kim, A.P.M Gorgels.

Author reply: Performance of angiographic, electrocardiographic and MRI methods to assess the area at risk in acute myocardial infarction.

Heart. 2012, 98:1257-1258.

B. Weijs, M.W. Smulders, B.S.N. Alzand.

Case report: Semi-Final Masked hypertension.

The Netherlands Journal of Medicine. October 2010; 68: 10. 
S.C.A.M. Bekkers, M.W. Smulders, V. Lima Passos, T. Leiner, J.L. Waltenberger, A.P.M. Gorgels, S. Schalla.

Clinical implications of microvascular obstruction and intramyocardial haemorrhage in acute myocardial infarction using cardiovascular magnetic resonance imaging.

European Radiology. 2010; 20:2572-2578.

\section{SUBMITTED}

M.W. Smulders, L.M.R. Van Assche, S.C.A.M. Bekkers, R. Nijveldt, C.W.H. Beijnink, H.W. Kim, B. Hayes, M.A. Parker, R.M. Judd, R.J. Kim.

Microvascular obstruction in acute myocardial infarction: insights from the epicardial surface area of infarction.

M.W. Smulders, A.J.J. Aerts.

Post-myocardial infarction pericarditis - Dressler's syndrome.

Y.J.M. van Cauteren, M.W. Smulders, R.A.L.J. Theunissen, S.C. Gerretsen, B.P. Adriaans, G.P. Bijvoet, A.M.A. Mingels, S.M.J. van Kuijk, S. Schalla, H.J.G.M. Crijns, R.J. Kim, J.E. Wildberger, J. Heijman, S.C.A.M. Bekkers.

The diagnostic role of cardiac magnetic resonance imaging as initial test in non-ST-elevation myocardial infarction.

J. Elias, M.W. Smulders, G.W.M. Wijntjens, M.A. van Lavieren, L.P. Hoebers, T.P. van de Hoef, M. Ilhan, J.P. Aben, D. Koehn, R.N. Planken, M. Groenink, H.J. Verberne, A.J. Nederveen, M.J. Post, J.P.S. Henriques, S.C.A.M. Bekkers, J.J. Piek, A. Hirsch.

Value of cardiovascular magnetic resonance imaging for the assessment of collateral-dependent perfusion in chronic total occlusion patients. 
Appendices 221 
Acknowledgements / dankwoord 
Dank u wel voor het lezen van mijn proefschrift. Er zijn veel mensen die mij tijdens mijn promotietraject direct of indirect hebben geholpen. Ik wil graag iedereen bedanken die heeft bijgedragen of mij heeft gesteund in deze periode. Ik wil ook alle patiënten hartelijk bedanken die hebben deelgenomen aan de onderzoeken. Zonder hen zou er überhaupt geen studie of proefschrift zijn. Deelname aan een wetenschappelijk onderzoek tijdens een onzekere periode waarin lichamelijke klachten worden ervaren, verdient veel respect en getuigt van een grote betrokkenheid voor het verbeteren van de gezondheidszorg en een buitengewoon vertrouwen in de behandelend artsen en onderzoekers.

Een aantal mensen wil ik in het bijzonder bedanken.

Allereerst mijn promotieteam, 2 hoofden van 2 afdelingen en $2 \mathrm{Ba}(\mathrm{ss} / \mathrm{z}) \mathrm{en}$; 3 cardiologen en 1 radioloog; CTA en/of CMR voorstanders; 4 verschillende invalshoeken zowel klinisch als wetenschappelijk, $u$ allen heeft mij als onderzoeker en mijn promotietraject gevormd.

Beste prof. dr. Crijns, beste Harry, u heeft altijd weer een verfrissende en nieuwe kritische blik op de studieresultaten en de presentatie hiervan. Ik ben nog altijd onder de indruk van het tijdstip van uw reacties op mijn e-mails; hoe dieper in de nacht, hoe sneller ik een mail terug kan verwachten. Dank voor alles wat u voor me mogelijk gemaakt heeft, denk aan een (zeer langdurige) promotieplek, vele congresbezoeken, een duo-presentatie als opening van het NVvC congres, een opleidingsplek tot cardioloog, en nog veel meer.

Beste prof. dr. Wildberger, beste Joachim, in ons onderzoek komt beeldvorming en cardiologie samen. Een uitstekende en uitdagende combinatie, welke zonder uw inzet nooit zo geslaagd zou zijn geweest. Uw methoden om out-of-the-box te denken, te letten op de kleinste details, mensen te prikkelen en om ook eens besprekingen te houden op een alternatieve, zeer zonnige locatie van het Koninkrijk der Nederlanden zullen me bijblijven. Veel dank voor de begeleiding en samenwerking, en ik hoop in de toekomst samen met u nog vele mooie projecten te kunnen opzetten en samen de klinische zorg te verbeteren.

Beste dr. Bekkers, beste Bas, alweer 11 jaar geleden klopte ik bij je aan als vierdejaars student geneeskunde, ik wilde onderzoek gaan doen met beeldvorming in een populatie met acute cardiale problematiek. Ik denk dat we beiden niet hadden kunnen bedenken, dat het tot zo'n succesvolle en leuke samenwerking zou leiden. Je hebt me veel bijgebracht op het gebied van cardiologie, CMR, wetenschap en presenteren. Je bleef altijd kritisch totdat de laatste punt op papier stond. Bedankt voor alle kansen en begeleiding die je me hebt geboden, zonder jou was dit hele traject er niet geweest. Als begeleider stond je deur dagelijks voor mij open, maar er was daarnaast ook voldoende tijd voor ontspanning en hebben we het nodige meegemaakt. Enkele zaken om niet te vergeten: vele reizen naar de USA, onderzoeksdagen die we afsloten met IPA aan de bar, burn-outs en 0-100 mph testen in diverse muscle cars, ijshockey, op pad/de bar in Nice, Independence Day viering in het stadion van Duke, superbowl kijken in een tropisch resort, live op de radio.... Op naar nog meer ervaringen en mooie onderzoeken samen.

Beste dr. Kietselaer, beste Bas. Je bent de CT expert binnen het team. Je hebt me doen overtuigen van de waarde van CT binnen de cardiologie en me aangeleerd om deze adequaat te analyseren. Ironisch genoeg hebben we in onze gezamenlijk studie echter geconcludeerd dat in laag risico patiënten er geen waarde is voor aanvullende diagnostiek (inclusief CT). Je geeft 
me veel vrijheid met de uitvoering van onze projecten, bent altijd welwillend om bij te springen en bent sterk in de uiteindelijke verwoording en communicatie. Dank voor je begeleiding tijdens mijn promotietraject.

Voorzitter prof. dr. Jan Hoorntje en leden van de beoordelingscommissie van mijn proefschrift, prof. dr. Eline Kooi, dr. Steven Meex, prof. dr. Robin Nijveldt en prof. dr. Robbert de Winter, hartelijk dank voor de kritische en positieve beoordeling van mijn proefschrift.

Gelukkig sta ik er bij de verdediging van dit proefschrift niet alleen voor en word ik bijgestaan door mijn paranimfen Yvo en Yvonne. Ik ben jullie zeer dankbaar voor deze steun, maar ook voor alles wat we de afgelopen jaren hebben meegemaakt. Hoewel jullie namen doen vermoeden dat dit een selectiecriterium was, betekenen jullie veel voor me en ieder op zijn of haar eigen wijze.

Yvo, we kennen elkaar vanaf de eerste minuut van de studie geneeskunde bij de introductiedagen en al snel bleek dat we dezelfde interesses hebben. Enkele ervaringen die ik niet snel zal vergeten: de duizenden kilometers samen op de racefiets; onze voorliefde voor speciaal bieren met onze wekelijkse (soms vaker) bier avonden, vaste klantenkaart in 't Pothuiske, ons bezoek aan de Sint-Sixtusabdij om een houten bak Westvleteren 12 bier in te slaan; bijna-buren en dan met een bijpassend bierglas in de hand in de lift; legendarische stapavonden eindigend in de Maas (of toch niet Lianneke...); 24 uur op het circuit tijdens de race van Spa Francorchamps; Top Gear event (nog met het oprichtende trio); ons gezamenlijke werkbezoek in de USA, de USA road trip en de diverse bars en clubs in Virginia en North Carolina; hoe snel een appartement onbewoonbaar wordt door een stokbrood in de magnetron en leidt tot een bezoek van de brandweer; getuige bij je huwelijk; ronde-arts bij de ronde van Simpelveld; onze parallel lopende carrière (met ook nu weer gelijktijdige indiening van ons proefschrift naar de leescommissie) en samen dienst doen bij de interne geneeskunde. Heel veel dank voor je steun en de leuke jaren die we gehad hebben en ons nog te wachten staan!

Yvonne, we kennen elkaar pas een paar jaar, maar we hebben in die tijd heel veel samengewerkt. Je trekt de vervolgstudies van CARMENTA door, hebt me geholpen met de laatste analyses van het eerste manuscript en je bent daarom inmiddels ook met verve Ms. CARMENTA geworden. Het is fijn om samen te werken, vooral de combi-avonden borrel/diner en research zijn erg gezellig en productief. We hebben een soortgelijk traject achter de rug en kennen de ups en downs daarvan. Daarnaast ben je altijd in voor een feestje, praatje, koffie, borrel en praat me weer bij over de laatste nieuwe feiten en roddels (hoe kan het toch dat jij die altijd als eerste hoort...?). We zijn nog samen naar Duke afgereisd en ik herinner me nog goed je eerste (en bijna laatste...) 100 meter achter het stuur van de Mustang... Op de feesten van congressen of cursussen trok je iedereen mee tot in de kleine uurtjes tot diep in de nacht. Bedankt voor alle gezelligheid en al je hulp de afgelopen jaren. Heel veel succes met jouw proefschrift! De ruggengraad van je proefschrift staat en ziet er goed uit. Je bent inmiddels aan je opleiding tot cardioloog begonnen, een moeilijke combinatie met je promotie, maar ik wil je er graag bij helpen. Nog even en jij staat je proefschrift hier te verdedigen.

Inmiddels ben ik er achter dat de lengte van een promotietraject bijna lineair correleert met het aantal directe collega onderzoekers. Hierbij een poging om al mijn directe collega's van de afgelopen jaren te bedanken: Bob, mijn allereerste publicatie (op papier) en mijn allereerst 
toertocht wielrennen (Amstel Gold Race) waren met jou. Bouke, mede CMR onderzoeker en fietsliefhebber, mooi wat je voor elkaar hebt gekregen tijdens je onderzoeksperiode en dat allemaal i.c.m. een jong gezin. Die combi is trouwens nog vastgelegd op de gevoelige plaat, jij met je dochtertje op schoot op de onderzoekskamer samen Nijntje kijken, de foto heb je nog tegoed! Tot snel in de kliniek. Caroline, een speciaal woord van dank aan jou. De eerste jaren van mijn onderzoekstraject hebben we samen veel doorgebracht. We hebben o.a.: vele tientallen uren achter de scanner doorgebracht voor optimalisatie van sequenties tot soms in de weekenden aan toe, een van de eerste adenosine stress studies verricht in het Maastricht UMC+, jaren werk gehad aan onze gezamenlijke en oneindige meta-analyse met o.a. 61 pagina's aan tabellen (!) in de appendix, vele congresreizen waarvan ik de reis bij jou in de auto (was dat nu achteruit op de snelweg..?) spannender vond dan jij de vlucht.., mooie feestjes zoals op ons eerste congres in Nice of clubbing in Miami na 2 liter cocktail, de oprichting van het MCMRC, .. Het waren mooie jaren en ik hoop in de toekomst nog vaker met je te kunnen samenwerken zowel in de kliniek als wetenschap! Casper, de enige collega onderzoeker die 2x mijn collega is geweest en tussendoor "even" cardioloog is geworden. Bewonderingswaardig hoe je je eigen traject hebt gevormd, succes met je carrière en hou vooral je dans-moves vast... Elton, Mr. ACWAS a.k.a. RACE 7 , complimenten hoe je die studie hebt opgezet en draaiende hebt gehouden, zoals je al zelf memoreerde zaten we in hetzelfde schuitje met een klinische RCT. Ik zal je verschrikkelijke youtube liedjes die je graag meezong op de vrijdagmiddag nooit vergeten. Frederique, diegene die altijd maar blijft doorgaan, is het niet met een marathon lopen, dan is het wel met een "rustig en vlak" oefen ritje op de wielrenfiets dat wat uit de hand liep, ofwel tot vroeg in de ochtend op de befaamde congres feestjes (zelfs erg vlak voor je promotie...). Net als je verdediging deed je het allemaal met een glimlach, blijf dat vooral doen en ik hoop dat we nog een leuke opleidingstijd samen hebben. Kimberly, bedankt voor je werk en gezelligheid in het CMR team en veel succes met je carrière als huisarts. Ione, het lijkt alweer eeuwen geleden, maar het was een eer om bij je op de kamer te zitten. Ik ken oprecht niemand die alles zo positief inziet zoals jij. Naast collega onderzoeker hebben we samen nog enkele leuke jaren op het hockeyveld gehad. Jammer dat je de cardiologie hebt verlaten, maar misschien kunnen we nog eens wat radiologie/cardiologie projecten opzetten! Jort, een passie voor auto's is nog een understatement als je zelfs benzine aanziet voor aftershave, ik hoop in de toekomst nog eens samen of tegen je op het circuit te rijden! Manouk, je kwam binnen als een rustige WESP-studente maar hebt je inmiddels ontpopt tot een ware wetenschapper. Succes met je droom als huisarts! Mark, al vele jaren (ook voor je promotie) DE post-doc onder de onderzoekers. Respect hoe je kliniek, onderzoek en thuis weet te combineren (of is het je vrouw die de eer toekomt!?). Mooi dat we ook nu in de kliniek weer directe collega's zijn. Wanneer gaan we samen eens samen een project doen? Marije, bedankt voor de jaren dat ik je bureau-buurman mocht zijn. Masih, je deadlines waren non-verbaal perfect af te leiden en ik herinner me ook je photoshop kunsten met je figuren van je papers nog levendig. Respect hoe je ook tijdens het begin van je opleiding nog structureel bij ons op de kamer aan je onderzoek kwam werken in de avonduren, inmiddels ben ook ik ervaringsdeskundige op dit gebied... Op naar nog vele mooie jaren samen in de kliniek, zoals afgelopen jaar in Heerlen. Mindy, twee NEJM letters in de eerste maand van je onderzoekstraject en je leek wel klaar met je promotie! Gezien je boekje zijn er toch nog wat bijgekomen! Succes met je verdere carrière en wie weet tot op de werkvloer. Nick, DE hartfalen man van de onderzoekers en iedereen wist je te vinden voor weer een project. Dank voor alles wat te maken had met motoren, feestjes, Apple, biefstuk en de uitleg over het mooie dorp Maria Hoop ( ${ }^{*}$ ik garandeer je, $99 \%$ van de lezers wist niet van het bestaan af). Nikki, a.k.a Ms. ACWAS, ondanks dat we maar kort samen hebben gezeten, viel op dat vele kilometers reizen, dagenlange analyses en hard werken zich mooi hebben 
uitbetaald met jullie paper! Ömer, samen waren we de vaste klanten van de assistentenfeestjes, bedankt voor de gedenkwaardige avonden. Ik heb er mooie herinneringen aan, net als aan ons bezoek aan het ESC Rome (tenminste, de momenten dat je wel thuis kwam en niet ergens in de stad (ergens aan) was blijven plakken). Robert, nadat je proefschrift viral was gegaan, nu lekker aan het werk in de warme delen van ons Koninkrijk. Ron, geweldig hoe je los kon gaan op de dansvloer, maar tegelijkertijd een van de meest gedreven en serieuze onderzoekers van de afdeling was. Ruud, na jaren databases doorzoeken heb ook jij je promotieonderzoek kunnen afronden. Er was altijd wel wat te doen met jou op de kamer, de discussies met jou waren levendig, net als hoe je kon vertellen over het vinden van een gouden munt op een verlaten akker (die $1^{\mathrm{e}}$ zouden we toch delen?) en als je studenten weer te horen kregen "eerst 10-x-opdrukken, dan praten we verder!" Sandra, respect hoe jij onderzoek, privé en intensief sporten zo kon combineren. Je laat niet zomaar over je heen lopen, bent altijd in voor een fietstochtje, feestje en die spontane after-work borrel die om $5 u$ in de ochtend eindigde in de sneeuw zal toch altijd bijblijven. Sema, je liet mij en vele collega's met mij onze allereerste Turkse bruiloft meemaken, wat een ervaring. Succes met het afronden van jouw proefschrift en ook bedankt voor de tijd samen in Heerlen. Sibel, cardiac CT mattie, wat hebben we er toch samen veel weg gekeken. Je zat wat verder weg op de uni, maar de congressen en cursussen samen waren altijd weer gezellig. Theo, we hebben jaren samen op de kamer gezeten en ik kan me oprecht niet $1 \mathrm{x}$ herinneren dat jij je ergens druk of kwaad om kon maken. Een voorbeeld voor velen, inclusief mijzelf. Je was altijd te vinden voor een drankje, pub-quiz of avondje lekker eten, mits je klaar was met je 50.000 electroden ECG bevattende karretje die je altijd netjes 1 voor 1 schoonmaakte.

De lijst wordt te lang om iedereen persoonlijk te benoemen die heeft bijgedragen aan alle projecten, daarom een groot woord van dank aan een kort samengevatte lijst: alle verpleegkundigen op de eerste hart hulp (m.n. Jos Uyttersprot voor de organisatie en communicatie), CCU en verpleegafdeling, cardioresearch voor de ondersteuning en screening (m.n. Daniëlle Gijssen en Lieke Alberts), secretaresses/office-manager (m.n. Nicoline Nanninga, Miriam Habex-Froidmont, Saskia Buskes en Inge de Roo), vaatkamerpersoneel, cardiale CT laboranten, het vaste team cardiale MRI laboranten (wat hebben we vele uren samen achter de scanner doorgebracht en jullie waren altijd geïnteresseerd, in voor iets nieuws en flexibel in tijd, m.n. Liesbeth Boymans, Thea Klinkenberg-Sevriens, Laura Relou-Borsboom, Ilse van Duinen-Sampers, Kim Brouwers, Roland Kersemakers), laboranten klinisch chemisch lab voor alle nabepalingen, (WESP-)studenten (m.n. Anna Liefhebber, Juliëtte Vervuurt, Jasper Vermeer, Michal Kawczynski, Jules Olsthoorn en Kirsten Kramer), assistenten cardiologie en cardiologen.

Afdeling cardiologie; dank aan prof. dr. Hans-Peter Brunner-La Rocca voor uw bijdragen in diverse papers, prof. dr. Anton Gorgels voor uw begeleiding en mijn allereerste cardiologie congres (MALT in Aarhus Denemarken), dr. Simon Schalla voor de training in CMR en ondersteuning met de meta-analyse welke door de jaren heen minimaal 10x gereviseerd werd op verzoek van diverse reviewers, dr. Ralph Theunissen voor je ECG en CAG beoordelingen van de CARMENTA trial, dr. Lex Ruiters en dr. Mustafa Ilhan voor jullie medewerking aan de ANTARCTICA trial en later mijn training in hartkatheterisaties, dr. Jordi Heijman voor je (snelle) hulp en inzichten om het manuscript van de CARMENTA nog verder te verbeteren. Prof. dr. Van 't Hof en Tobias Pustjens voor jullie vernieuwende inzichten in de combinatie interventie-non-invasievebeeldvorming bij patiënten met acute pijn op de borst, ik kijk uit naar onze gezamenlijke projecten en papers. 
Afdeling beeldvorming; naast prof. dr. Joachim Wildberger ook dank aan dr. Suzanne Gommers, dr. Suzanne Gerretsen, dr. Marco Das, dr. Casper Mihl en dr. Jan Bucerius, dank voor alle steun op beeldvormend gebied. We hebben een goede samenwerking op zowel klinisch als wetenschappelijk gebied wat studies zoals CARMENTA mogelijk maken. Ik hoop dat we dit kunnen blijven voortzetten.

Afdeling statistiek en epidemiologie; prof. dr. Pieter Dagnelie en dr. Sander van Kuijk, dank jullie wel voor jullie hulp met de opzet en analyses van de CARMENTA trial, jullie hebben me veel bijgebracht en ik heb de samenwerking als zeer prettig ervaren. Dr. Patty Nelemans, we hebben maar 1 project samen gedaan (meta-analyse prognose), maar wat we daar allemaal mee hebben meegemaakt, had een boek op zichzelf kunnen zijn. Bedankt voor je onvoorwaardelijke steun, oplossingsgerichtheid en doorzettingsvermogen.

Afdeling fysiologie; prof. dr. Mark Post, dankzij u kwam er uiteindelijk geld beschikbaar om mij aan te stellen voor een promotietraject. Helaas werd de CARMENTA studie later afgewezen binnen het EMINENCE project, waardoor onze samenwerking wat minder intensief werd in de loop der jaren. Desalniettemin, veel dank voor uw begeleiding en financiële steun.

Afdeling klinische chemie; prof. dr. Van Dieijen-Visser, dr. Steven Meex, dr. Alma Mingels, dr. Noreen van der Linden en dr. Dorien Kimenai, allen dank voor jullie hulp met onze gezamenlijke projecten, zowel in uitvoering als met de analyses en presentatie van resultaten. Ik hoop nog lang met jullie te mogen samenwerken.

Dank aan alle onafhankelijke beoordelaars van diverse elementen van de CARMENTA trial; prof. dr. Jan Hoorntje, prof. dr. Robin Nijveldt en dr. Maureen van der Vlugt, voor jullie tweedaagse komst naar het MUMC+ om alle CARMENTA patiënten door te nemen, een finale diagnose te stellen en de opgetreden events te beoordelen; dr. Patty Nelemans, prof. dr. Koen Nieman en prof. dr. Robin Nijveldt voor zitting te nemen in de onafhankelijke interim analyse commissie; dr. Rogier Rennenberg, dr. Vincent van Ommen en dr. Estelle Nijssen voor de beoordeling van contrast geïnduceerde nefropathieën; en dr. Cecile Jeukens voor de hulp met de berekeningen van de effectieve stralingsdosis.

Dank aan mijn opleiders prof. dr. Harry Crijns, dr. Emile Cheriex, dr. Trang Dinh, prof. dr. Coen Stehouwer, prof. dr. Richard Koopmans en dr. Timo Lenderink voor uw bijdragen aan mijn opleiding tot cardioloog, steun in de uitvoering van mijn onderzoek en soms vrij plannen van klinische taken ten faveure van het onderzoek. Dank ook aan alle betrokken specialisten en assistenten van de afdelingen: interne geneeskunde, nefrologie, intensive care, longziekten en cardiologie (Maastricht en Zuyderland Heerlen).

Dear prof. dr. Kim, dear Ray, I would like to thank you for giving me the opportunity to collaborate in several research projects, for allowing me to visit your lab at Duke University many times and our numerous telephone conferences. Visiting you and talking to you on the phone has always been very inspiring to me. It's an honor working with you, as one of the founders of current daily clinical cardiac MRI care. Furthermore, many thanks to Mikki for your (statistical) support in our discussions and T-cons. I will never forget your old room filled with thousands of papers, I am curious how your new room looks like. I hope we can continue our collaboration and I hope to visit your new lab in the near future. 
David, bedankt voor het doorlezen van de introductie en discussie van dit proefschrift en de taalkundige verbeteringen. Ondanks dat je in Florida woont hebben we elkaar afgelopen jaren toch regelmatig gezien rondom werkbezoeken of congressen, ik hoop dat we dat kunnen blijven doen en we snel weer samen rijden in een muscle car, de Daytona 500 zien, speciaal bieren drinken, barbecueën, Nederlands elftal kijken en nog veel meer.

Maryam en Mahboobeh, bedankt voor jullie enthousiasme en hulp om dit proefschrift mooi vorm te geven. Ik vind het bewonderingswaardig hoe jullie het ontwerp aangepakt hebben. Na een gesprek waarin ik mijn proefschrift toelichtte, kwamen jullie met een mooi, origineel en volledig passend ontwerp voor mijn proefschrift. Onze samenwerking heeft wel even geduurd, illustratief voor mijn gehele promotietraject, maar desondanks "leken" jullie nog niet gek te worden van al mijn mailtjes en aanpassingen. Heel veel dank en ik hoop dat jullie het boekje net zo mooi vinden als ik.

Vrienden uit Breda, Maastricht en inmiddels door het hele land verspreid, dank voor de gezelligheid, weekendjes weg, borrels en paracetamol nadien. In velen van jullie ogen was het een oneindig promotietraject, en kreeg ik regelmatig vragen van "hoe kun je nu toch zo lang doen over een paar A4-tjes schrijven?" Soms vraag ik me dat ook af, maar jullie steun en interesse hierin hebben me ook door deze tijd heen geholpen. Daarnaast hadden we de nodige ontspanning op zijn tijd. Toch een paar mensen die ik apart wil benoemen, bedankt: Pieter en Rinske voor alle etentjes, BBQ's, borrels en vakanties samen, en niet te vergeten ceremoniemeesters van elkaars bruiloften! Pieter bedankt voor de zadelpijn na de duizenden kilometers op de fiets en de onvergetelijke ervaring La Marmotte en ons 11 uur durende rondje ljsselmeer van $340^{\mathrm{km}}$. Waar is die conditie gebleven? Na mijn promotie wil ik graag een snelcursus, zodat we samen over 3 maanden de Maratona dles Dolomites kunnen fietsen. Ronald en Bjorn voor de leuke borrelavonden, brandweer bezoeken, fietstochten (vaak toch zonder Bjorn) en het zijn van onze overburen. Yvo en Lianneke, voor alle gezellige avonden, wandelingen en uitjes met de kids, borrels en het delen van de leuke adresjes in het heuvelland. Sebastiaan en Ronald voor de mooie vakanties in een koekblik (excuus Suzuki Alto), gingen we de caravan nog eens uittesten? Bart, voor de game/fiets/bier en de all-you-can-eat frikandel-speciaal avonden. Mannen uit Breda, dank voor de vele liters Jupiler, pokeravonden (waar zijn ze gebleven de laatste tijd?), weekendjes weg, kanotochten, mountainbike tochten (die voor een enkeling al na 100 meter eindigde op het terras...). Buurman Niels, voor de ontspannende avonden tussen het werk door. Mocht uw naam er niet tussen staan, dan is deze wellicht door een drukfout weggevallen, u bent zeker niet vergeten, en daarom hierbij alsnog mijn dank!

Lieve schoonfamilie, Jenny, Gianni, Mariëlla, Shauni, Claudi, Quinty, Cayne en inmiddels net zo'n aantal aanhang. Ik ken trouwens weinig families waarin de I en Y zoveel voorkomen, waarom doen jullie dat? Het is altijd weer gezellig als jullie op bezoek komen. Dames, bedankt voor jullie vele oppasmomenten op Sil en Evi als ik weer eens moest werken aan mijn onderzoeken of opleiding. Zonder jullie had het wellicht nog langer geduurd!

Lieve Angelique, zusje, voor de kids tantie Angie, en inmiddels drs. Smulders - huisarts! Zonder dwang en eigenlijk zelfs op afraden van onze ouders zijn we dan toch allebei de gezondheidszorg in gegaan. De numerus fixus probeerde nog roet in het eten te gooien voor je, maar je hebt die tegenslag fantastisch opgepakt met een AKO-traject en bent inmiddels een gewild huisarts. Enkele jaren terug kwam je Thomas tegen, iemand met dezelfde hobby's als ik, dat heb je goed gedaan zusje! Nu ik Sil en Evi samen bezig zie, besef ik me soms ook hoe ik jou behandeld moet 
hebben als kleine zusje, sorry daarvoor :- Maar het is toch allemaal goed gekomen met je, dus het was vast ergens goed voor... Thomas, bewonderingswaardig hoe je je blijft amuseren met klusjes, techniek, opknappen, auto's, fietsen etc. We hebben al heel wat projectjes samen gedaan en ik heb genoten van de ritjes in de MG cabrio, snelle Volvo en gewoon op onze carbonnen tweewielers. Bedankt Angie en Thomas voor alle gezelligheid, oppasdagjes en er "gewoon" voor ons zijn! Heel veel succes met jullie carrières en veel geluk samen met elkaar.

Lieve papa en mama, hoewel cliché hebben jullie het toch maar gedaan, echt alles voor me mogelijk gemaakt, me gesteund in mijn carrière en de optimale omstandigheden gecreëerd om te bereiken wat ik nu heb en nog ga bereiken. Zonder jullie had ik hier letterlijk en figuurlijk niet gestaan. Jullie zijn fantastische ouders en sinds enkele jaren ook opa en oma. De kinderen zijn ook helemaal gek van jullie en het is ook altijd weer een feestje als jullie hier komen of als Sil en Evi bij jullie komen logeren. De laatste jaren hoorde ik wel steeds vaker: "Wanneer is je boekje nu af? Je moet er ook een keer een punt achter zetten. Ga je alweer op congres/werkbezoek, en je boekje is dat dan al klaar?" Nou hier is het dan eindelijk! Heel erg bedankt voor de leuke tijd samen thuis tot m'n $18^{e}$, alle steun, interesse, trots, liefde, adviezen, hulp, gezelligheid, vakanties en altijd dat super warme welkom. Nog even en we gaan met de hele familie naar Kreta op vakantie om lekker te genieten.

Lieve Sil en Evi, een boekje waarin jullie namen genoemd worden, dat hebben we nog niet eerder gevonden in de bibliotheek. Jullie zijn nog te klein (ja Sil, je bent echt al heel groot en vooral heel snel) om het allemaal te bevatten, maar wat zijn mama en ik blij met jullie, echt een verrijking van ons leven. Het is geweldig om jullie te zien opgroeien, ontwikkelen en de geweldige liefdevolle band die jullie met ons en met elkaar hebben vanaf het eerste moment. Er zijn ook zeker momenten dat we jullie achter het behang geplakt hadden, als we dat thuis hadden gehad..., maar eigenlijk genieten we iedere seconde met jullie. Thuiskomen van het werk en beloond worden met 2 dolblije enthousiaste kindjes die op je afrennen, allebei om het hardste papa roepen en je stevig komen knuffelen, dat maakt van elke dag een topdag. Ik kijk uit naar de jaren die nog komen en hoe jullie verder opgroeien, de tijd gaat zo hard...doe dus maar rustig aan!

Lieve Ellen, mijn liefde van mijn leven, mijn vrouw, moeder van onze kinderen, pop, steun en toeverlaat, vroegere stuurtje en mijn alles. Hoewel het traditie is om je als laatste te benoemen, hoor je eigenlijk ver bovenaan deze lijst te staan. Ik ben zo blij dat ik jou ben tegengekomen. Het is allemaal begonnen bij de studentenvereniging Saurus, waar je het stuurtje van mijn wedstrijd roeiploeg was. Een goede boeg, een goede ploeg was het credo, maar voor mij meer een reden om de hele training bij je te zijn in onze voorgestuurde boot. We zijn al samen sinds ongeveer een jaar voordat ik met onderzoek bij de cardiologie begon, je hebt dus het hele traject met de pieken en dalen van dit boekje meegemaakt en me er altijd weer doorheen getrokken en gesteund. Dat is zeker niet altijd makkelijk voor je geweest en je hebt ook veel moeten investeren en moeten laten om mij de ruimte te geven voor dit promotietraject. Vooral de laatste jaren na onze gezinsuitbreiding en het starten van mijn opleiding waren pittig, waardoor het erop neerkwam dat ik vele avonden en vrije dagen achter de computer doorbracht. Ik hoop dat ik daar de komende tijd verandering in kan aanbrengen. Op 23 mei 2014 vierden we ons huwelijk op een dag die nog mooier was dan we hadden kunnen dromen. Alweer 4 jaar geleden werd Sil geboren en ruim 2 jaar later Evi. Je bent een geweldige moeder voor die lieverds van ons. We houden van jou! We hebben al onvergetelijke jaren achter de rug samen en ik ben benieuwd naar wat we nog allemaal gaan beleven samen. Dankjewel voor alles. 
